


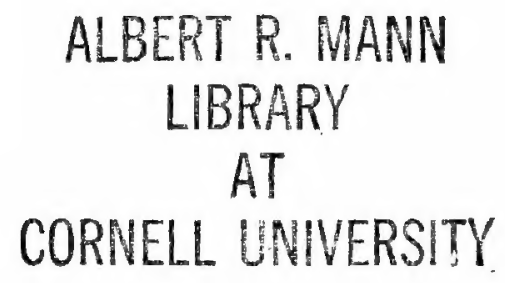




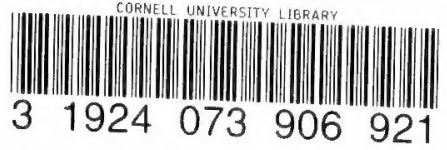




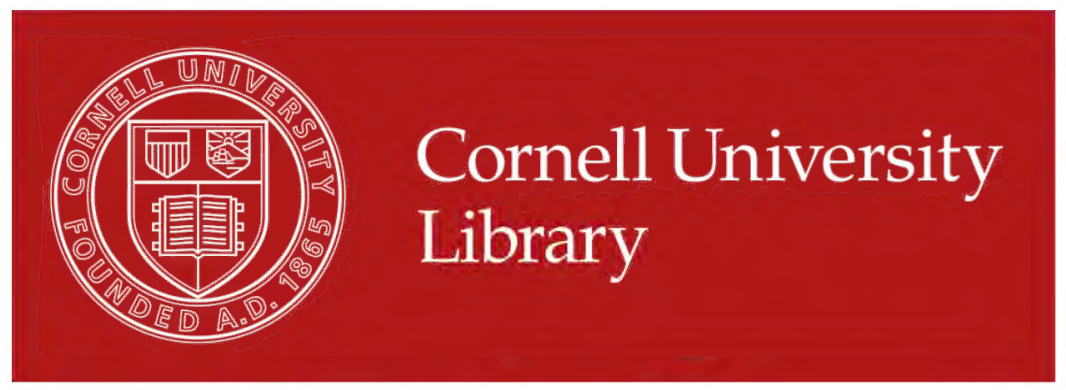

The original of this book is in the Cornell University Library.

There are no known copyright restrictions in the United States on the use of the text.

http://www.archive.org/details/cu31924073906921 


Production Note

Cornell University Library produced this volume to replace the irreparably deteriorated original. It was scanned using Xerox software and equipment at 600 dots per inch resolution and compressed prior to storage using ITU Group 4 compression. The digital data were used to create Cornell's replacement volume on paper that meets the ANSI standard 239.48-1992. The production of this volume was supported by the National Endowment for the Humanities. Digital file copyright by Cornell University Library 1995.

Scanned as part of the A. R. Mann Library project to preserve and enhance access to the core Historical Litèrature of the Agricultural Sciences. Titles included in this collection are listed in the volumes published by the Cornell University Press in the series THE LITERATURE OF THE AGRICULTURAL SCIENCES, 1991-1996, Wallace C. Olsen, series editor. 



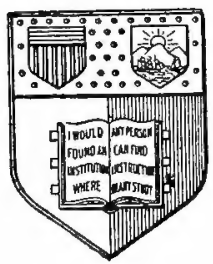

Pew 翼ork

State College of Agriculture

At Carmell anniversity

3thaca, 32. 是.

\section{互ibrary}






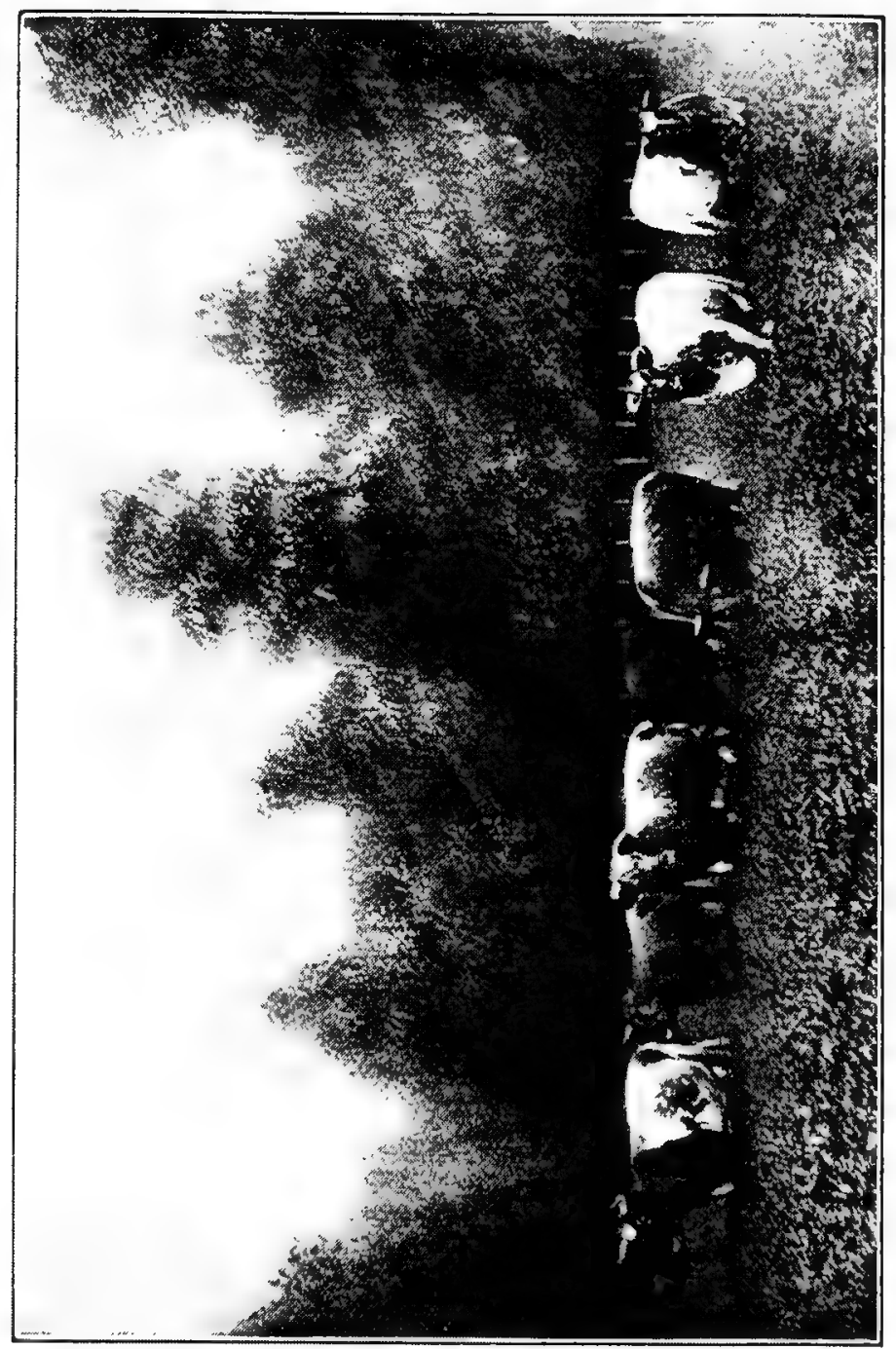

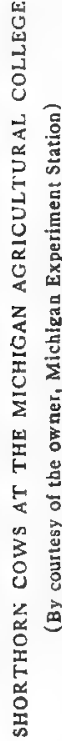




\title{
The Management
} and

Feeding of Cattle

\author{
By \\ Thomas Shaw \\ Lase Professor of Animal Hnsbandry at tho \\ University of Minnesota
}

\section{Author of}

Soiling Crops and the Silo, The Study of Breeds, Animal Breeding, Grasses and How to Grow Them, Clovers and How to Grow Them, Feeding Farm Animals, Etc.

\section{New York}

ORANGE JUDD COMPANY

\section{London}

Kegan Paul, Trench, Trubuer \& Co., Limited 1909 
Copyright, 1909, by

\section{ORANGE JUDD COMPANY}

All Rights Reserved

Entered at Stationers' Hall

LONDON, ENGLAND

Printed in U.S. A. 
To all students of the Agricultural Colleges who are interested in the Study of Cattle and to all persons interested in growing the same, this book is respectfully dedicated by the Author 


\section{ACKNOWLEDGMENTS}

The author desires to acknowledge his indebtedness to the bulletins issued by the agricultural experiment stations in the various states of the Union which bear upon the subject discussed in the pages of this book. $\mathrm{He}$ also desires to acknowledge his indebtedness to the experiment stations of Michigan, Minnesota, Iowa, Illinois, North Dakota and Washington for the sketches furnished by these respective stations. 


\section{THE AUTHOR'S PREFACE}

As far as the author has been able to ascertain, no book has yet appeared on this continent that treats specially and in orderly sequence of the Management and Feeding of Live Stock. Several books have been written which ably discuss the subject of feeding in a general and also in a scientific way, and in these more or less attention is given to the management of cattle. But the information thus given, valuable as it is, is more or less fragmentary and incomplete. That there is room for such a book, therefore, and urgent need for the same, must be conceded by all who have thought upon this question. In the hope of meeting such a need, this book has been written.

It has been the aim of the author, while writing it, to cover with some minuteness the whole ground relating to the feeding and management of cattle from birth until disposed of. The discussion of the principles that relate to feeding has been purposely avoided, since, in the book "Feeding Farm Animals," issued in $\mathrm{IgO}$, that phase of feeding has already been discussed. Effort has been centered upon the actual processes that relate to feeding cattle and upon the preparing and administering of foods. It has also been centered on the details of management that must be observed by the growers and feeders of the various classes of cattle who hope to attain success in their work. It has further been the aim to discuss the subject in an orderly manner, and in the discussion to express thought in language simple and as free as possible from the use of technical terms. The degree in which these aims have been attained must, of course, be determined by those who may have deemed the book worthy of perusal.

Thomas Shaw.

St. Anthony Park, Minnesota. 



\section{TABLE OF CONTENTS}

CHAPTER I

Page

\section{CALVES FROM BIRTH UNTIL ONE YEAR OLD}

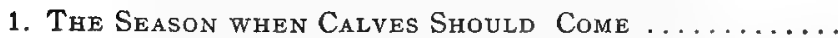

(a) This is not entirely under the control of the owner.

(b) Can be weaned with less hazard of arrested development.

(c) The grower has more time to care for them.

(d) They are stronger to enter the first winter subsequent to weaning.

(e) Winter dairying is the more profitable.

(f) Prolonged milking is more easily sustained in the cows.

(g) The steer calves are ready for market at the most suitable age.

(h) The cows are dry when the pastures fail.

(i) Under some conditions autumn production is unattainable.

2. Economy of Rearing on Dams or by Hand...................

(a) The annual cost of cow and suckled calf.

(b) The annual cost of cow and hand-fed calf.

(c) The returns from the cow and suckled calf.

(d) The returns from the cow and hand-fed calf.

(e) Rearing more than one calf per cow.

3. Calves for Feeding, Breeding or for Milk Production

(a) Calves for feeding.

(b) Calves for breeding.

(c) Calves for milk production.

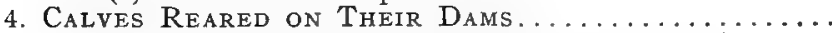

(a) Management when they run with the dam.

(b) Management when the calves are confined.

(c) Supplementary food when confined.

(d) Supplementary food in the pastures.

5. Calves when Reared on Skim Milk......

(a) Duration of the whole-milk period.

(b) Management while on whole milk.

(c) Changing from whole to skim milk.

(d) Supplementary concentrates.

(e) Supplementary fodders.

(f) Amount of milk to feed.

(g) Duration of milk period.

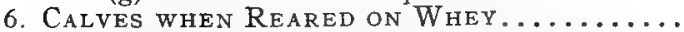

(a) Aim to start them well on skim milk.

(b) Supplementary concentrates. 
Calves when Reared on Whey-Continued

(c) Supplementary fodders.

(d) Amount of whey to feed.

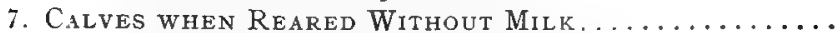

(a) The difficulties to be overcome.

(b) Aid from hay tea.

(c) Starting them on meal and roots.

(d) Concentrates and fodders.

(e) Aid from calf meals.

8. Management While Weaning...................... 29

(a) The hazard to be met at weaning.

(b) The age at which to wean.

(c) Weaning calves hand fed.

(d) Weaning calves that suck their dams.

9. Management Subsequent to Weaning........... 32

(a) Autumn calves then go on succulent food.

(b) Food during the summer for autumn calves.

(c) The nature of the quarters for autumn calves.

(d) Spring calves then go on dry food.

(e) Food during the winter for spring calves.

(f) The nature of the quarters for spring calves.

10. Growing Calves for Veal ................ 34

(a) Growing them on whole milk only.

(b) Methods in foreign countries.

(c) Growing them on whole milk and adjuncts.

(d) Growing them on skim milk and adjuncts.

11. Grazing for Calves.................... 36

(a) Location of the grazing.

(b) Nature of the grazing.

(c) Soiling in lieu of grazing.

(d) The nature of the soiling.

(e) Supplementing the grazing.

12. Miscellaneous Considerations.....................

(a) Discrimination as to which shall be reared.

(b) Grading in the apartments.

(c) Feeding milk and whey in proper condition.

(d) Feeding a number of calves simultanecusily.

(e) Giving salt and water to calves.

(f) General sanitary considerations.

\section{CHAPTER II}

CATTLE ONE YEAR OLD-SUMMER AND WINTER

1. Autumn Calves the Second Winter.

(a) The shelter called for.

(b) Kept in stalls or loose.

(c) Suitable coarse fodders.

(d) Suitable concentrates.

(e) Succulent foods. 
2. SPRING CALVES Page

(a) The shelter called for.

(b) In stalls or loose.

(c) Suitable coarse fodders.

(d) Suitable concentrates.

(e) Succulent foods.

3. Grazing in Summer.

(a) The most suitable grazing.

(b) Abundance in the grazing.

(c) Protection while grazing.

4. Supplementing the Pastures

(a) Supplementing with coarse fodders.

(b) Supplementing with rape.

(c) Reserve grass pastures.

(d) Supplementing with concentrates.

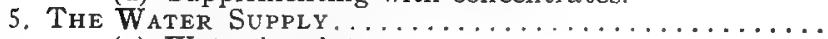
(a) Water in winter.
(b) Water in summer.
(c) Water at all times accessible.

6. Other Important Considerations
(a) Grading in winter.
(b) A comfortable bed.
(c) Turning out to graze in the spring.
(d) Changing to dry feed in the autumn.
(e) The salt supply.
(f) Retaining the better foods for late feeding.
CHAPTER III

CATTLE TWO YEARS OLD-SUMMER AND WINTER

1. Autumn Calves the Third Winter..............

(a) The shelter called for.

(b) In stalls or loose.

(c) Suitable coarse fodders.

(d) Suitable concentrates.

(e) Succulent foods.

2. Spring Calves the Third Winter.............. 64

(a) The shelter called for.

(b) In stalls or loose.

(c) Suitable coarse fodders.

(d) Suitable concentrates.

(e) Succulent food.

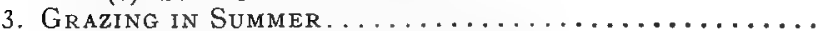

(a) The most suitable grazing.

(b) Abundance in grazing.

(c) Protection while grazing.

(d) Reserve grass pastures.

4. Supplementing the Pastures

(a) Supplementing with coarse fodders.

(b) Supplementing with rape.

(c) Reserve grass pastures.

(d) Supplementing with concentrates. 
5. The Water Supply $\ldots \ldots \ldots \ldots \ldots$

(a) Water in winter.

(b) Water in summer.

(c) Water at all times accessible.

6. Other Important Considerations.

(a) Grading in winter.

(b) A comfortable bed.

(c) Turning out in the spring.

(d) Changing to dry feed in the autumn.

(e) The salt supply.

(f) Reserving the better food for late feeding.

\section{CHAPTER IV \\ GROWING BABY BEEF}

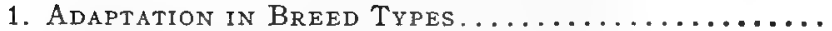

(a) Calves of the various beef types.

(b) Calves of the various dual types.

(c) Calves of the beef dairy types.

(d) Calves of the various dairy types.

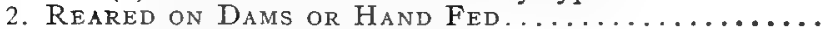

(a) When reared on dams.

(b) When reared by hand.

(c) Relative profits from the two systems.

3. Necessary that the Animals Start Well...........

(a) Unpromising calves should not be so reared.

(b) No periods of arrested development.

(c) Gains must be rapid from the start.

(d) The condition of flesh higher than for breeding animals.

4. The Nature of the Fodders................. 80

(a) Must be palatable and nutritious.

(b) Not fed in too large proportions.

(c) The best fodders for such feeding.

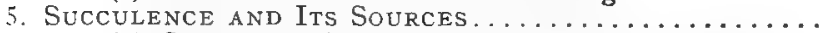

(a) Succulence from pasture and its value.

(b) Succulence from soiling food and corn ensilage.

(c) Succulence from field roots and their value.

6. The Nature of the Concentrates.

(a) Such as will produce and maintain flesh.

(b) Such as will not cloy or disturb digestion.

(c) Kinds best adapted to such feeding.

7. Amount of Concentrates to Feed

(a) During the milk period.

(b) During the following winter.

(c) During the next summer.

(d) During the next winter.

8. Age at Which to Sell............

(a) How influenced by type.

(b) How influenced by food and feeding.

(c) How influenced by market values. 
9. ThE VALtue Page

88

(a) The influences that affect profits.

(b) Fractional difference in prices.

\section{CHAPTER V \\ HEIFERS DURING PREGNANCY AND SUBSEQUENTLY}

1. Age at which to Breed Heifers.............. 90
(a) For the dairy.
(b) For beef production.
(c) Objections to breeding too young.
(d) Objections to breeding long deferred.
(e) The sires used and the manner of service.

2. Food Suitable for Pregnant Heifers............ 94

(a) Should be rich in nitrogenous elements.

(b) Should be capable of maintaining flesh and growth.

(c) Should be possessed of ample succulence.

(d) Should be liberal in supply.

(e) Food that is suitable.

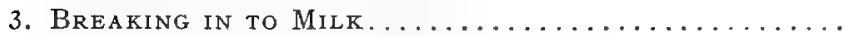

(a) Greatly important that this should be done

(b) The value of previous handling.

(c) Essential qualities in the milkers of such heifers.

(d) Same methods not always equaliy successful

(e) Milking cows that are confirmed kickers.

4. Treatment Subsequent to Parturition.

(a) Food liberal and nourishing.

(b) How soon to breed again.

(c) Habit in breeding.

5. Rearing Calves from Heifers.

(a) Not usually reared in the dairy.

(b) Generally reared for beef production.

(c) Lessons to be drawn therefrom.

\section{CHAPTER VI}

\section{THE FEEDING AND CARE OF BULLS}

1. Bulls of the Three Types.................. 104

(a) The aim in growing bulls for the dairy.

(b) The aim in growing bulls of the dual type.

(c) The aim in growing bulls of the beef type.

2. Food and Care During the Milk Period..

(a) Feeding and management of bulls of the dairy breeds.

(b) Feeding and management of bulls of the dual breeds.

(c) Feeding and management of bulls of the beef breeds. 
xiv

TABLE OH CONTENTS

Page

3. Food from Weaning Until Maturity.............. 109

(a) Food for bulls of the dairy type.

(b) Food for bulls of the dual type.

(c) Food for bulls of the beef type.

4. Management from Weaning Until Matured......... 111

(a) Boxstalls, paddocks, pastures

(b) Training to lead.

(c) Putting in rings.

5. Food for Mature Bulls..................... 114

(a) Compared with food prior to maturity.

(b) Standard summer food.

(c) Standard winter food.

(d) Food when service is taxing.

6. Management of Mature Bulls............... 116

(a) Should not run with cows.

(b) Securing sufficient exercise.

(c) Trimming the feet.

7. Extent and Duratron of Service............... 120

(a) Extent of service until well grown.

(b) Extent of service during best years.

(c) Extent of service during declining years.

8. Bulls that are Vicious..................... 123

(a) When to retain them.

(b) How to confine them.

(c) How to use them.

9. Restoring Begetting Power in Bulls.............

(a) Causes of impotency.

(b) When may restoration be possible.

(c) Means that may restore lost power.

10. Purchase and Disposal of Bulls............
(a) Why bulls should not be bought young.

(b) Why prepotent bulls should be preferred.

(c) What changes in food may lead to.

(d) Disposal of old bulls.

\section{CHAPTER VII}

FINISHING LATER IN THE STALL, SHED, OR GROVE

1. The Supply of Animals for Finishing............ 128

(a) Animals grown on the farm.

(b) Animals grown on other farms.

(c) Animals grown under range or semi-range conditions.

(d) Inheritance of the animais.

(e) The age for purchasing.

(f) When the feeding should begin.

2. Finishing in the Stall, Shed, or Grove . . . . . . . . 132

(a) Conditions determine which system is best.

(b) The influence of climate.

(c) The cost of the shelter.

(d) The cost of the labor. 
Finishing in the Stall, Shed, or Grove-Continued

Page

(e) The individual needs of the animals.

(f) The demands upon litter.

3. Leading up to Full Feeding

(a) The object sought in fattening cattle.

(b) Why fattening cannot be hastened beyond certain limitations.

(c) The time required in preliminary feeding.

(d) The foods suitable for such feeding.

4. The Concentrates to Feed ...........
(a) The concentrates that may be fed.

(b) The choice of concentrates.

(c) How to prepare and feed them.

(d) The changes called for in feeding them.

(e) The amounts of concentrates to feed.

5. The Fodders to Feed...................... 14

(a) The different fodders that may be fed.

(b) The choice of fodders.

(c) How to prepare and feed them.

(d) The changes called for in feeding them.

(e) The amounts that will be consumed.

6. The Succulent Foods to Feed................... 146

(a) The sources of succulence.

(b) Feeding com ensilage.

(c) Feeding field roots.

7. Finishing on Beet Pulp and Grain................ 148

(a) Only practicable near the factories.

(b) Mode of ensiling the pulp.

(c) The method of feeding pulp.

(d) The amount of grain to feed.

(e) The cost of the pulp.

8. Duration of this Feeding Period.............. 150

(a) How affected by conditions when feeding begins.

(b) How affected by age of animals.

(c) How affected by the foods fed.

(d) How affected by the prices of foods.

(e) How affected by the time when put on feed.

9. Standard Rations in Different Centers............

(a) For the northern states.

(b) For the Middle West.

(c) For the southern states.

(d) For states far south and southwest.

(e) For the western mountain states.

(f) For Washington, Oregon, and Idaho.

(g) For areas northward

10. Observations Regarding Foods

(a) Meat made from alfalfa only.

(b) Supplementing corn with corn and cob meal.

(c) Feeding large quantities of oil cake.

(d) Feeding cottonseed meal.

(e) Corn ensilage not duly appreciated. 
Observations Regarding Foods-Continued

Page

(f) Sore mouths from feeding corn.

(g) The frequency of the feeding.

(h) Daily increase from feeding.

11. Miscellaneous OBSERvations.............

(b) Removing lice and skin troubles.

(c) Supplying water and salt.

(d) Amount of exercise to give.

(e) Regulating food fed by the appetite.

(f) Treatment when off feed.

(g) Shipping promptly when finished.

12. Coming Modifications in Feeding .............. 162

(a) Corn fed in excess in corn belt.

(b) More coarse fodders relatively will be fed.

(c) Silage will be fed to a much greater extent.

(d) More labor will be expended in preparing food.

(e) Modifications in the corn belt.

(f) Modifications in the North.

(g) Modifications in the South.

\section{CHAPTER VIII \\ FINISHING CATTLE ON PASTURE}

1. Wintering Prior to Finishing on Grass............ 165

(a) Feeding influenced by time of marketing.

(b) Variation in food rations.

(c) Adjusting the grain to the roughage.

(d) Feeding grain for early shipment.

(e) Feeding grain for later shipment.

(f) Shipment without feeding grain.

2. The Most Suitable Pastures................... 168

(a) They will vary as to kind.

(b) They should be abundant.

(c) They should not be over-succulent.

(d) They should be without hazard.

3. Turning out to Graze.................... 172

(a) The shrinkage that may follow.

(b) How to prevent it.

4. Finishing with or without Meal.............. 17

(a) When meal does not increase the gains.

(b) Several methods that may be adopted.

(c) The amount of meal that should be fed.

5. Avoid Short Periods of Grazing.
(a) What leads to such grazing.

6. (b) The shrinkage following turning out to graze.

ISHING IN THE EARLY SUMmER................ 176

(a) The care called for when changing to pasture.

(b) The kind of concentrates to feed.

(c) The amount of grain or meal to feed.

(d) The method of feeding the concentrates. 
7. Finishing in the Late Summer................ 178

(a) Extent of the reduction in the grain fed.

(b) Increase and the amount of the same.

(c) Feeding new corn on pasture.

(d) Selecting for shipment.

8. Miscellaneous Observations................... 179

(a) Water, salt, and shade must be ample.

(b) Mode of feeding the grain.

(c) Protecting from flies scarcely practicable.

(d) The marketing should be early.

9. Relative Profit from Finishing on Grass.......... 181

(a) The trend from experiments conducted.

(b) The influences that affect profits.

(c) Finishing must go on at all seasons.

\section{CHAPTER IX}

\section{COWS THAT ARE MILKED BY HAND}

1. Hand Milking and Milk Production............. 184

(a) It promotes capacity to give milk.

(b) Should never alternate with sucking calves.

(c) Veal calves from milch cows hand fed.

2. Management During the Period of Rest.......... 186

(a) Duration of the milk period.

(b) Total production with and without rest.

(c) The storing up of reserve power.

(d) Influence upon the progeny.

3. Management at Parturition .......................

(a) Food as parturition draws near.

(b) When confinement may be necessary.

(c) The removal of milk before parturition.

(d) The administering of purgatives.

(e) Removing milk subsequent to parturition.

(f) Food following parturition.

4. Shelter Required in Winter.

(a) Should be confined in the stall or shed.

(b) Should be comfortable as to temperature

(c) Should be given conditions that are healthful.

(d) Each should be given its food separately.

5. The Exercise Called For.................. 192

(a) Three methods of giving exercise.

(b) Confining in the stalls during all the winter.

(c) Exercise, stamina, exposure, and milk giving.

6. Protection Required in Summer................. 194

(a) Protection from storms.

(b) Protection from sunshine.

(c) Protection from flies.

(d) Protection from wasted energies in taking food. 
7. Cows in Milk Should be Driven Gently............ 197

(a) The hazard from a boy on horseback.

(b) The greater hazard from a dog.

(c) The manner of response to a call.

8. What Good Milking Means.................... 198

(a) That the milk be kept clean.

(b) That it will be promptly withdrawn.

(c) That it is taken by one who loves the worl.

(d) That it is done by the same party.

(e) That it is promptly done at stated times.

(f) Milking by means of machines.

9. Keeping Milk Records

(a) The great practical value of these.

(b) Milk records relating to quantity.

(c) Milk records relating to quality.

10. Odors that are Hurtful to Milk. . . . . . . . . . . 202

(a) The source from which such odors come.

(b) The means used to prevent them.

(c) The different kinds of absorbents used.

11. The Druing of Cows... . . . . . . . . . . . . . . . . . . 204

(a) Influences that make drying more difficult.

(b) The method to be pursued.

(c) Guarding the udder against harm.

12. Management Relating to Breeding. 206

(a) The aim in freshening cows.

(b) The frequency of the periods of freshening.

(c) Removal of cows in time of heat.

(d) Keeping records of service.

\section{CHAPTER X COWS THAT SUCKLE THEIR YOUNG}

1. Management while Pregnant................ 208

(a) Care during pregnancy.

(b) Food during pregnancy.

(c) Duration of the rest period.

(d) When it should be curtailed.

2. Care at the Time of Parturition.......

(a) The condition of the digestion.

(b) The fear of milk fever not usually presc:it.

(c) The use of purgatives.

(d) The food and care subsequent to parturition.

3. Removing The Surplus Milk . . .
(a) Why the surplus milk should be removed.

(b) Why it should be removed as long as present.

(c) Why abundant milk giving should be encouruged.

4. Management when Calf Remains with Dam........ 21

(a) Two methods of management.

(b) Management of the calves.

(c) Management of the dams. 
5. Management when the Calf is Confined ......... 214

(a) Management of the calves.

(b) Management of the cows.

(c) Drying off the cows.

6. Food and Care in Winter........

(a) The two classes of cows.

(b) The aim in managing pure-breds.

(c) Keeping cows indoors all winter.

(d) Character of the fodders.

(e) Character of the concentrates.

(f) Wintering grade cows.

7. Food and Care in Summer..

(a) Nature of the supplementary food.

(b) Protection from storms, sunshine, and flies.

(c) The water supply.

8. Management Relating to Breeding.

(a) The aim in breeding.

(b) Food and breeding.

(c) Watchfulness over the herd.

\section{CHAPTER XI}

\section{CARRYING CATTLE THROUGH THE WINTER}

1. Conditions for Wintering Cattle Cheaply......... 222

(a) Those that relate to the furnishing of food.

(b) Those that relate to the furnishing of shelter.

(c) Those that relate to production.

2. Cattle that May be Wintered Cheaply............ 223

(a) Mature cows in calf and yet dry.

(b) Mature cows carried over for finishing on grass.

(c) Steers grown cheaply on extensive pastures.

3. Nature of the Winter Quarters................ 224

(a) Stabling frequently not necessary.

(b) The shed, the yard, the stack.

(c) When stanchions are helpful.

4. General Character of the Food Fed

(a) The aim should be to feed much roughness.

(b) The aim should be to feed but little concentrates.

(c) The aim should be to feed succulence only as necessary.

(d) The aim should be to maintain flesh.

SUCH WINTER FEEDING ...................

(a) Hay is usually too expensive.

(b) Straw only is too innutritious.

(c) Much grain is too expensive.

(d) Utilize cheap winter rations.

6. Foods that Deteriorate with Age

(a) Enumeration of the chief of these.

(b) Feed such foods first.

(c) Comparison between foods in deterioration. 
(a) Calamitous to be on short supplies.

(b) These should be secured in advance.

(c) Making the most of roughage when supplies are short.

8. Improving the Ration as Winter Advances......... 236

(a) Why such change is necessary

(b) Changes that may be practicable.

9. Feeding Cows Forward in Pregnancy ............ 237

(a) Should have food nourishing and succulent.

(b) Should not run in yard with horses.

(c) Should be removed some time prior to calving.

CHAPTER XII

FOOD FOR MILCH COWS IN SOMMER

1. Grazing for Cows.

(a) The chief requisites in pastures for cows.

(b) The plants that furnish such pasture.

(c) The best pastures for cows.

(d) Plants that should not be grazed by cows.

(e) The most suitable pastures in different areas.

2. Changing from the Stable to the Pastures........ 242

(a) Pastures should be reasonably abundant before grazing begins.

(b) The change from dry food to grazing should be gradual.

(c) The method to be followed when changing.

3. Feeding Grain when on Pasture............... 244

(a) Opinions differ as to the profit from such feeding.

(b) The difficulties encountered in such experimentation.

(c) Conclusions that may be safely drawn.

(d) The course that should be followed.

4. Solling Food For Cows................... 246

(a) When to feed soiling foods.

(b) What constitutes a valuable soiling food.

(c) Soiling toods available.

(d) Provision should be made for them.

(e) Soiling foods of problematic value.

(f) Soiling foods cheaper than grain.

5. Ensilage for Summer Feeding. . . . . . . . . . . . . . 249

(a) Relative suitability of ensilage.

(b) Relative cheapness of ensilage.

(c) Relative convenience in feeding.

(d) How to provide summer ensilage.

(e) The relative size of the silo.

(f) Should other soiling food be provided.

6. Feeding Soiling Foods to Cows in Summer

(a) Feeding in the stall or in the pasture.

(b) Cutting and feeding the food. 
Feeding Solling Foods to Cows in Summer-Continued

(c) When cutting should begin and end.

(d) Preparing the food for feeding.

7. From the Pastures to the Stable...

(a) Removal from the pastures usually gradual.

(b) Protection from cold and storms imperative.

(c) Food fed on the pastures in the autumn.

(d) The concentrates to feed in the autumn.

8. The Carrying Power of Pastures

(a) Not easy of determination.

(b) An excess much better than a short supply.

(c) How such pastures may be improved.

\section{CHAPTER XIII FOOD FOR MILCH COWS IN WINTER}

1. The Nature and Kinds of the Fodders........... 259

(a) The legumes stand first in suitability.

(b) Next to these come grain and fodders.

(c) After these come corn and sorghum fodders.

(d) Then comes hay from the grasses and millet.

(e) Lowest in suitability is the straw of the small cereals.

(f) The grain should always be adjusted to the fodders.

(g) These are always fed ad libitum.

2. The Nature of the Succulence..............

(b) The essentials in succulent foods.

(c) The foods that will furnish these.

(d) The great value of corn as ensilage.

(e) Adding protein to the ensilage.

(f) Field roots as succulence.

(g) The amounts of succulent food to feed.

3. The Nature of the Concentrates.

(a) The necessity for feeding them.

(b) The two sources from which obtained.

(c) The concentrates purchased.

(d) The concentrates home grown.

(e) Balancing the ration with concentrates.

(f) Favorite combinations of concentrates for feeding.

4. The Amount of Concentrates to Feed.......... 272

(a) The influences that affect this.

(b) The aim should be to economize in concentrates.

(c) The injury from feeding over-much.

(d) The amount of concentrates to feed.

5. Preparing and Blending the Food.............

(a) The conditions that call for blending.

(b) The blending of concentrates.

(c) The blending of various foods. 
6. The Most Suitable Winter Ratrons.............. 277

(a) In the New England states.

(b) In the northern states.

(c) In the Dakotas and northern provinces of Canada.

(d) In the mountain states and westward.

(e) In the central Atlantic states.

(f) In the Central States.

(g) In the mountain states southward from Montana.

(h) In the Gulf states.

\section{CHAPTER XIV THE DISPOSAL OF COWS}

1. Cows in Pedigreed Herds.

(a) The best should not be sold.

(b) When cows relatively young may be sold.

(c) When they should not be sold.

(d) Value of immature and mature females.

(e) When investment in aged cows may be profitable.

(f) Final disposal of aged cows.

2. COWS IN THE City DAIRY.

(a) Sometimes milked for but one season.

(b) The great sacrifice in cows resulting.

(c) How such sacrifice may be prevented.

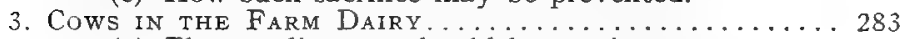

(a) The weeding out should be continuous.

(b) Basis on which such weeding should rest.

(c) The age to which cows may milk profitably.

4. Fattening Milch Cows for the Block............ 286

(a) Selling cows without fattening.

(b) Fattening begun while yet in lactation.

(c) Fattening on grass.

(d) Fattening cows of the dual type.

5. Disposal Influenced by Source of Supply........ 287

(a) Supplies for the city dairy.

(b) Supplies for the farm dairy.

(c) Opportunity for professional breeders.

\section{CHAPTER XV}

\section{MARKETING CATTLE WHEN FINISHED}

1. The Season for Marketing. . . . . . . . . . . . . 290

(a) It should be fixed upon when feeding begins.

(b) The influences that determine the choice of season.

(c) The degree of the finish to give.

(d) Why marketing should be prompt when finished.

2. The CHOICE of MARKETS..............................
(a) The influences that affect such choice.

(b) How the small feeder may reach the best market.

(c) Disposal of ill-finished and well-finished cattle.

(d) Bringing buyer and seller into close touch. 
Page
P. PREPARING CATTLE

3. Preparing Cattle for Shipment. . . . . . . . . . . . . 294

(a) Securing cars for shipping.

(b) Bedding and litter for the journey.

(c) Modifications in the food.

(d) From the stable to the cars.

(e) The grading of the animals.

(f) The basis of charge as to weights.

(g) Driving on foot to the market.

4. Care While in Transit... . . . . . . . . . . . . . . 296

(a) When the run does not exceed 28 hours.

(b) When the run does exceed 28 hours.

(c) When to aim to reach the market.

5. Sitrinkage While in Transit.

(a) The variations in shrinkage.

(b) The causes of such variation.

(c) Shrinkage of cattle sold at home.

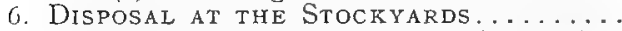

(a) To whom to consign the cattle.

(b) Unloading, feeding, and watering.

(c) Grading the cattle for sale.

(d) Inspecting the cattle.

(e) Weighing the cattle.

(f) The sale of the cattle.

\section{CHAPTER XVI \\ GROWING AND FITTING CATTLE FOR EXHIBITION}

1. How to Secure the Animals................ 303

(a) The character of the breeding.

(b) They will be purchased or bred.

(c) The care of the dam when pregnant.

(d) Indications at birth.

(e) The character of the development and finish sought.

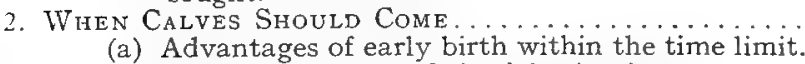

(b) The arrangement of the fair circuits.

(c) The senior and junior classes.

(d) The rules apply to all classes of cattle.

3. Milk Furnished AND its Sources.
(a) Milk furnished by the dam.

(b) When to introduce nurse cows

(c) Character of the production in nurse cows.

(d) Breed or grade of nurse cows.

(e) Feeding and management of nurse cows.

4. Fodders Fed at Different Ages.

(a) The best fodders for feeding:

(b) Fodders during the calf period.

(c) Fodders during the one-year form.

(d) Fodders during the two-year form.

(e) Green fodders and when to feed them. 
xxiv

5. Grain Fed at Different Ages.............. 312

(a) The standard grains for such feeding.

(b) Feeding grain while yet in the calf form.

(c) Feeding grain while in the one-year form.

(d) Feeding grain while in the two-year form.

(e) How to feed the grain.

6. Roots Fed at Different Ages............... 315

(a) Suitability of roots and ensilage.

(b) Roots during the calf period.

(c) Roots and ensilage during the one-year form.

(d) Roots and ensilage during the two-year form.

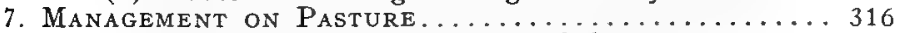

(a) The location and character of the pasture.

(b) The term of pasturing during each year.

(c) The time when out on pasture.

(d) The apartments during the day.

8. TRAINING FOR THE FAIRS ......................
(a) When and how to begin training.

(b) Training as the shows draw near.

(c) The extent of the training.

(d) Benefits from training.

9. Washing Cattle to be Shown................ 320

(a) More practiced with fat cattle.

(b) Washing by means of rain.

(c) Amount of washing ustually given.

(d) Mode of washing followed.

10. Show CatTle in TRANSIT AND AT Fairs......
(a) Reduction in food before and on cars.

(b) Food when at the fairs.

(c) Details relating to shipping.

(d) Effect of showing on gains and production.

11. Management on Returning from the Fairs....

(a) Management after showing the first season.

(b) Management after showing the second season.

(c) Management after showing subsequently.

(d) Benefits from reducing the grain feed.

12. Exhibiting Bulls in the Beef Classes........... 326

(a) Proper condition for showing.

(b) The difference in the feeding from steers.

(c) The difference in the exercise.

(d) Amount of service in different years.

(e) Reducing after the fairs.

(f) Duration of the showing period.

13. Exhibiting Breeding Females in Beef Classes..... 329

(a) Condition as to pregnancy when shown.

(b) Duration of the nursing period.

(c) Exercise for females shown from year to year.

(d) Reducing after the fairs.

(e) Duration of the showing period.

14. Exhibiting Dairy and Dual TyPes.
(a) Proper condition as to flesh. 
Exhibiting Dairy and Dual Types-Continued

(b) Time of lactation when shown.

(c) The food given in transit and at fairs.

(d) Milk contests at fairs.

15. Miscellaneous Observations

(a) The milking of the dam during the first weeks.

(b) Castration and spaying. (1 mo. and 3 mos.)

(c) Scours during the milk period.

(d) Time and method of weaning.

(e) Stalls, yards, and paddocks.

(f) Giving water and sait, and frequency of feeding.

(g) Feeding boiled food.

(h) Grooming and litter supply.

(i) Blankets and their use.

(j) Trimming the feet.

\section{CHAPTER XVII \\ STABLING SUITABLE FOR CATTLE}

1. The Location of a Stable.................. 341

(a) It should be near a dwelling.

(b) It should be on well-drained ground.

(c) It should be protected.

(d) It should be near the center of the farm.

2. The Influence of Climate on Stable Construction. 342

(a) Stabling in mild areas.

(b) Stabling in climates cold and dry.

(c) Stabling in climates raw and damp.

3. Important Requisites in a Stable

(a) That there is large capacity for storing food.

(b) That the food should be easy of access.

(c) That the stable should be dry.

(d) That it shall be well lighted.

(e) That it shall be amply ventilated.

(f) That it may be easily and cheaply cleaned.

4. Conveniences in a Cattle Stable.............. 345

(a) Provision for a feed room discussed.

(b) Provision for a root cellar discussed.

(c) Provision for a silo discussed.

(d) Provision for storing bedding discussed.

(e) Provision for stalls discussed.

(f) Provision for water supply discussed

5. Stables Built on the Basement Plan........... 348

(a) A basement stable defined.

(b) The site for a basement stable.

(c) Leading forms of construction in basement stables.

(d) Superiority of basement stables.

6. The Materials of Construction

(a) Where sods may be used.

(b) Where straw may be used. 
The Materials of Construction-Continued
(c) Where logs may be used.
(d) Where lumber may be used.
(e) Where stone may be used.
(f) Where bricks may be used.
(g) Where cement may be used.
(h) The material for the roof.
(i) The material for the floor.

7. Barn and Stable Built by the Author............ 357

(a) The reasons for submitting the sketches.

(b) Capacity of barn and basement.

(c) Construction of the floor.

(d) The plan of the stalls.

(e) The plan of the mangers.

(f) The plan of the feed racks.

(g) How water is furnished.

(h) Plan of the rear passage.

(i) How ventilation is secured.

(j) The ground plan of the barn.

8. Stalls and Mangers in Stables. ......................
(a) Wood fittings must b. used to some extent.

(b) Considerations relating to cattle stables.

(c) The partitions in stables.

(d) The method of tying.

(e) Construction of mangers.

(f) Construction of stalls.

(g) Stalls and mangers for animals that weigh 1,000 pounds.

(h) Stalls and mangers for dairy cows.

(i) Stalls and mangers for heavy cattle.

(j) Stanchions and mangers for calves.

9. Rack and Mangers for Loose Cattle............. 371

(a) Description of manger.

(b) Description of rack.

(c) Enlarging both for larger animals.

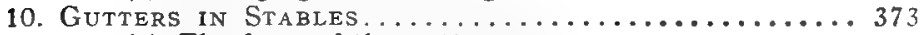

(a) The form of the gutter.

(b) The materials of the gutter.

(c) The dimensions of the gutter.

11. Passageway in Stables.

(a) Passageways defined.

(b) Influences that affect their width.

(c) The width of passageways.

(d) Width of stables for two rows of cows.

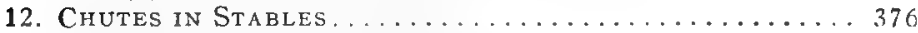

(a) The use of chutes.

(b) Construction of hay and straw chutes.

(c) Construction of meal chutes.

13. The Lighting of Stables

(a) The value of light in stables. 
The Lighting of Stables-Continued

(b) Relation between stable space and light.

(c) Considerations regarding lighting stables.

14. Ventilating Stables. . . . . . . . . . . .
(a) The question not yet mastered.

(b) The King system of ventilation.

(c) Aids to ventilation.

\section{CHAPTER XVIII}

\section{DEHORNING, SPAYING, AND CASTRATING CATTLE}

1. DEhorning of Recent Introduction............ 381

(a) Why horns were originally bestowed.

(b) The evolution of hornless breeds.

(c) When introduced into America.

(d) The opposition to its introduction.

2. Why CATTLE ARE DEhORNED ........
(a) To prevent injury from goring.

(b) To render feeding more practicable in the absence of stalls.

(c) To secure greater freedom from disturbance.

3. When Cattle Should be Dehorned ............... 384

(a) When grown for slaughter beyond calfhood.

(b) When grown as grades for breeding uses.

(c) When purchased for fattening while loose.

4. When Cattle Should Not Be Dehorned............ 385

(a) When they are to be slaughtered at a tender age.

(b) When they are purely bred and horned.

(c) When grown on the open range.

5. Facts Which Bear UPon DeHoRning............. 387

(a) The best age for dehorning.

(b) The best season for dehorning.

(c) Temporary loss from dehorning.

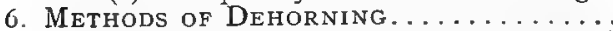

(a) Dehorning by preventive methods.

(b) Dehorning with clippers.

(c) Dehorning with a saw.

(d) Leaving some animals undehorned.

i. Facts Regarding Spaying Cattle.............. 390

(a) The chief objects sought.

(b) The best age for spaying.

(c) The best condition for spaying.

(d) Spaying more critical than castration.

8. Females that Should be Spayed .....................
(a) All females grown for meat on the ranges.

(b) All females grown to maturity for meat on the farm.

(c) Breeding and milch cows to be sent to the block.

9. The Different Methods of Spaying............ 393

(a) Spaying through the vagina.

(b) Spaying through the flank or side. 
The Different Methods of Spaying-Continued

Page

(c) Spaying through the belly.

(d) Precautions to be used in spaying.

10. Facts Regarding Castrating Cattle..

(a) The chief object sought.

(b) The best age for castrating.

(c) The best season for castrating.

(d) The best condition for castration.

11. Males that Should be Castrated.............. 397

(a) All those grown for meat beyond the milk period.

(b) All pure-bred males if inferior.

(c) Mature males that are to be finished on pasture.

12. The Methods of Castrating................. 398

(a) Castrating calves.

(b) Castrating older males while standing.

(c) Castrating older males when thrown.

(d) Castration by using ligatures.

(e) Precautions when castrating.

\section{CHAPTER XIX \\ INSECTS IN JURIOUS TO CATTLE}

1. Ringworm on Cattle

(a) The origin of ringworm.

(b) The indications of ringworm.

(c) Injury resulting from ringworm.

(d) Remedial measures for ringworm.

2. Warbles on Catrle.

(a) The origin of warbles.

(b) The indications of warbles.

(c) Injury resulting from warbles.

(d) Remedial measures for warbles.

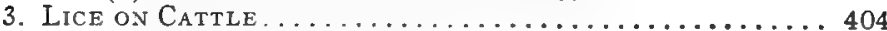

(a) Lice and their sources.

(b) The indications of lice.

(c) Injury resulting from lice.

(d) Remedial measures for lice.

4. Fi iEs ON CATTLE.

(a) Flies and their sources.

(b) The season for fies.

(c) Injury resulting from flies.

(d) Protective measures against flies.

5. Mange on Catthe.

(a) Mange and its sources.

(b) Indications of mange.

(c) Injury resulting from mange.

(d) Remedial measures for mange.

6. Southern, or Texas, Fever

(a) The cause of Texas fever.

(b) The life history of the ticks.

(c) The area infected.

(d) The indications of Texas fever. 
Southern, or Texas, Fever-Continued

(e) Injury resulting from Texas fever.

(f) Protective measures against Texas fever.

\section{CHAPTER XX \\ THE MORE COMMON ALLMENTS OF CATTLE}

1. Tuberculosis in Cattle.......................419

(a) Tuberculosis and its sources.

(b) How tuberculosis is communicated.

(c) The symptoms of tuberculosis.

(d) The tuberculin test.

(e) Injury resulting from tuberculosis.

(f) Protective measures against tuberculosis.

(g) Disposition of tuberculous cattle.

(h) Keeping herds free from tuberculosis.

2. Abortion in Cows.

(a) Abortion and its causes.

(b) The indications of abortion.

(c) The losses from abortion.

(d) The preventive and remedial measures for abortion.

3. Milk Fever in Cows ........................ 430

(a) Milk fever and its causes.

(b) The indications of milk fever.

(c) Loss resulting from milk fever.

(d) Preventive and remedial measures for milk fever.

4. Actinomycosis, or Lumpy Jaw, in Catte......... 433

(a) Lumpy jaw and its cause.

(b) The indications of lumpy jaw.

(c) Injury resulting from lumpy jaw.

(d) Preventive and remedial measures for lumpy jaw.

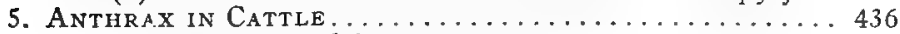

(a) Anthrax and its cause.

(b) The indications of anthrax.

(c) Injury resulting from anthrax.

(d) Preventive and remedial measures for anthrax.

6. Blackleg in Cattle.................... 43

(a) Blackleg and its cause.

(b) The indications of blackleg.

(c) Injury resulting from blackleg.

(d) Preventive and remedial measures for blackleg.

7. Hemorrhagic Septicemia in Cattle............ 441

(a) Hemorrhagic septicemia and its cause.

(b) The indications of hemorrhagic septicemia.

(c) Injury resulting from hemorrhagic septicemia.

(d) Preventive measures for hemorrhagic septicemia.

8. Cornstalk Disease in Cattle................ 444

(a) Cornstalk disease and its causes.

(b) The indications of cornstalk disease.

(c) The losses from cornstalk disease. 
Cornstalk Disease in Cattle-Contimued

(d) Preventive measures for cornstalk disease.

9. Removing the Afterbirth from Cows.............. 446

(a) Retained afterbirth and its causes.

(b) The indications of retained afterbirth.

(c) Injury resulting from retained afterbirth.

(d) Freventive and remedial measures for retained afterbirth.

10. Eversion of THE WOMb in Cows.................. 448

(a) Eversion of the womb and its cause.

(b) The indications of eversion of the womb.

(c) Losses resulting from eversion of the womb.

(d) Preventive and remedial measures for eversion of the womb.

11. Hoven, or Bloat, in Cattle

(a) Bloating and its cause.

(b) The indications of bloat.

(c) Injury resulting from bloat.

(d) Preventive and remedial measures for bloat.

12. Scour in Calves.

(a) The various forms of scour in calves.

(b) The various causes of scour in calves.

(c) The indications of scour in calves.

(d) The losses resulting from scour in calves.

(e) Preventive and remedial measures for scour in calves. 


\section{LIST OF ILLUSTRATIONS}

I'AGE

Shorthorn Cows at the Michigan Agricultural College

Frontispiece

Yearling Galloway Heifer, Vesper of Wavertree,

I4297 . . . . . . . . . . . . . 74

Pure Bred Aberdeen Angus Yearling Steer, Eclipser 75

Holstein Friesian, Sarcastic Lad, 2397I . . . . 105

Pure Jersey Bull, Czar . . . . . . . . . II3

Imported Guernsey Bull, Golden Knight, 3405 . . II7

A Minnesota Farm Steading . . . . . . . 134

Prize-Winning Grade Shorthorn Steer, Jack . . 142

Cattle in Pasture at Iowa State Farm . . . . 170

Pure Jersey Heifer . . . . . . . . . . 185

Prize-Winning Holstein Friesian Cow . . . . I96

Ayrshire Cow, Duchess of Smithfield, 4256 . . . 201

George Craig . . . . . . . . . . 302

Aberdeen Angus Steer, Black Rock . . . . . $3^{\mathrm{I}} 4$

Pure Shorthorn Steer, Crimson Robe . . . . 320

Grade Shorthorn Calf, College Boy . . . . . 322

Two-Year-Old Pure Aberdeen Angus Steer, Andy 338

Basement Barn Built by Author . . . . . . 350

Plan of Basement in Barn . . . . . . . . 356

Plan of Ground Floor Basement . . . . . . 360

Section of Stalls in M. A. C. Grade Beef Barn . . 365

Section of Stalls in M. A. C. Grade Cattle Barn - 366

Section of Stalls for Pure Bred Beef Cattle at

M. A. C. . . . . . . . . . . . 368

Calf Stanchions at M. A. C. . . . . . . 370

Feed Rack for Baby Beeves at M. A. C. . . . . 372 



\section{CHAPTER I}

\section{CALVES FROM BIRTH UNTIL ONE YEAR OLD}

The discussion of this question will consider: (I) The season when calves should come in the year; (2) The relative economy of rearing them on the dams or by hand; (3) Calves for feeding, for breeding, or for milk production; (4) Calves reared on their dams; (5) Calves when reared on skim milk; (6) Calves when reared on whey; (7) Calves when reared without milk; (8) Management of calves while being weaned; (9) Management subsequently to the time of weaning; (I0) Growing calves for veal; (I I) Grazing for calves; and (I2) Miscellaneous considerations that relate to the rearing of calves.

The season when calves should come.-The season of the year at which calves will be born may be regulated by the owner, but such regulation is not entirely under his control. Some of the females may fail to come in heat at the season when mating is most desirable, but may do so at a later period. In such cases, it would not be profitable to maintain these cows for many months before breeding them, with a view to have them produce only at certain seasons. In other cases, impregnation does not follow mating, hence the females must be bred later, or a period follows when no return is given by the cows for their maintenance. Usually it is possible and practicable to have all or nearly all the calves come at or near the season desired. Where cows must of necessity be housed in winter, it is usually considered more desirable to have the calves come in the autumn or early winter, whether reared by hand or on the dams, for the following reasons: (I) The grower has more time to care for them properly during the milk period, which is the most critical in the life 
of the young animal. The reasons why the grower has more time at his command in winter will be apparent, since during that season working in the soil is not practicable. This greater leisure makes it possible to give the calves that closeness of attention which is necessary to produce the most desirable results. This may not always be possible during the busy seasons of seedtime and harvest on farms which are without the services of a professional feeder.

(2) The calves may be weaned at that season when the hazard is least, that development will be checked by the weaning process. More especially when calves are reared on the dams, the hazard is present that they may lose flesh and weight when milk is withheld. Autumn or early winter calves will be ready for weaning sometime during the spring months, when the weather is becoming mild and green food abundant. Under such conditions there should be no cessation in continued development when the management is proper. It is much more difficult to maintain such development when calves are weaned at that season when the weather is becoming colder and when green food is not so readily available. Calves born in the spring must be weaned under such conditions.

(3) When weaned in the spring, they are not only better able to meet the conditions of winter fare during the first winter after weaning, but they can take a larger proportion of their food in a cheap and coarser form than when weaned in the autumn. Calves weaned in the autumn, being less advanced in development than those that are weaned in the spring, are less able to withstand conditions such as relate to exposure not in consonance with highest development. As in many cases, they are subjected to such conditions, they do not maintain growth equal to that which characterizes calves which have been weaned in the spring under similar conditions of exposure. Nor can they utilize to the same advantage cheap and 
coarse fodders, owing to the less advanced development of the digestive organs, the possession of which gives capacity to turn such food to profitable account.

(4) Winter dairying is more profitable than summer dairying. This follows from the less extent to which it is practiced, linked with a demand for dairy products, which is greater in winter than in summer. For these reasons dairy products, especially butter, are usually much higher in winter than in summer. The difference in the increased cost of providing butter in winter, if there is a difference, is not nearly equal to the difference in the price paid for butter. Where cheese-making only is the prime object sought in dairying, the advantage of winter dairying over summer dairying may be open to question, but where cheese is made in summer and butter in winter the advantage is fully as great as when butter only is sought. Even where cheese is the primary object in dairying, some of the cows should freshen in the autumn and early winter that the calves to be reared for the maintenance of the herd may get a good start by feeding on skim milk rather than on whey.

(5) Prolonged milking is more easily sustained in the cows, and the even continuity of the milk flow is more easily maintained. As is generally known, any decrease in the milk flow as lactation advances tends to increase the difficulty of securing subsequent increase sought by furnishing food better adapted for the production of milk. Decrease in milk yields produced by underfeeding, or by giving improper food, not only results in present loss, but it also has the further effect of increasing future loss, or at least of lessening future possible gains. When cows freshen in the autumn or early winter, the milk flow may be reasonably well maintained until the season for turning out onto fresh pasture, the succulence of which usually results in increasing the milk flow more or less for a time. On the other hand, when cows freshen in the spring, the 
tendency in the milk flow is to lessen with increasing dryness in the autumn pastures, and when the cows are housed and given food that is even less succulent, which is frequently the case, the milk flow is still further lessened. It is doubtless true, therefore, that the average cow that freshens in the autumn will give more milk during the entire period of lactation than she would give if she came into milk in the spring.

(6) Autumn calves are ready for market, all things considered, at a more suitable age than spring calves, when grown into finished beef. Cattle, grown for meat on arable farms and finished on the same, are now usually sold at an age not exceeding three years and not less than two years. Though sometimes finished at an age younger than two years, it is at least questionable if the greatest profit results from selling them so young and consequently so far short of possible development. When dropped in the autumn and well cared for all the while, they will be well matured at the age of 30 to 33 months. This would bring them into the market sometime between the months of March and August, a season when meat is relatively high. They could be sold from the stall or pasture as desired. To market animals dropped in the spring at a corresponding age would involve selling them when six months older or as many months younger. At the former age, they would not be so well grown; at the latter, the relative cost of growing them would be enhanced.

(7) Under some conditions, however, it is not practicable to have calves come in the autumn. Such are range conditions, where the winters are characterized by low temperature. To have calves come in the autumn under such conditions would involve the risk of losing both the cow and her progeny. It would also be injudicious to have calves come in the autumn under the extensive conditions sometimes found on large farms which necessitates giving the cows a diet consisting of dry fodder only during all 
the winter. Such food would not produce sufficient milk for the calves, and they would be much injured by the cold. Even where the winters are virtually without frost, calves should not come in the autumn when the dams must feed on pastures that have lost their succulence.

Economy of rearing on dams or by hand.-The economy of rearing calves by allowing them to suck their dams or by feeding them on skim milk and adjuncts during the milk period is largely determined by the conditions under which they are reared. Under range conditions, it is impracticable to rear calves in any other way than on their dams, for reasons that will be apparent. Under arable farm conditions, it is usually less profitable to rear them on their dams than on skim milk and adjuncts, as is shown below.

The annual cost of keeping a cow on the arable farm will, of course, vary. It has been estimated on high authority that it will not be less than, say, $\$ 25.00$ when the cow suckles her calf, and $\$ 28.00$ when milked by hand. The additional cost in the latter case results from the additional concentrates required because of the more prolonged period of milk-giving.

The only return from the cow that suckles her calf at the end of the year is her calf. The return from the hand-milked cow is her calf reared by hand, and the clairy product which she has furnished. Her calf will be reared mainly on the skim milk obtained from its lam and certain food adjuncts added. Only a part of the skim milk secured from the dam is required by her calf, and for not more than four months of a lactation period that covers nine to ten months. The skim milk furnished in excess of what is taken by the calf will considerably more than offset the value of the adjuncts given to the calf, in excess of those called for by the calf that takes milk from its dam during the milk period. The weight of the two calves when one year old will 
not be far different. In addition to the calf, the cow hand-milked should furnish cream or its equivalent in dairy products worth not less than $\$ 40.00$. The calf suckled by its dam should weigh not less than $75^{\circ}$ pounds, and that hand-reared not less than 700 pounds. Though the former sell for 5 cents a pound live weight, the latter should sell for $4 \frac{1}{2}$ cents.

The account, therefore, will stand as follows: $\$ 37.50$ the value of the calf reared on the dam, less $\$ 25.00$, the value of the food consumed by the cow, leaves $\$ 12.50$ as the net cash return for keeping the cow and her calf for a year. In the other case, $\$ 40.00$, the value of the cream or its equivalent, plus $\$ 3 \mathrm{I} .50$, the value of the caif, less $\$ 28.00$, the value of the food consumed by the dam, leaves $\$ 43.50$ as the net cash return. This amount will be increased by adding to it the value of a part of the skim milk, which will be more than offset by the greater cost of the labor involved in handling the milk. The value of the manure must also be considered, but it will be practically the same in both cases.

It is evident that on high-priced arable land, with the prices for food that have ruled during recent years, but little profit can be made from calves reared on their clans when but one is reared for one season, and is disposed of at the age of I2 months. But more profit should result if the calf is grown until two years old before it is sold, as then but half the cost of the food consumed by the cow during the year that she suckled the calf would be charged against it. It has been found profitable in some cases to grow beef under arable conditions, when sold at the age of one or two years, though reared on the dam. But such animals must be of some beef breed high in favor with dealer and consumer. They must be grown by the system of high-pressure feeding, and must be finished in the best form. The profit accrues from the high price which such meat 
brings when sold. These results can only be reached by skillful feeders.

If beef is ever to be extensively grown on the arable farm, the calves grown into beef must be furnished by hand-milked cows. This will follow, even though the system. described below of requiring one nurse cow to furnish milk for several calves should be adopted. The cows which produce them must be of the dual type. If of the straight dairy type, the progeny will not possess the desired requisites for making beef. If of the straight beef type, they will not furnish enough milk. Material modifications, yet in the future, in the relative prices of meat and milk, may lead to results quite different, but in the meantime, the farmer who grows meat from birth onward on the arable farm must obtain it from the dual type of cow.

The method of requiring one cow to suckle from two to five calves has been practiced on some of the farms of Great Britain. There would seem to be no legitimate reason against introducing it into America. It is in outline as follows: The dual type of cows is maintained and they are milked by hand. The progeny to be grown into meat are suckled by nurse cows. These nurse cows, as soon as they come into milk, are required to nurse two calves for, say, three months. The calves meanwhile are so fed that, by the end of the period named, they take to other food readily, which prepares them for being weaned without the hazard of checking growth. Two more calves are then put on the cow, and are similarly managed for the next three months. Then a fifth calf is introduced, which is suckled during the next three months. The cow rests during the following three months, until she freshens again. When but three calves are reared on the cow, the nursing period is, of course, prolonged. 
The advantages from such a system are: (I) It gives the calves a somewhat better start than when they are early put upon skim milk. (2) It is to some extent labor-saving. (3) It makes available a large proportion of skim milk when wanted for other uses. The chief difficulty to be overcome is that of securing calves from the milking herd just when they are wanted. This may in some cases be partially overcome by obtaining calves from cows kept for family use, providing the calves are not the progeny of straight dairy sires.

Calves for feeding, breeding or milk production.The object for which calves are reared should have a modifying influence on the methods to be adopted in rearing them. In some cases, the methods to be followed in rearing them for feeding and breeding may be approximate, but in others they materially differ. In all cases the rearing of calves for milk production chiefly differs from rearing them for feeding, but it does not always differ from the methods that are best suited to rearing them for breeding. Much depends upon the object for which they are bred. The methods that will be proper for growing animals reared mainly for milk production will be proper also for growing dairy animals kept mainly for breeding uses. Speaking in a general way, it will be correct to say that the diet for calves grown for feeding should be generous and rich in carbolhydrates during the whole period of calfhood, that for calves reared for breeding less so, and that for calves leared for milk production chiefly should be largely nitrogenous.

Calves for feeding on the arable farm, whether reared on the dam or by hand (see p. I2), should be given a diet that will not only promote good growth of frame and muscle, but that will also result in the free laying on of fat. While the calf is young it must be fed new milk or the equivalent of butter fat contained 
in the milk, in the form of suitable adjuncts. This is necessary, not only to secure satisfactory growth and weight, but also to strengthen the digestive habit of laying on flesh freely when the elements that produce it are sufficiently supplied. They should not only be kept in a good condition of flesh during the milk period, but subsequently. The meat thus produced is juicy and tender and is spoken of as "calf flesh." Up to a certain limit, it exercises an influence on the quality of the carcass subsequently. This influence, however, in all probability, weakens as the period of calfhood is receded from. When once lost this calf flesh cannot be restored; that is to say, although the animal should become fat again, the carcass will not be so juicy as if it had never been allowed to become lean.

It would be possible to secure and maintain excessive fatness in calves reared for feeding, although in the practice of growing them such a condition is the exception and not the rule. Fatness is excessive when it has been secured at the sacrifice of growth, that is, of bone and muscle. Such a condition may be produced by feeding food too rich in carbohydrates and too lacking in protein. Development otherwise possible will not be attained by such an animal, even if kept until maturity. It is also excessive when secured at the expense of weakened digestion or weakened stamina. The degree of the high flesh that should be sought should depend to some extent on the age when the animal is slaughtered, and also on the cost of securing it. The younger the animal to be slaughtered, the higher the condition of flesh in which it may be maintained, and vice versa. When an animal is to be sent to the block under the age of 12 months, its growth is seldom seriously impaired by excessive fatness.

When growing calves for breeding, the methods will be to some extent modified by the particular object for 
which they are grown. When distinctively of the beef class, and purely bred, they are usually suckled on the dams, and are in addition fed a supplement of meal or grain from the time that they will take it indefinitely onward. The wisdom of feeding the grain supplement and the amount that may be fed with profit is dependent on its relative cost, on its composition, and on whether the calves are to be retained or sold. Usually the cost of grain is not so much as to preclude feeding more or less of it at a profit, and especially when sufficiently rich in protein to promote desirable development. When calves are purely bred and the grower aims to sell them at an age not exceeding one year, the grain supplement fed should be more or less rich in carbohydrates. This aids in the quick disposal of the calves, on the principle that the dominant influence exerted on the prospective buyer is that which comes from a high condition of flesh, and because it is pleasing to the eye. Such a condition of flesh is not necessarily beneficial to the calf. If carried to excess, the result will be the opposite. Not more than reasonably high fleshing should be sought in such animals when retained for breeding.

When growing calves for breeding of the dual type, they should be hand-fed on a skim-milk diet, except when they are to be disposed of as veal at an early age. To rear them on their dams would add too much to the cost of growing them. It would also tend to beget in them that habit of digestion which would favor flesh production rather than milk production in the females, when of sufficient age to produce milk. By parity of reasoning, it would seem correct to assume that keeping breeding males in a very high condition of flesh from the first would tend to transmit the flesh-producing rather the milk-producing tendency to the progeny. But with this class of cattle, more flesh is wanted than with straight dairy cattle. The mistake of growing 
them in a condition of flesh too low rather than too high is in actual practice the more common of the two by far. Animals of this type, when grown for beef only, may with equal propriety be kept in as high a condition of flesh as animals of the distinctively beef types grown for the same ends.

In growing calves of the dairy types for breeding, the aim should be to grow them in moderate but not in low flesh. This can only be done by rearing them on a skim-milk diet with suitable adjuncts. To rear them on their dams would be adverse to the development of the milking quality, and it would be prejudicial to the same in the dams that suckled them.

What has been said about the rearing of calves for breeding of the dual and dairy types will apply equally to rearing them for milk production. They ought, of course, to be fed on a protein diet. It would be a mistake to keep them on a diet so lacking in nutrition that a reasonable maximum of development in frame and muscle would not be attained. Nor is it necessary to feed food that is bulky to the extent of creating distension of paunch in the young animals that would detract from their symmetry of form. This has in some cases been advocated with the view to increase the depth and capacity of the body. With correct feeding, such distension will come gradually and increasingly as it is needed.

Whether calves are reared for feeding, breeding, or milk production, the economy of keeping them pushing well ahead from the day of birth, whatever the use may be that they are to serve, should not be overlooked. Reasonably quick growth is not so important in the milk-producing as in the meat-producing animal, but it is important notwithstanding that it is growth which differs in kind from the other. The most rapid growth attainable should not always be sought, as to secure it 
may involve too much outlay for high-priced food. It may prove more economical to be content with less rapid development, and to take a longer time to reach the end sought. Conditions affect materially the exact method to be followed.

Calves reared on their dams. - When calves are reared on their dams during the milk period on the arable farm, they are sometimes allowed to remain with them all the while, but in other cases and more commonly, they are confined, and only allowed to nurse the cows at stated intervals, usually morning and evening. Of course, under range conditions, the calf remains at all times with the dam. Under farm conditions, as a rule, only pure-bred calves are allowed to remain with the dam all the while until weaned, and in a majority of cases even these are only allowed to suck the dams at stated intervals. When more than one calf is suckled by each cow, it would not be practicable to allow the calves to remain with their dams, as one might get more than its rightful share of milk, and from the frequency with which both would seek food, would become a source of unrest to the cow. Calves that are to be vealed will do better, as a rule, when they take their milk from the dam, but it is not imperative that they be so reared.

The following are chief among the advantages from rearing calves on their dams: ( I) They are started in growth under conditions that are most favorable to a healthy development, as they take their food from the dam without excessive haste, as in the case of calves that drink it down quickly, and they also take it with that frequency which is conducive to healthful assimilation. (2) A proper amount of exercise is secured, which is conducive to the development and maintenance of stamina. (3) Much less labor is called for in caring for the calf. 
Prominent among the benefits that result from confining them are the following: (I) Much less room is called for by either cow or calf during the period of housing. (2) The disturbance to the cow is less when the milk is withdrawn from her only at stated and regular intervals. (3) It is probable that the dam will furnish more milk when the milk is taken only at stated intervals than when taken irregularly, as when the calf is with the dam. This assumption is based on the known tendency in irregular milking to reduce the milk flow in the cow that is milked by hand. (4) When confined the calves may be fed supplemental food more easily and more satisfactorily than when they run with the dam. They are in this way so accustomed to such food that they may be weaned with but little hazard in arresting growth; and (5) they can be more perfectly protected from flies in the fly season, and from hot sun in exceedingly warm weather. The preponderance of opinion favors confining such calves to stalls and paddocks until the weaning season is past.

When calves remain with the dam until weaned, when not on pasture, both cow and calf must be kept in a box stall. Into this the cow should be placed several days before she is expected to calve, as a precautionary measure, should parturition take place in the absence of the attendant. The calf, if healthy and strong, will take nourishment sufficiently early, but if weak, it may be necessary to help it to do so, and if weak beyond a certain degree to give it some of the dam's milk, it may be with the aid of a spoon. The attempt to retain such weaklings should not be made, unless when of much value because of inheritance in blood lines that are much prized. Such animals seldom attain to development that puts them in the first rank of excellence. When once well on its feet, a calf will usually take care of itself. But it is greatly important 
that due attention should be given to withdrawing the excess of milk remaining in the udder above the needs of the calf. (See page 212.)

When calves that are suckled are kept separate from the dam, it would seem to be advantageous to allow them to remain with their dams when practicable, in a box stall in winter, or in a stall or small paddock in summer, until they are, say, one week old. The machinery of digestion is thus allowed to begin its work under the most favorable conditions that it is possible to secure. When practicable, the calves should then be allowed to take nourishment from their dams three times a day until they are, say, three weeks old, by which time they will be able to take some food from other sources.

When thus confined, the nature of the supplementary food given will be influenced by the purpose for which the calf is reared. If the object sought is maximum growth at maturity, concentrates and also the fodders fed should be rich in protein. Wheat bran, oats, and oilcake should prove suitable in the proportions of say 45,45 , and Io per cent of each, respectively. But other concentrates and combinations of the same may be used, providing they are rich in protein. If but one concentrate is fed, oats will best serve the purpose. If the calves are to be grown for baby beef, bran, oats, and corn, fed in equal parts by measure, will be suitable. The corn should always be ground, and also the oats, for calves quite young. Such a grain mixture will also prove suitable for pure-bred calves that are to be pushed forward for sale at an early age. For starting them on such food see page 21. Alfalfa and clover finely grown, cut early, and well cured furnish the best roughage, but other fodders may also be used. (See page 23.) For the amount of concentrates to feed and the continuance of the feeding see page $2 \mathrm{I}$. 
When calves run with the dams, they are seldom fed any grain supplement, but it is possible to feed them such food, and under some conditions it is profitable to do so. Particularly is this true of pure-bred calves that are to be pushed forward for sale. When the pastures are not abundant, the necessity for such feeding is all the greater. When so fed, an inclosure is made with openings through which the calves only may pass at will. Troughs of suitable height are placed in these, which cannot be easily overturned, and in these troughs the supplementary meal is placed. A roof to protect the troughs from rain will prove economical in a country of frequent rains. The inclosure should be located near the place where the dams take water, if watered from a well, or, in the absence of such a condition, where the dams are much prone to congregate and take rest, as near the salting troughs. The calves are thus brought more into proximity to the feeding places than would otherwise be the case. The food fed may be the same in kind as that mentioned above. Some cattle growers feed only oilcake in the nut or pea form. The chief objection to such feeding is its cost, but the oilcake may in some cases be eaten so freely as to produce too much laxity in the digestion.

When more than one calf is to be reared on one cow, it is important that the cow shall not only produce milk freely, but also that she is of a gentle and tractable disposition. Some cows are so unruly that they will not allow a strange calf to take nourishment from them, unless the attendant is present to restrain them, and some are so vicious as to try to injure both the attendant and the strange calf. Those cows are not suitable for such a use. Much care is necessary in giving supplemental food to these calves, especially should the cow be required to rear five in one season, as the period with them for taking milk is short. They should be 
given more concentrates relatively than those that are given milk for a longer period.

Calves when reared on skim milk.-However calves may be reared, it is important that the first food given them shall be the milk of the dam. In this milk, usually spoken of as the colostrum, is a purgative principle, which is usually effective in expelling from the digestive tract all matter that has collected there before the birth of the calf. Without such expulsion, the normal processes of digestion cannot properly perform their functions. Unless these substances are expelled within a reasonable time subsequent to the birth of the calf, death will result. Should anything occur to make it impossible to feed the milk of the dam to the calf as its first food, a suitable dose of castor oil or some other purgative administered to the calf soon after its birth and before any food has been given to it will prevent such a result. From one to two ounces of castor oil should suffice.

The calf that is to be reared on its dam will, of course, take its nourishment from her as soon as it should be taken, and as frequently where the conditions are normal. Should the calf, however, be too weak to take nourishment within a short time subsequent to its birth, it may be necessary to withdraw some milk from the cow and give it to the calf, which sucks the fingers of the attendant while it is taking the milk. When the calf is to be reared by hand, opinion is divided as to whether it should be given its first meal as just described or take it from the dam. The chief objection to the latter method is the increased difficulty in getting the calf to drink subsequently. The preponderance of argument favors not only allowing the calf to take its first meal from the dam, but to continue to take sustenance from her for two or three days, or until that time arrives when the milk of the dam may be 
used in the dairy. Unless the digestive processes are properly started at the first, the young animal begins existence under a handicap which it may never be able to overcome completely. Because of this, that method of providing sustenance that will conduce to such an end should be adopted. Nature's method is unquestionably the best, which allows the young animal to take ncurishment from the dam when disposed to do so. By the time that the milk of the dam is fit for use in the dairy, the young animal should have made a good start, thus preparing it for the more artificial methods of feeding that are to follow. Should it be objected that the calf thus allowed to take nourishment from the dam will not readily learn to drink milk subsequently, it may be answered that if allowed to become sufficiently hungry, it may soon be induced to take milk with or without the hand. The hunger thus permitted may prove a slight check to development, but it will not be in any degree serious with a calf that has been given a good stärt in life.

The continuance of the period during which new milk only should be fed will depend to a considerable degree upon the object for which the animal is to be reared. (See page I8.) It will usually vary from one to four weeks. The time occupied in making the transition from all whole milk to all skim milk is about the same. The duration of both periods is influenced by the price of new milk, the object for which the calf is reared, and the inherent vigor of the calf. The higher the value of new milk, the greater the necessity for restricting its use, but this should never be done to the extent of preventing reasonable development, both present and prospective.

When reared with a view to furnish milk chiefly, the shorter period of taking whole milk only, and of changing to all skim milk, may be in order, but when 
reared with a view to furnish beef only, the longer period should be preferred. When reared to provide both meat and milk, the intermediate period should prove satisfactory. Thus calves reared for dairy uses may be taking skim milk only at four weeks from birth, calves of the dual type at six weeks, and for beef uses only at eight weeks. But the inherent vigor of the calf as indicated in capacity for growth may furnish sufficient reason for lengthening or shortening those periods with all three classes. A calf with strong digestive capacity may be put on a less nutritious diet without any serious hindrance to development much more quickly than one with weak digestive capacity.

While on whole milk, the calves usually require no other food, such as meal or fodder. The digestion of the young animal is not yet prepared to utilize such food, at least until the calf has reached the age of two or three weeks. The whole milk thus given should be fed as soon as practicable after taking it from the cow, that it may reach the calf while yet fresh and without diminution of temperature. When fed more frequently than morning and evening, as it ought to be to calves so young (see page I7), to feed the milk at the proper temperature will call for heating. This should not be neglected, as close attention to all details in feeding the young calf will be abundantly rewarded.

The change from whole to skim milk is made by withholding a small amount of milk the first day, a larger amount the second day, and a still larger amount the third. The amount withheld is thus gradually increased from day to day, and in a way that will insure complete change from all whole milk to all skim milk within the time fixed upon to effect such change. An amount of skim milk must be added, at least equal to the quantity of new milk withheld, until the change has been completed. 
As soon as the substitution of skim milk for whole milk begins, it is greatly advantageous to add to the milk some substance that will supply an equivalent of the fat contained in the new milk withheld. No substance has been found better for such a use than linseed meal, that is, ground flaxseed. Oil meal will answer the same purpose, and is far more frequently fed than ground flax, for the reason, probably, that it is relatively cheaper. When the latter is used, it is necessary to feed a larger quantity than of the former. In some instances, and more commonly, the meal thus added is stirred in the milk, but in other instances, as when the calves have learned to take meal before the change from new to skim milk has begun, it is simply added to the meal. By adding the meal to the milk, the amount to be fed for a time at least may be more easily determined than by adding it to the dry meal, as the calves when young may not consume enough of the dry meal to give them a sufficient amount of the oil meal. But at a later period, when meal is eaten freely, it will be found much more convenient to feed the meal in that way, and should also effect the purpose sought as well.

Formerly the practice was common of preparing a gruel from flaxseed and adding the same to the milk with each meal. This was prepared by adding to the flax, say, ten times its bulk of water, allowing it to soak therein for several hours and then boiling for one hour, or until the seed has become softened and the whole mass has been transformed into a jellylike substance. Enough may be prepared at once to last for several days when the weather is sufficiently cool to preserve it in suitable condition for feeding.

The jelly is most conveniently prepared and kept in a vessel in which it may be heated in a stove from time to time as required for feeding. When thus heated, it tends to raise the temperature in the milk when added 
thereto. This method of furnishing the requisite amount of fat to be fed with skim milk was more necessary before separated milk was available than it is now, as when separated milk is fed soon after milking it is not necessary to add heat from an artificial source. It may still be advantageously practiced where separated skim milk is not to be had, and where a supply of flaxseed is also on hand. The jelly may be made from linseed if more convenient.

The amount to be fed may be regulated, for a time at least, by the influence that the meal or the jelly exercises on the digestion. If too much is fed, the digestion will be unduly lax, a condition that is easily corrected by reducing the quantity fed. Usually a heaped spoonful of the ground flax, or two of the oil meal, or, say, two-thirds of a cupful of the jelly, will be sufficient at the first. After a time the limit of the profitable feeding of the flax or oil meal may not always be indicated by the character of the digestion. There comes a time when the amount consumed without disturbing digestion would be too costly for the most profitable feeding. The fact remains that this most excellent food adjunct may be more or less used with profit in all or nearly all kinds of calf rearing. The physiological influence which it exerts is most beneficial apart from the nutrition which it furnishes.

The supplementary concentrates fed will vary with the age of the calf, with the precise object of the feeding, and with the concentrates that may be available in any given locality. For calves that are quite young. meal without coarse hulls is the most suitable, as these are irritating to the digestive organs, but after feeding upon it for a time, say, two or three weeks, coarser meal may be given instead.

The relative proportion of the protein fed in the concentrates will be the greatest with calves that are 
reared for milk production, and of the carbohydrates with those that are to be fattened, and more especially with those that are to be fattened at an early age. All or nearly all the concentrates grown may be used in feeding calves, but, as a matter of economy, attention should be first centered upon those grown in the locality.

As the first meal given separately from the milk, none is more suitable than ground oats with the hulls sifted out. Ordinary oatmeal answers admirably but for its relative cost. At the end of, say, two or three weeks, the oats may be fed either ground or crushed and without sifting, and finely ground corn and wheat bran added to the mixture. This combination is, in not a few instances, fed from the first, and when so fed usually proves fairly satisfactory.

As a standard meal ration for calves on skim milk, the following may be recommended as eminently suitable: Ground corn, ground oats, wheat bran, and oilmeal in the proportions of 3,3 , I, and $\mathrm{I}$ parts respectively by weight. During the milk period they should be given all of this that they will take, but subsequently the amount should be regulated. The regulating factor is the degree of flesh sought in the calves, those intended for milk production being maintained in lower flesh than those of the beef types reared for breeding. But in no instances would it be wise policy to allow them to become lean. When calves have a good start and safe, growth subsequently cannot be produced so cheaply from concentrates as from more bulky foods, hence one reason for restricting their use subsequent to the milk period. Prior to that time they are not likely to eat so much of the meal as to make it unduly expensive.

Various other grain supplements have been fed and in various combinations, and on the whole have proved 
fairly satisfactory. Among these are the following: (I) Where corn meal is plentiful and oil meal is lacking, a mixture consisting of equal parts by weight of corn and cob meal finely ground, ground oats, and wheat bran, has given good results, but some feeders prefer corn ground for calves without the col. Where oats are not available, corn meal and bran in the proportions of 1 and 3 , respectively, may be fed, but not so advantageously probably as the former. (2) Where peas and barley are mucl grown, as in Canada and the mountain regions of the II est, ground oats, peas and barley, wheal bran, and oil meal in the proportions of 4, I, I, 2, and I, respectively, has been found to answer well, especially for calves reared for milk production. (3) In the northwestern states, where millet grows well, it is highly probable that a mixture of ground millet, oats, bran, barley, and oil meal, in the proportions of $2,3,2, \mathrm{I}$, and I parts, respectively, will prove a good food for calves, but cxperiments made with millet seed in feeding calves lave not been numerous. (4) In the southern states, the concentrates that could be most cheaply furnished are corn meal and cottonseed meal, but the latter has not proved entirely satisfactory when fed to calves during the milk period. Because of this, oil meal and wheat bran as a source of protein, though both should have to be shipped in, would be more economical. For southern conditions, corn meal, wheat bran, and oilcake in the proportions of 3,3 , and I parts, will probably be found suitable.

When calves on skim milk are to be pushed for the block at the age of six to nine months, they, like calves for other uses, can be best started on a supplementary meal ration of ground oats without the hulls and oil meal. As soon as they will eat the dry meal freely, finely ground corn meal may be added. The mixture may then be fed in the proportions of 4,4 , and I parts 
of the corn meal, ground oats, and oil meal, respectively. When the calves are six to eight weeks old, it is not essential that the oats or corn shall be ground. For such feeding the standard ration given above will also answer well, but for highly forced feeding the proportion of the corn may be increased with advantage as the feeding progresses.

Should the feeder be confined to the choice of one grain, it should be oats. Properly fed, satisfactory results should follow feeding oats only during the milking period. Before the calves will take the meal dry, it may be fed as porridge in the milk, later as ground meal, and still later as whole oats. It is one of the safest foods that can be fed, hence it is sometimes fed as a corrective to scours. Oats promote the growth of muscle, maintain enough flesh, and provide sufficient material for bone. The chief obstacle to feeding oats thus freely arises from the high relative value of oats in the market.

As soon as calves will take fodder, it should be given to them. They will begin to nibble at it when not more than two or three weeks old. No fodder is more suitable for them than clover or alfalfa hay. This will be more relished when fine in character, cut early and cured so as to preserve the bright green color. When many calves are reared, effort should be made to provide them with such fodder. Clover of the second cutting is quite suitable, and the same is true of guod cowpea hay. Timothy and millet are less suitable, but may serve the purpose when leafy and of fine growth. Corn fodder and sorghum may also furnish such fodder, but when so used it is imperative that both shall be of fine growth. Oat hay and barley hay will also be relished if cut at the proper stage of growth. For a time the fodder furnished 
should be in excess of the needs of the calves, the uneaten portion being removed from time to time and fed to older animals.

Corn ensilage or field roots, or both, may be fed to calves even while yet on milk with much profit. Either may be fed up to the limit of consumption by the calves. Of the two, ensilage is the cheaper, but field roots are superior in the influence which they exert on a vigorous digestion and in producing large growth. The free use made of field roots in Great Britain and Canada are unquestionably responsible in a considerable degree for the large and sappy growth attained by the cattle of those respective countries. Where both can be fed, the ideal method would be to feed ensilage one end of the day and roots the other. Both or either may be fed during the milk period up to the limit of the ability of the calves to consume them. The roots may be prepared by slicing them with a root-cutter, or by running them through a pulper.

Authorities differ greatly as to the amount of milk that should be fed to calves. Some recommend beginning with 6 to 8 pounds daily, while others recommend twice the quantity. The amounts specified differ thus widely throughout the feeding period. The difference in view arises from a marked difference in the capacity of calves to take milk. With reference to this question, the following observations will hold good: (I) The amount of milk fed should be determined by the observed capacity of the calf to take milk, and by the relative cost of skim milk and adjuncts fed along with it. (2) During the first weeks of the life of the calf, or until it begins to eat other food freely, it should be given all the milk that it will take without disturbance to the digestion. (3) Subsequent to that period, the amount fed should be determined in part at least by the relative value of the milk. The feeding of skim milk up to the 
limit of the capacity to digest it is favorable to large growth, but with suitable adjuncts nearly as much growth can be secured with a moderate amount of milk as with a maximum amount of the same, and at less cost. It would seem correct to say that usually it would be safe to begin with 6 pounds of milk daily, giving 8 pounds at the end of the first week, and to add I pound eacli week subsequently until the age of Io to I2 weeks is reached. Any excess of milk given at once disturbs the digestion, and is usually followed by too lax a condition of the bowels.

The period during which milk should be fed will depend to some extent on such considerations as the purpose for which the calf is reared and on the milk supply. Where at all practicable, it should be fed for not less than three months, and it is seldom necessary to feed it for a longer period than four months. When calves suck their dams and milk is furnished for but one or two, they are usually allowed to take milk for five to seven months. Skim milk has been fed to calves, and in la:-ge quantities, until fully 18 months old, and with satisfactory results when seeking the largest growth attainable at an early age. Skim milk is peculiarly well qualified to furnish large development of muscle.

Calves when reared on whey.-The testimony of experienced growers is practically unanimous that calves should not be fed whey in large quantities until they are at least six weeks old, but that after that age is reached the liquid portion of the diet may be gradually changed from skim milk to whey, taking one or two weeks to make the change. To feeding whey at an earlier age there are the following objections: ( I) It is too lacking in the elements of nutrition to properly sustain calves, until they have learned to partake freely of supplementary concentrates. (2) The quantity called for, 
even to maintain moderate flesh, is such that it produces undue distension of the paunch, which renders the animal less attractive to the eye, without giving any compensating benefits in return. (3) The whey which, in most instances, comes from the vat at the cheese factory is frequently so far injured by unsanitary conditions as to be a menace to the well-being of a young calf. Subsequent to the age mentioned, whey may take the place of skim milk, in whole or in part, without any detriment to the ultimate development of the calf, and when so used it furnishes a food more economical than skim milk.

The objection to feeding whey to calves at a younger age than was mentioned above may be met in part, if not, indeed, entirely, by having the calves that are to be reared come in the autumn, winter, or early spring, while the cheese factories are not yet in operation. In the ordinary dairy it is not necessary to rear even all the female calves to replenish the herd. The aim should be to have those that are to be reared come at that time when the cheese-factory season begins, that is, before it will be necessary to feed whey. In this way some of the calves will have almost or entirely reached the weaning period before the time has arrived for feeding whey, and others will have gotten past the danger point of inferior development resulting from a change from skim milk to whey.

Taking it for granted, then, that calves should not be put upon a diet of whey with adjuncts before they are six weeks old, when necessary to make such a change, it may be done as follows: Up to the age menticned, the calves may be fed exactly as described when reared on skim milk. (See page 16.) The change is then gradually made from all skim milk to all whey, taking one or two weeks, as intimated, to make it. The amount of whey fed should be much the same as of 
skim milk, but it should not be fed to the extent of creating undue distension of the paunch. As whey is less nutritious than milk, it will be necessary to increase, where practicable, the quantity of the adjuncts fed. These may be the same as for calves on a diet that is essentially skim milk. When not practicable to change the amount of the grain supplement, as when the calves are allowed to eat of this at will, its nutrients should be strengthened by increasing the proportion of the corn meal or barley meal, for instance, in the mixture. The fodders may be the same also as when rearing the calves on skim milk. (See page 23.) It may also be advantageous to continue feeding whey for a longer period than it is really necessary to feed new milk.

Much care should be taken to feed the whey as fresh and free from taint as possible. At cheese factories, the whey vats should be thoroughly steamed and so kept clean and sweet. No washings from the utensils used should reach the same. Every reasonable care should be exercised to feed the whey in as sweet and pure a condition as possible. Much of the disappointing results from feeding whey are due to feeding it in an unsanitary condition.

Calves when reared without milk.-Theoretically it would seem possible to furnish some substitute that would take the place of milk, and that would cost less. In practice this has never been completely realized. In no way can quite the same thrift be obtained from the young calf as by giving it the milk of the dam, and no method has been found quite equal to allowing the calf to take milk from its dam. This may be owing, in part, to the more natural way in which food reaches the stomach when taken directly from the cow. But the cost of new milk usually renders it prohibitive to feed for any considerable period on the arable farm. Next to new milk, skim milk is the best food for calves. But 
instances may and do occur in which skim milk even cannot be had. Is it possible to raise calves practically without milk, and if so, will the results justify the effort? To both these questions an affirmative answer may be given. Good cows for the dairy have been raised under such conditions. How can this be done?

To give the calf a good start it should have new milk for a few days at the first. Unless when the dam has been lost at parturition, or has met with serious mishap, as when attacked by milk fever, it would be possible and practicable to give the calf the milk of the dam without any hindrance until it is fit for use. It will be greatly advantageous if the milk can be continued for a week or two, even though it should only form a part of the liquid food given. As soon as any portion of the new milk is withdrawn, add some hay tea to that given, but do not add enough to produce distension of the stomach. The hay tea is best made from earlyharvested clover or alfalfa, cut fine by a straw-cutter and made to simmer for a considerable time over a slow fire, and then strained through a suitable wire sieve. This is added to the milk and fed at a suitable temperature, and is fed, if possible, not less than five times for the first week, and three times the second and third weeks. When the calf is a week old, flaxseed gruel may be added to the liquid, and also thoroughly cooked oatmeal and wheat middlings. The cooking is chiefly intended to encourage the calf to take such food when quite young. When the calves take dry meal freely, it may be discontinued, but oilmeal must continue to form one of the factors of the meal.

If the calf or calves can be kept in a box stall in which is an older calf, but not so old as to rob them unduly of food, they will sooner learn to eat meal from the example of the latter. But such feeding may be hastened by taking a little meal in the hand and putting 
the hand into the mouth of the young calf. Calves may also be taught to eat roots by putting a thin, narrow slice in the mouth similarly.

The meal adjuncts fed may be virtually the same as for calves reared on skim milk. (See page 2I.) The fodders also may be the same, with the one difference that roots rather than corn ensilage will prove the more satisfactory, since the latter is a carbonaceous food. It is also probable that "alfalmo" can be used for such feeding with benefit. This product is simply alfalfa hay of tender growth ground up into meal. Because of its fine mechanical condition, calves may be made to consume it somewhat earlier than they would take the hay, and also in greater quantity, at least for a time. As soon as the calves chew the cud, it would seem beneficial to feed meal mixed with finely cut hay. Many calf foods have been put upon the market. For some of these the most extravagant claims have been made, and this has led many to shun them altogether. It is with these, doubtless, as with condimental foods; they will differ greatly in their feeding value, and all of them, it may be, are unnecessarily costly. Yet the fact remains that some practical men feel that it is to their advantage to use certain of these more or less. If used at all, it would seem reasonable to suppose it would be fitting to feed them when calves are reared almost entirely without milk.

Management while weaning.-In very many instances there is a loss of flesh in calves, for a time at least, following the weaning, that is, the withholding of the milk from them. This loss of flesh is usually greater in calves that have sucked their dams. This follows for the reason, first, that when the milk of the dam is withheld, it deprives them of a more nourishing food than skim milk furnishes; and, second, that they have been less accustomed to such meal adjuncts as usually accompany the feeding of skim milk. The aim shou'd 
be so to prepare the calves for being weaned that this loss of flesh would be entirely prevented or at least reduced to a minimum. This can best be done by having them so accustomed to the adjuncts that accompany the feeding of milk, especially during the later stages of the milk period, that the withholding of the milk will be no serious deprivation. If flesh is lost subsequent to the weaning, there is not only a loss in weight, but a distinctive loss in the sappy flesh known as milk or calf flesh, which it is almost impossible to restore. Subsequent grain feeding may result in the carrying of an increased quantity of flesh, but it is harder and less sappy than the calf flesh.

The age at which calves are weaned has an important bearing on the results that follow weaning. The older that calves are when weaned, the less do they feel the deprivation when milk is withheld from them. Theoretically, therefore, it would follow that the weaning period should be deferred as long as possible, but in practice there may be good reasons for shorteming it, as, for instance, a shortage in milk in the case of handfed calves, and a desire to spare the dams in the case of those that suck. As previously intimated, calves hand-fed are usually weaned at about six or between the ages of five and seven months.

When weaning hand-fed calves, the milk should be reduced gradually rather than taken away suddenly. This may be done by reducing the quantity of each feed, or by withholding one of the two feeds, or by combining the two processes. When done in this way, the total withdrawal of the milk will scarcely be noticed by the calf, and will not affect it adversely. The time to be occupied in the weaning process is influenced by the age of the calf. The younger the calf, the more gradual should be the weaning. It may usually be accomplished in one week, and in no instance would it seem necessary to prolong it to more than two weeks. 
When the calves have been accustomed to a meal supplement, this should be continued, in most instances, virtually the same. For calves of the beef types reared for breeding, the standard ration given on page $2 \mathrm{I}$ will be very suitable. For those intended for slaughter while yet young, a meal ration of corn, oats, and oil meal in the proportions of 4,2 , and I parts, would be quite suitable. For those of the dairy type, the standard ration referred to above, fed in moderate quantity, will answer, or it may be substituted by the following: Oats 4 parts, shorts I, bran I, and oil meal I. The quantity fed to breeding animals should be limited by the amount of flesh carried and by the cost of producing it. If weaned in the spring, good pasture will furnish ample supply of succulence without anything else, but if weaned in the autumn the aim should be to furnish an ample supply of field roots. In the absence of roots, corn ensilage will probably be the next best substitute.

When the calves have taken milk from the dams, the weaning of those that have not followed the dams in the pastures may be accomplished with but little or no check to their growth, as, if properly cared for, they have so accustomed themselves to supplementary food as to rely largely upon it, even before the weaning season. The weaning with these may be in a sense gradual: that is, the nursing from the dams may be reduced from twice to once a day for a short time before milk is finally withheld. This will also aid in the gradual drying of the dams. When the calves have run with the dams up to the time of weaning, it is necessary to confine them for a time to accomplish the weaning and also to get them to take supplemental grain food. While it would not be impossible to wean them gradually as just described, it would not be easy to do this, as such calves are wild and intractable compared with the former. Pefore these take freely to supplemental meal, they will almost certainly lose more or less flesh. The 
standard meal ration (see page $2 \mathrm{I}$ ), will be quite suitable for the former, but the latter should be given more relatively of fat-producing food for a time than the standard ration calls for to counteract the tendency to lose flesh.

Management subsequent to weaning.-Calves that come in the autumn are weaned or are ready to wean by the time that fresh pasture comes in the spring. When this can be abundantly supplied, it settles the question meanwhile, as to fodder, that is, as to the bulky portion of the food given. No other kind of bulky food can be given while grass is succulent that is superior to it. Of course, some attention is necessary to guard against a too lax condition of the bowels caused by the tender grass, but, in most instances, the grain or meal that is fed will sufficiently counteract this tendency.

Whether the meal portion of the food shall be continued will depend to some extent upon the attendant conditions. Pure calves of the beef breeds, being made ready for autumn sale, should get enough of grain or meal to keep them well fleshed. The same is true of calves to be matured early for beef; calves retained for breeding uses of the beef types should be given a less amount and calves for the dairy may sometimes be carried through the summer without grain. But in no instance should calves for breeding uses be allowed to consume all the grain that they will take, first, on the ground of economy, as grass is usually cheaper than grain, and, second that there is hazard that the digestive organs shall be overtaxed. For feeding at this time no meal mixture is superior to the standard mixture mentioned on page 2I, but, if desired, the oil meal may be supplanted by an equal amount of oats while grass is plentiful. If one kind of grain only is fed, while the grass is plentiful and succulent neither roots nor ensilage is necessary. 
Should the grazing become cither scant or overdry, additional food must be furnished in some form, either in the form of supplemental grazing (see page 37), of soiling food, or of field roots. As soiling food, nothing is superior to corn grown so thickly that the stalks are fine. Ensilage is good, but may not be attainable at such a season. Fall turnips grown so thickly in the row as not to be large, pulled and strewn claily in the paddocks, are excellent. No cessation in growth should be allowed.

The first summer such calves should, if possible, have access to a stable or other inclosure when the weather is hot, and especially in time of flies. During the fly season the open windows should be covered with coarse sacking to darken the place, and at the same time to make ventilation. No cooler place can be found at that season than a basement furnishes. They should also have access to a pasture. Where this cannot be furnished a paddock is, in a sense, a necessity. In this they will lie at night. There is no doubt that quite as much of growth can be obtained from calves that have only a paddock in which to go the first summer as from those that have access to pasture, but the cost of caring for them is considerably more.

When calves come in the spring, they are weaned at a season when the pastures have lost or are losing their succulence. This may possibly be supplied for a time by a rape or some other late pasture. It may also be furnished by feeding fall turnips as described above. If large roots are fed, they must be cut up in some form. When a silo is at hand, ensilage may be given in place of roots, or both may be fed until the following spring, and in large quantities until grass comes again. If only one of these can be fed, roots are decidedly preferable. Meal must be more freely fed to such calves than to those weaned in the spring, as they are not inclined to eat so freely of dry fodder as of fresh grass, but the 
amount fed should be limited. The meal or grain fed may be virtually the same as that given the calves weaned in the spring, with the difference that more corn may be fed in the mixture during the coldest months. The fodder may be the same as for calves while yet on a milk ration. When ensilage is present, the meal can be profitably fed with this, but where it is not more complete, digestion of the meal will be secured by chaffing some of the hay and feeding meal along with this.

Such calves may be most cheaply wintered in an inclosed shed or stable, in which they run loose, except when eating this grain. When thus engaged it is better to confine them in stanchions erected on some such plan as those just described on page 370 , that each calf may get its rightful share. The inclosures should be reasonably warm and well ventilated, and should give easy access to a protected yard or paddock attached. Every care should be taken to guard the calves from exposure to early storms and early frosts. It is especially important to guard them from cold rain or sleet storms. Special attention is fully as necessary in changing the calves from grazing to winter quarters as when changing them from winter quarters to grazing.

Growing calves for veal.-Veal in the strict sense means the dressed flesh of the calf that has been fed milk only. Veal produced from feeding whole milk only, and especially when the calves are not marketed at too young an age, is at a premium in some of the best European markets. In America the prices paid do not, in very many instances, justify the feeding of new milk for a longer period than will bring them to a marketable age. Calves that are vealed are more commonly allowed to suck the dams, but sometimes they are handfed, and they are frequently sold at the earliest date that they can be put upon the market. To make one pound of increase usually calls for 8 to 9 pounds of whole milk. 
In some parts of Scotland calves are fed new milk until about six weeks old, and then are vealed. In some instances they are given the first milk drawn from the dams while they are being milked. This is given to them during the first few weeks of life, and that last drawn is given to the calves that are older. The first drawn milk, being less rich in fat, does not overload the stomach and produce scouring, as does that last drawn. That last drawn produces flesh, fat and juicy, and can be taken with less hazard to the digestion by the older calves. In some parts of Holland the calves are kept in single stalls inclosed to the height of 4 to 5 feet, and so narrow that the calves may not turn around in them. The floor is latticed, and ample bedding is supplied. The stables or apartments are kept comfortable as to temperature. The object sought is to keep the calves quiet and undisturbed. They are muzzled so that they cannot eat the bedding. Certain ingredients, as fresh ground shells, are given to prevent scouring. They are sold at the age of Io to I2 weeks.

In some instances calves are grown on whole milk and adjuncts, and are sold at the age of, say, six to nine months, at which age the flesh can scarcely be called veal. This is practicable when two to three calves are reared on one cow. It is too costly where but one calf is reared during the entire period of lactation. The calves are fed adjuncts as soon as they will take them. The standard meal ration supplement given on page 2I will suffice while the calves are taking milk. Should that be withheld, then ground corn, oats, bran, and oil meal may be fed in the proportions of 4, 2, I, and I parts by weight, and as much as they will consume. In many instances such calves are kept even longer than the age mentioned.

Calves from dairy cows, the progeny of sires of the beef breeds, are sometimes sold at a similar age to those referred to in the preceding paragraph. They are given 
whole milk until two weeks old, and are then gradually changed to new milk. (See page I8.) The method of changing is sometimes adopted by which the cream is so separated that it is not all removed, but a larger proportion is removed from day to day until the change is made. The change from whole milk to new milk should be completed by the time that the calves take meal and nice, tender fodder freely. Subsequently whole or ground corn, whole or ground oats, bran, and oil meal may be fed as mentioned above. They take the market better at the age mentioned than when older, as with increasing age the dairy form becomes more pronounced.

Grazing for calves.-Where any considerable number of calves are grown, the aim should be to provide grazing especially for them. It is important: That it shall be near the shelter in which the calves are fed. (2) That it shall be abundant and succulent, and (3) that it shall be provided in a succession that will cover the season. Usually grazing will furnish the cheapest food that can be given to calves.

Any kind of grass or clover possessed of succulence, nutrition, and palatability in a fair degree will answer. Where bluegrass will grow successfully it cannot be excelled for grazing, spring and fall. In the summer it should be supplemented with dwarf Essex rape, and this may also be made to furnish autumn grazing, but as in pasturing sheep on rape, it is desirable to give also access to a grass pasture. Clover in any of its varieties will be helpful, the common red being especially so because of its persistent growth. But some caution is necessary in grazing clover when very succulent, and also rape, lest bloating should occur, and the danger from pasturing alfalfa is still greater. Grains mixed and sown together make good grazing for calves in the absence of grass pasture, but the season during which they furnish it is short. In the South, winter or spring grazing may be furnished by sowing such grain as winter oats, barley, 
or vetches alone or in conjunction; and summer grazing can probably be best furnished by Bermuda grass and cowpeas. In order to provide continuous grazing it is necessary to have at least two inclosures of suitable size set apart for the purpose. If the grazing gets beyond the ability of the calves to keep it down, the mower should be used on it. In the autumn, rowen from the meadows may furnish suitable grazing for calves that are weaned.

Where grazing cannot be had, soiling can ustlally be secured. Soiling food can usually be provided, and plentiful in supply from a relatively small area. As a matter of convenience, the aim should be to grow it near to the farm steading. Some herdsmen prefer to follow this plan, especially when the aim is to secure maximum growth and finish in the calves, but when animals for breeding are thus grown the benefit that would accrue from taking free exercise on the pastures is lost. Where cultivation is intensive, this method of growing green food calls for considerably less land relatively than the other.

Many plants may be used in furnishing such soiling. In the North, the list includes alfalfa, common red clover, the Canada field pea, or the common vetch, and oats, or all three grown together, dwarf Essex rape, fall turnips, corn, and sorghum. As the legumes furnish the most suitable soiling food, the aim should be to grow them in preference to other plants as far as practicable. Where alfalfa grows well, it has highest adaptation among these plants. Next to it in this respect, probably, is dwarf Essex rape. This wonderful forage plant is far too little used in providing either grazing or soiling food for calves. In the South, alfalfa, grain, and vetches grown together, cowpeas, corn, and the sorghums may all be used. But corn and also the sorghums should be sown so thickly as to furnish fodder fine rather than coarse. 
In many instances, grazing and feeding soiling food may be combined with advantage, soiling food being made to supplement the grazing when the latter fails. When feeding such green food as may induce bloating, a slight degree of wilting in the food will take away the danger. The character of the soiling food fed should be considered when determining the meal supplement that shall be given. The more of the protein there is in the soiling food, the less is the amount called for in the meal supplement.

Miscellaneous considerations.-In the successful rearing of calves are several considerations, miscellaneous in character, relating to the feeding and care, which cannot be ignored. Prominent among these are: (I) Careful discrimination as to which shall be reared. Grading in the apartments. (3) Feeding milk and whey in proper conditions. (4) Feeding a number simultaneously. (5) Giving salt and water, and (6) general sanitary considerations.

Only some calves should be reared for breeding or for meat production. While it is not possible, in any instance, to be quite sure of the nature of future development, it is possible, in nearly all instances, to form an approximately correct judgment. When a calf comes into life prematurely, in some instances, it may reach maximum development ultimately, but it is more probable that such will not be true of it. The same is true of a calf that is of weak vitality. Among the indications of good vitality are good size and strength at birth, and the possession of six or eight well-developed teeth. When selecting calves for the dairy, the udder should be possessed of four good teats well placed and one or more rudimentaries to show milk force. Should digestive derangement show itself to the extent of seriously retarding growth during calfhood, it will frequently be more profitable to dispose of the calf promptly than to attempt to rear it. 
It is important, in certain instances, as when growing pure-bred calves, to have them graded in the box stalls in which they are confined. The food can then be more exactly adjusted to the needs of the calves. This, however, is not so necessary where the calves are fed in stanchions, though allowed liberty at other times. Yet under such conditions, the strong are more or less liable to crowd the weak, and so get the choicest of the food. They also get the lion's share.

It is very important that skim milk and also whey shall be fed in the best condition possible under the circumstances. Skim milk is never in better condition for feeding than when it is fed fresh from whole milk separated as soon as possible after it is taken from the cow. Rugged calves, and especially well onward in the milk period, can take more or less of acid milk and also curdled, without apparent harm, and even with positive benefit, but the fact remains that skim milk sweet and fresh is superior. While skim milk obtained from factories may, and many times does, serve a good purpose in feeding calves, in more instances, probably, it reaches them not in good condition, owing to such causes as inattention to the milk vats, bacterial contamination in the vessels in which it is carried and fed, and because of low temperature.

The temperature at which milk and whey are fed to young calves is also a question of much importance. That of new milk is approximately $100^{\circ}$ to $102^{\circ}$ when taken from the cow. The nearer, therefore, that the skim milk approximates this temperature, the more suitable is it for calves. Cold milk lowers the temperature of the body, which means relative increase in food consumption in proportion to relative gains. Skim milk obtained by the setting or gravity process is at all times below the requisite temperature, and can only be brought up to it by the adoption of artificial measures. These include adding hot water or hot gruel, or heating over 
a fire. The first of these methods is the simplest, but is open to the objection that it adds too much to the bulk of the milk.

The gruel added usually fails to raise the temperature to normal, but materially reduces the amount of hot water that it may be necessary to add. Heating on the fire involves labor, and may also be inconvenient. As skim milk obtained from the separator on the farm may be fed at a normal or nearly normal temperature, this fact alone gives it a long lead over other skim milk.

When any considerable number of calves are fed simultaneously stanchions add greatly to the convenience of feeding, so much so that they are a real necessity. For the construction of these see page 370 . The milk is first apportioned in the feeding pails placed in the alley in front of the stanchions. While this is being done the calves will get in line in the stanchions and will be so fastened. The pails are then placed in the mangers, where the calves take the milk. To quiet the sucking propensity which drinking milk arouses, a little dry meal may be thrown in the bottom of each pail, not liberating the calves until it is consumed, or, if desired, the pails may be removed and the fodder fed. Thus indulgence in that baneful habit of sucking after having drank the milk is entirely prevented.

Furnishing salt to calves of sufficient age should not be neglected, and the same is true of water. During the first weeks of a calf's life it is probably not necessary to add salt to the food. Particularly would this seem to be true of milk provided by cows that are given sufficient salt. But when calves take other food, it would seem to be as necessary to give them some salt, as more mature animals. Until they learn to take salt from a box at will, there is probably no better way of giving it than by sprinkling a little into the meal given to them, beginning with a trace, and at no time adding 
much until they begin to help themselves, when it is not necessary to add any more to the meal.

For a few weeks subsequent to birth, calves do not require water other than what the nilk furnishes, but from the time that they will take it separately onward, the aim should be to keep pure water constantly within easy access. The amount that calves will thus consume in addition to a liberal supply of milk would surprise those who have not given attention to this question. In warm weather, especially, calves are frequently allowed to suffer from lack of water, to their detriment. Ordinarily, for a time at least, there is no better way of providing water than that which supplies it in a pail, bucket, or tub, which may be emptied at will.

The general sanitary conditions include ventilation, light, exercise, and cleanliness. Ventilation may be secured for calves as for other stock. (See page 378.) Dark apartments may aid in the quick fattening of calves for veal, but they will prove harmful to those that are to be reared for breeding, on the principle that animal life cannot be reared in highest vigor when deprived of ample light. The only time when prolonged darkening of the stables is in order is during the season when flies are numerous. A reasonable amount of exercise is indispensable to healthy development in the young calf. The more of this they will take voluntarily, the better it is for their development, and the degree of the exercise which they take is proportionate to the favorableness of the conditions for taking exercise. Favorable conditions include room and sunlight, hence the necessity for paddocks. Cleanliness relates to such considerations as scalding the milk pails, keeping the stalls well bedded, and the paddocks dry. The milk pails should be scalded daily to prevent the presence of germs that may produce disease. Metal pails are the most easily kept clean. The mangers should be cleaned 
42 THE MANAGEMENT AND FEEDING OF CATTLE

out frequently and the stables abundantly littered. Dryness in yards or paddocks may be most easily secured from porous soil. When they are covered with soil the opposite in character, litter may supply the deficiency in prolonged periods of wet. 


\section{CHAPTER II}

\section{CATTLE ONE YEAR OLD-SUMMER AND WINTER}

The care of carves that come in the autumn and also in the spring, up to the age of one year, is given in Chapter I. This means that the food and care suitable for the former have been given until the beginning of the second winter, and for the latter up to the beginning of the second summer. In the present chapter will be discussed the following: (I) Autumn calves the second winter; (2) Spring calves the second winter; (3) Grazing in summer; (4) Supplementing the pastures; (5) The water supply; and (6) Other important considerations.

Autumn calves the second winter.-The second winter, autumn calves can endure considerably more exposure without harm than it would have been prudent to subject them to the first winter. The nature of the shelter required will depend, first, upon the object for which the cattle are reared, and, second, upon the climate.

When the winter temperatures are low, even though the normal winter day is bright and clear, it will be advantageous to have quarters for them that may be closed at will and so constructed as to exclude extreme cold. A basement with ample light is very suitable. Other inclosures may be made warm by using building paper when inclosing them. Where temperatures may not fall so low, but where precipitation frequently occurs in the form of rain or sleet in winter, apartments that may be closed are fully as necessary as when temperatures are much lower, but where the precipitation 
comes mainly in the form of snow. Where such protection cannot be furnished, a shed made of poles and covered with an abundance of straw will answer. Such a shed, open in front, should have considerable depth, but it is not necessary that the covering or roof shall give a higher space below than, say, 6 to 7 feet. It should face the early or midday sunshine.

There winter climates are moderate, and the thermometer but rarely falls below zero, any kind of structure that will shut out drafts and protect from falling storms will be ample. In some portions of the United States the winters are so mild and dry that protection other than that furnished by a cliff or deep ravine or dense grove is not necessary when there is an occasional storm. Under any conditions, cattle of the age mentioned may be successfully wintered in open sheds, but the amount of food consumed will be less when the inclosures can be made to bring reasonable comfort to the animals all the time.

Animals that are being pushed for baby beef must be kept so warm as to be subjected virtually to no discomfort from cold. Stamina and endurance in these is not a necessity further than that they shall be possessed of enough of both to enable them to bear up well under forced feeding given under artificial conditions until ready for slaughter. It is not a real necessity that these conditions will have any considerable bearing on the development of stamina of the highest type.

With animals grown for beef, and to be finished at maturity or when approaching it, the possession of ruggedness is relatively more important. They go on for a longer time and ultimately pass through a forcing period when getting ready for the block. They must needs be given greater liberty than the former for taking exercise. Such continuous confinement in winter may be and is sometimes advantageous for the former, but never for the latter. 
That ruggedness shall be maintained and, if possible, strengthened in animals that are kept for breeding, is still more important, hence, though confined at night and in stormy days, they should have abundant opportunity for exercise at other times. With no class of cattle is inherent ruggedness more important than with animals intended for the dairy. This arises, first, from the heavy strain to which the digestive organs are to be subjected through feeding large quantities of meal; second, from the succession of years through which such feeding is continued; and, third, from the highly artificial conditions as to confinement and temperature to which animals in milk are subjected. The maintenance and development of ruggedness in these, therefore, should be the constant aim from birth until the period of lactation is reached. Because of this, freedom to exercise at all times with animals of this class will probably be advantageous. This would mean that they would not be housed in closed sheds. Something might thus be lost in growth and something also in food, but there would doubtless be compensation in increased hardihood.

With ample space, there are no serious objections to keeping the animals in stalls over night, further than that which arises from the extra labor that is entailed in caring for them, and the less degree of exercise they are able to take. The first is an important objection in a country in which such labor is relatively high. But it is a matter of considerable importance that they shall be fed in stanchions while they are eating meal or roots given to them, so that each may get its rightful share. For the pattern of stanchions see page 372 .

If the fodder is fed in the mangers connected with the stanchions, these should be left open, except when meal and roots are being consumed. Even in mild climates it will be advantageous to feed such food in stanchions except in stormy weather. It may be fed 
in racks of suitable make in the yard. It is usually more convenient to feed coarse fodders, as corn, in such racks.

The second winter, young cattle are able to use to a considerable extent, fodders that are on hand, and yet are not suited to some other kinds of feeding. For instance, straw of various kinds may form a considerable proportion of the fodder given to such calves, with suitable adjuncts, whereas the same would not furnish suitable fodder for milch cows, at least in any considerable quantities, and yet cattle at the age of those now being considered cannot utilize the coarsest foods as can those that are older. Those intended for baby beef must have the best of hay; those for beef at a later stage of maturity can utilize a coarser grade of hay, and it may be also straw, while those intended for breeding may be largely fed on straw, providing the other adjuncts are suitable. Where clover or alfalfa are abundant and cheap, these alone may be made to carry the cattle through the winter in good form. If corn fodder or any of the sorghums are fed to these, the aim should be to feed them of fine growth rather than coarse.

The concentrates fed should be chosen with reference, first, to the objects for which the animals are being grown; second, to the fodders available; and, third, to the relative cost of the concentrates. Those grown for beef at a later period may or may not need concentrates, but usually more or less may be fed to them with profit. Those one-year-old that are being grown for baby beef must be fed heavily of concentrates. Those grown for breeding may not need concentrates. If given suitable fodders and roots they may come through the winter and make a sufficient growth without them.

When straw of the cereals only is fed, or stalks, as of corn or the sorghums, the aim should be to feed concentrates rich in protein, as wheat bran, middlings, oilcake, pea meal, soy bean meal, or cottonseed meal. Ground oats are always in order for such feeding when 
not too expensive, but corn, rye, barley, and sorghum seed, if fed, should be fed somewhat sparingly, and all the more so if a liberal supply of corn ensilage is being fed at the same time, or if nubbins are present in any considerable degree in the fodder.

It would hardly be possible to give what may be a standard meal ration for such feeding, but it would seem safe to say that the protein in the meal fed should not be less than io per cent. It may also be admissible to feed more than enough corn to balance the ration, if corn is cheap enough to admit of so feeding. That it is not only allowable, but, in some instances, commendable to feed foods not in perfect balance, cannot be gainsaid, because of the influence that food values may exercise. The standard meal ration submitted for calves (see page 2I) could not well be improved upon for yearlings under northern conditions. For southern conditions, cottonseed meal and ground hulls would be substituted for the oats. Where field roots are fed freely, the oilmeal may be omitted.

The amount of concentrates to feed will vary much. While heavy feeding is a necessity in growing beef, it is not admissible for other one-year-olds. Usually it will not pay to give more than 2 or 3 pounds of meal a day to young animals being reared for breeding. On the other hand, it will generally pay to feed some meal, more, of course, to those of the beef types than to those of the dairy types. The animals should be so fed that $I$ to $I / / 4$ pounds of increase in live weight should be made daily during the winter months. The meal is best fed when mixed with a little cut fodder or ensilage.

Another way, and probably a simpler one, of feeding the grain, is in the straw. If suitable grains are grown together, cut a little under-ripe and feed as hay, or what is usually better, in the bundle, it may not be necessary to add other grain. Among these mixtures are oats and wheat, oats and peas, oats and vetches, and winter 
oats and vetches. A little flax in the mixture, where it can be grown, will further improve it. Which shall be grown must be determined by the conditions. When food is thus grown and fed, it serves as fodder and grain without threshing or grinding, and renders it unnecessary to purchase such foods, when they may be grown in sufficient quantities.

Ensilage and field roots are about the only classes of succulent foods which it is practicable to furnish to cattle that are housed in winter, whatever may be their age. Of these, ensilage is usually the cheaper, but not the more valuable in promoting development. Either will serve a good purpose in helping to keep the digestion in tone, more particularly in the absence of oilcake, but of the two for such a use field roots are decidedly the superior. Where both can be fed, the most satisfactory results are likely to follow, when cost and thrift are both taken into account.

The amount of either to feed will be dependent in a considerable degree upon the other foods that may be available; but where ensilage may be had in plentiful supply the aim should be to use it up to the limit of the capacity of the animals to take it safely unless dry fodders should be on hand that, if not fed, would be wasted. In such an event, but a limited amount of ensilage should be given. The limit for safe feeding for such animals may be put at about 20 pounds daily for prolonged feeding, but this will vary. In feeding field roots, the aim should be to feed minimum amounts that will effect the end sought. From 25 to 30 pounds daily would probably be maximum amounts, but it will seldom be necessary, or profitable, to feed more than I 5 pounds daily, and even 5 to Io pounds will have an appreciably favorable influence on development. For animals so young, the roots should be sliced or pulped. If both ensilage and roots are fed, it will be more con- 
venient to feed one in the morning and the other in the evening, and will answer the purpose quite as well.

Spring calves the second winter.-When calves that come in the spring enter the second winter, they are approximately I 8 months old, whereas those that come in the autumn enter the second winter at the approximate age of but 12 months. While the food and care suitable for the latter will, in the main, be equally suitable for the former also, the older animals can do with less careful housing and can make use of somewhat coarser fare. These results follow from their more advanced age. The rule holds good with all classes of farm animals, that they are better able to use coarse foods as they advance toward maturity.

If these young animals are simply to be carried through the winter, nearly all that has been said ahout autumn calves the second winter will apply to them. (See page 43.) The shelter will be the same except that it is less necessary to house them in closed sheds or stables, nor is it so necessary to have these quite as warm as for the former. The stanchions and mangers may be just the same in kind. The animals should be at liberty except when taking food, but should be dehorned, which is not so necessary in the case of younger aninals. The fodders given may be the same, but as intimated above, may also be coarser. Such fodders, for instance, as portions of hay rejected by work horses and milk cows, may be given to them, and they may be allowed to pick over corn fed to animals that are being fattened, the latter having first been removed from the feed lot. This, at least, will hold good of such animals as are simply being grown for breeding. The concentrates may also be the same in kind, but for breeding stock the proportion of concentrates fed need not be so large as in the former instance, as, owing to their more advanced age, they have greater capacity for digesting coarse fonds. The more rugged the animals, the better use relatively 
can they make of those cheap foods, and the more cheaply in consequence can they be grown. They can also utilize a few more pounds of ensilage daily than the former, and, where easily obtainable, it should be given to them freely because of its relative cheapness. They can also utilize more field roots, but it may not be profitable to give them more because of relative cost. They should be so fed that even when kept for breeding, as with the calves that come in the autumn, the gains should not be less than I to I $1 / 4$ pounds daily during the whole of the second winter.

If the cattle are being reared for the block, and are to be finished on grass the following summer, the grain ration fed must be at least somewhat liberal in supply. The amount required will depend, first, upon the fodders fed, and, second, upon the period of the summer at which the animals are to be made ready for the market.

Should the fodder be leguminous, that is, composed mainly or chiefly of such plants as clover or alfalfa, not more, probably, than half as much concentrates will be wanted as if composed of other fodders, such as corn and straw of the cereals. If corn ensilage, rich in practically mature grain, is fed along with legumes, the concentrates required will be still further reduced. In fact, with a liberal supply of such corn ensilage, say, 25 pounds daily, and this class of fodder, no further feeding of grain may be necessary during the early winter in any event, and only after midwinter, when they are to be finished early on grass. The same will hold true if field roots are fed in quantity somewhat larger, and it is more emphatically true if such corn ensilage and roots are fed together.

Should the other fodders named be fed alone or in conjunction with such foods as hay from the grasses, as timothy, redtop, Bermuda, and also millet, some grain in addition will prove advantageous and ustrally profitable, and it should be rich in protein. It may be 
made up of corn, barley or rye, oats and cottonseed meal, or oilcake, or wheat bran, or middlings in equal proportions by weight. A less amount of oilcake will answer under some conditions, as when a small quantity of field roots is fed. In the South, cottonseed hulls may take the place of oats. A mixture of wheat and oats, grown together, about one-third wheat, is also suitable.

Fixed amounts of grain cannot be given. Usually it will answer to begin with 2 to 3 pounds daily, a head. This will be gradually increased to 4 or 5 pounds with the advance of the season, and to 6 or 7 pounds by the time for turning out on grass, when the finishing is to be completed in the early summer. For such finishing the grain should be fed so that the animals will gain not less than $I / 2$ pounds daily during the winter.

Where the fodder is corn with the ears unremoved and reasonably plentiful in supply, no other grain is needed. Such a ration will not be in balance. Nevertheless, it may be the cheapest in some instances. If the cattle are to be carried over till the following winter, minimum quantities only of grain should be fed. Should they be given ear corn ample in supply, no other grain would be required even in the absence of ensilage, but of the two, ensilage is the cheaper, because of its greater succulence and less waste in feeding.

Grazing in summer.-Autumn calves will be approximately i 8 months old when they reach the grazing period of their second summer, and spring calves virtually 24 months. The grazing suitable for both is really the same, except when the spring calves will be finished on grass. For such finishing see page 86. The chief features to be considered with reference to summer grazing are, first, its suitability; second, its abundance; third, the supplementary food when needed; and, fourth, the protection that may be necessary.

It would seem safe to say that all pastures are suitable for making increase when they furnish an ample 
supply of grass with more or less succulence. Pastures are usually suitable in proportion as they are palatable and nutritious, and as they produce abundantly. Among the most palatable and nutritious are bluegrass and open range pastures, the latter usually bearing a variety of grasses. They differ exceedingly in their producing power. In some parts of the arid range country, from 20 to 30 acres are required to carry a cattle beast through the season of grazing. On the other hand, the Montana Experiment Station carried I 8 head of cattle on 5.04 acres of irrigated alsike clover, for a period of 102 days, and the increase obtained an acre was 904.7 pounds of live weight. At 4 cents a pound the said increase was worth $\$ 36.19$. Pastures least suitable are those that are excessively wet and produce mainly coarse and relatively innutritious water grasses.

If results completely satisfactory are to accompany summer grazing, it is absolutely essential that the pastures shall be abundant at all times, or if not abundant they must be supplemented by other foods. The seasons for such supplementing are usually spring and autumn. Insufficient supplies in the grazing lead to lack of relative increase, increase in the food of maintenance, and decreased production in the pastures. Pastures are never sufficiently abundant to meet the needs of the animals unless they can get what food they need so readily that they may rest during the larger portion of the day. Overstocking pastures is usually the one great source of loss to those who keep cattle during the season of grazing

For animals of the ages now under consideration, no shade is, on the whole, more satisfactory than that furnished by a grove or rim of forest within the pasture or accessible to it. The more dense the shade, the more perfect is the protection from flies, and the more complete also is the protection in inclement weather. Single 
shade trees scattered through the pastures are a great improvement over no shade, but to these there is the objection that, through the congregating of the cattle beneath them, causing the accumulation of the droppings, the conditions are made exceedingly favorable to the increase of flies.

In pastures that are to remain as such for successive years, shade should be provided by planting trees where they are absent. Only those varieties should be planted that are not readily injured by the treading of the soil over the roots. They should be planted in large clumps in the open or, what is better, in the corners of the fields, or on a rim of the same, preferably on the most exposed side. On many western prairies, summer protection may be most conveniently furnished by allowing the cattle access to a portion of the willow or other kind of grove around the farm buildings.

The wisdom of planting shades in temporary pastures where the fields are frequently cultivated may be questioned, except when planted in clumps in the corners, when the fences may be regarded as permanent. But it may be wise in these to furnish shade by making a roof composed of poles and covered with hay or straw. It will be supported by posts of suitable length planted in the ground. As the object is to furnish shelter from the sun, a covering of old hay or straw of some kind is ample. It is best located on the higher ground where the summer breeze is more pronounced than on low ground.

Supplementing the pasture.-Should the pastures prove insufficient they should be supplemented either with coarse fodders or other pasture sown to meet such an emergency, and in some instances with concentrates. Where much grazing is done, the aim should be also to have reserve pastures which have been so managed that they will furnish abundant grazing at that season when it is most needed. 
Of the coarse fodders used to supplement such grazing, none is better than corn. For such a use, it may be grown in nearly all arable sections of the United States and in many of those in Canada. It is most suitable when thickly grown, and when well advanced toward maturity. But it may be necessary sometimes to begin using it at a much earlier stage of growth. When the supply is ample for the needs of the animals until winter, it is not necessary to provide other food. The corn will be fed, first, from the row, and later from the shock, each day's supply being strewn on a fresh part of the pasture. Where cattle that are being finished on grass are fed large quantities of ear corn in contiguous pastures, these young animals may get enough to supply their needs if allowed to glean after the former. In certain areas, sweet sorghum and the non-saccharine sorghums, especially Kafir corn, may furnish supplementary food more cheaply than corn. When these are fed, they may be managed in precisely the same way as corn.

Other pastures that have been sown with such an end in view may be provided to furnish grazing at the opportune time. One of the most suitable of these is dwarf Essex rape, sown alone or with grain. Over wide sections of the western prairies it may be thus sown along with small cereals, and more commonly without injury to them, one pound of seed more or less being mixed in with the grain put upon each acre of the land sown. The rape plants which usually furnish luxuriant grazing a few weeks subsequent to the harvesting of the crop, may thus be made to supplement other pastures at but little cost. The other plants that grow amid the grain will go far to eliminate the danger from bloating which is sometimes present in grazing rape. When rape is grown separately, it should always, where practicable, be grazed in conjunction with grass pasture, first, to lessen the tendency to scouring, and, second, 
to reduce une hazard from bloat. That cattle should in no instance be turned into a rape pasture when hungry should never be forgotten.

Supplementary pastures may be provided in another way, that is, by keeping them in reserve. For instance, in a pasture or pastures according to the need, they may be grazed closely for a short season in the spring and the stock then removed. By the autumn, they will provide abundantly suitable grazing. Particularly will this be true of Kentucky bluegrass. With an abundance of such reserve grazing, supplementary fodders even may not be necessary. Second growth clover and timothy also furnishes a good reserve pasture. Usually pasture only furnishes the cheapest food that may be given to such animals, as it practically eliminates the element of high-priced labor. It may be different in areas where labor is cheap.

With an ample supply of pasture alone, or of pasture and supplementary fodders, supplementary concentrates will not be needed for cattle reared for breeding, nor, indeed, for any purpose, except for making what is usually spoken of as Christmas beef. This is more emphatically true if corn fodder with more or less ears is the supplementary fodder fed. Finish animals for Christmas beef is further discussed on page I8I. Should the supply of both pasture and supplementary fodders be insufficient, then grain should be fed rather than allow the animals to stand still in the process of developing, and especially when being grown primarily for beef. For such feeding, no kind of grain is more suitable than corn, but when it is fed, some swine should be present in the same pasture. In the absence of corn, barley, or barley and oats ground, are usually next in availability. The amounts fed must be gauged by the purpose of the feeding.

The water supply.-In winter the sources of the water supply are wells, cisterns, running streams, ponds, 
and more rarely artificial basins made in the earth. Obtained from any of these sources it is suitable for winter use, judged from the standpoint of purity, especially in a cold climate, but in such a climate the temperature may be such as to more than justify the effort to have the water furnished at a temperature higher than it possesses naturally at that season.

When the animals drink from a pond, the water is icy cold, hence they will not drink enough in very cold weather to meet their needs. The temperature of the body is unduly lowered, which means an increased expenditure of food. The labor of keeping the ice holes open is considerable, and there is some loss in fertility in the droppings so frequently deposited while the animals are drinking. These objections apply in a less degree to drinking from running streams, as the water in these is always accessible where the current is considerable without making openings in the ice. Notwithstanding the objectionable features, there is probably no better way of furnishing water to young cattle when the stream is of easy access and near by. It may be different with cows in milk.

When the water is furnished in a tank in the yard, it should be heated to the extent, at least, of keeping it free from ice. Suitable tank heaters are on the market, and may be obtained at small cost. The fuel commonly used is wood or coal, the latter being preferable, since it burns so much longer than wood without renewal. When the tank can be located within the shed or stable in which the young animals run loose, it can usually be kept free from ice by banking it around with coarse litter and covering it over, with an opening in the cover only large enough to allow the animals to drink one at a time. This method, where not too costly relatively, is idea1, as it allows the animals to drink at will. When they drink from a pond, they should have access to it 
twice a day, morning and evening, except when the weather is extreme.

The sources of water supply for such animals in summer are wells, streams, springs, lakes, ponds, natura] or artificial, and artificial basins. The latter differ from ponds in that the animals are not allowed access to them. No better water supply can be furnished for this class of stock than that which comes from the presence of running streams in the pastures, or springs so copious in the waters which they furnish as to make a rivulet. Such is living water, and it is nearly always pure. Permanent pastures should be made to include such water supplies. Where suitable water can be obtained from wells in the pastures, it will usually pay to pump it by wind-power into a trough or tank of easy access to the cattle, and surrounded with material that will not mire in hot weather. Water from a pond is objectionable in the summer, since it is stagnant, and the cattle befoul it with their droppings while drinking, and yet there may be conditions where to use it for a time is a necessity. Water conveyed from an artificial basin to a trough or tank on a lower level is usually quite wholesome.

The most ideal conditions for supplying water are those which make it possible for the animals to take it at will. The frequency with which young animals will drink depends upon the food consumed and the weather. Under no conditions of feeding practiced in America, so far as known to the author, can cattle do without taking water in addition to that which may be furnished in the succulence contained in the food. It is different with sheep. But the amount required by cattle is reduced relatively in proportion as the food is succulent. It is possible to feed field roots to cattle, even while being fattened, to such an extent that they will consume but little water. When ensilage is fed the amount of water is also appreciably low. When, 
therefore, the food contains much succulence, water is not usually required more frequently than once a day, but when the food is dry the cattle should have access to it at least twice a day. In hot weather in summer, and especially when the grasses lose much of their succulence, cattle will drink with profit more frequently than twice a day.

Other important considerations.-Prominent among these are: Suitable grading of the animals in winter: furnishing a comfortable bed; the manner of turning out in the spring; the method of changing to dry feed in the autumn; the giving of salt, and the retention of the better foods for the later winter feeding. The relation between progress in development and the fidelity with which these attentions are given is inseparable. To neglect or slight them will be followed by a proportionate penalty.

When the number of animals is not large enough to result in any crowding, it may not be necessary to grade the young animals when fed in stanchions, especially when the difference in the age is not great. But when the difference in age, development, and vigor is considerable, then it is important that grading shall be done to the extent, at least, of making it possible to feed them separately. The less developed animals may then be given feed that is better adapted to their needs.

The necessity for grading may also arise from the different uses for which the animals are kept. Some may be intended for beef, when matured, and some for breeding. If the former are to be pushed forward more rapidly than the latter, they must, of course, be fed separately. This may be accomplished by putting a separating fence in the shed or stable in a way that will give each lot access to the feeding mangers. Both classes may be given access to the same yard. Whether they should occupy the same yard by day with mature animals will depend upon circumstances, but the aim 
should be to give them a separate yard or portion of the main yard that they may have the chance to take their proper fodder at will.

It is greatly important that the sheds or stables, and also the yards in which the animals are kept, shall be well littered. The litter, from whatever source it may come, should be ample to keep the animals dry and clean. To accomplish this it may be necessary to add fresh litter quite frequently. When straw or coarse hay is fed in the mangers, the residue removed between the times of feeding and strewn over the floor may furnish all the needed litter. Because of the accumulation it may be necessary to remove the manure in the sheds once, or oftener, in the winter, which is easily done, as it seldom freezes. When a straw stack is in the yard, to which the animals may or may not have access, this makes a ready source of litter for the yard. It is usually preferable to allow them to pick over the straw in the stack, the waste or rejected portion only being used for bedding. A little attention to throwing aside any frozen clods that may be present will add to the comfort of the animals when taking rest.

Turning the animals out in the spring to graze should be done with care. The better plan is to allow the grazing to become abundant before admitting the animals to the pastures. They may then be allowed to graze for a short time only the first day, less. probably, than an hour, and increasing the length of time each day, until they may remain out. The amount of dry food, grain, and fodder is gradually and increasingly reduced until none is given. By this method of turning out, the purging that would otherwise result from abruptly changing from dry foods to tender grazing and the consequent loss of flesh that would follow may be almost entirely obviated. The time called for in making such a change need not usually be extended beyond Io to I 4 days, but sometimes this depends upon 
the tenderness of the grass. In bluegrass pastures not grazed close in the autumn, if the turning out is done just at the opportune moment it may be quite practicable to turn out abruptly, as the dead grass consumed will counteract the tendency to scours.

When the cattle are put on winter feed the special need for succulence and palatability in the food should not be forgotten. Stagnation in growth or loss of flesh at such a time is unfortunate, as the loss thus sustained cannot be overcome so easily as similar loss could be in the spring. Roots and ensilage will most cheaply supply such succulence. In the absence of both, bran or oilcake, or what is better, both, may be fed in limited quantity to prevent the constipation that is likely to come from the change. The more palatable fodders given at such a time may be gradually changed to less palatable when the animals have become reconciled to the changed conditions.

Salt should be accessible at all times. In winter there is no better way of giving it than by keeping it in a box under cover, as in the stable or shed in which the young animals are running loose. In the summer it should be made accessible at all times in the pastures. The box in which it is kept may be located preferably near the watering place or the gateway leading into the field, where the animals are more prone to congregate than at other places. In large pastures broken with hill and valley or woodland, such an arrangement may save considerable time in the frequent inspection of the animals, to make sure that all is well with them. Common salt is usually considered preferable to rock salt, as under some conditions, at least, the animals do not take enough of the latter to supply their needs. The supply should be given moderately, and frequently renewed, rather than given in large quantity and seldom, to lessen the loss from dissolving rains when exposed and to prevent incrustation. No objection can be 
offered to giving salt daily in the food, when the object in thus adding it is to give increased relish for the same, providing too much is not given. It may be commendable to give it thus, but when so given this may not entirely preclude the necessity for keeping it at all times accessible to the animals. The reasons for feecling salt are given at some length in the book, "Feeding Farm Animals," by the author.

When carrying such animals through the winter the aim should be to feed foods lowest in palatability in the early part of the winter, reserving those that are more palatable to a later period. Among the reasons for so doing are the following: (I) The whole systen is possessed of more vigor relatively, as a rule, in the early winter than toward spring, hence the appetite is keener. (2) In consonance with the above, and as a result of it, the digestion and assimilation are in better tone. (3) Certain foods, as fodcler corn and the sorghums, lose considerably in palatability and also in nutritive qualities as the season advances. When the fodder supply consists of straw of the small cereals and corn or sorghum fodder and hay, the aim should be to consume straw and corn or sorghum fodder first and the hay later. Similar discretion should be exercised in regard to the feeding of different varieties of field roots, owing to a difference in the keeping qualities. As a rule, when grain is fed, the quantity fed is increased more or less toward spring. Serious loss will result when the food fed toward spring must of necessity have less palatability and nutrition than that fed in the early winter. 


\section{CATTLE TWO YEARS OLD-SUMMER AND WINTER}

There are many points of similarity in the feeding and care of cattle, when in the two-year form, to the feeding and care of them in the one-year form. In the present chapter, where the management and care are practically similar, in order to avoid repetition, the proper and necessary references will be made. The extended discussion will embrace only the points of difference. It will consider the following: (I) Autumn calves the third winter; (2) Spring calves the third winter; (3) Grazing in summer; (4) Supplementing the pastures; (5) The water supply, and (6) Other important considerations.

Autumn calves the third winter-Such animals enter the winter at the age practically of two years. When grown on the arable farm for beef production, in nearly all instances they will be finished during the winter and sold toward or in the spring, at the age approximately of 30 months, a very suitable age at which to dispose of such animals. If thus finished, the methods that relate to finishing in Chapter VII, will apply to them.

If they are to be simply carried through the winter the shelter given as suitable for autumn calves in the yearling form will be suitable for them also. (See page 43.) But, in the two-year form, because of more advanced development, they are better able to withstand inclement weather without harm than younger animals. The reasonableness of such an assertion will be the more apparent when it is said that a strong two-year-old on 
the open range can carry on a more successful battle for existence when wintering on the same than a strong yearling. Of course, it would not be wise to expose them unnecessarily to inclement weather, nevertheless they will stand more exposure without taking harm. hence when animals in both forms are being wintered those in the one-year form should be given the better protection. Those in the two-year form will seldom really call for the protection of a closed shed. They have reached an age when they are able to rough it with about as little harm as at any subsequent age. They should, of course, be dehorned.

Females of the age under consideration will be pregnant, or should become so, during the winter. When not forward in pregnancy, there can be no serious objection to their going with other animals of similar ages that are not being finished, or that are not being pushed forward rapidly for early finishing on grass. If forward in pregnancy, such heifers would call for better care and special feeding.

The only times when such animals, properly graded, will profit from being fastened in stanchions is when they are eating grain or roots, should such be given to them. Even this may not be necessary where divisions are made which answer the purpose of single stalls. But where such divisions are made, the added expense of the ordinary stanchion is not much, and the cost of operating is scarcely to be mentioned. It is not at all necessary to feed fodders in the mangers connected with the stanchions, unless it is convenient to do so. They may be fed in any way that will result in greater convenience from feeding them. Unless when storms are falling, the fodder may be fed in racks out of doors and in yards favored with sunshine and shelter from winds.

When such animals are being fattened they must have good fodders, as hay or alfalfa and ensilage, when it may be had. When being pushed somewhat for early 
turning off on grass the fodder must be good, but not necessarily so good as in the former instance. When the problem is simply wintering the animals to be finished later, the coarsest and cheapest of fodders may be fed. Animals in the two-year form can use them to better relative advantage than when a year younger. When very coarse fodders are fed it may be necessary to so feed them that there will be more or less waste or rejected fodder. This may involve less loss than to force the animals to eat it clean. Corn and sorghum fodders, also corn ensilage, furnish cheap food for such animals, and if they can be fed along with not fewer than, say, I5 pounds daily of field roots or sugar beet pulp, the animals may make considerable gains on such foods. Where alfalfa hay only can be supplied, as in some parts of the semi-range country, they should make fair gains with no other food added.

Much of what has been said about feeding concentrates to cattle in the one-year form will also apply to those in the two-year form. (See page 49.) If concentrates are fed at all, the kinds and amounts fed nust be gauged by the fodders fed and other conditions sich as relate to the time and character of the finish sought, and other purposes for which the animals are grown. If they are to be turned off on grass, see page 50 for the amounts of grain to feed. If to be carried through the winter and finished on grass without grain. it may be cheaper not to give them any grain. It will be found that as a principle of feeding such animals are in less need of grain than those younger. At no time of life are they better able to titilize cheap foods. As a rule, it will be found profitable to supplement other food when necessary with that amount of concentrates that will insure a gain of not less than I pound daily for the season.

Spring calves the third winter.-Calves born in the spring enter the third winter at the age of 30 months, 
that is, at an age when, on the arable farm, they will be almost certainly fattened for spring sale rather than carried over. When grown on the arable farm, it is considered more profitable to turn them off at an earlier age even, unless when the conditions of farming are of the most extensive character; that is, when they are of such a character that the animals are grown and finished almost entirely on pasture. Such conditions are not common now, except in the newly cleared areas of what are termed "cut-over" lands, on rough tracts where stones and rocks interfere with the cultivation of much of the land, and on large holdings where lands are cheap, as in some of the semi-range country where such holdings prevent settlement. This, however, is a common age at which to buy range stocks for finishing. The winter finishing of such animals is discussed in Chapter VII.

The shelter called for when these are simply carried through the winter is practically the same as given above as suitable for cattle six months younger. The same is true also of the stanchions and the feed boxes. The coarse fodders fed may be practically the same. The same things may also be said about the concentrates and the succulent food fed. Like the former, they should also be dehorned.

The aim should be so to feed them when wintered on the arable farm that they will gain not less than a pound daily through the winter, but this may not be practicable under extensive conditions of farming or under semi-range conditions. Where pasture is cheap or entirely free and labor is high and where the conditions are not favorable to the production of farm crops, it may be more profitable, in some instances, not only with animals of this class, but also with those younger, to carry them through the winter on cheap food, which may not result in much if, indeed, any, increase. Under semi-range conditions, cattle are thus wintered in some 
instances because it is considered economical so to winter them.

When they are to be finished in the early spring on grass, they must be fed good fodders, and a considerable amount of grain. (See page 86.) Where cattle are being fattened on the same farm and corn fodder is being fed in large quantities, such animals, and also those discussed above, will glean after the fat cattle with much advantage, if allowed to do so. The food which they consume in this way is just so much saved, unless it could be consumed by other stock that is simply being carried through the winter.

In proximity to beet sugar factories such cattle may sometimes be carried through the winter very cheaply, and the same is true of cattle that are younger. When sugar beet pulp can be obtained at 25 to 30 cents a ton, as at present from some factories, it furnishes cheap food for such wintering. It may be fed with native hay, straw of cereals, alfalfa and corn, or sorghum fodders. Only cattle wintered within reasonable proximity to the factories can be thus wintered.

Grazing in summer.-Calves born in the autumn will have reached the age of 30 months when the third summer's grazing begins, and those born in the spring the age of 36 months. These will, in nearly all instances, be finished in one form or another on grass. For such finishing see Chapter VIII. The exceptions are stocks grown on the open range whose growth has been so checked by the privation endured by them during previous winters that they may not yet have completed their growth, even approximately. What has been said about the kinds of grazing most suitable for animals the second summer (see page 5I) will apply equally to these. What is said also about the benefit from abundant grazing will apply with greater force in the case of the older animals, as with them more energy will be expended in searching for grass when the graz- 
ing is short because of the added weight of frame which must be carried while thus engaged.

The protection called for by shade is practically the same as for animals during the second summer of grazing. (See page 52.) The point to be emphasized is the benefit that comes from furnishing protection. The benefit from having reserve grass pasture cannot be too strongly emphasized. In the spring and autumn such pasture is most needed, and also in the winter in climates sufficiently mild. The first is important in countries with low temperatures. The grass uneaten in the autumn makes grazing with fresh grass in the early spring and pre-eminently suited to the needs of animals when first turned out to graze. Reserve pastures for autumn are such as have been grazed down in the early part of the season and produce an abundant growth later, as, for instance, common red clover, Russian brome (Bromus inermis), and even Kentucky bluegrass. Reserve pastures for winter grazing are commonly maintained only under semi-range conditions, and are obtained by simply fencing out the cattle during the growing season. With such grass abundant, cattle of the age mentioned may be made to reach the market in fairly good finish, but, of course, not in finish so complete as when grain fed.

Supplementing the pastures.-The necessity for supplementing the pastures will depend on the abundance of the grass and the object for which the animals are grown. Under open and semi-range conditions such supplementing is ustually impracticable. Under widely extensive conditions, it may be more economical to sell the animals as stockers to be finished elsewhere. This may also be true, in some instances, of cattle in the yearling form, at or toward the close of the pasturing period. If finished on grass at any time, it will be necessary to supplement the pastures, at least, with concentrates and possibly with fodders, but such finishing 
is discussed elsewhere. (See page I74.) Usually when cattle are grown under intensive conditions, it will pay better to dispose of them at a younger age. As a rule, it is only under range, semi-range, and extensive conditions of farming that animals for meat can be grazed at all with profit the third summer, unless they have been purchased for such grazing from those who can afford to grow them up to the age now under consideration, and who cannot at the same time finish them with the aid of concentrates.

When supplementary food is needed, what is said with reference to supplying such food for cattle in the yearling form will apply equally to those in the twoyear form. This will hold true, not only of the fodders, but of the rape pastures, of the supplementary grass pastures and also of the concentrates. (See pages 50-54.) In reckoning the benefits from such feeding, the influence of the same on the pastures should not be overlooked. By changing the place of such feeding daily, land may be fertilized in a way that is reasonably effective and relatively cheap.

The water supply.-What has been said about furnishing water to cattle winter and summer in the oneyear form will apply equally to furnishing it for those in the two-year form. (See page 55.) The importance of furnishing it with the chill removed in winter should be duly considered. Even in the absence of ice in the water, it is too cold to give the best results with cattle when, because of its coldness, they will not take enough for their needs, or when they shiver to any extent after taking it. When water is taken from a pond or stream in cold weather, ice being present, it is too cold to give the best results. But it may be impossible to obtain water from another source without too much cost, and, in some instances, at any cost, as when water from wells is not suited to the needs of the animals. Under such conditions, if cattle can have ac- 
cess to water twice a day, or, what is better, at will, they are much less prone to take enough to chill the body at one time than if only allowed to drink once a day. Of course, ice may be removed from a tank, and when water is pumped up from wells, if the pumping only precedes the taking of water for a short time it will be less cold than after it has been for some time in the tank. In very large pastures, the aim should be to have a supply of water in more than one part of the pasture. On a hot day, if an animal is forced to journey a long distance to take water, it will make materially less increase than when water is sufficiently accessible to preclude the necessity of journeying far to obtain it. The taking of water will also be more frequent, a matter of much importance in such weather.

Other important considerations.-Whether the animals in the two-year form should be graded in winter will depend upon such considerations as relate to well-doing and to the objects for which they are kept. If all are strong and vigorous, there is no necessity for feeding them separately. If some are much weaker than others, this necessity may be present to some extent. It may not necessitate keeping them in different quarters, except when the weaker ones are given the opportunity to consume food better than what is given to the stronger animals. The better food thus given will usually accomplish the end sought if given with judgment but once a day.

It is possible, in some instances, to allow animals in the one-year form to feed together with those in the two-year form. This is more feasible when fodder only is fed, and in such quantities that each animal will have ample supply. Range cattle are frequently thus carried through the winter when fed alfalfa or other hay, and cattle grown on the arable farm under extensive conditions are also frequently wintered thus.

When reared for breeding, it may answer perfectly 
to allow haifers not forward in pregnancy to occupy the same quarters as those that are to be made ready for the block, unless the latter are being given grain to push them forward in quantities that would be excessive for the former; and even when more or less forward in pregnancy, no harm should result from the mingling of the animals, providing all are dehorned. It may also be proper, under some conditions, to allow the constant mingling of mature animals that are simply being carried through the winter. Where the mingling referred to in the two instances citerl is admissible, the whole problem of winter feeding is thereby much simplified.

What has been said with reference to providing the animals with litter in the one-year form, to turning out the same in the spring, and also with reference to changing irom pasture to winter rations in the autumn, will apply equally to the two-year-olds, and the same is true of what is said regarding the salt supply. (See pages 59-6r.) With reference to the first, it would seem only necessary to add that, when cattle are allowed to feed around straw stacks in the yards or elsewhere, care should be taken to prevent loss from the smothering of any of the animals from the falling of the stacks or portions of them that have been undermined; to the second, that judicious management at such a time may prevent any loss of weight; to the third, that alfalfa hay among fodders is best adapted to prevent constipation in the absence of succulent foods, and to the fourth, that the necessity for salt, though always present, increases with increasing succulence in the foods.

The importance of grading the feeding, as it were, so that the food fed shall improve in quality, should be duly considered. (See page 6r.) So important is the influence that may be thus exercised that it would seem correct to say that two feeders may be furnished with foods the same in kind and to be fed in the same way to the same class of animals, and yet the results will be 
CATTLE TWO YEARS OLD-SUMMER AND WINTER $7 \mathrm{I}$

greatly different at the end of the feeding season. The one who grades the feed by judiciously using the inferior foods first and gradually changing to the better will obtain results far ahead of those obtained by the other who follows the reverse process. 


\section{CHAPTER IV \\ GROWING BABY BEEF}

In this chapter, which discusses the growing of baby beef, the following phases of the questions are considered: (I) Adaptation in breed types; (2) Calves reared on dams or hand-fed; (3) Necessity for starting the animals properly; (4) Nature of the fodders required; (5) Succulence and its sources; (6) Nature of the concentrates; (7) Amount of concentrates to feed; (8) Age at which they may be sold at greatest profit; and (9) Value of high finish in the animals.

Baby beef means beef that is put upon the market beyond the age when it is classed as veal, and while the animals which have produced it are yet considerably short of maturity. Veal, properly speaking, is meat furnished by calves from an exclusive milk diet, and usually at an age that does not exceed ro to I 2 weeks. After cattle have reached the age of, say, 24 months, the carcass is no longer classed as baby beef. The term baby beef, therefore, may be applied to meat furnished by bovines between the ages of 3 to 4 months. More frequently, however, it means beef from animals in the one-year form.

Baby beef is essentially a product of recent years. Its production has been stimulated by the light obtained during recent years on the less rapid growth secured from animals as the birth period is receded from, and the changed demand in the market for a considerable proportion of that class of meat. It is most in demand at those seasons when heavier beeves are less plentiful in the market, as, for instance, in the summer months, but may be sold at any season. It is peculiarly a product of the arable farm, as it can only 
be produced under what may be termed forced feeding. The benefit to the grower comes, first, from the quick relative gains made from the food fed; second, from the relatively short period during which the animals have to be maintained on the farm, which tends to prevent over-stocking; and, third, from the good price relatively that such meat furnishes when well finished. The advantage to the dealer lies in his being supplied with meat that exactly meets the needs of a certain portion of his trade, and the advantage to the constmer consists in the tender and juicy quality of the meat furnished. The chief objection to growing such meat is found in the increase in the dams required to furnish a given weight of meat when marketed thus short of maturity. Because of the excellence of the meat, the demand for this class of meat is likely to grow more rather than less.

Adaptation in breed types.-The various classes of animals are by no means equally adapted to furnishing baby beef, although, in one of its forms, it may be produced from all of them. It is produced in best form from the various beef breeds. Next in suitability are the dual types. After these come what may be termed beef dairy grades, and lowest in adaptation are the dairy breeds.

All the beef breeds, viz., the Shorthorn, Hereford, Aberdeen-Angus, Galloway and Sussex, furnish the right kind of materials for growing baby beef. They turn the food given into profitable meat, are easily maintained in high condition of flesh, and retain the smooth beef form at all stages of development. Because of the extent to which smooth, even flesh characterizes the Aberdeen-Angus, they and their grades are pre-eminently suited to the production of this class of meat. Where the farmer grows such meat from year to year, sires that are characterized by much smoothness should be preferred, even though something should be sacrificed 
in size to obtain this, and they should be possessed of excellent fleshing properties. In baby beef, quality is a prime essential. It counts for more than size. The best types are those that are smooth and deeply covered with mellow flesh, and that carry bone inclining to fine, even to the extent of sacrificing something in flesh.

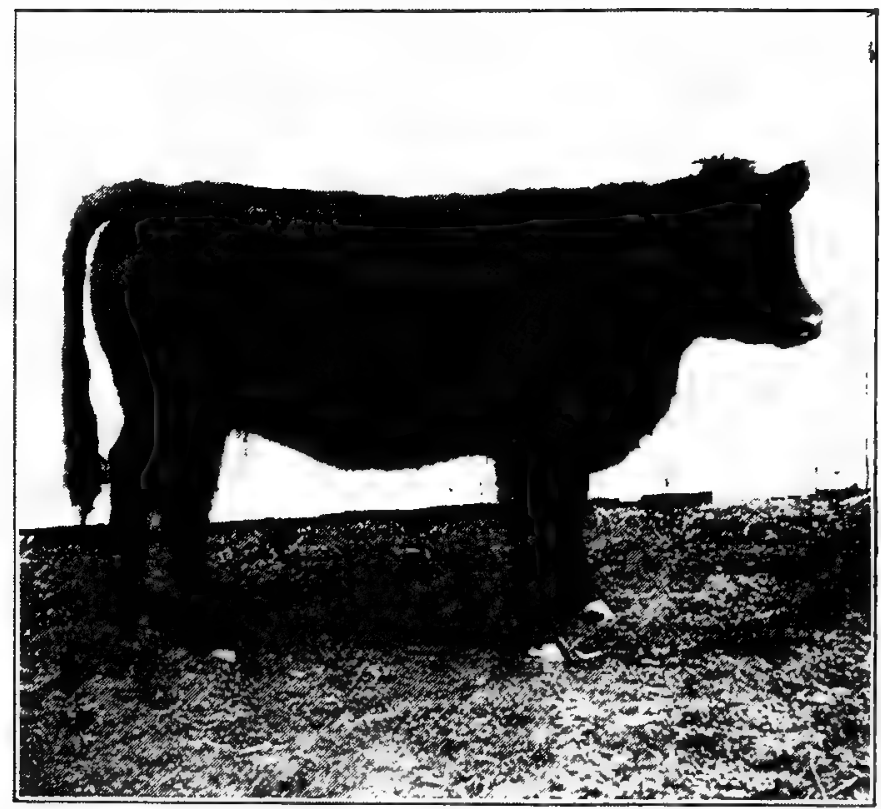

YEARLING GALLOWAY HEIFER, VESPER OF WAVERTREE, 14297

(By courtesy of the owner, Edward Paul, Dandee, Minn.)

The dual types, that is, the milking Shorthorns, the Red Polls, the Brown Swiss, and the Devons, will all furnish animals that may be grown into baby beef, but they will not be possessed of quality so high relatively as meat obtained from the straight beef breeds. The milking Shorthorns will be a little prominent at the 
angles and the Brown Swiss, though possessed of ample size, will be somewhat overstrong in bone. Smoother types should come from the Red Polls and Devons, fine in bone, but they will be something less in size.

By crossing beef sires possessed of much smoothness and high fleshing qualities on straight dairy cows, calves are obtained which make a fair quality of baby

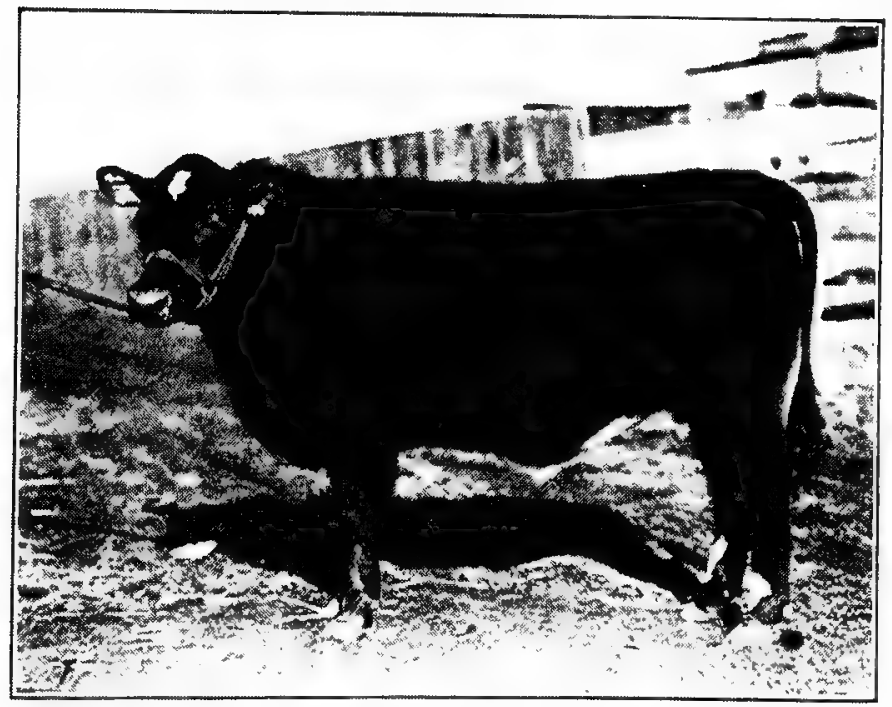

PURE BRED ABERDEEN ANGUS YEARLING STEER, ECLIPSER (By courtesy of the owner, Minnesota Experiment Station)

beef. This is sometimes done when the progeny of such cows are to be grown for beef. Although sires from any of the beef breeds may be used for such mating, none of these will be found superior or probably quite equal to the Aberdeen-Angus in producing progeny that will show dairy characteristics in but slight degree. These crosses are made only on grade females. The progeny are usually made ready for the block at an age 
not exceeding 18 months, and frequently at a younger age to avoid the increase in the direction of dairy form that comes later.

Calves from the straight dairy types are not equally adapted to furnishing baby beef. Lowest in adaptation probably are the Jersey and Guernsey types, as they show more of relative lightness in the hips and thighs. When grown for meat, they are frequently marketed under the age of one year. The Ayrshires may be carried somewhat longer, and the Holsteins even longer than the Ayrshires. The Holsteins show capacity for much growth, and when forced quickly do not show pronounced dairy tendencies in form until beyond the age of, say, I 5 months.

Reared on dams or hand-fed.-Calves grown for baby beef are reared on their dams or hand-fed. Each system has its proper place, and each has its advantages and its disadvantages. The highest quality of beef is obtained from calves reared on their dams, but this does not certainly imply that the highest profits will accrue from this method of growing them.

When reared on their dams, it is important that the dams shall be well chosen, as some dams do not milk freely enough to sustain rapid growth in the calves that nurse them. It would not be profitable to introduce nurse cows to supplement the milk given by the dams. The latter should be chosen with a view to their milkgiving qualities, as well as to their beef form. Such rlams can most readily be found as Shorthorn grades, because of the extent to which these preponderate, and because of the generally acknowledged better milking qualities of Shorthorn grades as compared with grades of the other beef breeds. Experience has also shown that when these are mated with Aberdeen-Angus or Hereford bulls, particularly the former, they have even higher adaptation for producing beef of high quality than when they are the progeny of Shorthorn sires. 
Aberdeen-Angus grades thus obtained stand highest in favor for producing beef at the present time.

Calves that suck their dams will thrive better, on the whole, if confined rather than when they run with their dams, as when thus managed they can be induced to take supplementary food at an earlier age, and may also be carried through the weaning process without in any way arresting their development. They should be allowed to nurse as long as the dams can give them any considerable quantity of milk. The supplementary food will consist of fodder, fine and palatable, and of meal that will maintain growth and good flesh. For concentrates, equal parts by measure of ground corn, ground oats, and wheat bran will make a good ration, but probably not superior to the standard ration given for calves on page 21 . Up to the weaning period, such calves may be allowed to eat at will of the concentrates given.

When reared by hand, more frequently, if, indeed, not always, the dams are of the dual or dairy type. The cream from the milk of these dams being wanted for other uses, the milk is only given in the skimmed or separated form. But since it is highly important that the calves shall start well, and since no substitute will serve the purpose so well as whole milk, this should be given to them for not fewer than, say, two to three weeks, notwithstanding its cost, and as long a time should be occupied in making the change from all whole to all skin milk.

For the procedure in making the change see page 18. When well started on meal, corn meal should enter freely into the meal ration. Corn, ground oats, and oil meal, in the proportions of 4,4 , and 1 parts by weight (see page 22), should answer. When the calves are to be sold under the age of one year, the proportion of the corn fed may be increased as the feeding progresses. Some feeders claim that as good results will be obtained from feeding the corn and oats unground 
as ground, at least until the milk period is past. Dut all seem to be agreed that for such feeding the cob should not be ground with the corn. When the skim milk can be spared, it may be fed up to the limit of the capacity of the calves to take it, but never to the extent of so overloading the stomach that scouring will be induced.

The relative profit from the two methods of growing such beef will be, in a considerable degree, subject to conditions. It is more influenced, probably, by the availability and cost of labor than by any other factor. Where labor on the farm comes from the farm itself, the larger profit will unquestionably result from hand-feeding. But it has been found quite practicable to grow baby beef when the cattle thus grown have been bought on the range at weaning time, that is, at the age of five to six months. Usually, however, such animals must be fed on until, say, 18 to 22 months old.

The animals must start well.-In growing baby beef it is manifest, first, that the animals must be given a good healthy start in the process of development; second, that growth will be interrupted by no prolonged periods of arrested development; third, that the gains must be reasonably rapid from the start; and, fourth, that the condition of flesh in which the animals are maintained is higher than would be necessary for the proper growing of cattle for breeding uses.

Unless the calves can be given a good start, the expectation of growing them into suitable baby beef would be hopeless; and the younger the age at which they are to be finished, the more forlorn would be the hope, as even though they should make satisfactory development later. which is more than problematical, the lack of weight would greatly reduce the return. Every care should be exercised, therefore, in giving them a start during the first weeks of life, and one that will in no way tend to impair a vigorous digestion. Feeding milk too infrequently 
in too large quantities at one time, and out of condition, is particularly to be guarded against. Judgment must also be used in determining which calves shall be reared and which rejected. A calf prematurely born, small beyond a certain limit, or showing evidences of a lacking stamina, should not be retained for such a use.

Interruption in growth by any considerable periods of arrested development would so far defeat the object for which the animals are grown. The profit arises, first, from the rapid increase made in proportion to the food that is fed; and, second, in the relatively high price that is paid for the high condition at the time of marketing. Neither result will be secured when prolonged periods of arrested development occur. The most common causes of arrested development in growing sucll animals are the overfeeding of milk or meal, so strong as to overtax the digestion. When calves for baby beef run with their dams up to the time of weaning, the weaning process will tend to arrest development for a time, but not to the extent of preventing satisfactory growth subsequently.

The necessity for having the gains reasonably rapid from the start will be apparent because of the character of the feeding. The food fed to such animals must be of the best. It is more costly relatively than food that will suffice to grow breeding animals of similar age. If good gains cannot be secured, the animals will not only be lacking in weight, but they will also be lacking in finish. To have them grow continuously under highpressure feeding without overtaxing calls for the exercise of no little skill on the part of the feeder, and it calls for constant vigilance at every stage of the work. Shot:ld there be the slightest indications of deranged digestion the animal should be at once isolated and put upon a reduced diet until recovered. More commonly the indications of such derangement will manifest themselves in scouring or in a loathing of food. 
In growing baby beef it is not enough to secure increase: the increase should be accompanied by a high condition of flesh. Large gains may result from rapid growth in the absence of a large amount of fleshiness. The amount of fat called for during the process of development increases with the earliness of the period at which the animals are to be sent to the block. Calves marketed at 6 to 12 months can scarcely be said to have a finishing period, as they should be in high flesh all the time. But in the care of those not to be marketed until 18 to 22 months old, though in good flesh all the while, the highest condition of flesh should be sought during the closing months of feeding. In other words, they are not to be fed so high when young as to lessen development at a later period.

The nature of the fodders.-The fodders fed must be palatable and nutritious. Unless they are palatable the consumption secured will not be enough. Unless they are nutritious the requisite gains will not be forthcoming. To secure both results they must be selected with due care, or, what is better, grown with a special view to the use to be made of them. Fodders perfectly suitable for grown animals that are simply being carried through the winter may be quite unsuited for making baby beef, and the same may be true, but to a less extent, of fodders suitable for animals of similar ages that are being grown into meat. While a certain proportion of fodder is necessary to secure the requisite distention in the digestive organs, such distention is not required to the same degree as in animals of similar ages to be matured, because of the relatively larger proportion of the concentrates fed, and the earlier that the calves grown for baby beef are marketed, the less is the need for such distention. Calves marketed at six months require but little fodder relatively, while those marketed at I2 months will profit from a fair amount at similar ages. 
Among the most suitable fodders are clovers of fine growth and alfalfa similar in quality. Second growth clover is good, because palatable, and the same is true of rowen. In the absence of the legumes mentioned mixed hay will answer, also native hay, Bermuda hay and even millet hay, but it is important that these shall be cut reasonably early and be well cured. Corn fodder may also be fed with the proper concentrates, but this also, if fed in the unprepared form, should be possessed of more fineness than such fodder usually possesses. Straw of any kind should be barred, being too lacking in nutrition, but, if necessary, may be used when chaffed as a medium with which to mix meal.

Whether the fodders should be cut or fed as they grew will depend on the facilities for cutting them, and, in some measure, on the availability of labor. When the fodder, or even a part of it, is cut and the meal fed is mixed with it, the greater economy and safety in feeding are not to be questioned. But should all the fodder be fed in the cut form, the caution must be observed not to make the proportion of the fodder too large. The reliance is more on concentrates than on fodders, hence the proportions must be so adjusted that the full amount of concentrates fixed upon for the ration shall be consumed. Thus fed, more concentrates can be utilized than would be safe if these were fed directly.

Succulence and its sources.-Baby beef of the highest quality cannot be produced in the absence of a reasonable amount of succulent food. This is necessary, first, to maintain that juiciness of flesh which is one of the most highly prized characteristics of baby beef, and, second, as an aid to safe digestion. The principal sources of succulence are, of course, soiling food, corn ensilage, and field roots.

When calves are put upon the market under one year, it is not greatly important that pasture should be provided for them. Those marketed at 15 to 22 months 
will usually profit by one season of pasture. Autumn calves will be grazed the following summer and sold sometime the following spring, frequently before turning on grass. Spring calves will be grazed the second summer and will usually be sold sometime in the autumn. Grazing on grass unduly succulent is to be avoided, as it will retard gains. The meal portion should continue through the season of grazing, but unless toward the finishing period a less amount may be fed.

Soiling food has special adaptation for being fed to calves to be marketed under one year. These can usually be kept in highest comfort in the stables or sheds, with a paddock attached in which to rest when the nights are warm. These only call for enough succulence to keep the digestion in tone. Clover, alfalfa, and rape have highest adaptation for such feeding, but various other soiling plants may be fed, including millet. cowpeas, and corn.

In the winter corn ensilage is undoubtedly the cheapest source of succulence. It is also perfectly satisfactory when judiciously fed. It alone may be made to furnish the bulk food with which the meal is mixed. The amount to be fed will vary much with the age of the animals and the character of the ensilage. Ensilage with more than the usual amount of acidity would be thus far detrimental to highest gains, and would have to be fed with more caution than what is termed sweet ensilage. To cattle in the yearling form, it would not seem advantageous at any time to feed more than 20 pounds of ensilage daily. It should never be fed to the extent of precluding the necessity for feeding more or less of any fodder.

Field roots may also be fed with much advantage in winter in the sliced or pulped form. They also may furnish the medium in which the meal is fed in the admixed form. Although more costly than corn ensilage where the latter can be readily grown, they have pecu- 
liar adaptation for making the highest quality of beef, and may be readily furnished in the absence of a silo. They are also a safeguard against digestive troubles when the feeding is forced. When abundant, they may be fed in even larger quantities than ensilage, but, if only a few pounds daily can be fed, they will aid in giving tone to the system. Ensilage once a day and roots once will probably be more satisfactory than roots twice daily.

The nature of the concentrates. - The concentrates should be of that character which will promote growth and at the same time will maintain a sufficiency of high flesh, which means enough fat to effect the purpose sought. The amount of this that the animal should carry is so far a staple quantity that it should never be low, and it is so far a shifting quantity that it should never be high enough to retard or hinder any future development that may be sought. The younger the age, therefore, at which the animals are to be finished, and the less rich the other food during the milk period, the richer and more forcing should be the concentrates fed and vice versa.

They should also be of a character that will not cloy or disturb digestion. Such a result will follow even at an early age if certain foods are fed in excess. This would result from feeding an excess cf oil meal, even during the milk period. It certainly would result from feeding cottonseed meal similarly, and it is even possible when feeding such foods as barley and rye.

While almost every kind of grain grown on the arable farm may be used during the milk period, the standard grain foods are corn, oats, and bran. It is usual to begin by feeding the corn and oat:; ground, but as soon as they are well accustomed to take the grain, some feeders claim that quite as good results will follow from feeding the grain whole. It has a freshness about it which does not always appertain to meal, es- 
pecially in warm weather, when ground sometime previously. For calves sucking their dams corn, oats, and bran in the proportions of 3,3 , and I parts, by weight, would be suitable. Those on skim milk and to be marketed at a later age, should do well on the standard ration (see page 2I), but if they are to be sold in the months not far distant from the weaning period, a large amount of corn would be needed. The proportions may be given as 5, 4, and I of corn, oats, and oilcake, respectively. If cottonseed meal is fed at all it should be with great caution to calves so young. Should oats and bran be expensive toward the finishing period, corn and oil meal, in the proportions of 7 and $I$ parts, respectively, could be given.

Spring calves, during the first winter, may be fed preferably on clover or alfalfa hay, or on mixed hay largely composed of clover. Corn may furnish 50 per cent of the grain portion, the balance being preferably made up of ground oats, bran, and oilcake. The grain mixture does not necessarily call for more than io per cent of oil meal. The balance may be made up of oats and bran in such proportions as relative prices will justify. Either will answer in the absence of the other, but not quite so well. There may also be instances in which it may be prudent to make the ration consist of corn and oil meal only, in the proportions of 80 and 20 per cent, respectively. Such a grain ration could be fed when the fodder was largely composed of corn fodder and hay other than clover, in the absence of bran and oats, but usually it will be found cheaper to furnish a part of the meal in addition to corn in the form of bran and oats, rather than all in the form of oilcake.

With spring calves the second winter, when the fodder is leguminous, the proportion of corn may be fully as large and, in some instances, larger than the grain supplement recommended above for spring calves. If the corn could be fed in the ground form, the grain. 
cob and husk being ground together, there would be less necessity for the addition of so bulky a food as bran or oats, and the additional protein could be furnished in the form of cottonseed meal or oil meal.

When on pasture, corn may furnish the principal grain fed, especially should the pasture be clover. If simply grass pasture, some protein food such as bran or oil meal should be added to the extent of probably io per cent of the one and 5 per cent of the other. If peas can be substituted for corn in all of the above mixtures, the gains will be quite as pronounced, providing less protein is furnished in the complements added to the peas.

Amount of concentrates to feed.-Since growing baby beef is virtually a forcing process, concentrates must be freely fed from the start to the finish. When suitable in kind and suitably fed, the young animals may be given, during much of the period, that amount of concentrates that they will eat with a relish.

During the milk period, or at least during, say, the first three months of it, the calves may be allowed to eat concentrates at will. If properly blended, as when the standard ration given on page $2 \mathrm{I}$ is fed, they will not eat to excess. This will hold good whether the grain is ground or unground. But it is not a good plan to keep concentrates in a feed box accessible to calves in quantities much in excess of their needs. They soon become more or less moistened with escaping saliva, and their palatability is further lessened from the breath of the calves, hence it is not a good plan to feed much if, indeed, any in excess of what the calves will eat up clean at any time. Scrupulous attention should be given at all times to the cleanliness of the feed boxes.

When the calves are to be sold under one year subsequent to the milk period, the feeding may be close up to the limit of consumption by the calves. The appetite will be more keen if the calves are given only what they will eat with a relish. If allowed to eat all 
they would consume of barley or rye meal, the appetite would become cloyed, and the hazard would be present that the digestive powers would be overtaxed, and yet barley meal and rye meal may serve an excellent purpose at such a time when properly fed.

The amount of grain to feed the first winter subsequent to weaning will depend somewhat on the age at which the animal is to be finished. If it is to be turned off in the early summer, it should be fed close up to the limit of its capacity to consume, but if it is to be carried on to the autumn, then feeding concentrates somewhat lower than what the animal will consume will be in order, on the principle, first, that high pressure feeding of concentrates long continued tends to weaken digestion, and, second, that feeding less than maximum quantities during these months will put the system in proper condition for making greater gains during the finishing months. In other words, vigorous growth during those winter months is more important than that degree of fat called for in the finished animal. But when the animal is to be finished in the winter, it should be pushed to the limit of its capacity to consume.

When finished in the summer on grass during the final months of fattening, the grain may be given to the capacity of the animals to consume it. Where corn is cheap, that will be the principal concentrate fed, but the ration will be in better balance, if, say, 20 per cent is oats or bran, or in the absence of either, when, say, Io per cent is oil meal, cottonseed meal or gluten feed. In the absence of corn, barley meal or barley and rye meal may take the place of corn, but not quite so advantageously.

As the feeding is, in a sense, high pressure all along. it will sometimes happen that the appetite will slacken and the digestion will evidence tokens that are not quile satisfactory. This may result in a change in tempera- 
ture or from maintaining the animals for a long time on a diet without change. Attention, therefore, should be given to such modifications of the diet as may be found practicable. In some instances the addition of one ingredient, as, for instance, oats, will add much to the relish of the food. Sudden changes of temperature from lower to higher should be followed by giving a reduced amount of food. In some instances the appetite will be strengthened and digestion improved by feeding some aromatic spice or condiment, home-made or otherwise, when known to be helpful under such conditions. But such feeding should only be temporary.

Age at which to sell.-The age at which to sell the finished animals will be influenced by the type, by the food and feeding, and by the market values. Reference has already been made to the fact that animals of dairy inheritance grow more pronouncedly in dairy form with advancing age. Such change influences market values adversely in proportion as it is present. Because of this tendency and influence it is the aim to market animals possessed of such types under the age of I 5 months, usually under the age of 12 months and very frequently as young as six months. The age at which high-class types are marketed is more flexible and may cover any period extending from, say, I4 to 22 months.

Animals reared on skim milk cannot usually be brought into high finish at an age so early as those which nurse their dams, and, therefore, the older age is usually preferred at which to market these; but to this there are some exceptions, as in the case of dairy types reared essentially on skim milk during the milk period. Those who purchase calves from the range annually must have the feed lots ready when the time comes to purchase feeders and so carry the animals to the farthest age limit.

Market values may hasten or retard the age at which to sell. There are seasons at which higher values 
are usually obtained for first-class meat than at other seasons, and the aim should be to finish at these seasons. It is usually possible to rush the animals to a finish if so desired, and so hasten the time of sale, as they are, or should be, in reasonably high condition all the while. It is also possible to carry them on for a time without loss, because of uncompleted growth. This is not possible in the case of mature animals.

The value of high finish.-Unless a reasonably higil finish in the animal is secured, one chief object in growing it, viz., to secure relatively large and quick returns for the outlay, will be so far unattained. The influences that affect profit include the first cost of the animals, the cost of food in connection with the rapidity of the increase, the value of labor, the interest on th investment and most of all the price obtained. The first cost of the animal when home-raised is much greater relatively when produced by the dam which it is allowed to suck during the milk period than when it is the progeny of a cow that is to be milked. The cost of food is usually much more under intensive than under extensive conditions, and yet baby beef is more commonly grown under intensive conditions. This applies to the milk period as well as to a later season. Of course, the cost during the milk period is much greater when the young animal is reared on new milk rather than on skim milk. The rapidity of the increase is much influenced by the capacity of the animal. The cost of labor is influenced by many considerations, chief among which is the amount that may be furnished by the young and developing family. The interest on the investment increases with the intensity of the conditions. The manure obtained from this class of stock is relatively valuable.

But the factor that most influences the profit is the price obtained for the finished product, and this is largely based on the finish and quality in the animals. Even a fraction of a cent a pound live weight materially influ- 
ences profit. Suppose that a finished aninal weighs 1,200 pounds, each quarter of a cent of advance in price makes a difference of $\$ 3$, and a difference of one cent a pound makes a difference of $\$ 12$. The difference in the value of a carload containing 20 such animals would be $\$ 240$, as shown in the preceding paragraph. The quality materially affects the price, a factor that may be less under the control of the individual than the character of the finish. 


\section{CHAPTER V}

\section{HEIFERS DURING PREGNANCY AND SUBSEQUENTLY}

In the discussion of this question the following points will be considered in the order given: (I) The age at which heifers reared for milk production should le bred; (2) The food and care suitable for them when pregnant; (3) Breaking them in to milk; (4) Treatment subsequent to parturition; and (5) Raising calves from such heifers.

Age at which to breed heifers.-Under this head will be considered the breeding of heifers, first, for the dairy and for furnishing beef; second, the objections to breeding too young and also deferring breeding to a period unduly late, and, third, the sires used and the manner of the service. The opinions of practical men differ materially as to the age at which heifers shall be bred, especially for the dairy.

The prevailing practice during recent years has been to breed heifers so that the first calf shall be dropped at the age of 24 months, and then to milk the heifer for a long period, as long frequentiy as 18 months before she produces her second calf. The standing argument advanced in favor of such a course is that it strengthens and more or less confirms free and prolonged milk giving in the future cow. That it does is probably true. If such an end could be attained without loss in any other direction, the wisdom of the practice should not be questioned, but there are some reasons for believing that the gain referred to is secured at too great a cost. During pregnancy, in order to sustain the fetus, there is a drain upon the assimilative powers, thus diverting 
food more or less from the system of the pregnant mother yet undeveloped and immature. This means, first, more or less arrested development, and, second, an extra tax upon the energies of the system; first, to sustain the fetus and, second, to carry it. As a result, the mature cow is of less size and vigor than if breeding had been deferred longer. The lessened vigor may not be discernible, but it is reasonable to conclude that it is present. It would seem to be more than questionable, therefore, if the gain resulting from thus attempting to strengthen the milking habit is not more than counterbalanced by the loss in the two directions men. tioned. There is the further loss in the lesser development of the calf (see page 102) produced by the heifer which comes into milk at 24 months as compared with that of the heifer bred later. Moreover, with the latter, the necessity for deferred production is also lessened, hence she may be expected to make up largely or entirely for the loss in milk production resulting from the later period at which she comes into milk. Because of the loss in size and stamina referred to, some of the most practical breeders of dairy stock are deferring the period of bringing heifers into milk to 27 months, and, in some instances, to 30 months, according to the strength and development which they possess.

Heifers reared to produce beef animals are not usually bred so young as those intended for the dairy. With the former, the first calf is commonly reared as well as those produced later. Experience has shown that if heifers of this class are allowed or required to breed at too young an age, sufficient growth in many instances is not obtained from the calf when matured or previously. The breeders of pure-bred cattle have erred probably more than others by breeding heifers at too early an age. The temptation to do so comes from the desire to secure quick increase from high-pricert stock. That the average of individual excellence in 
many pure-bred herds has been lowered to a serious extent by this method of breeding cannot be questioned. It would seem correct to say that heifers of this class should be bred so as to produce the first calf at the age of 30 to 33 months.

The objections to breeding too young, already touched upon, may be summarized as follows: (I) Lowering the size in the individual; (2) loss of size in its immediate descendants; (3) lowering of stamina in the individual, and (4) lowering of stamina in the immediate descendants. That size is thus lost is shown by experience and observation. This loss may not be very pronounced in a single generation, but, though thus gradual, the loss is cumulative where the practice is continued and at length becomes serious. That there is loss of stamina is well shown by declension in performance in animals thus managed. That such a view is firmly lodged in the minds of breeders is evidenced in the common practice among dairymen of usually rejecting the first calf produced by a heifer when determining which shall be retained for replenishing the herd. It is further shown in the almost invariable choice of animals to be grown for show purposes in beef classes, which are the progeny of dams that are mature or almost mature. The evil results from immature breeding would be vastly more apparent than they are if the only animals retained for future breeding were the progeny of those produced by immature dams. In such a herd it is reasonable to suppose, and it is even certain, that deterioration would be rapid.

As it is, declension is counteracted by the large number of the animals retained in the herd from mature dams. It would seem correct to say that the world has never yet seen the high average of excellence in studs, herds and flocks that may be attained by a system of selection to which no objection can be offered.

There are some objections to breeding long de- 
ferred. These include: (I) The maintenance of animals for a comparatively long period without obtaining any revenue from them in the form of progeny or of milk; and (2) failure to breed, that is, the loss or at least the apparent loss of the power to reproduce. The answer to the first objection lies in the fact that the value of the performance of the breeding animal is to be measured not by the earliness of the period at which it begins to produce so much as by the character of the production during the whole period of productivity. The value of the former is insignificant compared with the value of the latter. The important consideration, therefore, is to have animals that are to be retained in the herd come into productivity at an age which will prove no handicap with reference to their future usefulness.

Experience has shown that when breeding is long deferred conception is not so certain as at an earlier period. For instance, the number of cases in which animals fail to breed when required to drop calves at three years old is greater than the number in which they fail to breed when the aim is to have them drop calves at two years old. The first is that the breeding powers, like all the other powers that inhere in the animal, are strengthened by use, and the second is that females with which service is deferred to the later period frequently become so fleshy that the generative function becomes inactive. It has been argued in favor of early conception that nature is unerring in her determinations, and that nature would not make the ability to reproduce possible at an age too early for reproduction to begin. That is true where the processes of nature are left undisturbed. Wild animals do not become capable of breeding at too early an age. But cattle are reared under artificial conditions which are far from being the same as those which nature furnishes unaided. Apply to the human family generally the practice of reproduc- 
ing as soon as reproduction is possible, and think of the disastrous results that would come to the race.

Care must be exercised lest the uncastrated males remain too long with the females when both are kept in the same lot or inclosure during calfhood. Conception is possible at an early age, as early, in some instances, as six to seven months, and the same is true of generation. Of course conception at so early a period would be greatly harmful, and should be sedulously suarded against. During periods of heat prior to the suitable age for service, heifers should be separated from the other animals and confined until the period of heat is passed. Particularly is this necessary when steers run in the same inclosure. It is necessary because of the disturbance for the time which comes to other animals in the herd resulting in arrested gains.

When young heifers are to be served by large and heavy bulls, difficulty in the service is sometimes experienced by inability on the part of such heifers to sustain males so heavy. Particularly is this true of beef cattle. When the disparity in weight is very great between the animals permanent injury may follow in the case of the smaller animal. To avoid such trouble and hazard it may be necessary to employ a lighter and less mature bull for service, even though it should be necessary to go some distance in order to secure the service.

Food and care suitable for pregnant heifers.-The food best suited to the needs of heifers not yet in milk is not unlike in the character of the nutrients to that called for by cows that are in milk. It should be essentially nitrogenous in its general constituents. Since the growth of the frame is yet uncompleted, it is important that it shall be rich in ash. This is not only necessary to complete growth in the frame, but also to give sufficient bone and firmness to the same in the young animal. For this reason clover in all its varieties and alfalfa have high adaptation for such feeding, and corn 
and corn fodder adaptation that is much lower, except when fed as a balance of other foods.

The nitrogenous element is, of course, necessary not only to produce ample muscle to meet the needs of the heifer, but also to develop the young calf in embryo. A pregnant heifer yet immature will require food relatively more rich both in ash and protein than a cow that is pregnant but not in milk. And yet the maintenance of good condition, that is, a reasonable amount of fat in the heifer, is important for reasons given below. (See page 96.) Of course excess should be avoided in any direction. Too much protein and not enough carbohydrates would result in an overgrown calf while yet unborn, and also possessed of weak vitality at birth, the result of an insufficient supply of carbohydrates to balance the ration. Too much of carbohydrates with too little ash would result in a calf deficient in size at birtl, the deficiency resulting from the want of enough protein to balance the ration.

The food should be possessed of ample succulence. This is not required to the same extent as in the case of cows in milk, but it is important, nevertheless, in order to keep the heifers in that sappy condition of flesh, that is, in that soft and spongy condition of flesh, the invariable accompaniment of desirable growth in animals not yet fully developed, and because of the fact that such food is more or less of a preventive and corrective of constipation. It is especially important that an ample supply should be given to heifers as the time of parturition draws near, since constipation at such a time is more than usually dangerous. It may be necessary to exercise some caution in giving such foods to free milking cows when near the time of calving, lest milk fever should result, but this hazard is seldom if ever present with heifers which have heretofore been in milk. Of the common foods grass, roots, and ensilage most 
readily furnish such succulence. In relative suitability they rank in the order given.

While it is important that the supply of food shall be liberal for all pregnant animals, it is especially important that it shall be so with those of uncompleted growth, because of the double duty put upon them. It is greatly important that all dams shall be in a good condition of flesh when their young are born, because of the drain which follows during the period of lactation. Milk-giving, especially when abundant, acts as a drain upon the system to the extent of drawing upon certain of the elements of the body itself. This explains why free milk producers almost invariably lose flesh during the period of abundant milk-giving. When no reserve, as it were, of this is stored in the system before the young are brought forth, the ability of the dam to milk abundantly is lessened, and, in the case of heifers, the same standard of completed development is not attained such as would otherwise result. To underfeed cows when pregnant would result in future loss, but to deal thus with heifers would result in double loss. Of course excessive fatness would bring its hazards both to the present development of the young in embryo and to the dam and her progeny at parturition. Such excess in fatness, however, seldom occurs, and never in the case of animals that have been properly fed.

In summer no food is more suitable for pregnant heifers than succulent grass. If, for any reason, they should be deprived of pasture, as under certain conclitions of soiling, of course they should be given the equivalent of pasture in green food. Usually no additional food is necessary, either as grain or supplementary fodder, when the grass is abundant. In winter when the heifers have clover hay, as fodders or alfalfa good in quality and enough in supply, they may require no other food than a moderate amount, say, ro to 20 pounds of field roots or corn ensilage daily. In the absence of 
ensilage, fodder corn may be given, but in such an event some roots should also be given to supply succulence. Pregnant heifers thus fed will usually carry enough muscle and fat without any other grain than the corn furnishes. Should the fodder be hay other than clover or alfalfa, or essentially corn or sorghum fodder, or the two combined, field roots added in ample quantity would preclude the necessity of feeding grain, but, in the absence of these, then a few pounds daily of such food as ground oats, bran, and oilcake in the proportions of, say, 3, 6, and I parts, will furnish a suitable supplement. The quantity should be determined by the condition of the animals.

Breaking in to milk.-In some instances trouble is experienced with heifers in what may be termed the "breaking-in" process; that is, the process of making them submit to being milked without any resistance being offered by them. It is greatly important that this shall be done in a way that will reduce the friction, more or less usually present, to the lowest possible minimum. The future usefulness of many prominent heifers has been destroyed by improper treatment when breaking them in to milk. The process is new to the heifer, and it is almost certain that the first attempts to draw milk from her will be met with some resistance. The degree of that resistance will usually be proportionate to the natural nervousness of the heifer, to the extent to which she is unfamiliar with being handled, and to the degree in which harshness is shown by the person who withdraws the milk.

Some heifers are possessed of a highly nervous temperament, a positive recommendation in a milch cow, because of the relation between this endowment and abundant milk production. This temperament tends to quicken physical action. Because of this a heifer thus endowed will not only manifest more restlessness than one of the opposite temperament when milking is first 
begun, but will more quickly resent the innovation by kicking or prancing about with the hind limbs, which is simply an effort to make the milker desist. If the heifer has been handled occasionally and with sufficient gentleness previously to parturition, and especially if such handling has extended to the udder and teats, the resistance offered by the heifer while being broken in is likely to be much less than it would otherwise be. The previous handling of the heifer is of sufficient importance to merit careful attention from the owner. If the heifer should resist by kicking, she should not be paid back in kind, as is so frequently done. Doubtless the aim of the heifer is to get rid of the intrusion which she does not understand.

Three qualities, at least, should be prominent in those who engage in this work. These are self-control, firmness, and gentleness, important, probably, in the order named. The man who has not absolute control of his temper should not engage in this work or he will certainly wrong the heifer and in so doing will wrong himself. He must, neverthless, have firmness. By soothing the heifer with gentle words, which, in some way, even heifers seem to understand, accompanied by handling calculated to soothe, the individual at length gets his hand on the udder and teats, not necessarily drawing milk from them at first. By this time he should be in the attitude of one milking, but without a milk stool. His head may be rested gently against the hind flank. If the heifer should try to kick, a little pressure of the head at that instant will almost certainly prevent the blow from reaching him as it otherwise would. The heifer seems to understand this attitude of fearlessness on the part of the milker, and soon comes to respect it. Every movement should be gentle, and the utterance of soothing words occasionally will be helpful. Before the milker leaves, a little scratching on the top of the head behind the horns, or such petting otherwise as the heifer 
can understand, will prepare the way for a pleasant meeting when the milking is to be done. Usually in two or three milkings, managed thus, all danger of harm from the heifers will be avoided. They will soon come to regard being milked as a soothing process, such as it is unquestionably to older animals.

Not infrequently the udder is swollen at such a time, the outcome of a certain degree of inflammation present. This means, when the udder is pressed even gently, pain is the outcome of such pressure. This, of course, intensifies the impulse to resist on the part of the heifer. This condition more than doubles the necessity for the exercise of patience and gentleness on the part of the milker, and also for the exercise of perseverance, for it is important when such conditions are present that all the milk shall be withdrawn. When udders are thus affected, hot fomentations will prove helpful.

What is said above as to the breaking in of heifers is intended to be general rather than specific. Precisely the same methods may not work equally well with all heifers, hence, in regard to this work, much can only be learned by experience. It may be considered as safe to say, however, that the following should be regarded when breaking in heifers to milk: (I) No harsh or unkind word should be uttered, whatever the provocation; (2) hasty and sudden movements should be avoided; (3) no blow should be given with hand, foot, or club; and (4) cords or ropes should not be used to prevent the heifer from kicking, lest the necessity for this should continue. It is not only legitimate but frequently necessary to fasten the heifer by the head in a stanchion or by some other method before attempting to milk her.

Heifers and cows, in some instances, become so confirmed in the habit of kicking while being milked that it is positively dangerous to the milker to attempt to handle them unless they are restrained in some way from thus harming the milkers. When such instances 
occur it shows very clearly that they have not been managed properly during the breaking-in process. It may be affirmed with safety that when heifers are broken properly they will not become confirmed in the habit of kicking while being milked.

Should they become confirmed in this habit two methods of management are open. One is to restrain them so that they cannot harm the milker. Another is to correct the habit by kind treatment. Two methods of restraint have been resorted to. The first is tying the legs together with a rope before the milking begins. By the second method a rope is passed around the body in front of the hind flank, and is tied when thus placed. When the effort is made to kick, this rope is drawn so tight as to produce pain, so that the animal at once desists in its efforts to harm the milker. The objections to these methods are that they are troublesome and that they will never in themselves cure the habit of kicking in the heifer or the cow. Nor will a cow thus treated milk so freely as when milk-giving is pleasantly concurrent with her desires; that is, when it is to her a pleasantly soothing process. The other method is to correct the habit. Instances are on record where cows in milk have been corrected of the kicking habit through kindness on the part of the milkers. The weak point in the achievement lies in the fact that the cow will usually only behave thus with reference to the person whose gentle treatment secured for him or her immunity from harm. Consequently such animals are usually disposed of at the close of the period of lactation, however good their milking capabilities may be, and there is wisdom in such a course. Life is too short to spend too much of it in reforming kicking cows.

Treatment subsequent to parturition.-For a few days subsequent to the birth of her calf the heifer should be fed on a moderately low diet, lest milk giving should be stimulated to the extent of bringing on milk fever. 
When the danger is past the food should generous. Growth is yet incomplete, and, because of this, it is especially necessary to feed foods rich in protein. With grass pastures abundant and succulent no other food may be needed. When maintained essentially on dry foods, legumes rank highest among the fodders in providing such food, and clovers rank highest among legumes in all-around adaptability. Wheat bran and oats combined are very suitable as concentrates, with enough corn added to maintain a sufficiency of flesh in the heifers. But the mistake must not be made of giving heifers concentrates to the extent to which they are sometimes given to cows used to such heavy feeding. It is questionable if at any time it will be to the advantage of heifers ultimately if they are given more than Io pounds of concentrates daily.

The time of mating subsequent to the birth of the first calf will depend to some extent on the age at which they have produced their first calf. When the first calf is not produced till the age of, say, $3^{\circ}$ to 33 months is reached, which would seem to be early enough for judiciours reproduction (see page 90), the heifers, when well sustained, will usually come in heat in from 6 to I2 weeks from the time of parturition. It is usually considered unwise to have them served at the first period of heat, as it is likely that it would result in imposing upon them the burden of reproduction again without sufficient period of rest. Usually it is considered preferable to have service given at the second period of heat, but something, of course, depends on the distance of the same from the time of parturition.

When heifers are bred so as to produce their first calf at the age of two years, it is customary to allow several months to elapse before they are bred again, in order to facilitate growth before the burden of reproduction is imposed upon them again. This plan brings with it some hazard of failure to breed, though such hazard 
may not be very pronounced in animals so young. It is a fact, nevertheless, that regular breeding is materially affected by habit, as well as are other functions of the organization. Because of this the female that becomes impregnated within a reasonable time after the birth of her calf is more likely to breed regularly than the female with whom impregnation is deferred.

Rearing calves from heifers.-Grade calves from heifers bred at an early age are seldom reared. Those from heifers maintained for beef are usually grown for the block for the reason that, as a rule, they do not grow into cows so large and robust as those that are the offspring of mature dams. This does not mean that they are necessarily small and delicate, but simply that the tendency in rearing them for breeding would be downward. That it should be so is the natural outcome of diverted rather than concentrated energies in the dam in relation to reproduction. Uncompleted growth in the clam diverts sustenance that would otherwise go to sustain the fetus in the pregnant dam. The loss in stamina may not be much in any one instance, but the tendency is always in that direction.

Calves from grade heifers of the beef types are usually reared for the reason, first, that the heifers are frequently bred at a later age than heifers of dairy type, so that their calves are possessed of stronger relative development; and, second, that when grown for beef lack of large development is less objectionable than if grown for breeding. The animal grown for beef on the arable farm usually reaches the market under three years, while that grown for milk production may remain in the herd for several years, thus transmitting inferiority to its progeny.

The progeny of immature heifers of pure breeding, both in the beef and dairy classes, are almost invariably reared. They are thus retained for the reason that they will sell for more than meat price, and, in some instances, 
to hasten increase in numbers in the herd. The same objections, however, apply to the rearing of progeny from those heifers of immature development that apply to the rearing of progeny of immature heifers for the dairy. Those who buy such, therefore, should give careful attention to the question of the age of the dams that produced them at the time of reproduction. It would be interesting, could it be known, how much the standard of the average pure-bred has been lowered through immature breeding from parents, both male and female.

The lessons to be drawn are clear and may be summed up as follows: (I) The aim should be to avoid breeding heifers so that they will be well advanced toward maturity before producing their first calf. But it should be understood that development as used here means completed physical growth and not maximum performance in a particular line, as where, for instance, a cow or a horse becomes capable of making their best records for milk production or speed respectively. (2) When heifers are bred thus early, the aim should be to avoid rearing the progeny for breeding, lest the standard should be lowered in performance and also in breeding. (3) The aim should be to select for future production to the greatest extent possible animals produced by both parents when they are possessed of a maximum vigor. 


\section{CHAPTER VI \\ THE FEEDING AND CARE OF BULLS}

The discussion of this question will consider: (I) Bulls of the three types, viz., the dairy, beef, and dual types; (2) Food and care during the milk period; (3) Food from weaning until maturity; (4) Management from weaning until matured; (5) Food for mature bulls: (6) Management of mature bulls; ( 7 ) Extent and duration of service called for; (8) Handling bulls that are vicious; (9) Restoring begetting power in bulls when the same is lost; and (IO) Purchase and disposal of bulls. The discussion is taken up thus minutely and comprehensively for the reason, first, that the feeding and care of bulls is not nearly so well understood even by the average stockman as the feeding and care of cows; second, that the measure of success which attends the breeding of cattle is intimately dependent on the condition in which the males are maintained; and, third, that the mistakes made in the management of bulls in the past has not only resulted in much loss, but it has also proved a barrier to highest attainment in the effort to improve herds.

Bulls of three types.-The ordinarily accepted classification of cattle divides them into the three types mentioned above. The feeding and management of males of these differ materially in some respects, but in others they are the same. The differences are the outcome of the difference in treatment called for and are much fewer than the points of agreement in the same.

In growing bulls for the dairy, it is all-important that they shall possess the power to transmit good milkproducing qualities. Whatever will militate against such transmission should be sedulously avoided, and 
whatever will favor such transmission should be carefully followed. The transmission of such qualities is influenced more, of course, by inheritance than by the care and general character of the feeding, but both feeding and care influence such transmission.

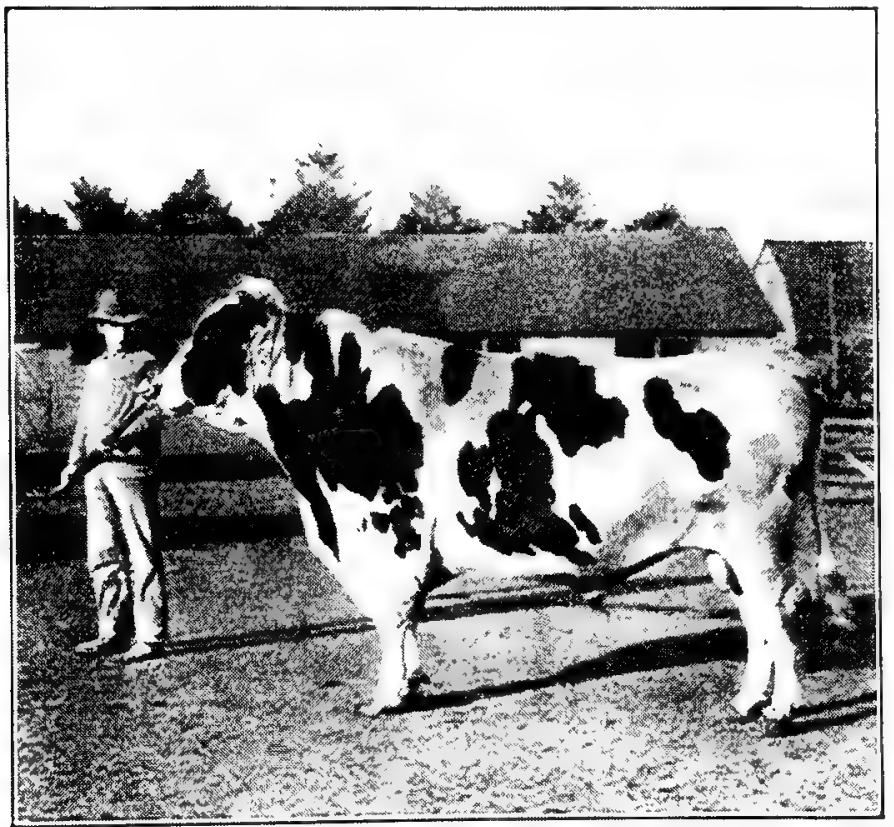

HOLSTEIN FRIESIAN BULL, SARCASTIC LAD, 23971

(By courtesy of the owner, Illinois Experiment Station)

The truth finds general acceptance that if a female - is kept in high flesh beyond a certain limit while being grown for the dairy, the tendency will be begotten in the digestive and assimilative system to continue to turn the food into flesh to a greater cxtent after lactation begins than would be the case had the heifers carried 
less flesh during the process of development. It is reasonable to conclude that if a high condition of flesh in growing heifers thus influences adverse performances at the pail, it will likewise, though, possibly, in a less degree, influence transmission in the same direction on the part of those heifers to their progeny. If this result follows, and it is generally conceded that it does, then it is reasonable to conclude that bulls of the dairy breeds kept in high flesh will transmit to their progeny more or less of a bias in the direction of turning food into flesh rather than milk, even after the period of lactation has arrived. This would indicate that the bulls of the dairy breeds should not be loaded with flesh during development beyond what is necessary to maintain sufficient growth and bodily vigor. On the other hand, they should not be maintained in flesh so low as to hinder or lessen maximum development in each instance, or size and stamina will be lowered.

Bulls of the beef type are maintained for the reproduction of animals that will use the food given to them in the production of flesh, and that will deposit the flesh produced on the carcass so as to meet in the most desirable manner the needs of the consumer. This means that the flesh-producing habit in them should be encouraged through liberal feeding of such foods as will maintain a good condition of flesh without carrying an excess of fat. An excess of fat is that amount which induces aversion to taking a sufficiency of exercise for the maintenance of sufficient stamina. On the other hand, a low condition of flesh during development will, in some degree, create a bias of the system in that direction, and this will so far militate against desirable transmission.

The dual type of bull is maintained for the transmission of the dual qualities of milk and meat production. The more nearly that these can be transmitted in equilibrium, the more perfectly will bulls of this class fulfil the end for which they are kept. If it is true that 
fleshiness beyond a certain degree in bulls of the dairy type militates against desirable transmission in flesh production, then it follows that any marked departure in what may be termed equilibrium in the condition of bulls of the dual types will so far militate against equilibrium of transmission in the same.

Food and care during the milk period.-During the milk period the management of bulls of the dairy breed or type will be essentially the same as that accorded to calves that are being reared for the dairy on skim milk and the accompanying adjuncts. (See page I6.) But it is more important relatively that the male shall be possessed of the best attainment possible; even more care should be given if necessary to insure the most suitable development. The aim should be to secure maximum growth, maximum symmetry, and maximum vigor. To secure the first, it is specially important that the digestion shall not be impaired by overfeeding, and that the diet shall be essentially nitrogenous and liberal in supply. Feeding skim milk for a prolonged period will favor such development. To secure the second calls for careful regularity in feeding and in the balancing of the foods given as to bulk, so that distention of the paunch shall be gradual and not excessive. Too rapid distention of the paunch tends to increase in the sway in the back, and is unnecessarily antagonistic to symmetrical development.

The sway back, though frequently possessed by dairy animals of both sexes, is in no way essential to high performance in the dairy, but is rather the outcome of overloading the paunch in calfhood until, in some breeds, it has become more or less a breed characteristic. To secure the third calls for abundant opportunity to take exercise from birth. Such exercise, in addition to maintaining stamina, tends to normal development in the organs concerned in procreation. Too much attention cannot easily be given to securing stamina in the 
male, because of the great influence through him which it imparts to the progeny. The temptation also should be resisted to bring young dairy bulls to a condition of flesh so high as to be antagonistic to their best use in dairy herds. Such feeding is sometimes practiced to facilitate sales.

Young bulls of the beef breeds will be reared on the dam or by hand. If reared on the dam, but little supplementary food, such as concentrates, is needed. especially during the early part of the nursing period, providing the dan is a sufficiently good milker. No food can be provided for the young calf that will. in all respects, equal whole milk in promoting normal development. If the dam does not give enough milk to maintain her calf in good form during the first two or three months of its life, without calling in the aid of a nurse cow to supplement the whole milk taken by the calf, she furnishes eviclence that her milking qualities are lower than they should be in a breeding cow, though kept primarily to produce progeny grown for beef. The food and care of such calves will be essentially the same as that given relating to calves reared for breeding on their dams. (See page I2.)

Although not absolutely necessary to insure stamina in a high degree, calves that run with their dams have the most favorable conditions for taking exercise that can be furnished to them. When feeding a supplement of concentrates, it is highly important that it shall not be too rich in carbohydrates; hence, in such a diet, corn, barley, and rye should not form any large portion of it. In order to secure quick sales at an early age breeders very frequently make such calves so fat that they become sluggish in action, and this lowers stamina and weakens the powers of procreation. The future usefulness of some young bulls of the beef breeds is destroyed before they have reached the age of one year. The buyers of young bulls are more responsible for such 
feeding than the growers of the same. Almost invariably the male calf preferred by the prospective buyer is the one that carries the most flesh. It is well to remember that even in a calf abundant flesh may hide deficiencies in form.

When such calves are reared by hand, much of what has been said when treating of calves reared on skim milk will be applicable. (See pages 16 to 25.) As they should be maintained in a reasonably good condition of flesh, however, the following points should be particularly noted: (I) To give them a good start they should be fed whole milk, where practicable, for three to four weeks from birth and a similar time should be taken to make the change from all whole to skim milk. (2) As a supplementary grain ration, none is better, probably, than the standard ration given on page 2I, though other meals may be fed. (3) The aim should be, as far as practicable, to feed leguminous fodders, as good, bright clover and alfalfa. (4) Every possible facility for exercise should be furnished. (5) The aim should be, where practicable, to feed field roots from the time that they will take them onward in liberal supply. (6) The calves should be maintained constantly in a good condition of flesh.

Young bulls of the dual types may be reared in the same way during the milk period as males of the beef types as outlined above, with the difference that a somewhat lower condition of flesh will suffice for them. This can be regulated by the amount of concentrates fed, the diet being the same in kind.

Food from weaning until maturity.-The food given subsequent to the milk period may be essentially the same in kind as that given previously, but more in quantity. During the entire growing period the aim should be, first, to feed food in kind that will result in maximum development, and that will at the same time keep the system in that sappy condition favorable to the proper 
sustenance of the procreative powers; and, second, to feed it in quantity so that it will sustain the animal in an equilibrium of flesh. To secure the first, foods rich in protein must be fed, which means that clover, alfalfa, or vetch hay should form a large portion of the fodder where one or the other of these may be had, and that oats and wheat bran should furnish the chief concentrates. Corn, barley, and rye, if fed at all, should be fed with due caution. Along with these foods succulence is greatly advantageous. This may be obtained from grass pasture or soiling crops in summer and from field roots or ensilage, preferably the former, in winter. In the absence of both in winter, oil meal should be fed as a regulator of digestion. To insure the second, the amount of concentrates fed should be determined chiefly by the degree of flesh sought. A higher condition of flesh is, of course, wanted in bulls of the beef breeds. While males are in process of development, feeding liberal and systematic at all times, but not forced at any time, will usually result in development far more complete and satisfactory than that accompanied by forced feeding at one time and low feeding at another. The necessity is not present for pushing such animals on to quick maturity as it is with animals being grown for the block.

For young bulls of the dairy type, and, in fact, for young bulls of any type, some legume, if possible, should be given once a day, and twice a day is even more satisfactory. Corn or sorghum fodders or good oat straw may furnish the balance of the fodder needed. Where timothy or native hay is fed, the protein in the concentrate fed should be increased. The standard concentrate for such animals would be wheat bran, ground oats, and oilcake, in the proportions by weight of 5, 4, and I parts, respectively, but, of course, other concentrates may be fed. The more freely that field roots are fed in winter, up to, say, I5 pounds daily for each animal, the more 
satisfactory will be the development and the less imperative is the necessity for feeding meal. When on good pasture, meal may not be necessary, and the same may be true when such soiling foods as rape and succulent clover are furnished in ample supply. While males of this class should not be kept fat, neither should they be kept lean. While excess in the former would unduly divert desirable transmission, excess in the latter would hinder maximum development.

For young bulls of the beef type the fodders will be the same as for those of the dairy type given above. The concentrates may also be the same in kind, but more in quantity. As higher flesh is called for in these than with males of the dairy, this will be more easily secured and maintained by feeding the standard concentrated mixture given on page xxx. Frequently young males of this class are kept too highly conditioned, more especially when they are held for sale, the result of feeding too much and too highly concentrated meal.

For young bulls of the dual types, either ration given above as suitable for males of the dairy and beef types, respectively, will answer. The intermediate condition called for may be regulated by the amount of concentrate fed. Cost in the ration of a growing bull is of less importance than proper development, hence the aim should be to seek proper development though at added expense rather than hazard obtaining less perfect development by feeding a cheaper ration.

Management from weaning until matured.- Up to the usual time for weaning young bulls, they and the heifers may be allowed to occupy the same quarters, when the supplemental food given to both is the same. In many instances, however, the males are sustained in higher flesh than the females, which, in practice, has been found a material aid in securing sale for them at an early age. Where this difference occurs in the feeding, it would mean that they and the heifers must be 
given separate quarters. Should weaning be deferred beyond the age of six months the sexes should be separated, as generation, in some instances, may occur thus early.

It is of first importance that young bulls shall be given abundant opportunity to take exercise. This is absolutely essential to their proper development, hence they should not be tied in stalls or held in stanchions during the developing period, unless when taking their food. They should have the liberty of a box stall with yard attached and also a paddock or pasture in the season of grass. The more completely such quarters can be located away from other animals of the herd, the more restful and free from disturbance will be the condition in which the young males may be kept. The fence around the inclosure should be strong. As soon as the young bulls come to know their strength, a weak fence will not hold them, especially when other cattle may be near, and, as a result, it may soon be found difficult to keep them within fences as ordinarily built. There can be no objection to keeping several young bulls in the same inclosure, and there are some advantages in so doing, as economy in space and the greater contentment which accompanies companionship, even in animals. But should some of the bulls remain unsold in the yearling form, they must be maintained in quarters separate from such as are younger.

In very many instances bulls are purchased as calves, even when they are to head a herd. When so purchased, the nature of the previous feeding should be carefully ascertained, that it may be continued as far as practicable. If found necessary to modify it, the modification should be gradual rather than sudden. Radical changes in the diet of newly purchased young males, when suddenly made, may react against their progress, especially when they have been maintained previously in a high condition of flesh. In their new quarters the 
aim should be to give them a box stall and yard attached. The companionship of one or more steers of like age may also be admissible.

Young bulls should be trained to lead at an early age. The aim should be to train them thus early, even during the milk period. The benefits resulting therefrom are the following: (I) They are then more easily

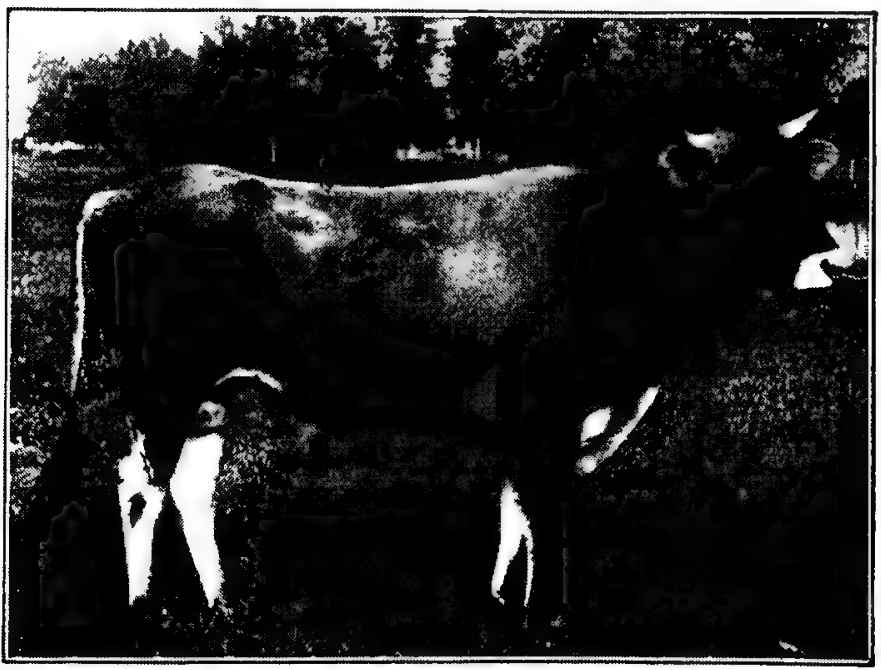

PURE JERSEY BULL, PRAIRIE CZAR

(By courtesy of the owner, North Dakota Experiment Station)

practiced in leading than at a later period. (2) They are usually more submissive at all times when trained thus early to lead. (3) Tractability, as thus manifested, aids in the sale of a young sire. For a time a halter will suffice when leading young animals of this class, but gradually they come to know their strength, and not infrequently show resistance to being thus led. As soon as such indications appear, a ring should be promptly 
inserted in the nose. Usually this should not be dcferred beyond the age of one year.

The rings in common use may be obtained in hardware stores, and are of different sizes. Those most commonly used are about $2 \frac{\mathrm{T} / 2}{2}$ to 3 inches in diameter. When inserting them the head of the animal should be tightly drawn to a post or other firm object, so that the muzzle points upward at a suitable angle. A hole is then made with a suitable implement through the cartilage between the nasal passages. For making the opening a large awl will answer the purpose in the absence of a better implement, but one of the best implements is a trocar. The opening should be forward rather than backward in the cartilage. The ring is then inserted, the two parts are brought together again, and they are held in place by a small screw. Much care is necessary in putting the screw in place, as it is easily lost on account of its small size. When thus ringed a strap or rope with a spring attached, which may be snapped into the ring, is all that is necessary for a time when leading the animals, but later it is a wise precaution to use what is termed a "lead" when handling bulls. A lead is a strong, tough, circular piece of wood 4 to 5 feet long, with a snap attached to one end. The advantages are: First, that the attendant has power to hold up the muzzle of the bull, which, in case of attack, is so far effective; and, second, that it enables the individual to keep his head at a distance.

Food for mature bulls.-When bulls are much used in service prior to maturity, the food fed to them should be highly nitrogenous, as they have then to bear the double task of completing growth and furnishing the materials concerned in generation. When full maturity is reached a less proportion of protein in the food will suffice. But this also is influenced by the extent of the service required of them. The more severe the exaction of the service is, the larger is the percentage 
of protein called for in the food. The rations given to mature bulls will vary with variations in the production of foods. When supplying these the following considerations should not be disregarded: (I) The food should contain more protein than would be suitable for animals that are being fattened. (2) It should be fed, as far as this may be practicable, in the bulky rather than in the concentrated form. (3) It should be possessed of more or less succulence.

That protein rather than carbohydrates is wanted in the food is evidenced in the fact, first, that the former is more favorable to the maintenance of begetting power; and, second, that an excess of carbohydrates encourages fat formation to the extent of generating a sluggish condition of the body organs, especially in the absence of enforced exercise. Food should be fed in the bulky form as far as may be practicable, first, on the ground of cheapness, and, second, to avoid overtaxing the digestive organs, and thus prematurely weakening them, a result which is quite liable to follow the continuous feeding of large quantities of grain. Succulence is necessary to keep the digestion in tone and to maintain that sappy condition of the system which favors successful generation.

The following may be looked upon as a standard ration for mature bulls in winter: Some leguminous fodder, as clover or alfalfa, fed once a day, some carbonaceous fodder as corn fodder, sorghum fodder, native hay, or oat straw, also fed once a day. When roots are not to be had, the meal ration may be composed of corn meal, ground oats, bran, and oilcake, in the proportions of $3,3,3$, and I by weight. Usually not more than 4 to 6 pounds daily should be fed. When wellmatured corn ensilage furnishes the succulence, corn meal should be excluded from the ration. When field roots furnish the succulence the oilcake may be excluded. Corn ensilage should be fed in moderation, not exceed- 
ing 20 pounds daily for prolonged feeding. When it is fed thus freely, the dry fodder should be leguminous, as far as practicable. Ten pounds of field roots daily should keep the digestion in tone, but considerably larger quantities may be fed with profit when the supply is abundant; when roots are fed freely, a less amount of grain will suffice.

When grazing is abundant and suitable, or soiling food may be had in the absence of grazing, only a small amount of grain, not more than two or three pounds claily, may be called for. When not much used in service it may not be necessary for a time to feed any grain. The meal ration may be the same in kind as given above. If oats are not to be had, wheat bran may be used instead.

The foods that are most to be avoided are those that contain mold, or that are possessed of an excess of starch and sugar. If mold is fed to bulls, either in the fodder or in the grain, impaired digestion will result, a condition which, when present in a valuable bull, may mean serious loss. Corn has entirely too much starch to make it the exclusive concentrate, and molasses has too much sugar for the needs of such animals. The free and prolonged feeding of either will certainly prove adverse to sure generation.

While males in service should not be allowed to get in a low condition of flesh, neither should they be allowed to become overfat. All sudden changes in food should be avoided. When service is severe, the meal fed should be increased proportionately to meet the additional tax put upon the system. Bulls past the meridian of vigor require more concentrates relatively than those younger. The amount of meal required for daily use may vary from none to more than 6 pounds.

Management of mature bulls.-As a rule, mature males should not run at large with the females of the herd at any time subsequent to the weaning period, and 
the larger the herd is, the more objectionable is the practice. It should be avoided for the following reasons: (I) The time of service may not always be known, hence it may not be possible to keep exact records of the same. (2) The energies of the male are needlessly drawn upon when the females are in heat in the excess of the service given. (3) There is at all times a positive element of

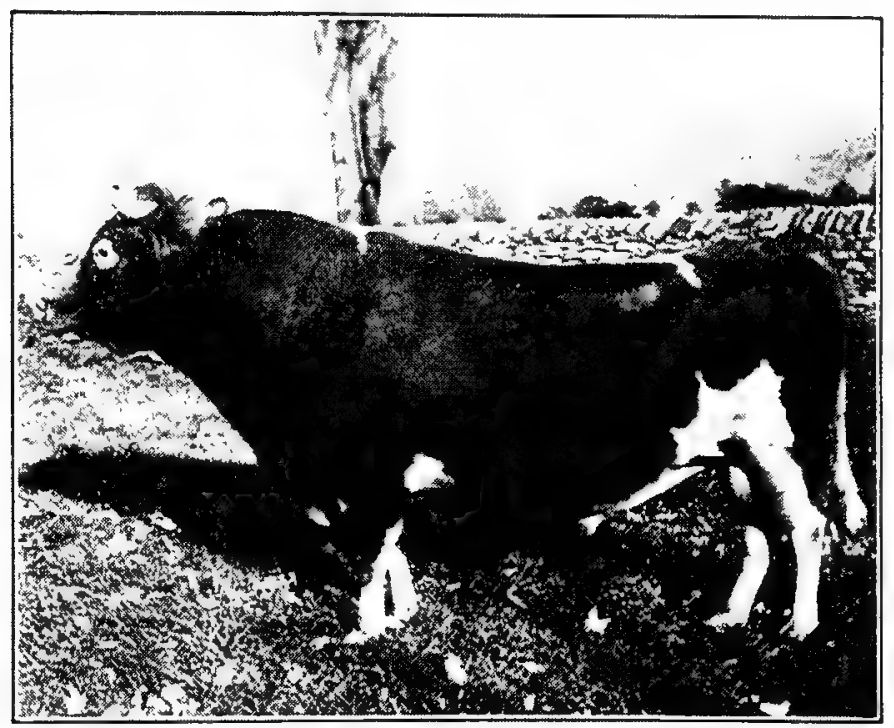

IMPORTED GUERNSEY BULL, GOLDEN KNIGHT, 3405

(By courtesy of the owner, Edward S. Clark, Cooperstown, N. Y.)

hazard, as the assurance of immunity from attack on the part of the male is seldom if ever present. Loss of life to the attendant and to others has frequently resulted from the practice. Dehorning so far lessens the hazard, but it does not entirely remove it. Under range conclitions it is necessary that the males shall run at large with the females during the mating season, as no other 
method of management is practicable. but it is not necessary on the arable farm.

The question of exercise for bulls should never be neglected. Insufficient exercise engenders impotency in the male, partial or complete in proportion as it is present. Even partial impotency, that is, lack of sureness in begetting power, so impairs the value of a sire that his presence may prove a source of serious loss because of the fitful and uncertain character of the breeding.

To avoid such a result the aim should be to furnish the sire with a stall in which he is at liberty, and a yard or paddock attached in which he may move about without any restraint. If the paddock is large enough to furnish pasture for summer grazing in partial or entire sufficiency, the encouragement to take exercise is so far increased. Bulls thus managed when properly fed and not overtaxed with service seldom become impotent. If, at any season when grazing is accessible, they are not wanted in service, if they can be given a pasture alone or in company with other cattle, the influence is favorable to potency.

Bulls may be tied in the stall and yet retain their potency, but when this method is adopted they should be given enforced exercise. In Great Britain the method of having an attendant lead valuable bulls daily half a mile or more was sometimes practiced. The American plan of setting them to work, as on a treadmill, is far more economical and quite as efficacious. The work thus performed by a bull may go far to repay the entire cost of his food. Of course, the labor thus required should not be carried so far as to result in undue leanness.

The feet of all bulls, except those which have the liberty of the range, should be trimmed occasionally. The frequency of such trimming will depend on the degree of confinement to which the bulls are subjected, 
When tied in the stall they should be trimmed about once a year. When cattle have full liberty the wear of the hoofs is sufficient to keep them in proper condition. When confined, the tendency in the hoofs is to grow forward and outward at the sides, thus tending to raise the front part of the hoof and lower the rear part. This gives undue slant to the pasterns. These conditions are unfavorable to firmness of tread, which so far militates against effective service.

By trimming is meant the clipping back of the horn of the hoof all around the outer edge of the same, and paring off a part of the sole. The clipping is done with a pair of pincers, which may be obtained in hardware shops. The sole is pared off until it is on a level with the outer rim of the hoof. Care must be taken to avoid cutting into the quick of the sole. Should this happen to a slight extent, the tenderness will not continue for many days. A little experience under the direction of one who understands such paring will soon enable the operator to know when the paring should cease.

Four methods have been adopted when trimming the feet of bulls and show cattle. By the first, the paring is clone while the animals are lying at rest. This can only be done in the case of those that are usually docile, and that carry flesh to the extent of making them in a sense sluggish. This condition is most frequent with show animals. In such instances, if the trimming cannot be completed at once it can be later by watching for the opportunity.

By the second method the feet are trimmed while the bull is standing. One end of a rope is fastened around the pastern of one foreleg. The other end is passed over the back just behind the withers. One standing beside the bull on the other side draws on the rope until the hoof is raised sufficiently for being trimmed. Similarly, the other front hoof is trimmed. To 
trim the hind feet, the animal is tied in a stall with upright studding at the rear. A smooth pole of sufficient length is then run in front of one hind leg only, and one end of the pole is raised so as to raise the leg from the ground. Struggling will follow to remove the limb, but finally the animal will desist. To prevent rubbing off the hair from the front part of the limb, sacking should be tied around the pole where the leg is to come in contact with it. Similarly, the other hind hoof is trimmed. This method is not altogether satisfactory, because of the difficulty found in keeping the animals from being restive.

By the third method a noose is made on the end of a rope, and through this the other end is drawn until it makes a circle of rope, which is passed over the head of the animal and back toward the breast. The bull is then tied securely to a post or tree with head well down. The rope behind the noose is laid back along the withers, passed around the heart girth, is pushed up inside of the portion above the crops, is carried back along the spine to a point in front of the hook points, and is again passed around the body so as to encircle it just in front of the hind flank. The unused portion is carried back behind the animal. When this is drawn on tightly by two or three helpers, the animal is forced down and is held thus until the trimming is completed. The objections to this method are, first, that it makes a nervous and restive animal more nervous and restive, and it calls for considerable help, but where only one animal is to be trimmed, this method will answer. Where the feet of several are to be trimmed yearly, the method submitted below is to be preferred.

By the fourth method a rack or inclosure is made into which the animal is led when his feet are to be trimmed. These racks are of various patterns, and, when properly constructed, are a great aid to such work.

Extent and duration of service.-Bulls are more 
commonly purchased when young. When so purchased the temptation is present to use them in service at an early age. That much harm has resulted from this regrettable practice cannot be gainsaid. On the principle that like begets like, it would seem reasonable to suppose that transmission from such males would tend to reduce size and to influence adversely stamina in the herd, in addition to hindering maximum development in the bull. It is questionable, therefore, if young bulis should ever be used in service under the age of one year. In breeding pure-bred cattle, the temptation is peculiarly strong to use in service, at an early age, sires which have sprung from distinguished families because of the favorable influence which such inheritance exerts on sales. The inevitable result is that high performance in those families cannot be long maintained.

It is admissible to use young males in service between the ages of one and two years when occasion calls for it, the times of service being most frequent during the earlier portion of the period. An occasional service should not harm the young sire, on the principle that the generative organs will be strengthened by judicious use. It would be impossible to state precisely the number of cows which a sire should be permitted to serve in the yearling form, owing to the difference in development in animals of similar age, but it would seem correct to say that the aim should be to mate such sires with not more than a score of cows.

After bulls have reached the age of 24 to 30 months there would be no good reason why they should not be used with much freedom in service until the vital forces begin to weaken. This would mean ordinarily that they may be used freely in service from the age of, say, 30 months until indications of waning power appear. When bulls are judiciously managed, such indications should not appear until they have reached the age of, say, seven to eight years. 
They should be able to serve from 50 to Ioo cows in a year without injury to themselves, more especially when the times of service are not too frequent. It is usually impossible, however, to so arrange that the times of service will cover all the year. The owners of herds desire to have the bulk of the calves come within a few months, and because of this the tax on the procreative powers of the bull is overmuch at certain seasons and none at all at other seasons. The aim should be so to use males in service that are highly valuable, that they shall not be overtaxed. The common practice, therefore, of not allowing them to serve common cows or cows that are simply to be renewed in milk production, regardless of any value that the calf may possess, is to be commended. Any excess in service tends to shorten the period of generative power in bulls, and unnecessary service should be avoided because of the drain which is thus put on the vital powers.

Ordinarily when bulls have passed the meridian of vigor, they should be disposed of, for the reason, first, that they are less able than formerly to transmit in the same degree the most desirable qualities; second, that they become too heavy and sluggish for some kinds of service; third, because of the increased cost of feeding them; and, fourth, because of the less price that will be obtained for them when sold for meat when they become aged. In the case of animals whose transmission has been of a high order, it may be wise to retain them in service as long as they retain sure begetting power. Progeny from them may be more desirable than progeny from younger sires, but without marked prepotency. The age to which bulls are able to breed successfully varies greatly. Instances are on record in which purebred bulls have begotten progeny until beyond the age of I5 years, but usually it is not profitable to retain them in service beyond the age of eight or nine years. The 
more freedom that has been given to bulls, the longer can they retain breeding capacity.

Bulls that are vicious.-It sometimes happens that viciousness develops in bulls with advancing age. This may result from want of tact and judgment in managing them, but, in other instances, it is the outcome of inheritance. Courage and firmness are essential qualities in those who handle and care for bulls, as the animal, in its own mute way, soon comes to understand when it must or may not render implicit obedience. But with these qualities a prudent wariness and caution should be blended. Viciousness more frequently develops in bulls of the dairy breeds than in those of other types, owing, probably, to the greater extent to which they are characterized by a nervous disposition.

When a bull is known to be vicious and is not possessed of any superior value, the better plan is to dispose of him as soon as practicable by sending him to the shambles. Nor is it desirable to breed from vicious bulls when the viciousness manifested by them is the outcome of inheritance, as the dangerous characteristic may go down to the progeny. But when viciousness has developed in a valuable bull whose ancestry were not thus characterized, its presence is not to be attributed to inheritance, and is, therefore, less liable to be transmitted. It is not only permissible, in such instances, to retain such an animal in the herd, but it may be desirable to do so. Instances are numerous where bulls of this class have been retained for years for service, after it came to be known that they were vicious. In managing them, however, at no time should the attendant be off his guard.

Vicious bulls may be most safely managed when they are kept tied in the stall. This may, in some instances, result in impotency, but such a result is not certain to follow, especially if the bull has reached maturity before being thus confined. When given the freedom 
of a stall, food, water, and litter may be given without necessitating the entrance of the attendant into the same.

When tied in the stall the bull may be easily managed when in service. The female in heat is tied in an adjoining stall. A safe inclosure is made in the rear of the bull in which one person stands. A rope with a snap or spring on one end, and which is kept in place by pulleys overhead, is snapped into the ring in the bull's nose by a second person. The person in the inclosure draws on the other end of the rope, which elevates the muzzle of the bull, so that he may be untied with safety. The rope is then slackened so that the bull steps back and serves the cow. The rope is then tightened, which brings the bull into the stall, where he is held in place until tied. When all the fastenings are secure the element of danger is thus entirely eliminated.

Restoring begetting power in bulls.-Valuable bulls sometimes become impotent. This may result from various causes, as too close confinement, feeding unsuitable food, forced feeding, excessive service, particularly at an early age, or from some organic defect in the generative system. The impotency may result from any one of these causes, acting singly or from two or more of them acting in conjunction.

When impotency results from organic derangement of the generative function, it may not be possible to restore it, but when it arises from any of the other causes named, it may sometimes be restored. Much will depend on the age at which the power to beget ceased and on the intensity of action in the causes that have led to it. The younger the animal, the less intense the action of these causes; and the shorter the period of the duration of their action, the greater is the hope that the lost powers may be restored, and the shorter is the period that may be necessary in which to accomplish this. 
When seeking to restore the loss of generative power the aim should be to feed food that is succulent and nutritious and withal rich in protein, and only in such quantity as will maintain a reasonable amount of flesh, to allow no attempts at service by the animal for a time, and to give the same bull liberty of exercise, and, if possible, under conditions favorable to restfulness. These conditions may be most perfectly secured in a pasture when no females unless such as are spayed are allowed. Restored powers are scarcely to be looked for during the reducing process. It is when the system becomes normal, or when building up begins, that the lost powers are most likely to return. With animals that are valuable such treatment may bring with it a valuable reward, but it will usually be more profitable to supplant an impotent male of only ordinary merit with another whose procreative powers are unimpaired.

Purchase and disposal of bulls.-The practice of purchasing bulls to be placed at the head of herds while still quite young is so common as to be almost universal. It rests upon the desire, first, to effect a saving in freight on the lighter animal, and, second, to dispose of him at an age when he may be readily prepared for the market. To the purchase of bulls under the age of one year, and, especially, during the milk period, there is the objection that not infrequently, in many instances, the form undergoes such modifications as development progresses that it changes materially, sometimes in the line of improvement and sometimes in the opposite direction. The character of the development, therefore, when the animal is matured, can be predicted with more certainty subsequent to the age mentioned than previously.

It is to the present advantage of the grower of bulls to dispose of them when young, as the cost of rearing increases with the advance in age. He finds it more or less difficult to dispose of bulls held for sale in the one-year form, and increasingly so as they grow older, 
as the choice animals of this class are usually sold at a younger age. Though the choice animals should not be thus sold, the suspicion is present in the mind of the intending purchaser that bulls in the one-year form and older have not been disposed of earlier because possessed of qualities not to be desired. When such animals, possessed of the requisite inheritance and form, can be purchased as cheaply as those purchased in calfhood, the investment is safer and more economical, as, when introduced into the herd, the character of the development is better known and they are ready for immediate service.

But so strong is the prejudice against the purchase of bulls in the one-year, and, especially, in the two-year form, when thus carried over in the herd, and so great is the expense of maintaining them in form for selling, that it will usually be more profitable for the grower to dispose of them for meat in the castrated or uncastrated form than to retain them for sale for breeding uses. Some breeders of pure-breds whose methods have been otherwise commendable, have found the business unprofitable, because of the extent to which they have attempted to carry this class of stock.

The prejudice against the purchase of mature bulls is even stronger than that against the purchase of yearlings and two-year-olds. It should not be so, as the prepotency of the former has been proved. The average age at which herd bulls are sold as meat is probably four years. At that age they should be in the zenith of highest usefulness. When they have shown transmitting qualities of a high order, they are possessed of a higher relative and absolute value than a young bull whose transmitting qualities are yet unproved, and usually they can be purchased at a price not much beyond that for which they will sell as meat. The owner sells them to avoid the necessity of breeding them to their own progeny. When their breeding record has 
been satisfactory, those seeking males should unquestionably prefer them to males untried. Their usefulness should continue for several years, or as long as it is usually desirable to retain them in the herd.

When purchasing such males, careful attention should be given to the character of the previous feeding, and to the methods by which they have been managed, and in both respects violent changes should be avoided lest the begetting powers should be harmed. These have, in many instances, been impaired and even destroyed by such changes.

When aged bulls are to be sent to the shambles it may be in the castrated or uncastrated form, that is, as stags. Usually it will be more profitable to sell them uncastrated, unless when sold quite young, as the difference in the price paid for the meat of stags as compared with that paid for the meat of bulls is not enough usually to justify the trouble of castrating before the final fattening begins. The degree of the fattening to be sought should be regulated by the age of the animals, and by the prospective price of meat. The older the bulls and the lower the price of meat, the less the profit resulting from giving the animals a good finish. 


\section{CHAPTER VII}

\section{FINISHING CATTLE IN THE STALL OR SHED}

In discussing this large question, the attempt will not be made to cover it in one chapter. The discussion in Chapter VII will be confined to winter finishing, while that in Chapter VIII will consider summer finishing. The present chapter will dwell upon the following phases of feeding: (I) The supply of animals for feeding; (2) Finishing in the stall, shed, or grove; (3) Leading up to full feeding; (4) Concentrates to feed; (5) Fodders to feed; (6) Succulent foods to feed; (7) Finishing on beet pulp and grain; (8) Duration of the feeding period; (0) Standard rations in different centers; (IO) Observations regarding foods; (II) Miscellaneous observations on feeding; and ( I 2) Coming modifications in feeding. It should also be noted that the discussion deals only with the fattening of animals that have passed the age of two years, that is, that have passed the age when they produce baby beef.

Supply of animals for feeding.-The sources of supply are, first, animals that may be grown by the farmer or feeder himself; second, animals grown on other farms; and, third, animals grown under range conditions. Which of these sources the feeder will draw from will be determined by the conditions of the feeding.

The large feeder, that is, the feeder who usually purchases food in addition to that which he grows, is generally so situated that he can only grow a limited number of the animals which he feeds and, in some instances, not any of them. Notwithstanding, farmers are frequently so situated that they can fatten, say, from half a dozen to a carload of cattle every year drawn from supplies which they have bred and reared on their 
own farms. When thus grown, the breeding of the animals can be controlled, and, as a result, it becomes possible for the feeder to put upon the market finished animals that will command the highest prices paid. The manure resulting may also be better utilized on a small farm than in feed lots not closely associated with farms. In no other way can animals be finished more cheaply for the block from the arable farm, as no expense is incurred in the purchase of the same or in transit, save when they are being sent to the market. The difficulty sometimes met in shipping in less than carload lots is, to some extent, an obstacle in growing cattle thus. But this may be overcome by two or three men, who are neighbors, acting in concert.

Should the farmer not be able to grow as many animals as he desires to feed, he can usually make up the number from neighbors with little difficulty where a proper spirit of co-operation is cultivated. Many farmers grow a small number of animals, usually classed as feeders, when possessed of sufficient age to justify the classification, and yet they may not desire to fatten them, for want of facilities or for other reasons. When not skilled in feeding, it is probable that they get the best returns that would accrue from selling them thus, notwithstanding that the purchasers may make a substantial profit from feeding them. From this source also large feeders, in some instances, obtain their supplies.

In some states many animals of this class are purchased from farmers at the age of 12 to 18 months, and are carried into range or semi-range areas, and there grown for one or two years on cheap pastures such as exist there. They are then shipped back again to graingrowing centers and fattened there. This movement of stock may be profitable to the ranchman, but it is not profitable to the grower, who should aim to grow his animals until ready for the feed lot, even though he should not attempt to finish them himself. Such animals 
beyond calfhood are able to turn rough and unmarketable foods to good account, better than almost any other class of stock kept upon the farm. Every time that a growing animal is sent by rail, the cost of transit comes from those who grow or feed the cattle subsequently.

No good reasons, apparently, can be given against the establishment of what are known as market days in all centers where many cattle are grown. These may be held in all such centers semi-monthly, monthly, or bimonthly. They bring buyer and seller together, and should aid greatly in the sale and purchase of animals for feeding as well as in the sale and purchase of many other classes of live stock. In some such centers those market fair days have been maintained for years. Why should they not be so maintained in all such centers?

In numerous instances large feeders draw their supplies for the feed lots from the range or semi-range country. More commonly these are purchased from some stockyard center, but where extensive feeding is to be conducted they may sometimes be more conveniently purchased in the range country. One objection to feeding range steers is their wildness, a result of the conditions under which they have been reared. Because of this, animals reared under semi-range conditions are to be preferred, other things being equal. The food which is given to them in the winter renders them more docile than stocks which practically rustle for themselves on the open range. Docility in the feed stable or lot is of much practical advantage. It is usually found most perfect in degree in animals that are reared upon the farm where also they are finished. It is true, nevertheless, that the average animal bred on the range is superior in breeding to the average animal bred on the arable farm, as more care has been exercised when selecting sires for the range.

The age at which to purchase must be determined by the conditions and also the season of the year when 
the purchases are to be made. Where pastures are abundant, the aim is to purchase the animals when young, as soon as possible after they are weaned, or as yearlings, and to carry them on until they are old enough to be put into the stables for winter feeding for finishing. This method is usually quite satisfactory when it can be followed, as the feeder can have them enter the stables under favorable conditions for feeding, which is not always true of animals purchased and put upon a finishing ration as soon as they reach the farm or feeding place. Usually, however, the latter method must be followed, although the instances may be many in which the animals may be grazed for several. weeks before they are tied in the stall.

As is generally known, more increase relatively may be expected from animals in the one-year form than from those two years. This should not be lost sight of when making purchases, nor should the influence of weight at the time of purchase on the gain from increase in the selling price be lost sight of. Whether animals fully matured, or even aged animals, shall be purchased for finishing will depend upon such conditions as the price, the age, and the character of the inheritance. As they feed slowly, and as the carcass is usually heavily discounted by the buyer, feeders usually very much prefer to feed animals not yet fully matured.

The influence of inheritance on subsequent development and market values is very marked. In making selections for feeding, it cannot be ignored, hence animals for such finishing should be chosen only by those who well understand the form of the beast required and the indications of inheritance that are favorable and unfavorable to the production of prime beef. The form required in the good feeding animal is given at length by the author in the book, "Feeding Farm Animals," in the chapter on "Type." It will only be said here, therefore, that the form should be of the low-down, 
blocky type, with limbs not more than medium in size. The indications of blood inheritance may be judged by such indications as the general form, the peculiarities of horn development, the color and the strength of the hair. But the proportions in which these blood elements are present cannot be accurately gauged from the indications.

Animals with a large percentage of dairy inheritance should be rejected for such feeding unless they can be purchased cheaply, not because they are unable to make good increase, but because, when finished, rightly or wrongly, the carcasses from such inheritance are much discounted in the markets. When such animals are purchased for finishing, they should be ready for the market before they get beyond the stage of baby beef. (See page 72.) The buyer should aim to purchase so that the price paid will be lower than the probable selling price by at least one cent a pound live weight, when concentrates sell for less on an average than one cent a pound. When these are dear, one cent a pound of advance would not be enough. Of course, the selling price can only be forecast at the time of the purchase of the animals. This element of uncertainty, however, should add to the carefulness of the buyer.

Winter finishing is usually begun as soon as the weather becomes so cold that the cattle cannot remain in the pastures overnight without discomfort. This will mean that in Canada and the northern states it will usually begin in late October or early November, but, of course, it may begin at any time desired with a view to meet the needs of the market or to have the animals finished by the time the food supplies are exhausted.

Finishing in the stall, shed, or grove.-Three methods of finishing are possible in winter, viz., in the stall when the animals are tied; in the shed, sometimes closed and sometimes open; and without shelter, save what is furnished by a grove or ravine or both. Which 
of these methods should be followed is chiefly determined by the conditions under which the animals are fed. These conditions are: (I) Such as relate to climate; (2) to the cost of furnishing shelter; (3) to the cost of labor in caring for the animals; (4) to the individual needs of the animals; and (5) to the amounts of litter called for.

In climates cold and wet and changeable in winter, unless cattle are closed in sheds when storms are falling, they will, probably, fare better tied in the stall. In winter climates, with but little precipitation, they will fare as well, if not, indeed, better, in open sheds with a yard attached on the sunny side and well protected from winds. Where storms are frequent and the cold is intense, it is advantageous to have the sheds so that they can be closed at will. Under other conditions sheds made of poles and covered with enough straw or old hay to keep them dry will suffice. In climates not severe and also dry, cattle may be fattened in good form with only the shelter of a grove or a bluff. They have been thus fattened even as far north as Minnesota, but, probably, at a large relative consumption of food. The conditions last named are best adapted to the dry climate of the western mountain country. To attempt to fatten animals thus in cold, wet winter climates is not even to be considered, as it would certainly fail. Experiments have shown that, viewed from the standpoint of food consumption, animals will make as good gains in the dry winter climate of the northwest, when fed in sheds, as when tied in the stalls.

The cost of materials for shelter is now great, and is constantly growing more. To build stables with stalls and floors is much more costly than to build sheds without floors. It is advantageous, in many instances, to have stanchions and some kind of division for stalls, even in sheds, for such feeding, hence the chief item of difference may be only in the cost of a floor, as a hard 


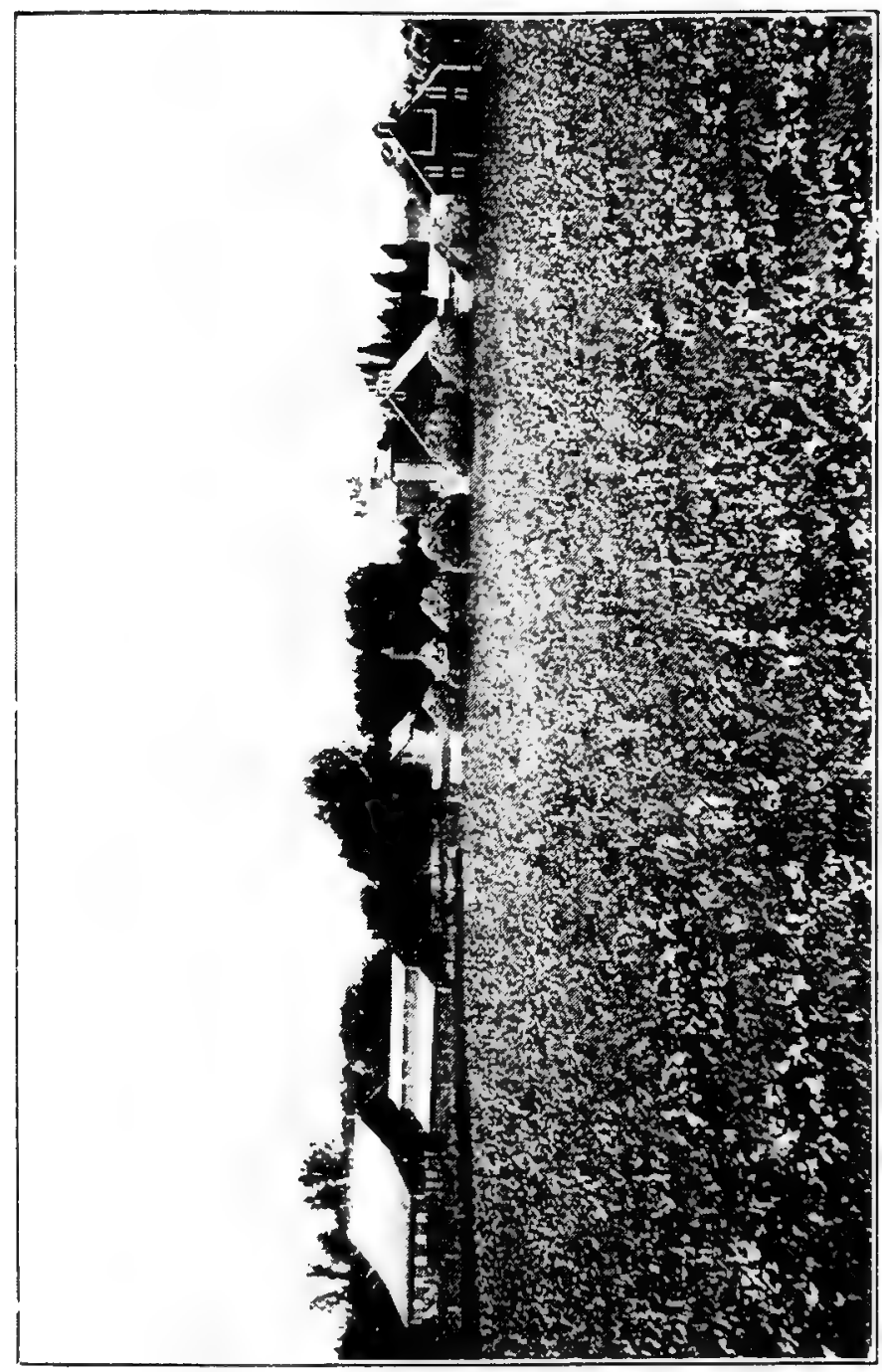

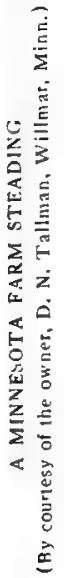


earth floor is ample in the shed. When fed in the grove the cost of providing shelter is entirely eliminated.

The difference in the cost of labor between these respective systems is probably the greatest difference that exists. This difference applies more to the cleaning of the stables than to any other single item of labor involved, but it also applies to giving the animals opportunity to exercise and to take water when this is not furnished in the stall. When finished in the open, no labor is involved in tying the animals, in supplying litter, or in watering them, the water being usually supplied from an adjacent stream.

Viewed from the standpoint of the individual needs of the animals, finishing in the stall has a most decided advantage over either of the other methods. It gives the feeder the opportunity to differentiate in serving the food to the different animals, which may be important in the case of individuals even of the same size. It also enables him to fatten animals of different ages in the same stable, which is scarcely practicable in the open shed or outdoor shelter without grading them and feeding the different grades separately.

The amount of litter called for in the stall is much less than in the shed. In the latter, litter must be supplied often and liberally enough to keep the animals dry. This means that it should be added every day or two. The extra bedding called for is probably compensated for, in part, at least, by the increased value of the manure, as in proportion as the cattle are confined in the sheds will the liquid be saved. But even greater amounts of bedding are called for in the yards. They should not be allowed to become miry if this can possibly be avoided, but should be kept in so dry a condition that cattle may lie on them in comfort. When fed in the open, cattle are not usually supplied with any bedding. This is wasteful of manure, as it means that all the liquid is lost, and some solid portions also, but 
usually the loss from leaching in such areas is not very great.

Stated concisely, the chief benefits from feeding in the stall are, first, the perfect protection that may be given to the animals; second, the complete control of the food for each animal; and, third, the amount of litter used. The chief objections to the system are, first, the greater cost of shelter; second, the greater cost of labor; and, third, the proper regulation of the ventilation. The chief benefits from finishing in the shed are, first, the less cost of the buildings; second, the considerable saving of labor; and, third, the increased value of the manure so far as made in the sheds. The chief objections are, first, the inability to adjust the food to the needs of the animals; second, the necessity that may exist for grading according to age, size, and condition; and, third, the amount of litter required. The chief benefits from feeding in the grove are the great saving over either of the other methods, first, in building materials; second, in the labor of feeding; and, third, in litter. The chief objections are, first, the great loss in fertility; second, the injury done by occasional storms; and, third, the inability to feed according to the exact individual needs of the animals.

Leading up to full feeding.-The object sought in fattening cattle is not so much to increase the lean meat as to increase the proportion of the fat by distributing it between the fibers of the muscles rather than by depositing it as fatty tissue, although both results will follow. When the fat is thus deposited, it gives to the lean a juiciness, a tenderness, and an increased nutritive value that it would not otherwise have.

This process calls for time proportionate to the condition of the animals when put upon a finishing ration, to their capacity to digest and assimilate their food, and to the character of the foods fed. Every practical feeder knows very well that a lean animal cannot be fattened 
quickly. Every exhibitor of fat cattle is conscious of the fact that maximum condition cannot be attained without months of careful feeding previously. Neither may he know the reason why. Dr. P. H. Armsby, in "Cattle Feeding," has made it clear that, before rapid deposition of fat can take place in a lean animal, it must first be brought into a well-nourished condition. This means that the organized and circulatory protein in the body must be increased, by means of which it becomes capable of digesting, resorbing, and storing up protein and fat. Such a condition is brought about by feeding a ration rich in protein rather than in carbohydrates, although considerable of the latter is wanted also. For a cattle beast weighing $\mathrm{I}, \mathrm{OOO}$ pounds a ration containing about 2.5 pounds of protein and about I2.5 pounds of non-nitrogenous substance is considered suitable. This gives a nutritive ratio of $\mathrm{I}: 5$.

It is very evident, therefore, that the time called for in such preparatory feeding will be greatly influenced by the character of the feeding previously given and by the condition of the animals when the fattening is begun. Animals kept in a good condition of flesh from birth, as when growing baby beef, do not really call for any special preliminary feeding before they can take the final finishing ration. They are virtually ready for it at any stage of growth, as with them muscle and fat have been put on together from the first. It is evident also that cattle from the range or elsewhere in a fair condition of flesh will not call for so long a preliminary period of feeding as those lean.

It is not possible, therefore, to say how long a period should be covered by such feeding. It may run all the way from four weeks in ordinary fattening to, say, eight weeks, with about six weeks as an average when the intention is to make the feeding cover not less than I80 days. Any excess of carbohydrates fed during this preliminary period not only does not hasten the 
fattening, but it may even retard it. It may be consumed, but will not be resorbed into the body, thus taxing the digestion to no useful end.

The foods called for during such feeding must be rich in protein, but the quantity of carbohydrates should be gradually increased. Leguminous fodders, as clover, alfalfa, or pea or vetch hay, can render great service during this preliminary period. The favorite concentrates are ground oats and wheat bran as the base of the grain food, either alone or, better, fed together. At first they should compose not less than two-thirds by weight of the meal fed. The other portion may be such meal as corn, rye, or barley. The former are decreased gradually so as to form not more than two-thirds of the meal fed, when the animals are on full feed. The amount fed at first should not be more than 6 pounds daily to animals not recently fed grain with some liberality, but it should be increased as they are able to turn it to good account until they are on full feed. To feed much grain at first would overtax the digestive organs before they could accommodate their action to such feeding. Such a result would greatly retard the fattening process. Food thus fed is worse than wasted.

Concentrates to feed.-The choice of concentrates for feeding steers must be determined by such considerations as relative suitability, relative cost, and the probable duration of the fattening period. Almost any kind of grain grown, when available, may be given a place in fattening cattle at some stage of the fattening. But no one grain is equally suitable for being fed in similar quantities during the entire period of finishing. Oats, probably, come nearest to this requirement, but their relative high price makes it necessary usually to call for feeding them in minimum rather than in maximum quantities. Corn, probably, comes next to oats in such suitability after the animals have been put upon full feed. The aim should be to feed the cheapest concen- 
trates that will effect the purpose sought, but in feeding such foods it may be necessary sometimes to feed a limited proportion of some concentrate or concentrates, the nutrients in which are relatively dear, in order to make the ration balance approximately or to exercise some physiological effect on the animals that are being fattened. Oilcake furnishes an illustration of such feeding. When animals are to be fed for short periods only, the concentrates fed must be richer in fat-producing elements than when fed for a longer period, but feeding those concentrates in such quantity as will force early finishing must be deferred until the animals have been led up to what is termed full feeding.

This means that in the feeding of cattle there is a place for the feeding of every concentrate grown upon the farm, not excepting wheat, when the price will admit of feeding it thus. It means also that almost every by-product of such grains can be utilized, but, in some instances, the hulls, if fed, should be fed as coarse fodders rather than as concentrates. But in making choice of these concentrates, the aim should be to so adjust them to the needs of the animals, that, in conjunction with the fodders fed, they will be approximately in balance. To feed foods thus will call for a nutritive ratio of I :5.5 after the animals have been put upon full feed. But, in some instances, it may be more profitable to feed concentrates in excess of what will balance the ration because of their cheapness. Corn, in former years, was fed thus in nearly all instances in the corn belt.

It should be the further aim to feed the cheapest concentrates that will effect the end sought. Such foods are usually found in proximity to where they are most commonly grown. This will mean that in the northwestern states and in the northwestern provinces of Canada such grains as succotash, composed of wheat and oats, barley, speltz, and to a certain, but less, extent, peas, rye, and millet, will be much used in fattening live stock. In 
the northern states and Ontario, Canada, the chief concentrates fed will be oats, oilcake, and corn fed on the stalk or in the silo. In the corn belt it is probable that corn will continue to be the central fattening food, tempered by a complement of some food rich in protein, as wheat bran, oilcake, gluten feed, or cottonseed meal. In the southern states, cottonseed meal tempered with some coarse substance will continue to be the leading fattening food for cattle, and in the western mountain states barley or succotash will hold a similar place.

The preparation which feeding these concentrates calls for varies with the conditions under which the feeding is done. But it will be correct to say, first, that all kinds of grain used for such feeding, except corn, should be ground before it is fed; second, when thus ground, it is beneficial to mix it with some coarse fodder cut up or with ensilage; and, third, that it is usually more satisfactory to feed oil meal in the nut form than as meal. Corn may be fed in the ear, shelled, or in the bundle. When fed unground on the cob, shelled, or in the bundle, enough swine should follow to consume all the undigested kernels in the droppings. When fed ground, it should be fed similarly to other ground grain. Which of these methods should be followed in feeding corn will be largely determined by the circumstances under which the feeding is done. When much of the corn is fed in the bundle other cattle not being fattened should glean in the yards or feed lots after the former, in order to utilize a part, at least, of what may be rejected by the cattle that are being fattened. Feeding meal on cut feed insures its more thorough mastication, since it is rechewed, and consequently its more thorough digestion and assimilation and its more porous condition while in the stomach render it less liable to disturb digestion than when fed directly in large quantities. For this reason corn and cob ground is a safer food than ground corn for direct feeding, and the same is true of 
such coarse concentrates as wheat bran and ground oats. One objection to feeding oil meal as compared with oilcake in the nut form is its liability to adulteration.

The finishing of cattle for the block may be said to cover three periods. The first is the preliminary period during which they are being led up to a full ration of concentrates, the second is the period during which the deposition of fat is chiefly made, and the third is the period of ripening or firming the flesh before sending the animal to the block. The duration of each cannot be stated by rule even relatively, owing, first, to the difference in the condition of the animals when put on feed, and, second, to the difference in the rations fed. The second period, however, is much the longest.

It has already been shown that during the preliminary period the food fed should contain a considerable proportion of protein at first, and that the carbohydrates in it should be increased until the animals are on full feed. The deposition of fat should be rapid and continuous during the second period, hence the carbohydrates should be abundantly present. During this period, the concentrates fed may be more uniform in kind and quantity than during the other periods, but there may be advantage sometimes in substituting one concentrate suitable in kind for another, in part, at least, because of the influence which it may have upon the appetite. Such concentrates as corn, peas, rye, barley, speltz, and millet may be used in large proportions during this period, large enough to constitute from 66 to 75 per cent of the concentrates fed, and when fed along with good clover and alfalfa may constitute all of the grain or meal. Such foods as bran and oilcake during this period are chiefly useful as regulators of digestion, but with good clover or alfalfa hay it may be possible to dispense with both.

During the third period, the appetite will almost 
certainly grow less, hence some modifications may be necessary to improve the appetite. To accomplish this, increase in protein is sometimes made. No food is more suitable for such feeding than oilcake, hence when it is too expensive to feed during the entire feeding period, its use should be reserved for this third period, during which it may be fed at the rate of $I$ to 3 pounds for each animal daily. It may also be advantageous to use some

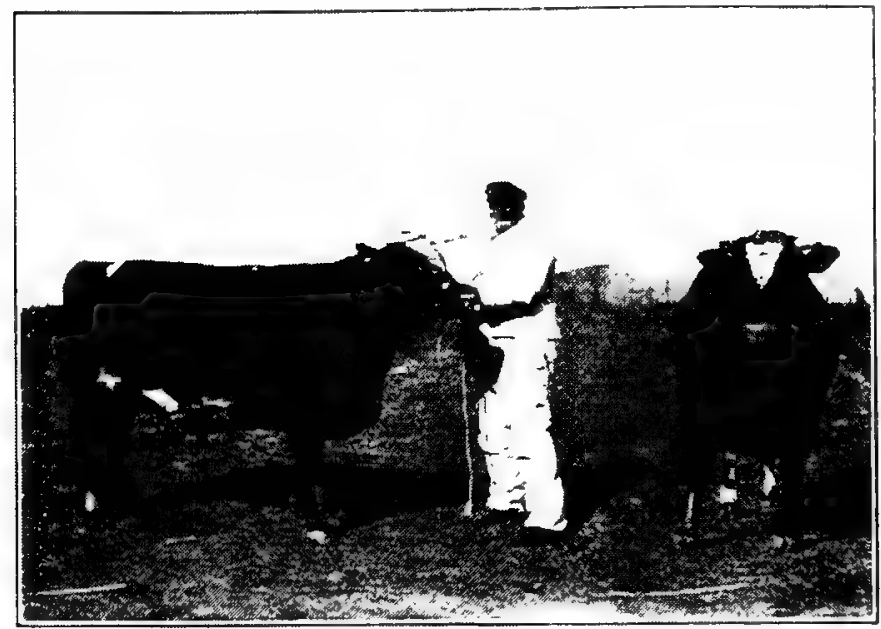

PRIZE-WINNING GRADE SHORTHORN STEER, JACK

(By counesy of the owner, Washington Experiment Station)

condimental food to whet the appetite and to stimulate digestion.

There is wide diversity in the practice of feeders as to the amount of concentrates that should be fed. The problem is complicated and many sided owing to: (I) Fluctuations in values in fodders and concentrates: (2) the difference in age and condition when the feed. ing begins and the capacity of the animal to utilize food: (3) the not easily determined (guantities of grain in corn 
fodder and corn ensilage when these are fed; (4) the wide difference which the accompanying fodders exert on the fattening; (5) the necessity that may exist for slow or rapid fattening. It is evident, therefore, that it is impossible to formulate hard and fast rules as to the amounts of grain that shall best suit each case. In practice the amount of grain fed to each animal daily is from 6 to Io pounds in Scotland, when large quantities of roots are fed, to 28 pounds of shelled corn daily in the corn belt, when swine glean among the droppings. W'here clover and alfalfa are fed along with grain, amounts of the latter as small as those fed in Scotland will usually suffice.

The following statements will serve as approximately correct guides with reference to finishing cattle: (I) Because of the greater relative cost of the concentrates, the aim should be to utilize coarse foods to the greatest extent consistent with desirable resultant gains. (2) That, because of the considerable cost of food used for maintenance, the aim should be to finish the animals as rapidly as is consistent with economical feeding. (3) The feeding of concentrates should never be carried to the extent of disturbing the digestion. The indications of disturbed digestion are a condition of the fæces which is not normal, and a pronounced loss of appetite in the animals. A skilled feeder can judge with much accuracy the degree to which the grain fed is being utilized by the fæces. When these are unduly hard or soft, when particles of undigested meal appear in them, and when offensive odors arise from them, he knows that the digestion is disturbed. When the appetite materially lessens, he knows that the disturbance is more serious. When such indications appear, less grain should be fed. (See page I6I.)

Usually when animals are first put upon feed, the amount of concentrates fed does not exceed 2 to 6 pounds daily. After the preliminary period of feeding 
is passed it would seem correct to say that for ordinary feeding the grain fed daily should be not much less than I pound for every Ioo pounds of the live weight of the animal, and that it should not be more than $\mathrm{I} / 4$ pounds. It may be less than the amount named when large quantities of roots are fed or of ensilage rich in corn. When first-class clover or alfalfa hay form the roughage, the grain fed may be reduced from 25 to 33 per cent as compared with nearly all other kinds of fodder. When corn is fed and swine follow, more than the amount named must be fed.

Fodders to feed.-The coarse fodders or roughage that may be fed to cattle being fattened may include almost every variety grown. Even the straw of cereals may be utilized with profit under some conditions of feeding, but usually as only a part of the ration. In the southern states, cottonseed hulls are, in some instances, made to take the place of roughage, at least to a very considerable extent. But before the coarse fodders that are low in palatability can be fed they must be chaffed and fed with meal or roots, or both, to insure their consumption.

The best fodders, regardless of cost, are the legumes. Of these clover, in one or other of its varieties, and alfalfa are most commonly fed. Next to these come corn and hay from the various grasses, and lowest in value is straw of the small cereals. The cheapest fodders that can be fed, where the conditions are favorable to growing them, are usually obtained from corn and the sorghums, and these may be most cheaply furnished under many conditions in the form of silage.

In feeding fodders, the feeder must, as a rule, feed such as he has. They are so bulky that transportation is usually too costly to admit of buying them. This means that the feeder, in balancing the ration, must aim to make the concentrates conform to what is lacking in the fodders rather than to attempt the opposite of this. 
In growing foods for fattening the aim should be to try to grow such fodders and concentrates as will furnish a balanced food when fed.

The preparation of the fodder called for, of course, varies. Fodders possessed of high palatability as, for instance, the clovers, alone or mixed with timothy, and also alfalfa, are usually fed without any preparation. Corn and the sorghums are also most commonly fed thus, but where more complete consumption is required they are, in some instances, shredded and in others run through a cutting box and mixed with other fodders. But the cheapest and most effective way of feeding these is to make them into silage.

When several varieties of roughage are on hand, which vary considerably in palatability, chaffing them and mixing them before feeding will insure a consumption of much of the less palatable foods, and if pulped roots are mixed in with the mass, it will all be consumed. But the cost of thus preparing fodders may sometimes make such preparation of the food prohibitory. Where straw of the cereals is used in any considerable quantities, the aim should be to feed it thus.

Usually there is less change in feeding the roughage, as the fattening progresses, than in feeding concentrates. Should different kinds of fodder be on hand, some more and some less palatable, the aim should be to reserve the more palatable fodder to the more advanced periods of the finishing. For instance, should corn fodder and clover hay be available, the fodder should be fed first and the hay later, as the appetite is much prone to wane as the feeding season progresses.

The amounts of fodder that will be consumed vary with the nature of the feeding. The larger the proportion of concentrates fed, the less will be the proportion of the fodder eaten, and the more will the feeding period be shortened. On the other hand, because food elements 
in fodders are usually cheaper than the same in concentrates, in prolonged feeding the aim should be to feed fodders up to that point that will not unduly retard the rapidity of the gains. The great difference in the relative value of fodders and of the same in different localities, makes it impossible to lay down any hard and fast rules for the guidance of the feeder bearing on this question. In the western mountain valleys where alfalfa may sometimes be obtained at a cost for production of less than $\$ 5$ a ton, it may be used to such an extent in fattening that the 1,000-pound steer may be fattened on a grain ration as low as 6 pounds daily, whereas in New England the price of alfalfa would probably make the feeding of it prohibitory. On the other hand, corn fodder may be so cheap that it will pay to make it the sole fodder fed, though fed out of balance. It would, probably, be correct to say that a cattle beast weighing I, 000 pounds, and that consumes not less than I2.5 pounds daily of grain, will not consume more than Io to 12 pounds daily of good hay. Of course, fodders are fed to such animals up to the full limit of their consuming powers.

Succulent foods to feed.-The sources of succulence for cattle being fattened are virtually three, viz., corn, the sorghums, and field roots. This does not mean that foods other than corn and sorghum may not be ensiled and fed alone or in conjunction with these. For instance, in certain areas it has been found entirely practicable to grow soy beans and to ensile them along with these crops as a source of protein, and also to make the second crop of clover hay, or one of alfalfa crops, into ensilage by putting it into the silo in some sort of alternation along with corn.

The standard silage product is corn, since it is on the whole better preserved in the silo than any other crop, is more universally grown and usually produces more nutrients to the acre. The sorghums, especially 
sweet sorghum, should not be ensiled until nearly matured or the ensilage will be unduly acicl. The value of corn silage for fattening stecrs is enhanced by increase in the proportion of the grain which it possesses. For furnishing a part of the roughage it is preferably the cheapest food that can be fed. The loss in nutrients is less than in fodder corn. There is no loss in palatability with the latter as with the former, and it is more easily handled when fed. The succulence exerts a favorable influence on digestion, and feeding it increases the percentage of water in the meat, which is to be desired, unless in the later stages of the fattening. So valuable is it as a factor in fattening cattle, that those who engage in the work from year to year in corn-growing areas should never rest content without providing every year a liberal supply of corn ensilage.

Silage should not be fed as the sole roughage to cattle being fattened. When of good quality and fed along with meal, they will make satisfactory gains. but the author found that when feecling it thus at the Ontario experiment station there was present the hazard of digestive derangement, which, in two instances out of six, proved fatal under prolonged feeding. Good silage may be fed with perfect safety, however, to steers weighing I,ooo pounds at the rate of 30 to 40 pounds daily through the entire period of feeding. This will, of course, so far lessen the consumption of dry fodder, and it will effect a saving of 3 or 4 pounds daily in the amount of meal fed down to no saving, as the ensilage has in it much or little grain.

Succulence in the form of field roots is furnished chiefly by rutabagas, mangels, and sugar beets. Because of the greater cost in growing sugar beets as compared with mangels, it will pay best to feed the latter as pulp after the sugar has been extracted. (See page I48.) Experiments have shown that considerably more dry matter may usually be obtained an acre from corn 
than from rutabagas or mangels, and at a less cost for production. This means that in areas suitable for the successful growth of corn in this country the use of roots in fattening cattle, in a large way, is not likely to become general. Notwithstanding, there are areas, especially in some of the northern states, in all of the mountain states east and west, in certain parts along the Pacific, and in much of Canada, where better crops of roots can be grown than of corn. In these areas, it is probable, they will be grown in considerable quantities for such a use, as they are now, and have been for many years, in Ontario. The principal question to be determined is deciding on the quantity to feed, as they may be fed with absolute safety to the extent of 50 to 75 pounds daily to an animal weighing $\mathrm{I}, 000$ pounds. No real physical harm would follow if roots were fed up to the capacity of the animals to consume them. The saving in both fodder and meal will be proportionate. It is advisable to feed some dry fodder because of the tendency in the roots fed thus freely to produce digestion a little overlax.

Finishing on beet pulp and grain.-During recent years cattle have been fattened on beet pulp and alfalfa hay without other food. The meat thus made is of fair quality and the gains are moderate, not so good, of course, as when a suitable grain complement is added. But they are more cheaply made without grain, as prices range at the present time. Increase has been made on sugar beet pulp and a moderate amount of fodder and no grain, which cost less than $\$ 3$ per roo pounds. Such feeding is only practicable within a reasonable distance of the sugar beet factories, as otherwise the cost of drawing and feeding the pulp would make it too costly.

The pulp in the western factories is usually ensiled by conveying it to an immense shallow basin in the earth, into which it is forced from the ducts that convey it from the factory by gravity pressure. Although it 
will keep admirably in silos as ordinarily built, such a system of preserving the pulp would be impracticable owing to the immense amounts that are made which, in some instances, cover acres of ground to the depth of several feet. The amount of loss from such exposure is small, indeed, relatively. The importance of having the feed yards near to the factory will be at once apparent. In the dry and relatively mild winters of the western mountain valleys, the shelter of a grove will suffice for the cattle. In areas farther north, as Michigan, for instance, the cold of winter and the greater cost of fodders make such feeding less profitable.

The pulp is fed in feed boxes and, in some instances, to the limit of the cattle to consume it. The alfalfa or the fodder is fed in racks, and may be so fed that the animals may eat without restraint as to quantity. Even when given all the pulp that they will take, they will consume, in addition, a considerable amount of alfalfa. Such fattening is, in a sense, on the self-feeding plan, but it is better to feed the pulp in quantities not more than will be eaten up clean. When cattle are fed thus, the consumption of water is small relatively, but, of course, access to water and also to salt are essential.

When grain is fed, the amount called for is relatively small, but as the price of the pulp advances, a result that is sure to follow, it will be found advantageous to feed grain. Regardless of the cost of hay, grain, and pulp, it should seem correct to say that for prolonged periods of feeding, not more than 8 to ro pounds of grain an animal daily would be necessary to secure good finishing. The grain tends to correct the tendency to undue laxity in the digestion, especially when alfalfa is the fodder fed along with the pulp. As much as 100 pounds daily will be consumed by an animal weighing $\mathrm{I}, \mathrm{ooO}$ pounds, and, in addition, several pounds of alfalfa or other fodders, but the best and quickest gains will result from feeding, say, 60 to 70 pounds of 
what has been siloed for three or four months, when thus obtainable, and from 6 to 8 pounds of grain daily with all the alfalfa that they will consume, which will be about 20 to 25 pounds daily.

The cost of the pulp runs from 25 to 50 cents a ton, thus furnishing a food that is exceedingly cheap. The cost of the fodder varies much, but, fortunately, sugar beet soils are also clover and alfalfa soils, hence the cost of these may usually be kept reasonable. Grain in such areas is usually costly. Climates exactly suited for beets are a shade too cool for the abundant growth of corn. They are usually suited eminently to the growth of barley, but the high quality of the barley in the West makes it too costly for such feeding, hence the tendency at present to keep the feeding of grain down to a very low limit. The healthfulness of such a ration is not to be questioned.

Duration of the feeding.- The duration of the feeding period will be influenced by various considerations such as relate to the condition of the animals when put on feed, to the age of the same, to the character and cost of the foods fed, and to the season when the feeding begins. More commonly feeders err by bringing the feeding to a close at too early a period. Beginners are much prone to make this mistake because of the large amounts of grain to make a fine finish in beef cattle.

The condition of the animals when put on feed has. of course, a most important bearing on the length of the feeding period. If animals for ordinary fattening could be put on feed in a similar condition to those that are to be finished as baby beef, the finishing period would not exceed Ioo days, but this, in ordinary fattening, happens but rarely. It is also apparent that animals in medium condition will not call for so large a period of feeding as animals that are low in flesh. The latter cannot be made prime in less than I80 days, the former may in 
less than I50 days. When finished on the farms on which the animals are grown, the grower can control the condition of the animal when it goes on a finishing ration, and so may be able to shorten the usual period of feeding.

Animals whose growth is yet uncompleted may be fed with profit for a longer period than older animals. With them growth continues simultaneously with the fattening process. This means that the food used in promoting growth cannot, to the same extent, be used in promoting finish, as if making such finish was the only mission of the food fed. This does not imply that profit from fattening the latter will be less, as the increase will be relatively greater, but that more time must be consumed in feeding them.

The foods fed exercise an important influence. An animal will reach a high finish more quickly on a ration of corn, practically unlimited, than on a ration in which a few pounds only of corn or other meal are fed daily, the balance of the same being bulky food. This furnishes the explanation, in part, at least, why animals fattened in the corn belt are frequently sent to the block when not more than 100 to I2O days on a fattening ration. It does not follow, however, that such feeding is the most economical. Such a ration more quickly reaches the point when increase ceases, hence if prolonged feeding is to be conducted with the same, such foods as oats, bran, or oilcake, or a combination of these, must be added.

The price of foods and of beef powerfully influence the time that animals should be kept on feed. When both are low or dear, high finish will be in order. If food is relatively cheap and beef dear, which happens occasionally. though rarely, the aim should be to make a very high finish, and to take all the time necessary in making it. If, on the other hand, food is dear and the beef cheap. which sometimes happens, though not often, it is evi- 
dent that prolonged feeding would be hazardous. Professional feeders have studied these points so carefully that by them they regulate the extent of their feeding operations for the season.

If the cattle are put on feed early, as, for instance, on the arrival of October or November, there is opportunity for prolonged feeding before the arrival of the grazing season, but if not put on feed until the holiday season, only four months intervene before grass is plentiful, and it is not a good plan to try to finish on grass animals that have been given for several weeks previously a heavy ration of grain, if the finishing period on grass is to be short. Of course, the feeding of such animals may be continued in the stall or shed, but after the weather has become warm, some difficulty will be found resulting from the failing appetite which warm weather brings. The best finished animals will usually be fed for not less than 180 days, although, as shown above, such finishing may sometimes be accomplished in a shorter period.

Standard rations in different centers.-Rations will now be submitted that have found much favor in various centers in the United States and Canada, and that may therefore be regarded, in a sense, as standard for these areas at the present time. That some of them, at least, will be modified in the future is shown below (see page I62). They are mentioned as suitable for animals being fed in the stall, shed, or feed lot for I80 days, and that weigh $I, 000$ pounds when put on a finishing ration.

In the northern states the following is one of the most economical and effective rations that may be fed: Feed, say, 25 pounds of corn ensilage daily and all the clover or clover and timothy hay that the animals will consume, which will be about 5 to 7 pounds daily. As concentrates, feed corn and cottonseed meal or oil meal in the proportions of 10 and 3 parts by weight. Begin with, say, 4 pounds daily, and gradually inctease 
until on full feed, but at no time feeding more than I pound daily for each Ioo pounds of the live weight of the animal. This ration should prove suitable for all the northern states east from Wisconsin and for those of New England. In the northwestern states which grow good crops of barley and oats, and also in Ontario, Canada, the ration would be the same, except that it may be more profitable to feed ground corn or barley and ground oats or bran, beginning with equal parts fed at the rate of, say, 5 pounds an animal daily, and ending with not much more than I pound daily of the mixture for each I,Ooo pounds of the live weight. At the close of the feeding term the proportions should be approximately: Corn or barley 6 parts, oats or bran 2, and oil meal 2. The latter may be fed from the first, but when so fed should not make more than 5 per cent of the meal ration. The meal would, in all instances, be fed upon the ensilage.

In the middle west the following may be looked upon as a standard ration: Feed daily 20 pounds of grain, of which, say, 3 pounds will be oil meal or cottonseed meal when the animals are on full feed, and increase somewhat with increase in the live weight until 24 to 25 pounds are fed. Feed cautiously until the cattle are on full feed. The roughage should be clover or alfalfa hay, but, when necessary, a part of it may be corn stover. Feed the corn with the least possible amount of preparation, and have swine glean amid the droppings. But it will be advantageous to feed some of the corn shelled or ground, and mix in with it the protein food in the absence of ensilage. This ration may be used in all the states of the corn belt, and even in parts of those states which border on them.

For the southern states the following is submitted as one of the best rations that can be fed, and it will apply to states that can combine the feeding of corn, cottonseed meal and some leguminous hay. Feed for 
roughness 30 to 40 pounds corn or sorghum ensilage and 5 pounds of the legume, which may be clover, alfalfa, or cowpea hay. As concentrate, feed from 2 to 5 pounds cottonseed meal, the balance being corn on the ear, shelled, or ground, and so fed that the whole amount of grain shall not exceed I5 pounds an animal daily at any time. Begin with 2 to 4 pounds daily and increase so that the animals will be getting 8 to Io pounds at the end of 60 days. At first the mixture should be half corn, and this should be gradually increased so that at the end of 60 days two-thirds shall be corn. If whole corn is fed, swine should glean amid the droppings. As much as 3 pounds daily of cottonseed meal may be fed without hazard to the swine. If the above ration should tend to undue laxity in the digestion, a very little corn fodder fed dry will act as a corrective. This ration may be fed with advantage in all the southern states, and, possibly, in those adjacent to them.

For states far south and southwest, that is, the best cotton-growing centers, the favorite ration at the present time is cottonseed meal and cottonseed hulls, fed directly in boxes and without protection for the cattle. The daily average ration covering the feeding period would be 6 pounds of the meal fed with from three to four times its weight of cottonseed hulls, the proportion of the hulls being decreased with the advance of the feeding period. Less than 2 pounds of cottonseed meal should be fed daily at first, but, of course, enough hulls should be fed to satisfy the animals. Black strap molasses, spread over the food in the feed boxes, serves the triple purpose of preventing the food from lifting with the winds, of adding to its relish, and of aiding directly in the fattening. In the absence of ensilage, in the far southwestern states, 3 pounds of cottonseed meal mixed with about all the Kafir corn that the animals will cat safely, is a favorite ration. The fodder usually fed is sorghum or Kafir corn threshed or unthreshed. 
In the western mountain states the favorite fattening ration is alfalfa hay and grain, such as may be grown or purchased most cheaply, not feeding at any time more than two-thirds the ustual amount of grain. (See page 146.) In the neighborhood of sugar beet factories, the favorite ration is sugar beet pulp, alfalfa fodder, and grain. (See page I48.)

In $W^{\top}$ ashington and Oregon, also Idaho, the grain ration will consist mainly of bran or oats and barley, wheat, or peas, beginning with 2 parts of the former and ending with 2 parts of the latter, and leading up to full feeding in the usual way. If both peas and barley are fed the ration is thereby improved. As roughage, the foods most fed are clover, alfalfa, vetch hay, and corn ensilage, but, to some extent, timothy and clover, wheat and barley hay are fed. The concentrates fed in these states do not usually exceed Io pounds an animal daily at any time, and the preliminary feeding is usually moderate. With good alfalfa and clover such moderate amounts may answer.

For areas northward so far that corn may not be depended on to reach maturity, in the absence of roots the following would be one of the most suitable rations that could be fed: Ground barley, speltz, and oats, or wheat bran, in equal proportions for the feeding period, but using less barley and speltz at first and more later. Oilcake may usually be fed with advantage, especially in the absence of bran. Five per cent of oilcake will suffice at first and ro per cent or more may be fed toward the end of the feeding. The meal is best fed on a small quantity of silage or other cut fodder, and at the rate of I to $I / 4$ pounds daily for each Ioo pounds live weight when on full feed. The fodder will be corn in the bundle, tame hay, such as may be grown, or millet or a mixture of these. Wild hay will soon be a thing of the past. Another grain mixture very suitable for such feeding is succotash grown so that about one-third of 
the mixture will be durum wheat and two-thirds oats. Peas and a little flax grown with the other foods will improve the mixture.

Observations regarding foods.-Certain observations regarding some of the more important foods and also certain facts relating to feeding are now submitted. They are as given below:

I. While no roughage has been found superior to well-cured alfalfa for making increase, and while cattle are, in some instances, prepared for the market, as in the mountain valleys, by feeding alfalfa only, there are the following objections to such feeding: First, the ration is not balanced, having an excess of protein; second, the meat produced is too highly colored; and, third, the increase will not be so great relatively as when a moderate amount of grain is fed along with it. When fed alone, and uncut, from 40 to 50 pounds are fed daily. the portion left being fed to stock cattle. When chaffed about 25 per cent less will suffice.

2. When cattle are being fattened, as in the corn belt, essentially on unprepared corn, that is, on corn in the bundle, good results will frequently be obtained by supplementing the corn thus fed with corn and cob meal to the extent of half the grain requirement, and adding I pound of a protein food to each 5 pounds of the grain thus added, as shock corn does not furnish enough grain, unless it is fed to a wasteful extent. The protein may be given in the form of oil meal or cake, cottonseed meal, gluten meal, or wheat bran. The amounts of protein concentrate should be kept to the lowest point consistent with good gains by feeding protein roughage, which is cheaper.

3. Oilcake may be fed in large amounts when fattening cattle, along with corn, even to the extent of making half the concentrate fed. Such feeding, however, is usually very costly, and while increase will be very rapid for a time, lessened increase soon follows to 
such an extent as to make the feeding for a longer period unprofitable. The true mission of oil meal is to furnish protein, to act favorably on the digestion, and to improve the coat and handling so as to insure high finish. These ends are probably best accomplished when not more than 3 pounds are fed an animal daily, and preferably during the later rather than the earlier months of feeding.

4. Cottonseed meal is not usually fed along with corn or its equivalent at the rate of more than I pound of the meal to 3 pounds of corn on the average during the entire feeding period, beginning with, say, 2 pounds and ending with 5 pounds a head daily, but it may be fed with safety when the increase is gradual up to ro pounds. When thus fed, however, the ration is not in balance; nor is it safe to have swine glean after cattle when more than, say, 3 pounds are fed daily. Possibly the amount of cottonseed meal fed could be carried somewhat further, if two lots of swine were used in such gleaning, alternating them at the end of two or threeweek periods. The hazard thus referred to furnishes an argument for feeding all the concentrates in the form of meal when much cottonseed is being fed.

5. The value of corn ensilage as a factor in making beef has never been duly appreciated. The small amount of waste when feeding is a strong argument in favor of feeding corn in this form, notwithstanding the greater labor in preparing it. The capacity of the country to produce beef would be greatly increased by preparing corn thus for feeding without increasing the quantity grown. The comparatively slow progress of the increase in silo building is one of the surprising features of our agriculture.

6. When corn is fed to cattle in the ear, and for prolonged periods, the mouth may get more or less sore from crushing ears large and hard and corn on them hard and dry. When the mouth is thus affected, they 
will not eat enough to promote rapid fattening. Such a condition is detected by the delicate way in which they take their food. The more inmature the animals are, the more liable are they to become thus affected. Cattle thus troubled should be at once promptly separated from the others and should be given concentrates in the form of meal until the soreness disappears.

7. When well-grown animals are being fattened it is not common to feed concentrates more than twice a day, and, in some instances, roughage is not fed more frequently. But many feeders give roughage three times daily with a view to have the same in more palatable form when consumed than if given in larger feeds. The old theory that cattle being fattened should be fed frequently and in small quantities finds little favor now. The thought now is that a full feed should be eaten and then allow the animals to lie undisturbed while it is being digested.

8. The daily increase of cattle well matured will vary greatly with the foods, the individuality of the animals, and the stage of the feeding. It should not be less than $\mathrm{I} .50$ pounds daily, and is seldom more than 2.25 pounds with prolonged feeding. The average is, probably, near I.75 pounds. The cheapest increase is made in the early stages of the fattening, and the most costly in the later, as there is usually gradual increase in the concentrates fed. The amounts of grain and fodder called for, respectively, to make Ioo pounds of increase vary much with the condition of the animals, the stage of the fattening, and the individuality of the animals. It is not possible, therefore, to state with precision, even in a general way, the increase that should be looked for from the food fed in each instance. It is seldom that I pound of increase is made from feeding 5 pounds of concentrates. More commonly, under the methods practiced in the corn belt in former years, nearly twice as much has been consumed to produce the gains 
mentioned. About 2 pounds of concentrates have been fed in the said area to one of roughage, but such feeding will probably be much modified in the future. (See page i62.)

Miscellaneous observations.-If the best results possible are to be obtained from cattle on full feed, certain attentions must be given to them, and with unfailing constancy, which, taken singly, may seem to be of minor importance. Prominent among these are the following:

I. When tied in the stall or allowed the liberty of a shed or yard they should be so cared for that filth will not accumulate upon them. This means that they should be well supplied with bedding. When in the stall it will further aid in keeping them clean to clip off the hair closely on the sides of the hips and over the thighs and buttocks.

2. Such cattle must be kept free from the annoyance of insect pests and skin diseases. Lice will so multiply, if present, that they will disturb the cattle to the extent of seriously hindering their gains. The idea is frequently cherished that lice will only be found upon lean cattle, but this view is very erroneous, hence examination should be made when the animals are put on feed to ascertain as to their presence. What has been said about the influence of lice in hindering gains will apply in a greater degree even to certain skin diseases, as mange. The treatment that will remove both insect pests and skin diseases is discussed in Chapter XIX.

3. Water and salt must be supplied to the full needs of the animals. The system that supplies water in the stall so that it is at all times accessible cannot be improved upon, but, because of the first cost, it will only be supplied thus in exceptional instances. To cattle that are not confined, there is no better way of supplying water than to furnish it under cover, in a tank, in the shed so that they may have access to it at all times. 
When the water tank is in the yard, as it is more commonly, the water should be heated to keep it virtually from being icy. The frequency with which cattle in the stall should be allowed to take water will depend on the character of the food. When much succulence is fed, water given once a day is ample. If fed almost exclusively on a diet of corn, it would probably be an improvement to give water twice a day, but when thus fed they are not usually so confined. When cattle confined in the stall are given liberty to exercise daily they will usually drink enough to supply their needs when at liberty. Salt is most easily supplied in troughs or boxes accessible to the cattle when thus exercising.

4. The necessity for exercise for cattle being fattened has been disputed. There can be no question but that they may be maintained in good health for I80 days, that is, for the long term of feeding, without any exercise at all. But it is equally true that if allowed to exercise daily in a yard when the weather is not stormy, the relative increase will be quite as good as from those that are not allowed exercise. The former may take a little more food, but the exercise improves the digestion. When the animals are to be shipped, those given exercise will shrink considerably less than those not exercised, hence the method which allows the cattle to remain out in a sunny and protected yard for an hour a day or more meets with general favor. When thus at liberty they take water and usually such an outing is given to them in the forenoon after the morning cold has been removed by the sun, and this is the most stitable time of the day for giving water. If necessary to have them drink thus in time of storms, they should be at once taken in after drinking.

5. The appetite of the animals should be constantly watched and the food supplies regulated accordingly. This, of course, cannot be done when the cattle are fed concentrates in self-feeders. When the temperature of 
the weather is constant, with judicious feeding, the appetite will also be similarly constant and uniform. But should there be a sudden rise in the temperature of more than one or two days' continuance, the amount of concentrates fed under high pressure feeding should be lessened, lest the needs of a less keen appetite shall be exceeded. The skilled feeder tries so to manage that the animals will always take their food with a relish, and this is more easily accomplished when the fluctuations in winter temperatures are least frequent and in degree least pronounced.

6. Should an animal get "off feed," that is, should the appetite be so weakened that any portion of the usual allowance is left unconsumed, it is an indication that the digestion is disturbed, and that, in consequence, the amount of concentrates fed should be at once reduced until the appetite becomes normal. Should the loathing of food be such that any considerable proportion of the concentrates is left unconsumed, it may be advisable to withhold grain or meal altogether for a time. Such an occurrence is unfortunate, as, in a considerable proportion of such instances, the digestion never becomes quite normal again. A condimental tonic will be helpful at such times, but no treatment will avail unless the concentrate is witheld to that extent that may be necessary. Such a condition may not be so readily detected when animals consume the concentrate from the same feed box, but a watchful feeder will soon discover an animal thus affected. When the discovery is made it should be at once removed to admit of its being properly dealt with. But the exercise which such animals take tends to lessen materially the liability to get off feed.

7. When the animals cease to make good increase, the aim should be to market them. Fattening cattle without increase is very expensive, and the older and heavier they are, the greater is the loss. It does not follow, however, that the returns from such feeding are 
altogether measured by the increase made, as the ripening process which will command a better price may go on for a time when the rate of increase has materially lessened. Such feeding may also be necessary to avoid marketing during a temporary glut in the market, should such feeding be of long duration.

Coming modifications in feeding.-In fattening cattle in some parts of the United States in the past, more food has been fed than was actually necessary to accomplish the same end had the food been prepared and meted out differently. This does not mean that the methods adopted were not the most profitable under the conditions. They were practiced because of the cheapness of the concentrates and the expense of labor. This made it profitable to feed the food to the animals with the least possible preparation. With corn at 20 cents a bushel and less, and corn fodder going to waste, the one aim in the corn belt was to induce the animal being fattened to eat as much as it could be induced to eat of both, to the almost entire exclusion of other foods. In consequence the amount of corn commonly fed to cattle approaching maturity was from 20 to 28 pounds daily, when on full feed, with swine following. Allowing 5 pounds for the swine, that is, for one animal gleaning after one cattle beast, which is the usual number, the grain portion left to the cattle beast is more than it can properly digest.

Coarse fodders furnish cheaper food than concentrates. When, therefore, they can be made to effect the same end sought without too much cost in preparing them, the aim should be to feed them to the greatest extent compatible with the end sought. In $1895-6$ the author fed three groups or lots of cattle with three in each group at the Minnesota experiment station. The feeding continued 150 days. The animals in all the groups averaged a little more than 1,000 pounds each when put on feed. Those in lot I consumed on an aver- 
age throughout the experiment 8.58 pounds of meal daily; in lot $2,10.48$ pounds; and those in lot $3, \mathrm{II} .94$ pounds. The ensilage consumed was about $2 \mathrm{I}$ pounds daily, and the mixed hay about 6.5 pounds. The average daily gains were, for the steers in lot $\mathrm{I}, \mathbf{1} .65$ pounds; lot 2, I.72 pounds; and lot 3, I.43 pounds; one animal in lot 3 was a poor feeder. Attention is called to the fact, however, of the large gains in proportion to the small allowance of concentrates composed of meal made from corn, oats, barley, and bran mixed. The experiment would seem to indicate that cațtle can be fattened on quantities of grain considerably less than those usually fed. Other experiments may be cited which point in the same direction.

Corn ensilage will be made and fed to cattle to a much greater extent in the future than in the past. That such a result will follow is extremely probable for the reasons now submitted: (I) It insures the utilization of the corn plant virtually without waste. (2) It stores the same in a structure of relatively cheap construction. (3) It prepares it in that form in which it may be most conveniently fed. (4) The silage furnishes an excellent medium on which to feed the meal, the mixing being done by the cattle while the food is being eaten. (5) The succulence in it, to some extent, favors digestion. (6) There are no stalks in the manure to add to the labor of handling it. In passing it may be mentioned that the concrete silo, with reinforced wall and truly built, will be the enduring silo of the future. As states grow older the tendency is to increase in the values in foodstuffs. The average price of corn, for instance, is fully twice what it was ten years ago, and there are no reasons for believing that maximum prices have been yet reached. The same is true of other foodstuffs, though probably in a less degree. This means that the higher foodstuffs become, the greater will be felt the necessity for economizing in feeding them. This 
means that usually more labor will be expended in preparing them for being fed.

In the corn belt corn will still be the dominant food fed, but it will be fed largely in the form of ensilage, and the grain fed will be added with the ensilage to insure its more thorough digestion. More legumes will a'so be grown that the ration may be fed in better balance and to aid in maintaining fertility in the land. This nethod of feeding will apply to all areas wherein reasonably good crops of corn can be grown.

In the far North, where large crops of field roots can be grown, much of the fodder, including some straw, will be chaffed and mixed with pulped roots, the grain being all ground and fed on the cut food. This is essentially the same method that has been practiced in Ontario for many years.

In the South and Southwest the aim will be to grow and feed more ensilage, as corn or sorghum, and more leguminous or other hay, because of the bearing which growing these has upon fertility. Cottonseed meal will be fed in reduced amounts because of enhanced values. Corn and the various sorghum seeds will be fed only as meal, except when stored in the silo. The use of molasses will also increase. When poured on the food or mixed with it, increased quantities of the coarser food will be consumed, and the molasses added will aid materially in the fattening. 


\section{CHAPTER VIII}

\section{FINISHING CATTLE ON PASTURE}

The subjects treated in this chapter are as follows: (I) Wintering cattle prior to finishing them on grass; (2) Most suitable pastures; (3) Turning animals out to graze; (4) Finishing with or without meal; (5) Finishing in the early summer; (6) Finishing in the late summer; (7) Miscellaneous observations on finishing on grass; and (8) Relative profit from finishing on grass and in the stall or shed.

Wintering prior to finishing on grass. - When catt!e are to be finished on grass, the character of the feeding the previous winter will be influenced chiefly by the feeding to be adopted when the animals are on pasture and by the season at which they are to be marketed, but more especially the latter. If they are to be marketed in the early summer, the feeding of a certain amount of grain is necessary. If they are to be sold stili later, they may, in some instances, be finished without grain.

The food rations will vary with the production which is most plentiful in the locality. The roughage will include one or more of any grasses, one or more of any clovers, or one or more of any of the varieties of corn or sorghum grown. The corn and sorghum may be fed in the dry form, but the results will be better when they are fed as ensilage. These may be fed singly, but it will be preferable to feed them in certain combinations. Where corn and sorghums may be grown successfully, the aim should be to make one of these fed as ensilage form a considerable part of the roughage, if not, incleed, the basis of the same, on the grounds of suitability and cheapness. Some kinds of 
straw of the cereals may be used more or less, but except when fed along with a goodly supply of field roots, these should not form the sole roughage fed. With corn, sorghum, or straw of the cereals, the aim should be to feed leguminous hay once a day, when practicable, to maintain equilibrium in nutrients in the roughage. Ensilage will be found helpful up to the extent of, say. 30 pounds a day, or even more, for cattle that approximate $I, 000$ pounds in live weight. The more corn in the ensilage, the less the amount of the meal that is called for, and the same is true of increase in the amount of field roots fed. With, say, 25 to 30 pounds a day, a small supplement of ensilage and good straw of certain cereals, it may not be necessary to feed any grain.

The aim should be, as a rule, to adjust the grain fed to the roughage, rather than to adjust the roughage to the grain, as it is much easier to dispose of surplus grain than of surplus roughage. It should also be the further aim to keep down the amount of grain to minimum quantities, for the reason that grain is more costly than roughage. But as corn is usually cheaper relatively in many areas than other concentrates. when such is the case it should be the aim to grow leguminous fodders to feed along with it, whether it is fed as ensilage or otherwise.

The amount of grain that should be fed will be influenced to a considerable degree by the season when the animals are to be marketed. If marketed in the early summer, it will usually be profitable to feed them grain somewhat freely. If marketed in the late summer less grain is called for. If marketed still later. under certain conditions it may not be necessary to feed grain at all. Trith these facts in mind, the amount of grain to be fed can be regulated best by the increase in the animals and by their condition of flesh.

Cattle that are to be sold on grass in the early summer should carry comsiclerable fat when they leave 
the yards, and, to produce this, may call for feeding grain somewhat freely during the winter. Growing animals should be given enough grain to cause them to increase not less than $I / 2$ pounds daily during the winter. This result should be reached ordinarily from feeding an average of, say, 6 pounds of meal daily, beginning with three or four pounds, and gradually increasing. The following fed daily would be a relatively cheap ration for such feeding where ensilage is grown; 25 to 30 pounds ensilage, 6 pounds meal and the balance clover or alfalfa hay. The grain or meal could be corn or barley 50 per cent by weight, wheat bran 25 , oats 20 , and oilcake 5 . In the South cottonseed meal could be freely used instead of bran, oats, and oilcake. In the northwest, where succotash grows in good form, a mixture of which wheat would form one-third by weight, the other two-thirds being speltz and oats, or oats alone, will be found suitable.

When the animals are to be finished in the late summer they should be made to gain not less than $I / 4$ pounds daily, and should be fed grain accordingly. An average of 4 pounds daily through the winter would suffice, beginning with 2 to 3 pounds and increasing gradually. The kinds suitable will be the same as for those to be finished early, and given in the preceding paragraph.

The finishing of cattle without grain is usually a necessity under range conditions, and it may be advisable sometimes under extensive farm conditions. But even when grain is not to be fed when finishing on grass, the cattle should be kept growing, if immature. The aim should be, not only to prevent them from losing flesh, but to advance them in weight not less than one pound daily. To accomplish this it may be necessary sometimes to feed grain. But when leguminous fodder is fed, as good clover or alfalfa hay, it is not likely that feeling grain will be necessary, as without grain 
animals fed on such fodder should gain from $I$ to $I \frac{I}{4}$ pounds daily. If ensilage well grown is fed, or shock corn, but once a day, it is not probable that more grain may be needed. The feeding of shock corn may also obviate the necessity of feeding grain to cattle finished for summer markets, according to the amount of the same that is fed. The fear need not be entertained that a small amount of grain fed to such animals will be lost. Other things being equal, they will show better finish in the autumn.

Whether the cattle should be tied in the stall or wintered in an inclosed shed will depend upon the conditions. When housed and the stabling is suitable, more uniform gains will be secured by tying them in the stall and allowing them out for a part of the day on fine days. When the ventilation is good it may not he really necessary to let them out at all during the winter. When hornless, and fed in a close shed, and allowed to go out only in good weather, in certain climates, a saving of food will be effected; but in various sections, as when lumber is costly and when the weather is not extreme, it may be more profitable to winter them in open sheds. Whether in closed or open sheds, the aim should be to have them take meal when fastened in stanchions.

Most suitable pastures.-All pastures are by no neans equally well adapted to the growing of beef, though the grass should be present in abundance, nor have the same pastures the same adaptation for such production at all seasons of the year. Each section has its special features of production with reference to variety as well as to quantity. Russian brome grass (Bromus incrmis) has been highly suitable for making beef on farms in the northwestern provinces of Canada, but more because of its abundant and prolonged growth as compared with the native grasses than for any superiority in nutrition. Bluegrass in the bluegrass region, and it is a very wide one, is famed for beef mak- 
ing. Bermuda grass in the South is quite satisfactory. The grasses of the western ranges are usually quite nutritious, but they are much wanting in relative abundance of production. The best grasses for beef production will usually be mixed grasses adapted to the locality and which insure continuity in growth in the pasture during the growing season. All the clovers furnish good pastures for beef production, except the sweet variety, Mclilotus alba, but none is superior or probably equal to the common red variety in amount of production furnished during the growing season. The clovers do not usually provide grazing for so long a portion of the year as grasses.

Whatever the variety or varieties of plants in the pasture, the grazing should be abundant. The laying on of flesh by cattle grazing is so far retarded when they are compelled to travel in search of food beyond what is necessary to furnish them with exercise. In other words, they lay on flesh when lying at rest rather than when exerting. It may not always be possible to adjust the stock fattened to the carrying capacity of the grazing, because of the variations in the seasons, but the aim should be, when stocking the pastures, to keep the number of animals introduced rather under than over the carrying power of the pastures, unless when it is the intention to supplement them with other food. In other words, it would be better in every way to have some pasture left uneaten than to have an under-supply. Where pastures are extensive, and on rugged lands, it may be necessary for the cattle grazing to travel much more in securing food than on grazing the opposite in character. When grazing is sparse and rugged, lightweight animals will gain more relatively on it than large and heavy animals.

The grazing should not be over-succulent. When the grasses are abundant, succulence in moderate degree will promote growth, but when present beyond a cer- 


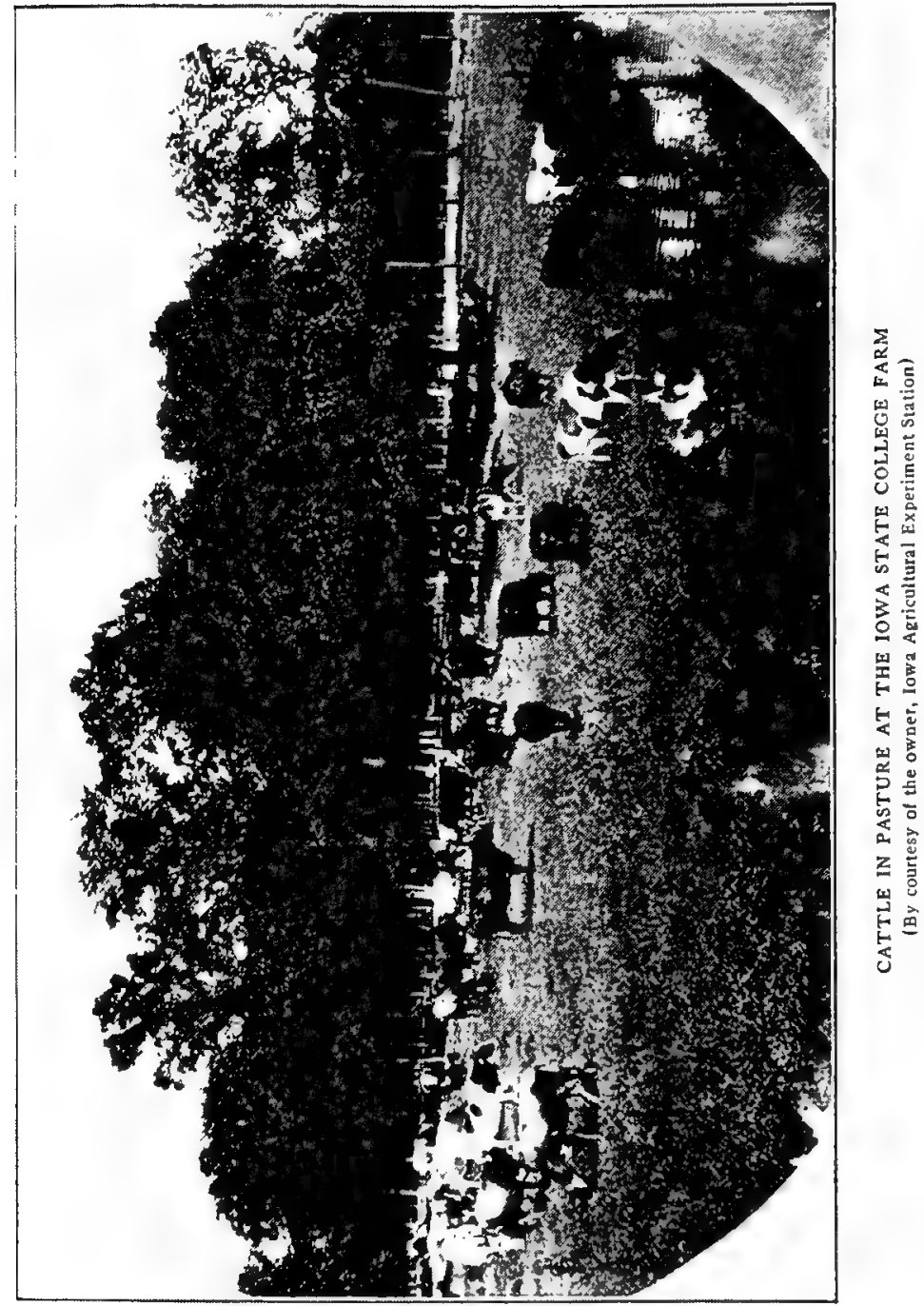


tain degree will not promote fattening. This is shown in the slight increase in weight made by cattle during the first weeks of grazing in the early spring. The experience of western ranchmen has shown them that the early autumn months have highest adaptation for fattening animals that are dependent wholly on pasture. It has also shown to them that in seasons of unusual rainfall, which means more than usual abundance in the grasses, they do not get the best results from fattening. The grasses are over-succulent. They are favorable to growth, but not to laying on fat. Similar has been the experience of those in arable areas during seasons of excessive rainfall.

With some grasses, much may be done to counteract the effects of over-succulence. This may be best illustrated probably in the management of bluegrass pastures that may be adopted. When not grazed closely in the autumn, a mulch of grass will cover the ground to the extent of several inches, according to the time when grazing was made to cease. Unless in winter temperatures exceedingly low, the under blades of grass usually do not lose their greenness. The top blades wither and turn brown. As soon as the first growth comes in spring the green blades will push up in myriads amid the dead ones. The grazing thus afforded is succulent, but not over-succulent. The deacl grass present counteracts the tendency in the fresh succulent grass to produce scouring, and in so far as it cloes it tends to increase the laying on of flesh. Again allow bluegrass to grow without grazing until growth ceases, then it rests and loses its succulence. If not grazed, a later growth appears as soon as the autumn rains come. Here again are the same conditions. The grass is abundant, but not over-succulent, hence it is well adapted to laying on flesh. This does not hold true of all grasses or clovers, but it does with some of them. though to a less degree, probably. If grasses of the 
range are not eaten down in the autumn, a result that is possible when they are inclosed with fences, in the cured form in the spring, they, along with the fresh grass, will materially advance the season of fattening on the range. Clovers cannot thus be utilized, as, soon after they are mature, when unharvested, they lose rapidly in nutrition.

Pastures should, of course, be without hazard to the cattle grazing on them. Practically all varieties of clover are without hazard after the cattle have been introduced to them, when not hungry and are not removed again. When, however, cattle are introduced to clover pastures in a hungry condition and when the clover has much succulence, the danger is present that bloating may be induced, which, if not relieved, may result in death. What has been said of clover is equally true of rape. The hazard from grazing alfalfa is still greater; in fact, it is so great that when alfalfa is possessed of much succulence and not grown along with other grasses, the propriety of attempting to graze cattle on it is to be questioned. For the treatment of cattle suffering from bloat see page 450 . The grasses proper clo not cause bloating in animals that graze upon them.

Turning out to graze.-When cattle that are to be finished on grass are turned out to graze, shrinkage may follow unless it is carefully guarded against. It is certain to follow when the change from winter to summer conditions is made abruptly. This results from the lax condition of the digestion from feeding on tender and over-succulent grass. The shrinkage may be so serious as to prevent increase for two or three weeks from the time grazing begins. Development thus arrested means serious loss and should be prevented as far as possible. It is entirely practicable, under average conditions, to change from the yard to the pastures without any loss in weight, but it is not easy to make the change and 
secure gains while it is being made equal to those that precede and follow it.

To prevent loss of weight at such a time the following measures may be adopted: First, the grain that was being fed previously to turning out the cattle should be continued for a time without diminution. If reduction is made in the grain, let it begin after the change is made. Second, fodder should be as usual morning and evening. It is important that the fodder fed at such a time shall be highly palatable to induce the cattle to eat it. No fodder is better suited to such feeding than good clover hay or alfalfa. Third, if succulent food is being fed, as field roots or ensilage, the amount fed should be at once reduced or withheld entirely, as it is not needed when cattle have access to young grass. Fourth, the aim should be to turn out on pasture which furnishes grass of both the old and new growths. (See page I7r.) Fifth, the grazing should not begin until the grass is abundant, as it is then less succulent than at an earlier stage of its growth. Sixth, the change should be made gradually. The cattle should be turned out after the morning meal has been eaten, and should not be left out for a longer period the first day than, say, an hour, lengthening the period about that much each succeeding day. Of course, the time called for in making the change is modified by conditions.

Avoid short periods of grazing.-In some instances, cattle that have been on full feed in the stall, yard, or paddock are suddenly turned out to graze on pastures but for a few weeks previous to sending them to the market. This line of action may arise from a shortage in the food supplies, from a desire to secure a higher price than is then being paid, or from a lack of knowledge as to the lack of increase which such a course may lead to. It may not be known that while, after the change has been made properly complete, cattle will gain as 
quickly on grass only as previously on grain and forlder, that this does not apply to the period of change.

Cattle thus handled will make but little increase in weight while on grass. For a week or two, at the first, they will certainly lose in weight, and this loss may, in some instances, be as much as 50 pounds in each animal. Though there should be an advance in price, it will probably be offset by the shrinkage or little increasc made, plus the value of the pasture.

There is the further objection that the cattle do not ship well. The over-succulence in the food has disturbed the digestion, and they do not take kindly to the dry food given preparatory to shipping and in transit, hence they shrink more than other cattle. They reach the market in a condition which the buyers term soft. hence they do not pay so much for them as for cattle more firm in flesh. The aim should be to graze cattle for a period not shorter than two months when finishing them on grass, and to so feed them that during the transition period they should gain rather than lose in weight.

Finishing with or without meal.- It cannot be said that the place for meal as an adjunct to grass in finishing cattle has been fully demonstrated. It is difficult to demonstrate, owing, first, to the involved nature of the problem which bears upon the amount of grass saved by feeding the grain, and, second, to the almost impossible determination of the extent to which the value of the meat has been enhanced by such feeding. That feeding grain does increase the carrying capacity of the pasture and that it does produce a finish that will bring a higher price, cannot be questioned, but who can tell how much it has saved the pasture, and, except in experimental feeding, who can say how much it has added to the intrinsic value of the cattle?

When pastures are abundant and rich, and not oversucculent, feeding grain will not add materially to the gains. But before the pastures reach this condition, 
and when they have gone beyond it, the gains will be increased by such feeding. The question then arises as to whether any grain should be fed during that period when it does not add materially to the increase. At first thought, the answer would be not to feed meal at such a time. The correctness of the answer would be unquestioned but for the influence the grain has in saving the pasture and in producing a higher quality of meat. There is also increase in the fertilizing value of the droppings of cattle thus fed. These reasons taken together would seem to show that, at the season indicated, it is sometimes admissible to feed grain even when the pastures are at their best.

One of the several methods may be adopted in finishing cattle on grass with reference to the amount of meal fed. First, they may be finished without grain; second, fed grain only during the later months of the grazing; third, fed only a small amount of grain during all the grazing period; and, fourth, fed all the grain they will consume. Which of these methods should be adopted will be determined by circumstances.

Animals that have been fed grain during the previous winter should certainly have the same continued, though in gradualiy diminishing quantity, during the transition period from the stable to the pasture. If the pastures are abundant and grains are costly, the highest profits may result from feeding on grass alone. But, in such instances, the cattle should usually be sold before grass finished cattle come in from western ranges. The better condition of flesh which they possessed, as compared with range cattle when turned out to graze, makes this, as a rule, easily practicable.

When pasture is abundant and grain is costly it may bring highest profit to defer feeding grain until the last two or three months of the grazing. This method is only applicable when the grazing period covers much of the season. The feeding of grain should 
I76 THE MANAGEMENT $\triangle$ ND FELDING OF CATTLE

begin after the grazing has passed its most valuable stage for the season.

The feeding of a small amount of grain, therefore, during the entire grazing period, is a safe way of feeding, especially when the grazing period covers several months. The moderate quantity fed keeps down the cost. The quality of the carcass is improved as compared with grass-finished meat, and the animals thus fed usually reach a condition of finish that is satisfactory to the dealer.

Large quantities of grain should only be fed when the animals are to be grazed for short periods, as, for instance, when they are to be marketed during the early summer months. In such instances it may be advisable to feed them quantities of grain almost equal to those fed to animals that are being finished in the stall.

From what has been said it will be manifest that the amounts of grain that should be fed to meet the different conditions cannot be stated in pounds. This can only be determined by the feeder. The thought, however, should never be lost sight of that grass is relatively a cheaper food than grain, and, because of this, the feeding of grain should be kept down to the lowest point compatible with the ends sought.

Finishing in the early summer.-As the cattle are to be put upon the market early it is doubly important with them that the gains shall be continuous. Great care should be exercised when changing from dry food to pasture. The grain or meal fed before turning on pasture should be continued without diminution. Good clover or alfalfa hay will furnish fodder more suitable than some other fodders at such a time, as the greater palatability of these will lead to greater consumption.

Various kinds of meal may be fed subsequent to the change as before it is made. When the pasture is mainly clover, shelled corn alone fed whole will furnish a cheap and entirely suitable grain supplement. Should 
the pasture be grass, then 90 per cent of corn and Io of oilcake will give better results considerably than corn alone. There will be less of a tendency to scours when the oilcake is fed, and experiments have shown also that more increase is made when oilcake is added to the corn. When fed in the nut form, the oilcake is not blown away by the wind as when fed as meal. Cottonseed meal or gluten meal may be given in place of oil meal, also wheat bran. In some instances the corn is prepared by soaking it usually for 12 hours, but it should not be soaked long enough to become sour, nor should it be fed so freely that any will be left unconsumed in the feed boxes, or it will sour. It is most conveniently soaked in a tight box on the wagon which conveys it to the place of feeding. When swine are not present, the corn should be thus soaked or ground.

In the absence of corn, barley meal, or rye meal, wheat meal or pea meal may be fed when the conditions favor such feeding. A limited amount of wheat bran or half the amount of oilcake will improve the ration. Oats, as part of the grain fed, are excellent for such feeding, but usually the price at that season forbids their use.

The amount of grain or meal that should be fed at such a time will vary with the character of the pasture. But little light has been thrown upon this question as the outcome of experiment. In some instances, as much as 20 pounds are fed daily to cattle weighing $I, 200$ to $I, 500$ pounds. These amounts are unnecessarily large, even when whole corn is fed and swine follow the cattle. Grass is certainly a cheaper fattener than grain, hence grain should be fed chiefly because of the influence it has on the quality of the meat. As the outcome of experiment it will probably be found that feeding less than I pound daily for each Ioo pounds of live weight will prove more profitable than feeding larger amounts unless when corn is very cheap. 
When the cattle are fed all the grain they can consume, it will answer to feed it in boxes, where they can eat in common. When fed limited amounts, they may be also thus fed when dehorned, but each will receive a more exact share if confined by stanchions while taking their grain.

Finishing in the late summer.-When cattle are to be carried on to the late summer on grass, the meal fed may be continued about the same as it was fed during the winter. (See page I66.) It may also be gradually reduced and even withheld finally, according to the character of the pastures and the season when they are to be marketed. It may be more profitable, in some instances, to withhold the grain altogether after the change from dry feed to grass has been completed until the grasses begin to fail. This means that, in many instances, grain may he withheld for at least three months. But, should there be any shortage in grass during these months, grain must be fed in amounts to make up the deficiency. The cattle should make increase all the while, virtually at the rate of 50 to 60 pounds monthly. Failure to make such increase would indicate some lack in the food or in the feeding capacity of the cattle, except it may be while flies are troublesome.

When grain is again fed, the amount given should be moderate, not more than a few pounds daily. The kinds that may be fed are the same as for those finished early (see page I76), or in areas which grow much corn the grain fed may all be given as corn of the new crop. Such feeding may begin as soon as the corn has approached maturity.

When new corn is fed, it is sometimes given as snapped corn at first and sometimes as shock corn. Some caution is necessary with reference to the amount to be fed, lest scouring should be induced. By gradually increasing the amount the cattle will soon be on full feed; that is, they will be eating corn in addition 
to the pasture to the full extent of their capacity to consume it. When corn is thus fed it is strewn over the pastures. Swine, of course, follow the cattle. When two pastures can be used for such feeding, much saving will be effected in the corn.

When shock corn is fed, the cattle that are being fattened consume practically all the ears and some of the fodder, and the next day they will feed similarly in the other pasture, thus alternating from day to day. Store cattle follow and gather up any ears left and also consume much of the stalks. Swine accompany the store cattle. The alternating in the feeding may be made daily, that is, with each meal, if necessary.

In areas where corn is abundant this is considered one of the most profitable ways of feeding it, because of the small amount of labor involved. When fed thus, husking and shredding are rendered unnecessary. and the resultant fertility reaches the soil without any labor involved in handling the same.

When cattle are fed thus in any considerable number, some will, of course, finish earlier than others. Those that finish first should be sorted out and sent to the market, the others being fed for a longer period. Those finished late will reach the market in competition with beef from the western ranges, that is, when supplies are plentiful in the market, but because of their better finish they will command a better price than the latter.

Should cold autumn storms prevail, it is greatly important to protect such cattle from them during their continuance; especially is this true of sleet storms. In certain areas it may also be necessary to give them the shelter of a shed well littered after the nights become cool beyond a certain limit.

Miscellaneous observations.-The following observations, general in character, will now be submitted: 
I. The cattle should be amply supplied with water, salt, and shade. It is, of course, advantageous to have these supplied in the pastures, and so that the cattle may at all times have access to them. It matters little as to the source of the water, providing it is pure and wholesome. If the cattle have to journey far for water and return to the pasture, especially in hot weather, the gains would be greatly retarded. Salt is best supplied in a box or boxes protected from rain and placed near the water supply when the water is taken from tanks. The salt supply should never be allowed to run short, as when salt is given again the cattle will take too much. The more succulent the pastures, the greater is the necessity for a plentiful supply of salt. Shade is best furnished by trees, and so plentiful that the cattle will not bunch when lying at rest. But when trees are too numerously scattered over the pastures they lessen the yields and quality of the grass. Where no trees are present, shade may be furnished by erecting a roof of poles, covered with straw or old hay, and located in an airy place.

2. The grain is usually fed in boxes from which the cattle eat simultaneously. The objection to this morle of feeding is that some animals may get more than their rightful share and some less when grain is not fed to the full capacity of the animals to consume it. Where only a few animals are fed it would be practicable to feed them in separate boxes, but not really so when the number is very large. It would be easily possible to construct a box somewhat like a manger, with poles obliquely placed to mark the stall divisions, so to speak. If the manger were placed in the line of the fence, the food could be put into the same without.

3. It has not yet been found practicable to protect cattle from the annoyance of flies when thus grazed. It is, of course, possible to spray them with certain substances that will protect them for a few days, but the 
labor involved and the cost of material have heretofore been greater, it is thought, than the material profit resulting therefrom. Systems of spraying of recent invention may yet be found profitable.

4. The aim should be to market grain-fed cattle on pasture when beef from other sources is not plentiful. It should reach the market, therefore, as a rule, after the supply of winter-fed cattle in the stall has been well exhausted, and before the full season of marketing range stocks. When grain is fed, marketing at such a time is entirely practicable. The advantage from such marketing is found in the relatively good prices that rule during the season mentioned. But, in some instances, it may be profitable, as with animals one and two years old, to carry them on for a more perfect finish to meet the demands of the Christmas market. In such instances, the aim should be to make them strictly prime, the finish being completed in the stable or shed.

Relative profit from finishing on grass.-The impression is abroad that finishing cattle on grass will result in the greatest profit. Such was the outcome of an experiment conducted at the Missouri experiment station bearing on this question, and such is the method of finishing practiced by many engaged in fattening cattle. But it will be apparent to any who study the subject that relative profit from stall feeding and finishing on grass will be a question of conditions.

The principal influences that affect profits are the price of land, its natural adaptation, the cost of labor, the character of the rotation and the markets. As these influences vary much, the variations in results will correspondingly vary.

With variations in the price of land will come variations in the value of pasture. The less value put upon the lands, the less relatively will be the value of the pasture. It is evident, therefore, that those who have low-priced lands and extensive pastures have so far an 
advantage over those with high-priced lands and circumscribed in area. The person living under semirange conditions may usually aim to finish on grass, as a portion of the pasture may be free and in no instance is it costly.

No influence will have a more important bearing on this question than natural adaptation. Some soils will produce grass abundantly, while they may not be so well adapted relatively for corn. Such are the soils of the hardwood timber areas southward from the Great Lakes. On such soils summer fattening would so far be the more profitable. Other soils will grow corn that will produce more beef an acre than can be obtained from the same in grass. Such are some of the soils in the corn belt, hence winter fattening in these, unless labor is too costly, may be the more profitable. An approximate idea may be obtained of the value of the grazing by the area required to maintain a cattle beast through the season of grazing. Without grain a cattle beast in, say, the one-year form, should give not less than 50 pounds a month on grass ample and nutritious. This furnishes a basis for carrying the computation further.

The cost of labor will have an important bearing on the outcome. Caring for cattle that are being finished on grass involves much less labor than caring for the same when fed in the stall, shed, or yard. In estimating the labor, the cost of hauling the manure should be included. The higher relatively the cost of labor, the greater is the saving effected from such outlay in summer grazing.

The nature of the rotation affects the question materially, through the influence which grazing exerts on fertility. When grass thus grazed is a feature of a short rotation, the land is thus cheaply supplied with humus and fertility to be used by the crops that follow. The more grain that is fed, the greater will be the amount 
of both put into the land and at a minimum of labor in outlay.

The markets in the meantime usually favor summer finishing. The average prices for good beef on foot are usually higher in summer than in winter for the reason probably that it is less plentiful. More especially does this apply to the three months of summer. While the conditions prevailing in the meantime seem to favor summer grazing, it may not be always thus. The variable conditions such as relate to the cost of labor may so fluctuate that the winter finishing may again become the more profitable. Nor should the fact be overlooked that many farmers are so situated that they can utilize time profitably in winter feeding cattle without employing labor from without, whereas the labor thus used would otherwise be less profitably employed or not employed at all. The time called for from farmers in finishing cattle in the summer may hamper them considerably in their farm work. 


\section{CHAPTER IX}

\section{COWS THAT ARE MILKED BY HAND}

In many respects the management of cows that are milked by hand is essentially different from that of cows that suckle their calves, hence these two classes will be discussed in separate chapters. In Chapter IX the following points will be considered with reference to the care and management of cows that are milked by hand: (I) Hand-milking and milk production; (2) Management during the period of rest; (3) Management at parturition; (4) Shelter required in winter; (5) Exercise called for; (6) Protection required in summer; (7) Cows in milk should be driven gently; (8) What good milking means; (9) Keeping milk records; ( Io) Absorbents in the stables; (II) Drying of cows; and (I2) Management relating to breeding.

Hand-milking and milk production.-That handmilking properly conducted tends to increase the capacity of cows to give milk cannot be questioned. The tendency with cows that suckle their calves is to provide only what the calf will take and to cease to - give milk when the calf is weaned. This means that ordinarily the cow that suckles her own calf provides milk for one calf, and not usually for a longer period than six months, whereas the cow of ancestry handmilked for successive generations may be made to give milk enough to feed several calves for a much longer period than with the former. In fact, it is quite possible to so stimulate milk production that a cow once in milk may be milked continuously for successive years. Inheritance, selection in breeding, food, management and the artificial conditions to which the cow is subjected may all be made to assist in establishing the habit of 
abundant and prolonged milk-giving. It is safe, therefore, to say that cows milked by hand and otherwise properly managed will give milk far beyond that furnished by the same breed of cows equally favored in respect to the food furnished. But the fact should not be lost sight of that it is possible so to manage cows

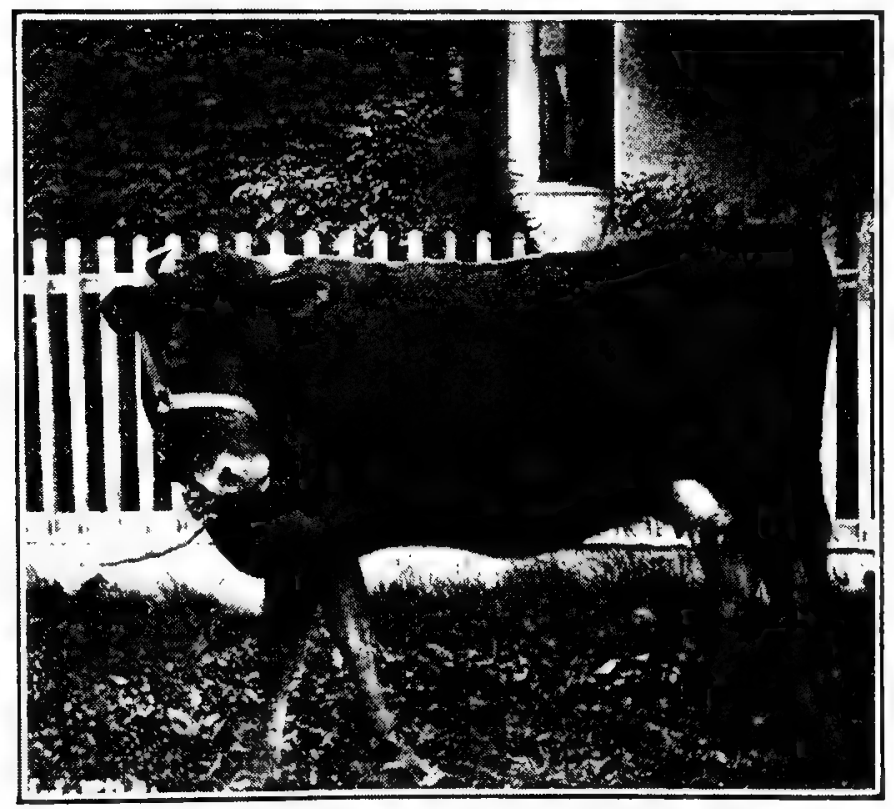

PURE JERSEY HEIFER

(By courtesy of the owner, Erland Lee, Stony Creek, Ont., Canada)

that nurse their calves as to bring the average of milkgiving in the cows up to a higher standard than ordinarily exists in herds thus managed.

This means, therefore, that if maximum milk yields are to be obtained cows should not be allowed at any time to suckle their calves. It follows, therefore, that 
cows of the dual type which suckle their calves will not be possessed of high milk-producing qualities. The same will be true of these cows when alternated by hand-milking some seasons and suckling their calves other seasons. So-called milking Shorthorns will not produce milk abundantly that have suckled their own calves even for a limited number of generations. The relation between hand-milking and the most generous milk-giving is inseparable. This makes it possible, should it be so desired, to improve milk-giving qualities in cows that ordinarily suckle their calves by milking them by hand during the first lactation period, should such a plan be deemed desirable.

When calves are to be vealed they should not be allowed to suck their dams, if the latter are to be handmilked subsequently. It is, of course, labor-saving to allow them to take their food thus, as compared with milking by hand and feeding the calf from the pail. Such feeding is somewhat less favorable to growth and fattening, but what is lost in that way, it is believed, will be much less than the loss that would result through the adverse influence on milk production in the dam, from allowing the calf to take its own food directly from her. Cows have power, to some extent, to retain their milk, and this power is sometimes exercised when the excess of milk is being taken from an udder from which a calf has already taken its meal. Any tendency to retain milk thus is prejudicial to milk-giving in proportion as it exists. It would possibly be claiming too much to say that influence thus exerted would, in all instances, be prejudicial to milk-giving. Much depends on the temperament of the dam, but ordinarily the general results would be against maximum yields.

Management during the period of rest.-With reference to the duration of the interval between the respective periods of lactation, there is considerable difference in the practice of dairymen. Some aim to have 
it cover not fewer than ten weeks, some eight weeks, and, probably, a large number not more than six weeks. In some dairies the milking of some of the cows is continuous. It goes on from year to year, even when the cows breed at regular intervals. It is quite possible to develop the milk-giving habit to such an extent that milk-giving may be so continuous as to cover several years without any cessation.

That a period of rest between the lactation periods is necessary in a breeding herd is evidenced in nature's plan. No female quadruped continues to give milk during the entire period covered between the birth of two successive individuals of the progeny. With cows thus at liberty, the rest period covers several months. The rest is necessary to enable the dam to restore the flesh lost during lactation, the better to nourish the young of the next birth and to lay up in the system a store of flesh that will be found of much advantage to the system and through it to free milk production during the next period of lactation. Of course dairy cows are kept under conditions which so far differ from those which nature furnishes that the animals may always be amply supplied with food. Notwithstanding, the incessant working, so to speak, cannot but tend to wear out the system more quickly than it would wear under management the opposite. The necessity for a rest period is shown in the analogy of perennial plants which have their period of annual rest, even in climates in which winter can scarcely be said to reign. It is fair to conclude that continuous milking will tend to exhaust at too early a period the energies of the animal, and thus in the end it will result in no increase in production. In other words, the female that is given a rest period of reasonable length during the year will give more milk during the lactation period than the female milked continuously will give in the year. It should also follow 
that the former will milk profitably for a longer term of years.

That such results should be expected would seem reasonable, first, from the known fact that during the rest period energy is stored up for future use, and, cecond, that a machine overtaxed wears out sooner than one not thus overdriven. During the rest period the system is fortified by increase in flesh and this, up to a reasonable limit, brings with it increase in nerve power. It stands to reason, therefore, that when the cow comes in milk again she will be able to milk better than the cow whose energies have been taxed by continuous milking. The machine; that is, the animal economy, is thus overtaxed by incessant work.

The influence of such continuous milking on the progeny is also adverse. It diverts to the making of milk at least a part of the nourishment that would otherwise go to the fetus. All the food given to such a cow is used in one of these ways, that is, in maintenance, in making milk, and in nourishing the fetus. It is very evident that the more it is diverted to one or another of these purposes, the less will there be for the others. This explains why a cow given rest usually increases in flesh during the rest period, while a cow milked continuously cannot make such increase. It also explains why development in the young should be benefited by a rest period in the dam before it is born. It is reasonable to suppose that as pregnancy advances he demands of the embryo on the support from the dam continually increase. Continuous milking, therefore, cannot but tend to a lowering of stamina, not only in the dam, but also in the progeny. The duration of the period of rest, therefore, is the only question that is debatable. It will differ with different animals, and should probably average not fewer than from eight to ten weeks. It would seem reasonable to suppose that it should be longest in the cows that milk most freely. 
Management at parturition.-As the time of parturition draws near some modifications in the food of hand-milked cows may be necessary, especially with those that are free milk producers. The exercise of judgment is called for in adjusting the food to the needs of the cows. Two things are to be specially guarded against, viz., constipation and excessive stimulation of the milk-producing functions. Trouble from the first source is chiefly liable to occur in winter, when the cows are on dry food, and from the second, in summer when they are on pasture, but it may also occur in winter when stimulating foods are fed too freely. The first condition may lead to trouble in various ways at the time of parturition, the second is very liable to produce milk fever. The remedy for the first is feeding a sufficiency of field roots, wheat bran, or oilcake to correct such a condition if present or to prevent it if absent, without feeding enough of either to incur hazard from the second cause mentioned.

To avoid the hazard of milk fever it may, in some instances, be a wise precaution to put the cows on a partially dry diet when the pastures are abundant. This will involve keeping them confined at night and feeding them some palatable dry fodder before allowing them to go on pasture for the day. Another plan, but probably not so good, would confine them to paddocks where they could not get a full supply of grass and to feed dry fodder in addition. Of course it is only when the grass is possessed of much succulence that the hazard from unrestrained grazing is present. To the methods of putting such cows wholly on a dry diet, as practiced by some dairymen, there is the objection that the equilibrium of the system may be too much disturbed thereby.

When the udder becomes very distended before the birth of the calf, the withdrawal of part of the milk has been resorted to, in some instances, as the time of parturition draws near, and without results apparently 
harmful. But the plan which so manages the cow that such an aggregation of milk will not be present at too early a period, is doubtless preferable. Milk thus removed before parturition brings with it some hazard to the new-born calf, because of the modified character of the milk caused by such removal.

Some dairymen have adopted the plan of administering a mild purgative to the cow within, say, a day or two of the time of parturition. The skilled dairyman can usually judge of the near approach of the time of calving with sufficient accuracy to properly adjust the time for giving the purgative. The only harm resulting from giving it earlier is in its being less effective in accomplishing the ends for which it is given. In some instances the purgative is given within a few hours subsequent to parturition and in other instances both before and after. The object is to make sure that the bowels at such a time are not in a constipated condition and to lessen the activity of the secretions. Epsom salts are the purgative most commonly used. They are given as a drench and the dose is from three-quarters of a pound to a pound. There is some difference of opinion as to the efficacy of such treatment, but where regularly practiced milk fever very seldom occurs. This fact is sustained by much evidence, though, as yet, largely unwritten.

Opinion is somewhat divided as to whether all the milk should be removed from the udder after the calf las taken its first meal. The common practice is to remove all the milk, but some claim that only a part should be removed where the object is to prevent excessive milk secretion. It is sometimes argued that there is less danger from milk fever, when nature's plan is followed of removing only a part of the milk at a time, for a day or two at the first. While this point is being investigated, and pending a decision, it would seem correct to say that the feeding before parturition stould be so guarded 
that after parturition removing all the milk that is present will do good rather than harm.

The cow should be given a sufficiency of water after the calf is born, but never colder than a tepid condition, lest it chill the system. She should be kept on a low diet, that is, not stimulating, for a few days; nor excessive in quantity, so that the disturbed condition of the system may have time to regain normal conditions. While fodders may be fed as usual in winter, the increase in the concentrates should be gradual until the maximum amount is reached. For a few days, or until the condition of the udder becomes normal, strong heat-producing grains should be fed sparingly or not at all.

Shelter required in winter.-More commonly cows in milk are tied in the stall or confined in some sort of stanchion, but, in some instances, they are given the liberty of a closed shed, except when taking their food and while being milked. The latter method gives the cows opportunity for taking more exercise than the former, which is a strong argument in its favor, but more bedding is called for in order to keep the cows clean. On the other hand, all the liquid manure is thus saved, being absorbed by the bedding which is added daily. The manure is also preserved from leaching by rain until drawn to the field. The cows must, of course, be dehorned.

Wherever kept they should be comfortable as to temperature. This means that they should be kept in an inclosure where the temperature should not rise above, say, 60, or fall below 40 . The aim should be to secure a temperature of, say, 45 , but weather conditions may render it impossible to keep the temperature as indicated. In properly constructed basement stables an even temperature is more easily secured than in other stables, since atmospheric changes do not quickly affect the temperature in them.

In addition to a comfortable temperature there 
should be present such conditions as suitable ventilation, freedom from dampness, and the ample admission of sunlight. Inattention to these matters, especially the first, is responsible for a large percentage of instances in which cows are affected with tuberculosis. It is imperative that attention shall be given to it in whatever kind of stables the cows are confined. The colder the winter temperature, the more necessary is it that careful attention be given to ventilation in addition to that secured by means of windows. (See page 378.) Dampness is most commonly present in basement stables which are built into a bank on three sides, and which are not properly ventilated. The proper construction of these is given in Chapter XVII. (See page 348.) Light, and especially sunlight, is the great force to destroy disease germs, hence the wisdom of having ample provision made for admitting light, and it also tends much to facilitate the ease and dispatch with which work may be done in a stable.

Whatever the nature of the confinement, it is necessary that each animal shall be given its proper portion of food. As shown on page 272, variations are frequently necessary in the amounts and kinds of food fed to effect a given result, hence whatever the nature of the quarters furnished for cows they must be confined with tie or stanchion when taking the grain portion of the food. This necessity may not always exist when taking fodder. (See page 193.)

Exercise called for.-Authorities are not agreed as to the best method of giving exercise to dairy cows in winter, and as to the amount of the same that should be given. Three methods of giving exercise have been advocated and practiced. By the first the cows are turned out for a short time in the warmest portion of the day in a protected and sunny yard, but only for an hour or two, and only on days when the temperature is not cold enough to bring discomfort. The weak point of this 
plan is that it only admits of turning out when the weather is good, hence in some climates there will be successive days in which the cows cannot be turned out thus at all. By the second method, the cows are turned into a closed shed with ample sunlight on the sunny side, and are there allowed to remain for several hours each day. Fodder to some extent may be supplied in this shed. The chief objection to this method is its cost. Where it is adopted, attention must be given to ventilating the inclosure. By the third method the cows are kept in apartments where they are at liberty, except when taking their food as described on page 19I. When thus kept it is not necessary to turn them out at all when temperatures without are low. On the other hand, they may be given prolonged freedom in a protected yard adjacent when the weather is good. This method of keeping such cows is the most favorable of the three, for the maintenance of stamina.

Several years ago the practice of tying cows in stalls in which they are given food and furnished with water, and of not allowing them out at all from the autumn to the spring was considerably practiced. It is but little practiced now, as it was found that herds kept thus became much preyed upon by tuberculosis. On the other hand, a limited number still follow the practice, and have done so for many years, more, in some instances. than a dozen. The herds, they claim, maintain good health and ample vigor. They attribute the tendency to disease referred to above to insufficient ventilation. This question, therefore, should not be considered as finally determined, although the preponderance of evidence at present would seem to be against the practice. It is certainly favorable to the maintenance of an equilibrium in the conditions, but it is doubtful if animals thus confined will consume as much food as those that are given some exercise, or that they will digest it as well. The 
results from fattening cattle confined or given more exercise lend countenance to the view thus expressed.

In managing dairy cows in winter there are certain influences to be considered which may become, in a sense, antagonistic in their action. These include stamina and milk secretion, and the influences which exercise and exposure exert on both. Without some exercise for a prolonged period, the natural conclusion is that stamina will suffer more or less. With over-exercise, both stamina and milk secretion will suffer, but especially the latter. Over-exercise is so little to be feared under winter conditions that it is not to be considered, however strong the influence may be that it exerts in summer. Exposure in winter to temperatures low beyond a certain degree does certainly influence milk secretion adversely, and yet it is to be feared, if cows are tied in the stall all the time, that stamina will suffer. Where this is the only method by which cows may be kept, it is certainly worth while to consider as to whether it may not be wise to lose somewhat in milk secretion, while the cows are exercising without for the sake of the increased stamina that will follow. The keeping of the cows at liberty in an inclosed shed, save when they are taking food, and giving them free access to a sunny and protected yard, when the temperature is suitable without, would seem to be the most feasible solution of the problem that can be adopted, notwithstanding it is less economical of space than stalls and calls for more litter.

Protection required in summer.-In summer the protection required is, of course, influenced by the climate. Climates differ much in the amount of rainfall, in the severity of the storms, in the intensity of the summer heat, and in tine extent to which insects, as flies, give trouble. The measures necessary to protect from these influences will correspondingly vary. Ordinarily it is not necessary to protect cows from mild 
and moderate rains, but from cold rains they should be protected. These too much reduce the system, and in proportion the milk yield is decreased. Exposure to prolonged cold rains, such as sometimes occur in certain climates after the season has arrived for pasturing, is particularly adverse to milk production, and will certainly be followed by corresponding shrinkage in the milk yields. At such times cows in milk should be fed and kept indoors.

Sunshine, so helpful to animals, becomes excessive when it produces discomfort. Whatever produces discomfort in the cow that is milked reduces proportionately the milk yield. Instinctively the cow will seek protection from sunshine when it becomes excessive, if the opportunity offers. The opportunity should be furnished. If not furnished by trees in the pasture, it may be furnished by making a roof of poles supported by posts and covered with old hay or straw. A rim of forest in the pasture or a grove furnishes shade better than isolated trees or than the roof just referred to. A rim of forest is better than a grove, as in the former the cows do not bunch in the shade as in the latter, and, therefore, do not furnish conditions which to the same extent encourages an increase in flies, which are very liable to be bred in the droppings.

The protection from flies is discussed further elsewhere. (See page 406.) The annoyance from flies may seriously reduce the milk flow, hence any protection that is effective and not too costly should be given at certain seasons. One of the most feasible methods of protection from flies is that which is furnished by a basement stable, well ventilated and yet darkened. It may be profitable, where practicable, to keep the cows in such a place during the warm portion of the day in time of flies. Any stable or inclosed shed may be utilized, but usually basement stables are relatively cooler at such seasons. Such protection is not perfect 
by any means, but it is helpful, as the activity of flies decreases with the decrease of light.

There should also be protection from the waste of energy in taking food. This, probably, is a kind of protection more frequently lacking than protection from the other influences mentioned. Insufficient pasture, in

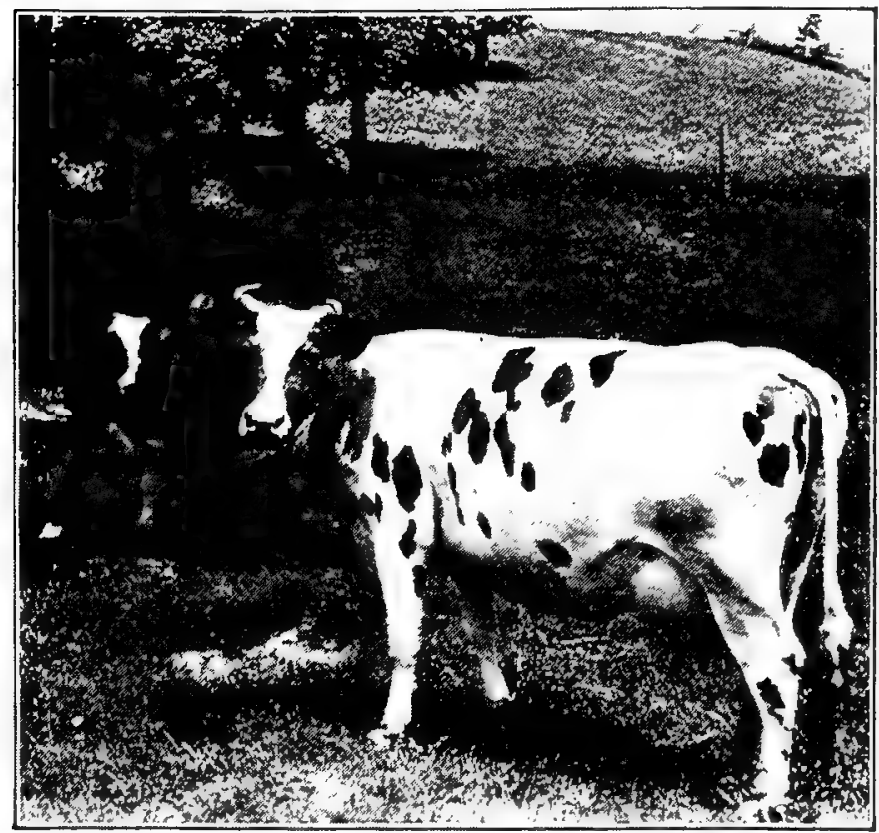

PRIZE-WINNING HOLSTEIN FRIESIAN COW

(By courtesy of the owner, G. W. Clemons, Brantford, Ont., Canada)

the absence of other fond, is a fruitful source of loss to the dairyman. While grazing in the pastures the exercise thus taken, up to a certain limit, will be helpful to stamina, and, therefore, directly or indirectly helpful to milk production. Beyond this point, however, it tends to lessen milk production and does not at the 
same time add to the stamina. Exercise thus enforced does not become excessive at the same time in all breeds. Light-weight cows can travel farther than heavy-weight cows in grazing, hence the wisdom of seeking adaptation in the choice of cows for pastures that are naturally rugged and sparse. Protection may be furnished from this waste of energy by stimulating production in the pastures through fertilization, through allowing the pastures to become abundant before turning the cows into them, and by feeding supplemental foods. It would probably be correct to say that the most valuable pasture crop in the aggregate of any crop is the most neglected and mismanaged

Cows in milk driven gently.-When cows in milk are being driven to and from the pastures, it should be with all gentleness. Undue haste and excitement will militate against maximum milk yields, and fast driving when the udders are distended may result in physical distortion of the udders. Any gait faster than the cows voluntarily assume, especially on the return journey from the pasture, is too fast.

The use of a horse in thus driving cows is usually hazardous, especially when ridden by a boy. The temptation is so great to hasten the movement of the cows by quick riding that it is not easily resisted and a large whip in the hands of a boy is a temptation to use it to excess. Some boys may be safely trusted to drive the cows at a proper gait, but all boys cannot be so trusted.

The driving of such cows by dogs is simply an abomination, when the dog urges undue haste, and dogs usually do. To do such driving as it should be done is usually beyond the capacity of a dog.

When cows are so managed that they will follow like the flocks of sheep in eastern lands, the relations between them and those who care for them will be as they should be. When an attendant can go to the pasture 
gate and call, and when the cows who hear the call at once respond by walking toward the gate, there need not be any fear that the cows will be overdriven by such an attendant.

What good milking means.-Good milking means, among other things, that the milk will be taken in a clean condition, that it will be taken with reasonable dispatch and by one who loves the work, that it will be done by the same person as far as practicable, and that it is done at stated times. The aversion shown by many farm hands to milking adds much to the difficulty of securing all these conditions in milking.

The quality of milk is easily injured, not only by coming in direct contact with foreign substances, but also by imbibing odors that may be floating in the air. To protect from the first, the milk must be drawn from ciean udders, with clean hands, into clean pails, and amid clean surroundings. To protect from the second, attention must be given to the condition in which the stables are kept. The udders of cows come in contact with foreign substances, both when in the pastures and in the stables. These should be removed before the milk is taken. Some advocate using a dry cloth when wiping the udder and teats before milking, but a greater number advocate using one that is damp, but not wet, carried beneath the lid of the milking stool. Of course, there may be instances in which it is necessary to remove filth from the udder by washing. The practice of further moistening the teats by dipping the fingers into the milk is reprehensible, and it is quite unnecessary. Metal pails are preferred to wooden ones, as they are more easily scalded, and are less likely to contain hurtful germs. To furnish aid in protecting the milk from foreign substances, some dairymen follow the practice of milking before the cows are fed, as in the process of feeding, especially when feeding fodders, many dust particles are macle to float through the air in the stables, 
but this practice is by no means universal. For the measures taken to keep down obnoxious odors see page 202.

The milk should be promptly withdrawn. This is necessary as a matter of economy on the part of the milker, and because of the influence in establishing habit in the cow with reference to yielding milk. Some cows let down their milk, so to speak, much more quickly than others. This habit may be influenced by the manner in which the milk is withdrawn. It is important, therefore, that it be withdrawn promptly. The importance of withdrawing milk with reasonable quickness is greatest during the first period of lactation. The difference in milkers in their ability quickly to take milk from the same udder is marked.

The milk is best withdrawn by those who find pleasure in the work. To obtain the aid of such is one of the greatest obstacles in the path of the dairyman. Such a milker will not be rough or boisterous with the cows, and will never abuse them. The boisterous, rough, unfeeling man who has a positive aversion to milking will prove a costly milker. When farm hands must needs be pressed into the work of milking, they approach it with a feeling of aversion, and the results are never entirely satisfactory. The dairyman who can milk his cows largely or entirely through help from his own household may be regarded as fortunate. Women make the most gentle milkers, and, in consequence, are the most satisfactory. When the girls of sufficient age, of the home, can do a part of the milking, it is good for the milk-giving of the cows and is good exercise for the girls. The danger is looming up, however, that milking may soon become a lost art to American women.

Experience has shown that, in very many instances, a change of milkers results in a decrease in the quantity of milk given. This does not follow with all cows, nor to the same extent with all milkers, but it does follow 
with sufficient frequency to make it desirabie to avoid such changes as far as it may be possible to do so. Such partial withholding of milk is one of the ways in which the inherent powers of cows to do thus is manifested. Milk-giving by the cows is most satisfactory when the relations between the milkers and the cows are, so to speak, friendly in character.

It is greatly important that the milking shall be done with unvarying regularity. It has been noticed that when, on the Sabbath, milking was deferred for a time in the morning, the whole amount given for the day was less than on other days, and there was some lowering of the yield the day following. The influence of the milk-giving habit is of considerable potency, and, as has been shown, such habit may be affected by various causes. Highest attainment in milk production cannot be reached with cows which are not milked at the same hour from day to day.

Whether milking machines will become so perfected that they will supersede hand-milking in large herds cannot be stated with the positiveness of assurance at this time. If such machines could be so perfected that they would do the work as well as it can be done by hand and more quickly and cheaply, it would work a revolution in dairying. There are grounds, however, for the apprehension that such machines will not entirely dispense with hand labor in milking, as the relation is as close between the manipulating of the udder by hand-pressure and milk-giving as it is between the "bunting" of the calf and milk-giving in the cow that feeds her calf thus.

Keeping milk records.-The great practical value of milk records cannot easily be over-estimated When properly kept, they make it possible to draw an approximate comparison between the producing power of the different cows in the herd. This comparison will be exact if all the food fed to the respective cows and all 
the milk taken from them is weighed and tested as to its quality from day to day. To do all this is scarcely practicable in the farm dairy. It is practicable, however, to keep a daily record of all the milk given by the cows, and to test the same as often as may be necessary. It may also be possible to keep an approximate record of

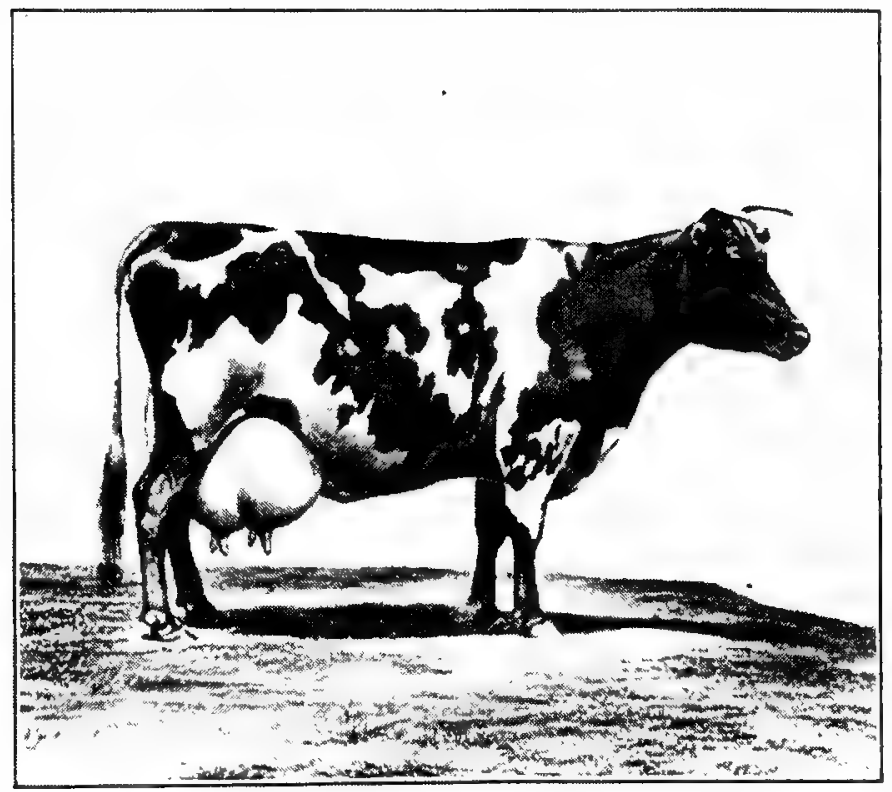

AYRSHIRE COW, DUCHESS OF SMITHFIELD, 4256

A Great Prize Winner at Eastern State Fairs

(By courtesy of the owner, Henry R. C. Watson, Brandon, Vt.)

the food, especially the concentrates, by weighing the same as often as a change is made in the amount fed. Such records make it possible, not only to draw a comparison between the value of the production of the respective cows in the dairy, but to trace the approximate profit, if any, from each cow. Such records will far more than 
pay for the cost of keeping them, first, in the weeding out of all cows that are not good producers; and, second. in the ambition that is thus generated to aim at securing still higher production from the cows.

It is entirely practicable, as intimated, to keep full daily records of milk production from all the individuals in a herd. To do this, record forms must be prepared and kept in the stable and in proximity to the weigh scale. As soon as the milk is taken from each cow it is weighed and the amount is marked on the prepared form. The summing up of these amounts is then a matter of convenience. To avoid accumulation it had better be done not less frequently than once a month. But if the milk is weighed morning and evening, say, twice a month, at the same date in each month, and the average of the two weights taken as the average of the month, the findings will be approximately correct, and to secure them involves much less labor than the method which weighs each milking.

To test the milk, say, three times a year, will give an approximately correct idea of the quality of the milk, viewed from the standpoint of its constituents, as these do not fluctuate to anything like the same extent as quantity does. The aim should be when making these tests to take them at about equal periods in advance in the lactation. The tests should, of course, be made from all the milk drawn at one milking. The average of the three tests will show approximately the character of the milk. That the approximation may be quite close, however, it will be necessary to test the milk of each cow for, say, three consecutive days at the same dates in each month of the lactation period. The average for the ihree days will represent the average for the month.

Odors that are hurtful to milk. - The scope of this treatise does not include the care of milk after it has left the stable. But so susceptible is it to the absorption of odors that its quality may be injured by these before 
it is taken to the milk room. These taints may come from within the stables, as, for instance, from odors in the droppings and urine; from without, as, for instance, from a hog house too near at hand; or from succulent food, as ensilage or field roots in decay. These taints once in the milk adhere to it, and, when pronounced, affect the quality of the products made from the milk, as, for instance, butter. This may also come from feeding freely such foods as rutabagas and rape.

The ain should be to protect the milk from such odors rather than to try to remove them when imbibed. When they come from within, such protection is afforded by having earth or concrete floors in the stables, by promptly removing the droppings as far as this may be practicable, and by using suitable absorbents. When they come from without or from decaying foods, the removal of the cause will anticipate the effect. When taint in milk comes from food, the food must be modified. (See page 265.)

All kinds of wood used in floors, especially in the construction of the gutters for the reception of the voidings, imbibe some of the liquids and in turn give off an odor that is more or less offensive, hence the advantage of making these cement, which has the further advantage of resisting deca

The degree to which hurtful odors are given off by the droppings is much influenced by the character of the feeding. When the digestion is not forced in a healthy animal, the odor from fresh voidings is not very offensive, but it is different when the feeding of concentrates is beyond the capacity of the cow to properly digest the same. Should the droppings remain long in the stables, in the absence of absorbents, odors arise, especially from changes in the urine which make it offensive. The more promptly the urine is absorbed and removed, the less odor will be present. In this is found 
an argument favoring the early removal of the voidings in the morning.

The chief of the absorbents used are dry earth, muck, litter, and such material substances as gypsum and phosphate. Earth may be used where other absorbents are not at hand, but to use either earth or muck means that a supply must be stored near at hand in the autumn. Muck has even greater absorbing power than dry earth. Litter in the natural form, but more especially when cut, that is chaffed, will always be a favorite absorbent because of the ease with which it may be handled as litter or as manure. Gypsum has power to fix and hold ammonia that to some extent is lost when absorbents are not used. The same is true of ground phosphatic rock and also of acid phosphate. These substances are strewn in the gutters after the manure has been removed. When litter and gypsum or ground rock phosphate, or both, are used in conjunction, odors from the droppings will be well held in check and the value of the manure will be enhanced. The litter is first strewn in the gutters and the mineral substance is then sprinkled over it.

Even when such measures are taken to keep the stables pure, the wisdom of not allowing the milk to remain in the stable after it has been withdrawn will be at once apparent. After all has been done that can be done to keep the stables pure, the atmosphere of a stable will not be so pure as the atmosphere of a milk room.

Drying of the cows.-The drying of straight dairy cows is a more difficult process than the drying of cows of the dual or beef types. The difficulties of the process increase with the high rank of the cow as a producer, with increase in the succulence of the food and with too close proximity to the time of the birth of the next calf. The first results in an increase in the tendency to continue in milk, the second to the giving of a larger present quantity, and the third 
to the antagonism resulting from the effort to cut off the milk flow after nature has again begun to replenish the milk supply for the next birth. It would seem correct to say that a free milking cow cannot be properly dried unless it is done previous to within three or four weeks of the time of calving.

When cows in the dairy are to be dried, correct procedure begins by milking them but once a day and by putting the cow on dry food. The importance of feeding dry food to free milking cows cannot be easily overestimated when the drying process is begun, and yet it would be possible to make the change so rapid as to disturb the digestion overmuch. The food may also be somewhat lessened in quantity. Inattention to the change in food and feeding thus recommended is responsible for much of the difficulty found in drying off dairy cows. After milking thus once a day for, say, a week or two, the milk is then taken only every other day, gradually increasing the intervals and not taking all the milk from the udder.

Meanwhile, especially during the later stages of the drying process, the udder should be examined more frequently than it may be necessary to take the milk from it. As long as it remains soft and pliant, it would seem safe to say that the danger line has not yet been reached. Injury to any portion of the udder as a result of the drying process to the extent of lowering capacity in the function of the same will lessen milk-giving in the future. Thus a cow which can give milk from but three teats will not furnish as much milk as a cow that can give milk from four. Whether the reduction is mathematically proportionate has not yet been fully demonstrated, nor does it seem possible of exact demonstration. Because of the difficulty found in drying off some cows, they are kept in milk from year to year. It is on record that the Red Poll cow Crocus, of the Norfolk dairy herd at 
Whittingham, England, was thus kept continuously in milk for nine years. But to such milking there are some oljections, as is shown below.

Management relating to breeding.-The aim of freshening dairy cows at certain intervals is to increase the milk flow and, in some instances, also to furnish progeny that can be reared for the dairy. When the first is the only object sought, the potency in the male used is the most important consideration regardless of blood lines, but when the calves are to be reared for any purpose, then the breeding of the sire becomes very important. If they are to be made into meat or grown for baby beef, pure-bred males only of the beef breeds should be used in service, but should they be wanted for the dairy, then too much care cannot be exercised in the choice of the males used in service with reference to inheritance and purity in breeding pertaining to milk-giving. When the only object is to renew the milk-giving qualities in the cow, even cheap scrub sires may serve the purpose quite as well as costly pure-breds.

The frequency of such periods of freshening is greatly important. The aim should be to have them occur at intervals of about one year. This would give the cows from nine to ten months for milk production, and the remainder of the year for rest and recuperation. There may be instances in which cows fail to become pregnant at or near the time when this may be desirable. Usually such cows should be disposed of at the end of the year's work, but there may be some instances when it will be profitable to keep them several months longer, and, in the case of valuable pure-breds, for a still longer period, in the hope that their breeding powers may be restored. Some cows will take service under certain conditions which will make the periods of renewal cover less than a full year. The wisdom of such a course is to be questioned, because of the tax which it puts upon the energies of the cow. 
When cows come in heat and are at liberty they should be removed from the herd as soon as this is known, and should be kept apart until the period of heat is over. This is necessary because of the disturbance which their presence gives to other cows in the herd, resulting, for the time being, in diminished milk yield.

It is important that a careful record shall be kept of the time of the service. Without such a record the dairymen cannot know when to begin the drying process, nor when to begin such modifications in the food given as may be for the benefit of the cows during the period of rest. 


\section{CHAPTER $\mathrm{X}$}

\section{COWS THAT SUCKLE THEIR CALVES}

The management of cows that suckle their calves, discussed in this chapter, dwells upon the following phases of the subject: (I) Management while the cows are pregnant; (2) Care at the time of parturition; (3) Removing the surplus milk; (4) Management when the calf remains with the dam; (5) Management when the calf is confined; (6) Food and care in summer; (7) Food and care in winter; (8) Management relating to breeding. The considerations submitted relate to the management of beef herds that are purely bred, and also to grade herds kept under extensive conditions.

Management while pregnant.-The discussion of this phase of the question will be confined to the period of rest subsequent to the drying off of the pregnant cows. This period usually covers from four to six months, and more commonly the latter period than the former, as calves are seldom allowed to nurse their dams heyond the age of six months. For the season when it is most desirable to have the calves come see page I.

The care called for during this rest period is not complicated. The cows should, of course, be gradually and carefully dried off, that the udders may not take injury. The drying-off process is gradual, and is facilitated by allowing the calves to suck but once a day for a week or two before final removal, and by keeping the cows on dry food. If the dry period occurs during grazing, the cows require no other care than providing them with pastures sufficiently abundant to keep them in good flesh, and to supply them with water, shade, and salt in the same. While on such pastures, this class of cows 
should increase in flesh, but not to the extent of incurring hazard at the time of parturition.

In winter the shelter of a shed will be sufficient for cows of ordinary value, and no harm should result from a number of them feeding together, providing they are dehorned or even when possessed of horns when it is known that none of them are vicious. It is hazardous to have horses in the same yard, lest they should injure the cows, and the hazard is much increased should colts have access to the same yard. Pedigreed cows of much value should be given a box stall for some time previous to the birth of their young. When thus kept, the element of hazard from injury by other animals may be practically eliminated, since it makes it possible to control the conditions under which they may take exercise. Under some conditions in range areas pregnant cows may run at large in winter and gather their own food, but under other range conditions they must be fed during severe weather. For the discussion as to whether they may be confined in the stall during the winter see page 217 .

The food during the rest period of whatever kind should possess the following characteristics: (I) It should possess enough protein to properly supply the elements of growth to the fetus. (2) It should be sufficiently nutritious to so maintain the cow that she will be in good flesh when her progeny is born, to fortify the system against the drain upon its energies during the milk period. (3) It should be possessed of enough succulence to prevent a constipated condition of the digestion. (4) It should be a cheap diet, as the cows are, in a sense, giving no return during this rest period.

In winter, on the arable farm, hay and corn fodder reasonably well eared, supplemented by a few pounds of field roots fed as succulence, should suffice without grain. The same is true of a diet of clover or mixed 
hay and silage. Good oat or pea straw may form a considerable proportion of the ration should the cows be lean, but it would be more profitable to feed the cows so as to bring them into good flesh than to allow them to produce progeny while yet in low flesh. Under semirange or range conditions, alfalfa will be found a very suitable winter food, since it does not rend to produce constipation as some other fodders do.

In answer to the question as to why so long a period of rest is given to such cows, it may be said, (I) that when the milk supply falls off materially both cows and calves will do better than when nursing is long continued, the former because they are relieved from the worry which large calves often produce in the frequency with which they take milk, and the latter because of the greater eagerness with which they consume other food. (2) The cows also call for less care, although this may probably be offset by the greater care called for by the calves.

When more than one calf is reared on the dam, and especially when a calf is put upon the dam after the first calf or pair of calves suckled by her simultaneously are weaned (see page 7 ), of course it is necessary to prolong the milk period. In such instances it may be prolonged even to nine months. Such prolongation of the milk-giving is in no way harmful, but it is rather helpful to regular breeding in the cow.

Care at the time of parturition.-Usually it is not necessary to make any difference in the food given to this class of cows before parturition from that which has formed the diet during the weeks and, in some instances, the months preceding. But the digestion should be carefully noted, and if any evidences of constipation are present, food which will correct the condition should be given.

With such cows the fear of milk fever is not usually 
present, as with them milk production is much less abundant, as a rule, than with other classes of cows, but even with cows of the beef-producing types, milk fever is by no means unknown, hence when they are known to be free milkers the same precautions in kind, though less in degree, should be used with them as with the other classes of cows when the calving season comes near. (See page I89.) It would not be wise to give them unrestricted access to pastures in the zenith of succulence. Nor would it be wise to feed large amounts of such foods as field roots or beet pulp, which tend to greatly increase the milk flow. Nor should large amounts of stimulating concentrates be fed at such a time. They tend to induce what is sometimes termed a heated condition of the system which is frequently associated with udders more or less inflamed at the time of and subsequent to parturition.

Whether mild purgatives should be used before or after parturition (see page rgo) is a point on which herdsmen are not in entire agreement. Some administer them both before and after parturition. This difference in opinion may be owing in part, at least, to a difference in the normal condition of the average of the herd as parturition draws near. As a constipated condition of the cows is a menace to the health at such a time, to administer mild purgatives is probably a wise precaution. For the method of administering them see page I9o. If administered but once, they may be given preferably before parturition.

Of course the attendant should aim to be present at the time of parturition. He can never be sure that complications may not arise which may prove serious and probably fatal in his absence. After the calf is born a little tepid water should be given to the dam to relieve the thirst induced by the fevered condition of the system. The diet for the first day should be quite 
moderate and increase gradually in the meal fed. As for a time the dan will probably give considerably more milk than will suffice for the calf, there is not the same reason for stimulating the milk flow at an early period ii) the lactation as in the case of dairy cows. Such stimulation is, of course, in order as soon as the calf can take all the milk, and no harm can come from such stimulation at an earlier period, if the surplus milk is wanted for other uses.

Removing the surplus milk.-The calf should, of course, be allowed to take the first milk from the udder and to help itself as frequently thereafter as it may desire. This means, of course, that both dam and calf will have the liberty of a box stall. In the season of pasture it will usually be more convenient to confine the cow and calf thus for a few days than to have them in the pasture.

After the calf has taken its first milk the residue should be drawn from the udder, and subsequently it should be taken twice a day for a time, and later once a day when supplying the needs of the calf has so far reduced the surplus that more frequent milking is not necessary. Such removal of the milk aids in bringing the udder into a normal condition, and in increasing the natural and healthful action of all the functions concerned in producing milk.

But there is another important reason for removing such surplus milk. It has an important bearing on the milk-giving of the cows. If not removed, the surplus becomes speedily reduced to the amount taken by the calf, which means no surplus, and, when thus reduced, subsequent increase cannot easily be made, notwithstanding the increase in the capacity of the calf to take milk. At a later period it can take much more milk and use it with much benefit. However, unless the cow has produced milk far in excess of the needs of the calf 
during the first days and weeks of its life, such milk will not be forthcoming. It is not necessary to dwell upon the inseparable relation between abundant milk supply and rapid growth in the calf.

Reasonably abundant milk-giving should be encouraged in this class of cows, because of the relation that subsists between milk production and regular breeding. It has been noticed that the regularity of the breeding in the cows and consequently the number of calves produced is greater in herds that milk more or less freely than in those in which nurse cows are numerously kept, and the same has been true of individual cows. This observed fact has exercised an influence on the choice of cows for breeding in some of the most famous herds of beef cattle. The fact is coming to be more and more recognized that a cow which does not give enough milk to induce good growth in her own calf during the nursing period is not the best type of a breeding cow, even in a beef herd, notwithstanding that her own fleshing qualities may rank high.

Management when the calf remains with the dam.Two methods of rearing calves of the beef types are practiced. By the first, the calves remain with the dam until weaned. By the second, after the first week or two they are confined and only allowed to nurse from the dams at certain times. The first method, now to be considered, involves less labor than the other, but to it there are the objections, first, that in winter more room is called for by the cows, since each must then have a box stall; second, that the cows thus managed do not, as a rule, become pregnant again at so early a period; third, supplementary foods cannot be so well given to the calves; and, fourth, growth through weaning is more liable to be arrested for a time with calves thus reared than with those that are confined.

When the calf remains with the dam from birth 
its management is simple. It, of course, takes its own food. But it sometimes happens that scours may be induced by some peculiarity in the food of the dam or by an excess in the quantity of milk taken. This, however, is much less likely to happen when the calves nurse at will than at stated times, as by the former method they are much less prone to take milk in excess of the capacity of the digestive organs to care for it properly. If trouble of this nature should arise, the calf should not be allowed to take full supplies of milk until the digestion has again become normal. Attention should also be given to the food of the cow.

When the calves are born in the stable it is possible to feed them meal so placed that the dam cannot have access to it. This, however, is seldom or never done except in the case of pure-bred calves of much value. It would be quite practicable to feed calves thus if both cows and calves were kept in a shed, the cows, of course, being dehorned. This method of feeding would be most suitable for young calves, as later they may take too much meal, unless possessed of concentrates not in excess of their needs. The foods suitable for such feeding are the same as those given on page $2 \mathrm{I}$. One method of giving supplementary food to calves which graze with their dams while nursing is given on page 15.

The management of the cows is simple. It consists in keeping them where they will be comfortable with reference to temperature, well supplied with fresh air and sunlight, and with suitable food, salt, and water. Of course every attention must be given to the removal of surplus milk, as long as this may be necessary, and to the proper drying of the cows when the calves are weaned. Whatever tends to promote thrift in the cow at such a time will tend to promote thrift in the calf.

Management when the calf is confined.-When 
calves that take milk from their dams are confined to the box stall, shed, or paddock during the milk period, they should be allowed to remain long enough with the dam to insure that the machinery of digestion will not be disturbed by surfeiting, which may easily happen when a new-born calf is only allowed to take nourishment at long intervals, as, for instance, but twice a day. When it is impracticable, therefore, to allow them to remain with the dam for a few days the first week or even for a longer period, they should be allowed to nurse more frequently than twice a day. For the benefits from rearing them thus confined see page 13 . For the supplementary food that will be suitable see page I4.

When calves are reared thus in the winter season the dams may be tied in the stall or they may be allowed the liberty of a shed. In the latter instance, however, the food should be given in stanchions, that each may get her proper share. Usually, as a matter of convenience, the calves are allowed access to the dams at the same time, and the aim should be to have the quarters in which the calves are kept in close proximity to those in which the cows are kept. When the quarters in which the calves are kept are across the passageway and immediately behind where the cows are tied, the arrangement is very convenient. When of different ages, the calves should be graded according to age, and kept in apartments so adjusted that each lot may be given its proper food.

When the cows go to pasture they must be brought in from the pastures morning and evening that the calves may get from them their proper food. Whether the cows will be tied in the stall when the calves are sucking them will depend on circumstances such as relate to supplementary foods given to the cows. Usually the calves may thus take milk from the cows in a yard adjacent to their quarters. When cows not long 
freshened are turned out to graze, the udders should be examined after the calves have taken from them what milk they want. The milk flow is frequently increased under such conditions, so that it may be beyond the needs of the calves, and, if so, it should be taken from the udders.

The drying of the cows that suckle their calves is a simple process. Usually it consists in allowing the calves to suck but once a day for a week or two before the final weaning. When the calves are not allowed to take milk longer from the dams, the food given to the latter should not be such as to encourage milk production. The udders should be examined each two or three days as long as necessary, and any milk removed in excess of what the absorbents can take care of. It is greatly important that no udder shall be allowed to take harm in any part thereof during the drying-off process. The cows should then be allowed a generous food ration to make up for the reduction in flesh which resulted from nursing the calves.

Food and care in winter.-Cows that suckle their calves in winter are usually purely bred. Grade cows thus managed more commonly produce calves in the spring. They are then dry in the winter, and may, therefore, be cheaply carried through that season. With the former, the aim is to produce calves in the autumn and early winter that they may be well forward in growth and thus ready for sale the next autumn. The difference in wintering the two classes will, therefore, be material. The feeding of cows that suckle their calves in winter will be considered first.

In the management of such cows the aim should be to so feed them and care for them that the calves will be well supplied with milk and the dams will not become too much reduced in flesh. The aim should be to so manage that nurse cows can be dispensed with save 
in the growing of show calves, and, as a matter of reputation, the breeder of pure-breds should aim to have his cows carry enough flesh at all times to give no room for criticism on the ground of lean condition from those who visit the herd. The food given to them, therefore, must possess ample nutrition to maintain a reasonable condition of flesh, ample succulence, to aid in free milking and sufficient palatability, to insure the consumption of a large enough amount of the same to secure the ends sought.

It is not absolutely necessary to feed such cows in stalls, but it is important that each cow shall take the meal fed to her separately, which means that she shall be confined in some way and protected while eating it. Whether such cows may be tied in stalls during the winter months without detriment is a disputed point. The balance of opinion is at present opposed to the idea, but the question is not yet to be regarded as absolutely settled. The author kept such cows thus at his Riverside farm, Ontario, Canada, for several successive winters without any perceptible indications of harm other than that some of them walked a little stiffly for a day or two when first turned out to pasture. But the conditions as to ventilation, cleanliness, light and litter were good Such a method is labor-saving.

The best fodders to feed are clover, mixed hay, or alfalfa. Where enough of these are obtainable at a cost not too great, no other fodders are necessary. Usually, however, corn fodders or corn stover may be more cheaply furnished. When fodders are scarce and high some kinds of straw may be fed, but when so fed the aim should be to chaff and mix it with meal when it is fed. In this way almost any kind of fodder may be used, at least to some extent.

The succulent foods are, of course, ensilage, field roots and sugar beet pulp. The first may be fed in any 
quantity up to, say, 30 to 40 pounds daily for a fullgrown cow, and the second and third in any quantity up to, say, 50 pounds a day. Usually, however, such feeding of roots will prove costly. Even 12 to 15 pounds a day will prove greatly helpful to the milk flow, in the absence of other succulent food.

The concentrates will, of course, vary in quantity and kind with the other foods fed. As the maintenance of reasonable flesh in the dam is not to be overlooked, corn or its equivalent in barley, rye, or speltz should form an important factor in the concentrate. When field roots are absent, the aim should be to add wheat bran, oil meal, or cottonseed meal. Meal made from succotash, such as wheat and oats, is excellent. But, as a rule, the quantities of meal fed should be considerably less than those given to cows that are being milked when the chief object sought is a maximum of milk production. It would seem correct to say that such cows, when mature, should not, as a rule, call for more than 3 to 6 pounds of meal daily, according to the nature of the other food fed. It will doubtless be more profitable to insure growth in the calf by feeding it through the cow.

The following may be submitted as a standard ration for feeding such cows in winter: Corn meal or its equivalent, about 50 per cent by weight; wheat bran or oats, or both, 40 per cent, and oilcake or cottonseed meal, Io per cent. The quantity fed must be gauged by the condition of the cow, hence it is greatly advantageous that the food given to each cow may be adjusted to her needs and so fed that she may continue consumption without molestation. The other food will be ensilage fed at the rate of 30 to 40 pounds daily, and such hay as may be on hand.

When grade cows that nurse their calves in summer are dry in winter, much that is said in Chapter XI about 
carrying mature cattle through the winter will apply to feeding and managing them. The aim should be to winter them as cheaply as possible, but in a way that will maintain in them a sufficiency of flesh.

Food and care in summer.-Cows that nurse their calves must have ample food supplies or both cows and calves will suffer proportionately. The cheapest form in which such food can be supplied is, as a rule, in that of pasture. The expense is usually too great to admit of feeding concentrates, even to such pure-bred cows on grass pasture, and is proportionately greater when fed to grades, as it does not increase the value of the progeny of the latter as it does that of the former. But should the pastures become so poor as to call for undue traveling on the part of the cows while securing food, supplementary food should be given in the form of soiling food or ensilage. Ensilage may be more cheaply furnished for such feeding in areas where corn may be grown, when the herd is large. Any form of soiling food will answer that can be grown in large quantities. Of such foods corn and the sorghums are usually most cheaply and abundantly grown. More commonly these supplemented foods are fed to cows of this class by strewing them daily over the pastures. Reserve pastures, when they can be provided for, will probably furnish food more cheaply than it can be furnished through soiling with conditions as at present.

Such cows and also their progeny should be protected from cold storms, from excessive sunshine, and, as far as possible, from the annoyance of flies. What has been said with reference to furnishing protection from the evils referred to in the case of cows that are being milked will be applied mainly to these also. (See page I94.) Protection from cold storms is even more important for cows whose calves graze with them, as 
the latter will suffer much more than the former from such exposure.

The water supply for cows whose calves graze with them should be furnished in the pastures rather than elsewhere, or undue travel will be called for on the part of the cattle in securing water. When the calves are confined, it may be furnished in the pastures or at the steading or in both places.

Management relating to breeding.-It should be the aim to have cows breed once a year, and, when it can be accomplished, approximately at the same season. To breed them more frequently is an undue strain on the vigor, and less frequently means added expense in proportion to the return from the cows. This would mean that they would be served about three months subsequent to the birth of the calf. Sometimes, however, they do not come in heat within that time, and when they do not the aim referred to cannot be realized.

When the males do not run at large with the herd, the time of mating is more perfectly controlled. W'hen the males run with the females, in some instances the latter would become pregnant at too early a period, in many instances the time of mating would not be known and harm would result to the male from unnecessary service. When the calves run with the dam, the herd should be visited daily to ascertain if any of the females are in heat, and, of course, for other reasons. When found thus, they should be removed until the period of heat is past, whether service is given or not. When the calves are confined, the matter of service is much simplified, as it may then be ascertained, when the cows come from the pastures, which are in heat, and the male is at hand to be used in service.

When cows that nurse their calves do not take service within the time limit mentioned, it may be possible to hasten the breeding impulse by feeding such succulent and nourishing foods as will stimulate the 
energies of the system. Whether it will prove remunerative to do so must be determined by the value of the cows. With grade cows it would probably be unremunerative, but with pure-breds it may, in some instances, be different. When cows fail to breed regularly, unless of high value, the best thing to be done, probably, is to dispose of them and to replace them with others as soon as this may be practicable. Cows that breed irregularly will lower the profits of a herd in proportion as they are present, and the hazard also exists that they may transmit the objectionable characteristic, at least in some degree, to the progeny. 


\section{CHAPTER XI}

\section{CARRYING CATTLE THROUGH THE WINTER}

This chapter will discuss the carrying of cattle through the winter in a way that will not be productive, for the time being, in any considerable degree. The object sought is to carry them through the winter at a minimum cost, and with a view to secure future production from them while being maintained on cheaper foods, as, for instance, grazing. The discussion will embrace the following: (I) The conditions under which cattle may be so wintered; (2) Classes of cattle that may be carried through the winter cheaply; (3) Nature of winter quarters; (4) General character of the food fed; (5) Food for such winter feeding; (6) Utilizing foods that deteriorate with age; (7) Sufficiency of food for winter; (8) Improving food as winter advances; and (9) Feeding cows forward in pregnancy.

Conditions for wintering cheaply.-Cattle may not be wintered cheaply under all conditions. When they are being grown for meat and are intended for quick maturing, to carry them through the winter by simply feeding food for maintenance would so far defeat the end sought. Likewise, when production is sought during the winter, the endeavor to secure it only in degree is usually less profitable than when it is sought in maximum amount. There are conditions, however, when it is more profitable to feed cheap foods through the winter than to feed those that are high, as shown below. Among the conditions that call for the cheap wintering of animals are those that relate, first, to the furnishing of the foods; second, to furnishing shelter; and, third, to production. So potent is the bearing of these upon results that they alone may determine the character of 
the feeding that should be pursued during the winter. It may be profitable to winter cattle cheaply under range conditions or semi-range. This follows from the fact that, on the open range, where pastures are obtained for nothing, it may be cheaper to allow cattle that are being wintered to lose some in flesh while they are being wintered than to go to the expense of providing food for them. But to make no provision for them, where the hazard of serious privation is present, is, in a sense, criminal. The story of the sufferings and loss of cattle from privation on the western ranges, could it be told, would be one of the darkest and most pathetic in all American history. Under semi-range conditions, more food is wanted than under range conditions, but even under these it may sometimes be more profitable to feed in a way that will not fully maintain flesh than to incur the outlay in getting more food for winter. The same may be true on extensive farms where the animals are grown chiefly on grass pastures, and on native hay cut from native meadows.

Cheap wintering is greatly influenced by the outlay necessary for shelter. The cost of such outlay may render it a matter of economy to seek production to a greater extent in summer than in winter. Such is particularly true of cows in cheese-producing districts where cold winters prevail. Under these conditions it may be better to have the cows idle in winter rather than producing milk because of the less cost of the shelter that may be necessary to carry them through the winter.

Cattle that may be wintered cheaply.-The classes of cattle that may be legitimately carried through the winter cheaply are: (I) Mature cows in calf and yet dry; (2) mature cows carried over for being finished on grass; and (3) steers or heifers grown chiefly on extensive pastures to be sent from these to the shambles, or to be finished for the block where the conditions are more intensive. Mature cows in calf and yet not in 
milk only require such food as will sustain them in a good condition of flesh, and with enough succulence in it to keep the digestive organs in a good condition. As they are not producing milk, all the food consumed goes to maintain flesh in the cows and to sustain the fetus that is developing within them. Such cows, therefore, may be carried through the winter almost entirely on cheap fodders possessed of a reasonable degree of palatability.

In some instances cows cease to produce at some time during the early winter months, and yet they are not in condition for immediate sale. The facilities may not be present for feeding them to a finish, and, if they were, the fattening process might be too costly. These would be carried through the remaining portion of the winter more cheaply even than the former, and almost if not entirely on fodder without other food. They may then be finished more cheaply on grass.

The third class that may be wintered thus cheaply includes steers and heifers of different ages that are to be grown chiefly on pastures until sold for the block or feed lot. They should not be wintered thus, however, during the first winter of their existence, or subsequent growth will be greatly hindered. Wintering this class of cattle thus is, of course, only applicable to conditions where land is relatively cheap, and where food costs but little or nothing during the grazing period. Young animals of the class now under consideration are able to utilize the lowest grade of fodders to better advantage, probably, than those of any other class, since they have youth and vigor on their side. The digestive and assimilative organs are also then more active than at a later period.

Nature of the winter quarters.-The nature of the winter quarters that will suffice for such wintering is, of course, greatly dependent upon the weather conditions. Where the winters are mild, and especially where 
both mild and dry, shelter besides that which will protect them from the winds may not be necessary. Such shelter is most cheaply found in groves located in the narrow basins of streams, or on the bluffy sides of the same. The few storms that come in winter will do some harm, of course, to the stock, but at such times the storms will not greatly retard development. The streams hard by furnish the necessary water. Cattle have been wintered thus in groves in the West, even farther north than the Canadian boundary, without losing any individuals of the herd through exposure. But in cold situations far north more shelter even for these classes of cattle would prove economical.

For such animals shelter furnished by stables is seldom necessary. It may be provided under some conditions by open sheds only, even on the exposed prairies. But when these are aided by high and close yard inclosures, or when the sheds and yards are located within dense groves or rims of forest, and further protected by an adjoining bluff, the physical conditions for wintering are just so much more complete. When storms are frequent, and especially when they occasionally assume the character of cold rain or sleet, the protection is a real necessity. The construction of the sheds may be of the cheapest, as, for instance, baled straw or poles, and a plentiful covering of straw, hay, or litter over them. Under arable conditions, sheds of construction that is more stable and which forms a part of the permanent shelter, will generally be used. In the absence of a high inclosure of windbreak on the windward side of the yards, or, what is better, around them, a high protection of close boards is greatly helpful. In its absence a protection made of hay or straw, or corn stalks, may take the place of the fence. Whether the animals shall have access to these or not must be determined by the plentifulness or the cheapness of the supplies. The fodders in these stacks should be fed so as to leave those longest 
that will furnish the most protection from prevailing winds.

When wintering animals thus, stanchions may not be necessary at all. Usually they will not be necessary where fodders only are fed, if the supply of these is ample. Where supplies are insufficient for full feeding they should be used by all means at least for the weaker animals. For these it would be necessary to have a separate place for feeding. Stanchions would also be necessary where a small amount of grain is fed, at least while it is being eaten, otherwise the weaker animals would get little or none of the concentrate.

General character of the food fed.-The general character of the food fed should be such as to aim to feed roughage to the greatest extent practicable, concentrates to the least extent required, and succulence only to the extent that may be necessary. Notwithstanding, the general principle holds good that at least a reasonable amount of flesh should be maintained, as flesh lost in winter, though regained in summer, is so regained only through the consumption of food that gives no return until all that was lost has been replaced. Under no other conditions can cattle be made to utilize to advantage so large a proportion of coarse and cheap fodders. When so used, the benefit resulting is practically all gain, where such food has no market value. If not thus fed, its food value will be lost. The only benefit that could be obtained from it would be that resulting from its manurial value and the manurial value is not materially lowered by feeding when the food is judiciously fed.

On the other hand, concentrates, unless damaged, have a market value, and this value, compared with that of rough fodders, is relatively high. Unless, therefore, such foods may be fed so as to bring profit in the end above what would result from feeding them, it is evident that the aim would be not to feed them thus. Even 
under the most favorable conditions for present production, it is sometimes impossible to secure an adequate return from the heavy feeding of concentrates. That it is very much more difficult, therefore, to secure profit from feeding concentrates, where simple maintenance is the chief object sought, will be very evident.

Succulence in connection with such feeding is chiefly needed because of the favorable influence which it may be expected to exercise on digestion when thus fed. It is only necessary, therefore, to feed it to the extent of keeping the digestion in tone when wintering such animals as indicated. But the only barrier to feeding it in larger quantities would be the extra cost of obtaining it. Ensilage is the cheapest form in which it may be obtained, as a rule. In some instances, beet pulp may cost less. When these can be obtained more cheaply than fodder, they may be a chief reliance in such feeding.

While in its relation to flesh production the chief aim in this class of feeding is to maintain it, if more than this can be accomplished with profit the aim should, of course, be to secure such increase. This may sometimes be done through the abundance of the coarse and cheap foods fed. For instance, in feeding coarse hay or corn stalks, either may be fed so sparingly as to barely maintain flesh, but should the supply be in excess of the actual needs of the animals, more abundant feeding would be in order. With these and other foods that deteriorate with age, such feeding will increase the proportion of the waste, but with foods that deteriorate quickly there will be waste in carrying them over. If, therefore, some increase in flesh is obtained by such abundant feeding, it is legitimate to seek it in the way indicated.

Foods for such winter feeding.-Good hay only is usually too expensive for such feeding alone, when of the class that is in demand in the market. This is 
especially true of timothy and redtop, and may also be true, sometimes, of some other kinds of hay, as clover and timothy mixed and alfalfa. Some classes of hay may not be much in demand in the market, and yet it may be so necessary for other uses that it would not be wise to feed them freely to animals that may be carried through the winter on foods not suited to serve those other uses. To illustrate: Should good clover or good oat hay be on hand, and also coarse stover and hay more or less damaged in the curing, and should cows in milk and cattle that are simply being wintered be maintained on the same farm, as is usually the case, the clover and oat hay should be given to the former and the corn stover and damaged hay to the latter. In other words, the aim should be to adapt the foods to the different classes of animals according to their needs. This would mean that in the line of fodders cattle that were being simply wintered would seldom be given, unless toward spring, at least as their exclusive diet, such fodder as good timothy, redtop, clover, oat hay, vetch, or pea hay and millet. Leguminous fodders, especially when of good quality, should be reserved for milk production, but it would be both legitimate and proper to feed all other fodders to the animals that were simply carried through the winter. The use to be made of alfalfa would depend upon its plentifulness, the market demand for it, and the opportunity for feeding it. Although excellent for milk production under some conditions, it cannot be put to any other use than that of carrying cattle through the winter.

Straw of the cereals, and also corn stover, furnish the cheapest fodders that can be given to live stock that are being carried through the winter. The former are too low in nutrition to furnish the exclusive diet of stock thus wintered, during all the winter, if of long duration. The same is true of corn stover, though in a less degree, and where either is fed alone, or where both 
are fed in conjunction, the food is illy balanced, being too low in protein, and when fed in long periods it tends to produce a constipated condition of the bowels. When even a small quantity of field roots is added to the ration, this tendency will be corrected. Flax straw also tends to prevent constipation. Straw from leguminous plants, as peas, when in good condition, is more valuable for such feeding than straw from those that are non-leguminous. It is quite possible, however, to carry cattle through the winter on straw only, but, in nearly all instances of such feeding, when at all prolonged, the animals so fed lose in flesh.

While it may be necessary, in some instances, to supplement a straw diet with grain, especially toward the dawn of spring, to feed much grain to cattle that are being wintered thus would entail cost that would result in loss. The aim, therefore, should be to avoid this when possible to do so. When grain or meal is fed to such animals, the aim should be to feed it along with cut fodders, as such feeding secures a reiatively large consumption of the fodder.

Among the winter rations that are quite suitable for such feeding are: (I) Straw of the cereals and field roots or ensilage; (2) corn or sorghum fodder and field roots or ensilage; and (3) corn fodder and cottonseed hulls. That mentioned last has highest adaptation for southern conditions.

Straw of the cereals and field roots furnish an excellent ration for such cattle. Any class of field roots will serve the purpose. The straw may be fed separately and the roots also. When of large size, the latter should usually be sliced or pulped. Twelve to I5 pounds daily of roots for each animal will usually result in maintaining flesh, and will further tend to keep them in a good condition of thrift. Near sugar beet factories pulp may be obtained for such feeding, and usually at a cost so low 
as to justify making the pulp constitute a large part of the ration.

Corn fodder, corn stover, and sorghum fodder in its various forms will also furnish a suitable diet along with field roots. The amount of the latter called for is about the same as when feeding the straw of cereals mentioned above. But where sugar beet pulp may be obtained cheaply and conveniently, as much as, say, 60 pounds of the latter may be fed to each animal daily. When fed thus freely, the amount of fodder called for will, of course, be correspondingly reduced. Corn ensilage may take the place of roots, when feeding straw of any kind. In areas well adapted to growing corn, ensilage may be thus made to take the place of roots. It will furnish food more cheaply than roots, except when the latter is fed in the form of raw pulp, but the influence on the system will not be so beneficent.

Cottonseed hulls fed along with straw or corn or sorghum fodder is a satisfactory food for animals thus wintered. It may, under some conditions, be made to form a large proportion of the ration, thus making it possible to practice economy in feeding straw, should the latter be scarce. When the supply of coarse fodder is limited it is important that it shall be fed with little waste. Such a condition may confront the farmer or ranchman occasionally in any part of the continent, but it will be of more frequent occurrence where the conditions are semi-arid. Where this occurs, waste in the fodder may be largely, and, in some instances, wholly prevented by running the fodder through a cutting box, and mixing it with a limited quantity of meal. If the cut fodder has first been sprayed or sprinkled with water before sprinkling the meal over it, more complete consumption of the food will be secured. Preparing food thus may become the means of carrying animals through the winter that would otherwise perish.

When horses are maintained, and they usually are 
on the arable farm, cattle that are being thus yarded will turn to good account much of the litter that has been used in the horse stalls. Something has been imparted to it, probably, by coming more or less in contact with the urine that cattle relish. It has not been shown heretofore that any detriment follows from allowing yarded cattle to pick it over when ejected from the horse stable.

Cattle thus wintered may be made to utilize rejected portions of food that have been fed to other animals for production of some kind. Such rejected food may be found in feed lots where cattle are being fattened, in the mangers of cows giving milk, and in the mangers of work horses. While those rejected portions may be unsuited to the needs of the animals mentioned, they may serve a good purpose in feeding animals of the classes that are now being considered. That they may glean after cattle that are being fattened an additional yard will be needed.

Under some conditions the tops of beets and the rejected portion of the roots adhering to them may be profitably used in carrying cattle through the winter. Especially is this true where the snow-fall is light, and the winter weather is not usually severe. More commonly the tops are left in heaps in the field where they grew, and there the cattle are allowed to help themselves. When they are given access to straw in the forepart of the day and to the beet tops in the latter part. the ration will be cheapened and its consumption prolonged. To put straw to such a use is, of course, vastly better than to burn it, as is so frequently done in certain areas of the West.

The precise methods of feeding straw and stalks to those classes of cattle will, of course, vary. When the supply is limited, the cattle should not be allowed access to the stacks. If located in the yard, they should be protected by some kind of a fence, and not until they have picked over the straw put into the feed boxes from 
this source of supply should the residue be scattered in the yard for litter. When the supply is abundant, the stack or stacks, as in the former instance, should be within the yard inclosure. The cattle may then be allowed to help themselves. That which is trodden under foot, along with the straw that has been spoiled by rain, should be scattered over the yard at intervals and over the floor of the shed that may furnish them with protection. This not only furnishes a bed, but also promotes decay in the straw, and it makes manure more even in quality than it would otherwise be. Care must be taken, however, to cut down the sides of the stack if necessary, so that it will not be so undermined as to endanger the lives of the animals by falling on them. In cold climates, also, it will save labor subsequently by scattering over the yard such portions of the stack as have been saturated with rain before it congeals into a solid mass. Where straw is superabundant, as when it is threshed in the field, in areas much devoted to the growing of grain, it is labor-saving to allow the cattle to feed around the stacks until they are demolished. They will furnish considerable food and will also be transformed into farmyard manure, but which will not be of high grade. This will be done at a minimum of outlay for labor. Such a method of disposing of them is greatly superior to the more common method of turning them into ashes.

When corn fodder or stover is to be fed directly to such animals, and in feed boxes or racks, the aim should be, where cattle are yarded, to stack the stalks adjacent to the fence on the approach of winter and close enough to admit of pitching the bundles from the same into the feed boxes or racks when in place inside of the fence. Sorghum fodder will not usually keep well in stacks, hence it must be drawn as wanted from shocks or heaps in the field where it grew according to the method adopted in curing it. Corn ensilage, or, indeed, any kind 
of ensilage that has been chaffed before putting it into the silo can best be fed in feed boxes or in mangers in front of stanchions.

The method of husking corn from the stalk and leaving the stalks in the field, and storing the corn in cribs, is practiced over wide areas of this country, more especially in what is known as the corn belt. Cattle being wintered are allowed to graze amid these practically at will. This method of harvesting corn originated in the excess of stover grown over the needs of the animals kept on the farm and also in the scarcity and high wages of help. The practice has become so thoroughly established in certain areas that many years must elapse before it will be entirely discarded. Notwithstanding the reasons given above for the adoption of the practice, to its continuance there are the following objections: (I) It is wasteful of fodder, which, if harvested at the right season, would furnish excellent food. Only a small proportion of the stalk is eaten and not until it has lost much of its food value. (2) While gleaning amid the stalks, the animals are, in some instances, unduly exposed to inclement weather, which is so far adverse to well doing. (3) Such grazing is frequently dangerous to live stock. The hazard is present that they will succumb to what is known as "corn stalk" disease (see page 444), the cause or causes of which are but imperfectly understood. In many cases it acts fatally and quickly, and it would seem correct to say that under no other conditions does it arise, which would seem to indicate that it is produced by some influence that is only present in corn stalks when managed thus. (4) In wet weather some soils are much injured mechanically by such grazing.

Fodders that deteriorate with age.-The feeding value of some foods, as mangels, for instance, improves for a time after they have been harvested. But the instances of such improvement are rare. When they do 
occur it is not because of any increase in nutrients, but rather as the result of chemical changes in consequence of which they are more easily digested and assimilated by the animals to which they are to be fed. As a rule, foods begin to deteriorate as soon as they have become fully matured. The process is arrested in part by harvesting, but in no instances is it so completely arrested, unless when put into a silo, that the product becomes effectively resistant to decay.

With grain the deterioration is much slower than with fodders, and in some fodders it is much slower than in others. Corn fodders deteriorate more rapidly than the straw of cereals or than hay in any of its varieties. Sorghum deteriorates more quickly than corn. Deterioration is most rapid in such foods as pumpkins, squashes, and certain tubers, as sweet potatoes. Among field roots, some varieties deteriorate much more quickly than others.

Such being the fact, the aim should be to feed such foods first as deteriorate the most quickly. In this way a larger consumption will be secured than if the foods were fed later, as, in nearly all instances, deterioration brings along with it a lessened palatability in addition to the loss of food nutrients. This would mean that the feeding of sorghum fodders should begin as soon as they are mature, if needed then, that corn fodders should come next in order of use, and that hay fodders should, as far as possible, be reserved for later feeding. Fall turnips should be fed earlier than rutabagas, mangels, or carrots, as their keeping qualities are not equal to those of the latter.

Sufficiency of food in winter.-When carrying such animals through the winter, it is simply calamitous to have the foods fail before the season of abundance of grasses, hence the wisdom of laying in large supplies of food where this may be possible. Even though the supplies should be sufficient to maintain life in all the 
animals until grazing is abundant, if they are not sufficient to prevent loss of flesh, the financial loss is proportionately serious, since some time must elapse after grazing begins before what was lost has been restored. Short supplies usually follow dry seasons, hence, when it is desired to keep the farm stocked to its full capacity, should such seasons occur, the needed additional food supplies should be purchased in the autumn. Where these cannot be obtained without excessive cost, the herd should be so reduced by sale that its needs will not be in excess of the food stores that are available. The great advantage from purchasing supplementary foods in the autumn lies in the fact that, in nearly all instances, they can be purchased much more cheaply at that season than in the winter or spring following.

Under semi-range conditions losses from a shortage of food occur more frequently than under farm conditions. This arises from the more or less dependence on winter grazing in the former. Because of this reliance the supplies of food laid up are not enough to carry the animals through the entire winter, should its rigors be such as to preclude the possibility of supplemental winter grazing. Such an occurrence brings great loss to the owners of cattle, and the only way to make sure that it will not occur on the arable farm is to have a sufficiency of food on hand to carry the animals through the entire winter. Should there be a surplus of food, especially in the form of hay or straw, it may be used the following winter.

A shortage in food supplies for winter usually results from dry seasons or from winter weather of unusual length, but it may also result from weather excessively wet and from injudicious overstocking. The coming of dry seasons cannot be forecast, hence the wisdom, especially where such seasons are of frequent occurrence, of growing relatively large areas of crops that may be cultivated, as corn, since the cultivation 
given makes the crop much more drouth resistant. When foods are destroyed through excessive wet, if this should occur sufficiently early, catch crops promptly sown may sometimes be made to provide a sufficiency of fodder. But the only thing that can be done to meet prolonged winter conditions is to be prepared for them, either by storing up every autumn a sufficiency of food to meet the needs of the animals, should such a winter occur, or by keeping the farm or ranch under rather than overstocked. Overstocking, in all instances, means diminished returns.

Of course when it is evident at the approach of winter that food supplies will probably be short, measures may be taken to make the most of them by securing their complete consumption through the entire winter. These measures have already been discussed. (See page I45.)

Improving the ration as winter advances.-When cattle are first taken in from the pasture they are usually in a good condition as to flesh, and they are also possessed of a corresponding degree of vigor. They are able. therefore, to turn to good account foods that would be less suitable for them toward spring. As the winter advances the tendency is in the direction of lowering the vital energies, including the functions of digestion and assimilation. The aim should be, therefore, to feed the less palatable and less nutritious foodstuffs first. and to supersede these gradually by foodstuffs of better quality. But this aim should never be carried to the extent of causing the animals to lose flesh in any material degree at any time during the winter. To prevent this when feeding the inferior foods it may be necessary to feed at the same time a certain proportion of the better class of food or foods.

To illustrate: Suppose the feeder has on hand, when the winter begins, such foods as sorghum, corn fodder, stover, silage, or field roots, hay, and grain. Sup- 
pose at the same time he is not so situated that he can cut the fodders or otherwise prepare them for feeding. He should begin by feeding the sorghum. This should be followed by feeding corn. The feeding of the straw of cereals would accompany the feeding of the other products, the straw being fed one end of the day and the sorghum and corn the other. Later would come the feeding of hay, the inferior being fed first and the better class later. In some instances it may be advantageous to mix the hay and straw cut or uncut in order to insure a greater consumption of the latter. The feeding of the roots or silage should, if possible, be made continuous, and so fed that the quantity will be gradually increased with the advance of winter. As feeding grain all the winter would unduly enhance the cost of wintering with this class of animals, it should generally be reserved for feeding toward spring. Were this process reversed by feeding the better foods first the results would not be satisfactory.

Feeding cows forward in pregnancy.-Cows well advanced in pregnancy should be well nourished while being thus wintered during the non-producing period. (See page 96.) While it will be to their benefit to have the freedom of the yard, it may be necessary to give them additional food at least once a day, apart from other animals, which also may have the freedom of the same yard. To allow them to fall away in flesh would proportionately lessen production when they are again in milk.

Pregnant cows should not occupy the same yard with animals undehorned, lest injury more or less serious should result from the goring by cattle thus armed. Nor should they be allowed to occupy the same yard with horses or colts. They will be liable to injury from the former through being kicked, and from the latter through being chased while the colts are taking exercise, simply because they are colts. 
238 THE MANAGEMENT AND FELDiNG OF CATtLE

It would not be wise to allow such cows to remain in the yard right up to the time of parturition, unless in instances that are exceptional. Several days before calving they should be taken to other quarters and cared for according to their especial needs. (See page 210.) 


\section{CHAPTER XII}

\section{FOOD FOR MILCH COWS IN SUMMER}

In this chapter the discussion of the foods for milch cows in summer includes the following: (I) Grazing for cows; (2) Changing from the stables to the pastures; (3) Feeding grain when on pasture; (4) Soiling food for cows; (5) Ensilage for summer feeding; (6) Feeding soiling food to cows; ( 7 ) From the pastures to the stables; and (8) Carrying power of pastures.

Grazing for cows.-Where suitable grazing can be furnished it usually becomes a cheaper source of supplying food nutrients than either soiling food, cured fodders, or concentrates, since the element of labor in preparing it for cows is almost entirely eliminated. Prominent among the chief requisites in a pasture for cows in milk are: Succulence, nutrition, palatability, continuity in growth through much of the season, and abundant growth. The degree of succulence is much influenced by the weather and the habits of growth in the plants and, therefore, can only be partially controlled. The nutrition is chiefly influenced by the inherent constitution of the plants, and the same is true of the palatability, but the latter is also influenced by the weather and the closeness of the grazing. All pasture plants decrease much in palatability if allowed to form seeds.

Continuity in growth is determined in part by the inherent characteristics of the pasture plants, by the blending of these when laying down the pastures, by the weather, and by the treatment of the pastures with reference to grazing and fertilization. The abundance in the growth present is determined by the producing power of the land and the closeness of the grazing. It 
will be observed that all these influences, save that of the weather, may be modified by the owner of the pastures whenever they form a feature of the rotation. It is different in rugged lands where nature unaided has produced the pastures.

The plants grown to provide pasture for cows are very many. They include virtually all the grasses, whether cultivated or growing without the aid of man, and all the clovers. In addition to these pastures, in certain areas supplemental pastures are furnished that are of temporary growth. They are grown, as it were, after the manner of catch crops and to furnish grazing when it is not sufficiently present from other sources. These crops include the small cereals sown alone or in admixture, and such legumes as cowpeas, soy beans, and vetches. In many instances, they are grown on land that would not otherwise be producing.

The best pastures, viewed from the standpoint of production, are those grown on lands that may be irrigated during the season of growth. These include pastures composed of clover or alfalfa and are found in greatest perfection in the western mountain valleys. But when alfalfa is thus grazed and also clover, but to a considerably less extent, it is necessary to sow along with these some grass plant, such as Russian brome or timothy, to eliminate the element of hazard from bloating. The amount of grazing that may be obtained from these is relatively exceedingly large. They also include pastures composed of a variety of grasses and are more or less permanent in character. They are usually made on moist lands, and the variety in the plants gives continuity in growth during the season. Permanent pastures are discussed at length in the book, "Grasses, and How to Grow Them," by the author. Bluegrass furnishes excellent grazing for cows early and late in the season, but it ceases to grow in summer. Russian brome 
in northwestern areas has proved a valuable grass for prolonged grazing.

Among the plants that should not be grazed by cows in milk, unless but for a short period after they have been milked, are rape and rye, because of the adverse influence on the quality of the milk. Nor should the sorghums be grazed by cows under some conditions, notwithstanding the abundance of the grazing that they furnish, because of the hazard that is sometimes present. Especially is such hazard present in second growth sorghum after periods of drouth, which seem to favor the concentration of a poisonous element in the plants that frequently proves fatal to the animals grazed on it.

The best pastures for cows in New England are those permanent in character and furnished by moist lands lying in the basins of rivers. The best pastures westward from New York to Dakota, and including the provinces of Ontario and Quebec, are the clovers and Kentucky bluegrass. The common red variety is the best pasture plant among clovers because of its continuity in growth. Those pastures most in favor at present in the Dakotas are Russian brome, with clover coming more or less into favor. The pastures most in favor in the northwestern provinces of Canada are Russian brome and timothy. Those highest in favor in the northern mountain valleys are clover under irrigation, and in inland Washington and Oregon alfalfa and orchard grass grown together. On the far Pacific slope, north from California, the grazing is about the same as in the central states. In the central states, both east and west, the clovers and bluegrass are the favorite pasture plants, with cowpeas as a supplement. In the Gulf states, Bermuda grass is the standard summer pasture. In the central and southern states of the western mountains the best pastures are furnished on irrigated lands by alfalfa, clover, and some grasses, as brome, grown with these legumes. 
From stable to pastures. - That the grazing shall be reasonably abundant before turning the cows into it will be apparent. Even with store cattle, it would not be prudent to begin grazing when grass is so lacking in growth that excessive exertion by them to sustain vigor would be called for. Much more would it be a mistake to allow cows in milk to thus expend energy that should be used in making milk, to say nothing of the injury that would come to the grass, especially on certain soils, from treading when the ground has not become sufficiently firm, and from too soon removing the blades through which the plants breathe. The proper time when grazing should begin cannot be determined by any fixed rule. Seasons sometimes vary fully three to four weeks in earliness or lateness, and the pastures are correspondingly affected. The time is to be fixed rather by the condition of growth in the grass. The wisdom of turning cows onto grass before it is higher than one's shoetops is questionable, unless when done under the constraint of short fodder supplies. Winter rye may be considered an exception to the above when the supply is relatively large, as unless kept grazed down reasonably close, it soon forms heads and becomes of little value for grazing with cows.

It is specially important with cows in milk that the change shall be gradually made, as with them any check in the flow of milk affects future production adversely. But, it may be asked, does not fresh grass tend to increase the flow of milk? Under normal conditions it does, but when the change from stable to pasture is suddenly made, it produces a lax condition in the digestion, which, in some instances, is so pronounced that it almost amounts to purging. When thus affected the cows will soon lose flesh, even though they should advance somewhat in milk-giving, and this means loss in milk production sometime in the future. The stables 
-) yards where the milking is done are also made more or less offensive at such a time.

The method of making the change will be in outline as follows: (x) The cows will not be turned out until after the food in the morning has been sufficiently consumed. The appetite will then be less ravenous for the new grass. (2) They will be left out for an hour or two the first day, and the time will be increased as prudence dictates until they may remain out all day. (3) Th time called for to effect the change should never be less than one week, and will seldom necessarily cover more than three weeks. (4) As soon as the change begins, the reduction in the succulent food, as ensilage and field roots, should also begin, for the reason that the influence which these exert on milk-giving is less needed. Whether the reduction should continue until none is fed by the time the change has been completed will depend on the use to which these can be put subsequently. (5) The dry fodder given should be continued morning and evening as long as the cows will eat it, and if fodder of high quality, such as wellcured clover or alfalfa hay, has been saved for such feeding, they will eat more of it than would otherwise be consumed. No kind of food will be more helpful in lessening the tendency to scouring than dry fodder. (6) There should be some reduction, and it may be modification, in the grain fed as described below.

The extent to which the grain shall be reduced will be influenced somewhat by the abundance of the pasture supply. When pasture is abundant, there should be decrease, as grass is cheaper than grain as a source of milk supply. But it may not always be prudent to begin the reduction in the grain as soon as grazing begins. For a short time, a full supply may be necessary to prevent loss of flesh from laxity in the digestion. Whether the reduction should be total is discussed in the subdivision that follows. The extent to which modifica- 
tion in the constituents of the grains may be necessary will depend on the character of the pasture. Should the pasture be composed wholly or mainly of the grasses proper, a protein concentrate, as wheat bran or cottonseed meal, with a small amount of carbonaceous concentrate, as corn, should be fed, but should the pasture be mainly or wholly clover, then the portion of these should be reversed.

Feeding grain when on pasture.-Whether cows should or should not be fed meal when grazing on succulent and abundant pasture is yet an undetermined question. The best dairymen differ in their practice in this respect. More commonly, however, no grain is fed while the grazing conditions are as stated above. This fact would seem to indicate that it is not so fed from the cherished belief that it does not pay to feed it. It is possible, however, that where this belief is held it has only considered the direct returns from the grain in milk, without having sufficiently considered other effects to be mentioned below.

The considerations that arise in the effort to determine this question are of so elusive a nature that it is scarcely possible to arrive at conclusions that may be regarded as final when sitting in judgment on them. If it were only a question of increased milk production in relation only to the cost of the meal fed, the problem would be easy, but in addition are the influences exerted by the previous feeding of the cow and by the residual effects from feeding grain on future production. The saving effected in the pasture and the added fertility must also be considered. That a cow turned onto pasture in a lean condition of flesh would profit more from grain fed on abundant pasture than one in a good condition of flesh, would seem reasonable, even in the absence of determining proof. That the grain fed does tend to increase future production has been determined with at least reasonable certainty. That some saving 
will be effected in grazing and that some fertility will be added to the pastures from feeding grain is selfevident. It will be equally apparent, however, that the exact measure of the influence exercised in each of these several instances cannot be reached.

The following conclusions regarding the question would seem safe: (1) When cows are fed grain when on pastures succulent and abundant, the tendency of such feeding is to increase the yield in the milk given. (2) The tendency in such feeding is also to promote some increase in flesh production. (3) The quality of the milk is not materially influenced by such feeding. (4) The residual effects from such feeding are considerable. These effects are usually shown in two ways: first, in building up the system, as it were, through increase in flesh; and, second, by increased subsequent production in the period of lactation that immediately follows. It has also been demonstrated that grain fed to heifers in milk, of yet uncompleted growth on such pastures, resulted in securing a more perfect growth than where it is not so fed. (5) Some saving will be effected in the pasture. While the amount of such saving is not easily determined, it is about certain that such saving will nearly equal the value of the grain fed, as pasture is relatively cheaper than grain. (6) The resultant fertilizer from feeding grain should have a tangible value. This value will be proportionate to the quantity of meal fed and to the fertilizing nutrients in the same. The increase in direct milk production, therefore, from feeding grain, tells but a part of the benefit from such feeding and probably not the most important part.

In the present status of this question, the following would seem to be a judicious course to pursue: When the pastures are succulent and abundant, and where the probable supply of the pasture is ample, omit feed grain from the time that the change from stable to pasture 
has been completed until the pastures begin to fail, either through shortage or lack of succulence. But should the prospective supply of grazing be short of the needs of the cows, continue to feed grain, but in as small amounts as, say, 2 to 4 pounds daily, and when the feeding of ensilage is continued, the grain should be fed on the ensilage. Corn meal and wheat bran or corn and cottonseed meal make a very suitable grain food, less corn being fed when the grasses proper are grazed and more when the clovers are grazed. It is probably never advantageous to feed large quantities of grain to cows in milk on pasture, because of its relative dearness. If grain is not fed when grass is flush it will usually be necessary in the northern states to begin feeding it again, say, in September, or later, according to the season.

Soiling food for cows.-Soiling food means any green food grown for cows to be cut and fed to them in the green form. It should be made to supplement the pastures as soon as they fail to furnish plentiful supplies of food, and also when they lose their succulence, even though still plentiful. Pastures may be abundant and yet not suited to abundant milk production because of lack of succulence. Such is the condition of bluegrass pastures in dry summers at that season of the summer when these cease to grow and of native prairie pastures as summer wanes. The soiling food is intended to furnish the element of succulence required for milk production as well as the elements of maintenance and production. In some instances the feeding of soiling foods is continued through the entire season of grazing, but more commonly only onward from the time that the grasses lose their succulence.

Soiling foods are valuable in proportion, first, as they are palatable; second, as they are abundant in growth, and also nutritious; third, to the feeding period during which they remain succulent; and, fourth, as they 
are rich in protein. Alfalfa fulfills these conditions taken together more profitably than any other single plant, hence, where it may be grown successfully, it is king among soiling foods that are cut and fed from day to day. With a sufficient area of alfalfa grown under favorable conditions, no other soiling food would be necessary. It is highly palatable, produces crops in succession, is sufficiently succulent, and it is rich in protein. Next to alfalfa comes corn, which, though not high in protein, produces more abundantly than any food grown over so wide an area.

The list of soiling foods is a long one in the aggregate. Among the small grains it includes winter rye, oats and peas, and oats and vetches grown together, millet in several varieties, cowpeas, and soy beans. Among grasses, it includes perennial and Italian rye, especially the latter, and among clovers, alfalfa, the medium red, the mammoth, alsike, and crimson varieties. It embraces corn of many varieties, and also the sorghums.

Winter rye is first ready, but it is not specially palatable, and becomes woody at an early stage of growth, and the yield is not large relatively. Oats and peas, and oats and vetches furnish a large amount of food per acre, but they should only have enough oats in the crop to prevent it from lodging. Millet yields well in a good soil, and is much relished. Cowpeas are good, but are not easily handled, and soy beans are not relatively high in the bulk furnished. The rye grasses, especially the Italian, will produce several cuttings a year when grown under irrigation in mild latitudes. Alfalfa will yield from, say, two to eight cuttings, according to the attendant conditions of growth. The common red clover will ordinarily produce two cuttings and the other varieties named but one. Crimson clover comes very early in the season. The large varieties of corn are usually preferred, and among these the large 
sweet varieties are high in favor. Sweet sorghum will produce from one to three cuttings a year, according to the conditions under which it is grown. But one cutting of the sorghums, saccharine and non-saccharine, are taken in a year, when grown under dry conditions.

The list may be further extended, but those not included are of minor importance, viewed from the standpoint of American conditions. Those who desire to carry further the study of soiling foods are referred to the book, "Soiling Crops and the Silo," by the author. Corn fed as ensilage is eminently adapted for such feeding, so much so that an entire subdivision will be devoted below to its discussion.

To provide these in a proper succession will call for the exercise of forethought. Some of the crops named may be sown at different times, that is, the same crop may be sown at successive periods with a view to prolong the season of feeding in the same. Such are peas and oats, and corn. In Canada and the northern states, among the most suitable soiling crops are peas and oats, and corn. In the southern states, the most valuable are alfalfa, corn, and sorghum; in the mountain states of the West, alfalfa; and in the Pacific coast states, oats, vetches, and rye grass.

However good the pastures may be, more or less of soiling foods will be wanted in a well-ordered dairy. It is the part of wisdom, therefore, to make provision for growing these so that they will be abundantly available when needed. Should the weather prove so dry in summer that the pasture supply proves inadequate, in the absence of soiling food the production of the cows is not only lowered proportionately, but it will also be less when food supplies become abundant again than it would otherwise be. During dry seasons, the crops that are cultivated while growth is advancing are the safer ones to grow to supply soiling food, since, because of the cultivation given to them, they suffer less from drouth 
than other crops, hence there is wisdom in growing more or less of such crops every season. It may be possible to obtain a full yield of corn, for instance, in a season so dry that the yield obtained from peas and oats grown together would be very light.

There are some soiling foods not enumerated in the list given above, the value of which is in a sense problematical. These include rape, the tops of field roots and the leaves of cabbage, after the heads have been removed. They are eminently suited to the production of milk, but to feeding them there is the objection that when fed in large quantities they taint the milk. This is less true of cabbage, but should the cows be allowed to graze where the cabbage grew, the consumption of partially decayed leaves may result in an undesirable flavor in the milk. Such foods may be fed in limited amounts if fed as soiling food rather than as pasture, and given after the milk has been taken from the cows. In a small dairy, or by the householder with but one cow, these foods may be best utilized. The labor of handling them is too much relatively to encourage feeding them extensively.

The importance of growing soiling food by the dairyman cannot be easily over-estimated. When it is abundantly present, it is not usually absolutely necessary to feed grain, although grain may be fed at the same time with advantage, in some instances, in order to balance what may be lacking in the soiling food. For instance, should corn or corn ensilage be fed with grass, it may be advantageous to add to the protein in the food by feeding wheat bran. As a rule, it can be provided by the dairyman much more cheaply than grain, especially by those who are not entirely dependent on outside labor.

Ensilage for summer feeding.-The feeding of ensilage as soiling food is growing rapidly in favor. It has been found well suited to the needs of the stock, 
and it may be cheaply provided. It may be conveniently fed and the supply may be assured, as the crop is grown the previous year. In order to feed it to the best advantage a summer silo should usually be constructed, adapted to such feeding as described below.

The suitability of ensilage for providing soiling food consists in its containing essentially the same nutrients and the same properties as green corn fed from the growing crop. In one respect, it is usually superior to the latter, being richer in nutrients, as it is usually cut at a more advanced stage of growth. It also consists in its palatability when it is well preserved. It has been noticed that cows while grazing on the best of pastures will, at the same time, consume a considerable quantity of ensilage with a relish, if given access to it. There is something about well-preserved ensilage which commends it to the appetite of cows.

That ensilage may usually be furnished more cheaply than other soiling food will be apparent from the fact that it is stored, as it were, in a wholesale way. The food is put into the silo at a small outlay, when thus stored, compared with the cost entailed by the labor necessary to cut and draw the equivalent in soiling food from day to day from the growing crop. As the cows must be brought from the pastures at milking time, the ensilage may also be very conveniently fed to them in the stall. If additional meal is given it cannot be more advantageously fed than by strewing it over the ensilage in the manger. Such feeding does not call for the use of any horse power in the summer when such labor may be pressing, and it effects a great saving in the amount of time occupied daily in the feeding. The cost of constructing the silo should not be overlooked, but if well built of concrete, it should last almost indefinitely, hence the proportion of cost to be charged against any one season would be small.

In order to provide summer silage in the best man- 
ner possible, it is, in a sense, necessary to have a silo built and reserved for such feeding. This is necessary for the reason that the amount fed daily is small compared with the amount fed in the winter, consequently the amount taken from a silo that would be suitable for a herd in winter would not take enough ensilage from the silo daily to keep the ensilage in perfect condition. The loss of succulence in ensilage increases with the amount of surface exposed and the slowness with which the food is fed out. Of course, when feeding from a winter silo, a section only of the whole surface may be fed down at one time, but, in such instances, more ensilage is lost by decay from the exposed side than when the whole surface is fed from.

When a separate silo is built for summer feeding, it should be of much less size than the silo for winter feeding, as the quantity of silage to feed in summer is usually much less than the same in winter. The decrease should relate to width more than to depth, for reasons that will be apparent from what has been said above. Where ensilage is fed, especially in northern latitudes, as intimated previously, the winter silo may be made to furnish food from, say, October I to May I. During this time it will frequently be in order to give the cows all that is prudent to feed of such food for a prolonged period of winter feeding, and this amount has been put at 40 pounds daily. (See page 266.) It would follow, therefore, that the summer silo would only be drawn upon during the intervening months, that is, during five months. While the amount fed will vary, it would probably be correct to say that not more than 25 pounds daily will be required for summer feeding. The number of cows being known, therefore, the size or the silo needed may be readily computed from the probable yield of the corn.

Feeding soiling food to cows in summer.-The feeding of soiling food to cows and the methods of feeding 
it are determined by the attendant conditions. These conditions are such as relate to feeding in the stall or in the pasture, the mode of harvesting the food and conveying it to the stock, the stage of growth when the feeding may begin, and if it shall receive any special preparation before it is fed.

When cows are fed ensilage as soiling food, it is, of course, fed in the stall. It may also be convenient to feed other soiling food thus or to feed it in a rack in the milking or feed yard. More commonly, however, it is fed in the pastures. When thus fed, it is simply drawn and strewn over the same, changing the place of feeding every day that the food may be less soiled while being eaten. The labor involved is usually less than in feeding either in the manger or rack in the yard.

When much food is fed, it is cut from day to day, or enough may be cut to last two days, when the weather is not too hot and dry, as mild wilting does not lessen the palatability of the food. When but a small amount is fed, it is cut with the scythe. Where much is wanted, a two-horse conveyance will be needed. A wagon or truck on which the platform or rack used is relatively low will save much labor in the loading of the food, which, because of its greenness, is heavy to handle, but it will probably add to the draught in conveying the food to the place of feeding. When but a small amount is fed, it has been customary with many to grow the soiling food in a field adjacent to the pasture. A narrow strip alongside of the pasture is devoted to such growth. When feeding the food, it is made accessible to the cows by simply cutting it as wanted and throwing it over the fence into the pasture. When the weather is rainy, the feeding of soiling food, in all instances, on time, may not be easy, and the labor involved in handling it is increased.

No hard and fast rule can be fixed as to the time when the feeding of the food may begin. Where more 
than one cutting is made this question is of much less importance than when growth ceases when the crop is cut. In the former instance what has not been secured in one cutting may be in the next, whereas in the latter the food that would have been furnished by subsequent growth would be lost. With these the aim should be to have growth well advanced before beginning to feed the food. It would not be practicable to give a general rule that will more correctly apply than that which would defer cutting alfalfa and all kinds of clover until the first blooms begin to show; Canada peas, vetches, cowpeas, and soy beans, when the first pods are formed, the other small grains, and millet, when coming into head. The cutting of corn may begin as soon as it comes into tassel, if absolutely necessary to feed it so early, but the food contains much more nutriment at a later stage of growth. When sweet sorghum is cut but once, and also the nonsaccharine sorghums, the aim should be to defer beginning to cut until the crop has produced heads. The feeding of all these crops as soiling food may be continued until they approach very near to the ripening period. Should there be an excess of these over the needs of the stock, such excess may be harvested at maturity and reserved for later feeding. If rye is fed, it should be cut, as a rule, before it is in head, as when it reaches the heading stage it has lost much of its palatability.

Usually no labor is expended in preparing the food for feeding by such methods as running it through a cutting box and mixing it with other food. Such labor under existing conditions will not, as a rule, repay the outlay. However, the statement that there are no instances in which it would be justifiable would not seem warranted, especially when meal is to be fed to give balance to the ration.

From pastures to stable.-The change from pastures to stable will be gradual, as a rule, on the well- 
known principle that the digestive powers cannot at once accommodate themselves to changed conditions. It is fortunate that it is so. More commonly the change begins by housing the cows at night, while they still have access to the pastures in the day. For a time it may not be necessary to house them in winter quarters, but simply to provide them with a well-littered shed to lie in overnight, giving them access at the same time to a rack filled with some kind of suitable fodder. The chief benefit of such a plan over keeping them in their proper winter quarters is in the saving of labor that results, but if meal is fed at such a time it will be necessary to confine them to stalls long enough to allow them to consume it

Injury from cold and storms at such a season is less easily overcome than if it occurred when changing from winter quarters to the pastures, for reasons that will be manifest. The milk-giving function in cows is easily influenced adversely by cold, hence exposure to cold at night beyond a certain degree will cause shrinkage in the milk several weeks earlier than such a result will follow from grazing during the day only, because of the marked difference in the mean temperature between the days and the nights at that season. The degree of cold that will produce shrinkage can be at once detected by the fact of the shrinkage, if in no other way. But it is better to anticipate any shrinkage by providing timely shelter at night. Cows in milk should not be exposed to a night temperature which lowers to the freezing point. They should be protected from cold earlier at night than cattle being fattened, since the latter are being fed on more heat-producing foods. It is even more important that the cows shall be protected from cold autumn rains. Each instance of such exposure may cause shrinkage in milk-giving for several days subsequently.

When on pasture in the autumn, soiling foods may 
be fed frequently that are possessed of less succulence than would suffice at an earlier period, as in the autumn the pastures are usually more succulent than in the summer. Where corn and sorghum are freely grown, they furnish excellent food with which to supplement the pastures. At that season the corn will be fed from the shock, and the sorghum from the shock or cock, according to the mode of harvesting. Corn grown for the purpose, and which has produced leafy stalks and not much coarse, and without great store of ears, furnishes food that is highly suitable. The waste from feeding corn will not be very much. It is important also that the sorghum shall not be coarse, and it is especially important that both shall be harvested promptly not later than the early stage of the ripening. Both are usually most conveniently fed in the pastures.

Pumpkins are sometimes also fed at such a time by strewing them over the pastures. To enable the cows to eat them it is necessary that they shall be broken open, but it is not absolutely necessary that they shall be further cut into small pieces. The popular view that the seeds, if consumed, are adverse to milk-giving is not sustained by experience. The supply of pumpkins is frequently limited. When on hand, much less labor is involved in feeding them thus than if they were gathered near the stables and fed at a later period.

As soon as the cows are put into winter quarters at night, the feeding of concentrates should begin if it has not begun sooner. More commonly in practice it will begin as soon as the cows are removed at night from the pastures. The kind of meal to feed and the amount will depend on the character of the grazing and the supply and nature of the soiling food, as the grazing then furnished is usually furnished as grass, rather than by leguminous plants, and as it is almost certain that the soiling foods fed will also be non-leguminous, the meal fed under such conditions should be rich in protein. The 
quantities to be fed cannot be named, so varying are the conditions, but they should be enough to maintain, first, an undiminished milk flow, and, second, adequate flesh in the cows. Any considerable loss from either source would be more harmful at such a time than at other seasons, occurring, as it were, on the advent of the most trying season for the maintenance of undiminished vigor and production in the cows. In winter dairying, the maintenance of both at such a time is especially important.

Carrying power of pastures.-The carrying power of pastures is not of easy determination. That this is true will be readily manifest, when the factors that lead to variation in the nutrients as to kind and quantity that the pastures furnish are considered. These factors include a difference in soil, variation in the varieties of grass, a difference in climate and season, and a difference in the management of the pastures. Notwithstand. ing, information that would throw light even approximately on the carrying power of pastures in the individual states, and on the production that may reasonably be expected from them under normal conditions, would be helpful to dairymen.

Such a problem is certainly within the field of experimentation. Considerable light has been secured through experiment as to both the carrying and producing power of pastures when growing beef, hence it should be possible to work out the same when producing milk. The information would be valuable that told which grasses in certain states could be relied upon to bring maximum production in milk. It is probable that medium red clover would be found king among the grasses in milk-producing power, because of its high protein content and its continuity in growth through the growing season. In the judgment of the author, the production in milk from an acre of clover pasture on irrigated land in the mountain valleys of the West 
would be, in a sense, phenomenal. It would be a guess to state the area of pasture that would properly carry a cow in milk through the season, the elements that may lead to a variation are so many. In areas northward, the opinion is common that two to three acres of Kentucky bluegrass are necessary to carry a cow properly through the summer. It would seem reasonable to expect, however, that where permanent pastures mixed in character can be grown, they could be so managed that one acre would sustain a cow through the grazing season. Where this can be done with cows well chosen, a rich return would result to the dairyman.

Because of the great variations in the carrying power of pastures in different seasons, the aim should be to have them in excess of the needs rather than short of them. If the assumption is true that grazing under existing conditions can be more cheaply furnished than other food to cows in milk, the importance of such an aim is emphasized. A shortage in the grazing means a lessened producing power in the pastures and a needless expenditure of energy on the part of the cows when grazing. An excess in such grazing is by no means all lost. It serves as mulch, which usually tends to increase subsequent growth. Happily the shortage may be met by furnishing soiling food. But, unless the latter can be furnished more cheaply and more suitably than grazing, it would not be prudent to grow it with a view to reduce beyond a reasonable limit the area of grazing. But, as labor becomes cheap, relative increase in soiling food and decrease in the grazing area becomes justifiable.

The producing power of pastures for cows in milk, as for other stock, may be greatly increased by the way in which they are managed. Their power to produce is decreased by close grazing, by the increase of weeds, and by the loss of succulence. The first and second of these infiuences may be almost entirely prevented by the exercise 
of sufficient forethought, but the third cannot, as it is the result of weather conditions. Their power to produce is increased by the lack of close grazing, by trimming down weeds and grass that have reached the heading stage with scythe and mower, and by dressing with fertilizers, commercial or home-made, or with both. The most productive fertilizers on such pastures are those which act both as a mulch and a fertilizer. This, in one of its best forms, is found in fresh farmyard manure applied in the autumn or winter. 


\section{CHAPTER XIII}

\section{FOOD FOR MILCH COWS IN WINTER}

In the discussion of this question the following points will be considered: (I) The nature and kinds of fodder fed; (2) Nature and kind of succulence given; (3) Nature and kind of concentrates used; (4) Amount of concentrates to feed; (5) Preparing and blending the foods for feeding; and (6) Most suitable winter rations fed in the various localities viewed from the standpoints of economy and effectiveness.

Fodders for feeding.-It would seem correct to say that, viewed from the standpoint of suitability, hay from the legumes alone or blended with some of the grasses, stands first in suitability for milk production; that after these come certain grain fodders; next in order are fodders from corn and the sorghums; after these is hay from the grasses and millet, and lowest in suitability is straw of the small cereals. Viewed from the standpoint of economy only, the above order may not hold good in all instances, owing to the abundant relative production of corn and the sorghums.

That legumes stand highest among fodders in suitability for milk production cannot be gainsaid. The question as to whether alfalfa, the clovers proper, cowpeas, soy beans, and vetches will produce the largest milk yields when fed as the sole fodder, has not been fully determined, but that alone, of course, should not determine which of these shall be fed. The determining factor is the ready adaptation to the conditions for growing and curing them, and the relatively low cost at which they may be furnished. Viewed from these standpoints, alfalfa will take first rank where it will grow well on irrigated land, owing to the number of cuttings ob- 
tained yearly and to the perfect condition in which it may be cured in regions with little or no rainfall. The clovers, however, will be fed over much wider areas, because of a wider adaptation possessed by these. Of the varieties of clover, the common red and the alsike take first rank for such feeding. They have less coarse stems than the mammoth and crimson varieties, and they are much more productive than the other varieties, as the small white and the Japan.

The value of alfalfa and the clovers for milk production is greatly influenced by the time for cutting them, and by the way in which they are cured. Alfalfa should be cut for such feeding when a small percentage only of the blooms have appeared, and the clovers when coming into full bloom, a trifle short of that stage rather than beyond it. These fodders should be secured so as to retain a green rather than a brown color, and entirely free from mustiness or mold. Thus prepared, these foods would suffice without any concentrates were the cows able to consume enough of them to insure maximum production, which they cannot because of the bulkiness of the foods. When fed, however, in the condition stated, the amount of concentrate to be added is relatively small. (See page 278 .)

Theoretically, these plants should be fed without admixture with any of the grasses, as the latter rank lower in protein and therefore lower in value for milk production, but in practice there may be good reasons for having more or less grass, as timothy, for instance, in the clover. Its presence may tend to prevent the clover from lodging to an extent that would injure it for feeding, and it also aids in the quicker curing of the hay when it is cut.

The other legumes mentioned are much more circumscribed in their growth, but each of them has its place in the economy of milk production. Usually more labor and cost is involved in growing and curing them, 
but, in certain areas, they may be grown in seasons when the clovers may have failed and in localities where they may not be grown.

Certain grain fodders have been made to furnish excellent hay with which to supplement hay from grass and clover. Prominent among these are oats alone, oats and peas, and in the South winter oats and vetches. These are so grown that usually they may be harvested with the grain, and they are cut just a little short of maturity. When the legume is prominently present in such hay it greatly improves it as a fodder for milk production.

Fodder furnished by corn or sorghum may usually be furnished more cheaply than other fodders. When grown so that the stalks are fine and leafy, and when cut just when nearing completed maturity and well cured, such fodder is excellent for milk production when fed with suitable concentrates. If the corn fodder has nubbins, its value in proportion to the bulk is improved, but even when grown so thickly as to preclude the development of nubbins, such fodder will be found excellent for milk production when well cured. The aim should be to feed the sorghums in the autumn and early winter, and the corn so that it may be supplemented by other hay when the winter is past, as later than the time specified, in each instance, for feeding these foods, they deteriorate. The value of corn fodder finely grown as a milk producer has probably been underrated by many who have discussed this question and who have based their opinions mainly on the chemical analysis of such fodders.

The value of hay made from the grasses proper in producing milk is much dependent on the fineness of growth in the variety, on prompt and careful harvesting at early maturity, and on the avoidance of excessive curing. Timothy hay, for instance, cut at early ripening and cured so as to preserve the green color makes 
reasonably good fodder for milch cows, but if coarse in growth, cut over-ripe and also over-cured, it is little if any better than straw of some of the cereals. The value of hay from the leading grasses, as timothy, Russian brome, and those furnished by the yet unbroken prairies, are not greatly different in their value for producing milk.

Straw from some of the small cereals is so unsuited for milk production as to be virtually without value for such a use when fed directly. Such are rye and wheat straw. Oat straw is valuable when well saved, and pea straw, bright and good, is of still higher feeding value. For feeding directly none of these is much used by dairymen, but when run through a cutting box and mixed with cut hay in quantities not too large, they may prove helpful when the supply of other and better fodders is limited.

When feeding for milk, and foods must be purchased to bring the feeding into approximate balance, it is more legitimate to secure concentrates that will accomplish this than to secure coarse fodders. The latter are too bulky to be transported to any considerable distance without undue relative cost being incurred. In other words, the aim should be to make the concentrates rather than the fodders bring the food ration into approximate balance.

It should also be noticed that the coarse fodders are fed to cows in milk up to the limit of their capacity to consume them after they have consumed the other food given. The grain fed and the succulent food when it is fed are given, first, in quantities that are limited, after which the coarse fodders are fed without any other restriction than that mentioned above.

Nature of the succulence.-The necessity that exists for feeding more or less succulent foods to cows in milk if maximum results are to be reached is recognized by all dairymen, however they may differ in their views as 
to the kinds of succulence that will best serve the ends sought, and as to the quantities that should be fed. Whatever may be the explanation, it is a fact that an equal amount of nutrients fed in the dry form will not result in producing milk yields so large as when a part of the food is fed as succulence. This explains why the milk yields from cows put out on good pasture naturally increase, whereas those from cows changed from succulent grasses to dry feed will almost certainly grow less. The necessity, therefore, on the part of those who keep cows, to make provision for a supply of succulent food all the year, is ever present.

Foods that furnish succulence, of course, differ much in suitability and consequently in value for such feeding. They should be helpful to the digestion and should produce no objectionable flavor in the milk. Those are best suited to the purpose which exert a markedly beneficial influence on the digestion. This alone, however, is not a sufficient ground of preference, as the item of cost in providing it may be relatively too much. In the favorable influence exerted on digestion, field roots are superior to corn ensilage, and yet the latter will doubtless be more used in all time in the United States in furnishing succulence for cows in milk, since it is more cheaply furnished. The objectionable flavors which rutabagas, turnips, and rape produce when fed, without careful discrimination, are much against their use in milk production. The degree of maturity at which succulent food shall be harvested is even more important than in the case of dry fodders. This is abundantly shown in the greatly superior value in corn made into ensilage that approaching maturity brings with it.

The plants that may be made to furnish succulence for the winter feeding of dairy cows are happily numerous. They include in corn all important varieties, sorghum of various kinds, all the legumes grown when cured in the green form, and field roots. In some in- 
stances, tubers also are fed as potatoes and artichokes. The feeding of legumes in the green form does not grow rapidly in favor, owing, probably, to the greater amount of nutriment an acre that can be obtained from corn, and that the quality obtained from it is frequently superior. Potatoes, though never grown directly to furnish succulence for cows, are sometimes fed to them when low in price. In adaptation for milk production, they do not rank high, since they are rich in carbohydrates rather than in protein. The labor of preparing them for feeding is also considerable, as they should be sliced to avoid the hazard of choking the cows. The labor entailed in handling artichokes makes it probable that they will also seldom be much grown to provide succulence for cows.

Viewed from the standpoints of relative production, cost and suitability taken together, corn ensilage is without a rival in providing winter succulence for cows. The sorghums are also well adapted for such a use, but will never become so popular as corn, where the latter will grow equally well with the former, as corn is more easily grown, and the hazard is less that it will produce ensilage over-acid, a hazard that is present especially with sweet sorghum, unless it is put into the silo at a proper stage of maturity. The suitability of corn increases with increase in the grain which it contains, combined with a lack of excessive coarseness in the stalk.

Many attempts have been made to add to the protein in the ensilage in order to furnish a food in better balance. The foods thus used include alfalfa, clover, cowpeas, soy beans, and sunflowers. It cannot be said that these efforts have been entirely successful, viewed from the standpoint of economy. To have the protein food reach the stage which best fits it for being ensiled at the same time that the corn is at the proper stage, has been found difficult. The extra time incurred in the harvesting of the two crops simultaneously has also 
proved, to some extent, a hindrance, though not a greatly serious one. Nor have the attempts that have been made to grow the protein crop along with the corn, so that it may be harvested together, proved entirely satisfactory. Cowpeas and soy beans have been planted, along with corn in the line of the row, but it has been found, in most instances, if not, indeed, in all, that the per cent of the protein crop has been so small as to make it questionable if any profit will result from such a course. Prof. A. M. Soule, who tested this method of growing protein in Tennessee, now favors growing the protein crop separately. Other experimenters have also ceased in their own practice to grow the crops together. The shade from the corn is more or less prejudicial to vigorous growth in the other crops. It is to be understood, however, that adding protein to the ensilage when grown separately from the corn should be discouraged. It may, in many instances, be found more profitable to grow it thus than to purchase it in other forms.

All kinds of field roots may be fed to cows in milk to provide succulence, if fed in limited quantities, and just after each milking, but the indiscriminate feeding of rutabagas and turnips will certainly result in producing an undesirable odor in the milk. This, however, is not true of carrots, parsnips, mangels, and sugar beets, which may be fed in large quantities. The beneficent influence which all field roots exert upon the digestion cannot be questioned, and their pronounced milk-producing qualities are everywhere recognized. But when mangels are first harvested they may induce too lax a condition of the bowels, a result that is not present when they have been stored two or three months.

Where corn is not a sure dependence, field roots will continue a favorite food for milk production, but when the latter can be furnished in the form of ensilage it can be furnished so much more cheaply than roots that the latter will not be much grown to provide succulent 
food for cows. The cost of growing the corn is less than in the case of roots, the dry matter furnished is usually more and the labor of feeding is less. But when a few pounds of roots can be fed daily, they certainly do, in a sense, safeguard the health of the animals to which they are fed. Roots are also decidedly superior to corn and sorghum ensilage when the roughage fed is carbonaceous; that is, when it is composed of such foods as corn stover, sorghum, or hay made from the grasses.

The amounts of succulence to be fed will vary. In those areas far south, where more or less pasture is obtainable in winter, the amount of ensilage to be fed will be proportionately less. The necessity for succulence increases also with the degree of the curing in the fodders. Succulence is more necessary in larger amounts when fed with over-ripe and over-cured clover hay than when fed with clover hay cut at the proper stage and properly cured.

The amount of corn or sorghum ensilage that may be fed for a prolonged period with safety and profit to a cow weighing $\mathrm{I}, 000$ pounds should not exceed, say, 40 pounds daily. This does not mean that an amount considerably higher may not be fed for a limited term, nor does it mean that harmful results will certainly follow, though more should be fed in prolonged feeding. But it does mean that such feeding is attended with some degree of hazard which may show itself in more or less disturbance in the digestion. It is either true or not true that green corn fed ad libitum to dairy cows all the year is a safe food. In the opinion of the author, it is not true, and yet it is not easy to demonstrate why. But it may be said, first, that it is not a balanced food; second, that unless dry food is given to some extent, there will probably be disturbance in the digestion; third, when ensilage is fed alone the acid in the food is excessive; and, fourth, the appetite calls for variation in foods because the system craves it. 
Mangels may be fed at the rate of 50 to 60 pounds daily when they can be spared. The same is true of sugar beets and sugar beet pulp when the pulp is in good condition. But rutabagas and turnips should not be fed in quantities so large, except when the fodders are low in digestible nutrients. From, say, 24 to 30 pounds daily will usually be as much as may be safely fed. When both ensilage and roots are fed, the combination is excellent, but the amounts fed should not generally exceed, say, 5o pounds of the two given daily. Usually not more than, say, I 2 to 15 pounds of potatoes or artichokes should be fed daily, but the food may be so balanced as to admit of feeding larger quantities. Where alfalfa hay and clover are abundant and cheap, it is not necessary to feed amounts of succulence so large as those named.

Nature of the concentrates.-Where relatively large yields of milk are to be obtained from dairy cows in winter, the necessity for feeding concentrates is ever present. This necessity is based on the inability of the cow to consume and digest enough coarse fodders to result in maximum production, even though the fodders are practically in balance in their constituents. Clover hay, for instance, is in itself a balanced ration for cows, and yet so large a return in milk cannot be obtained by feeding clover hay alone as by feeding suitable grain along with the clover. The more milk the cow gives, the greater is the necessity for feeding concentrates.

Concentrates are obtainable from two sources. They are either purchased or home-grown. Which of these they shall be obtained from, in whole or in part, will depend upon such conditions as the size of the herd in relation to the farm, the nature of the production, and the fertility of the soil. In many instances, they are obtained from both sources, the purchased being the complement of that home-grown. 
Prominent among the concentrates purchased are wheat bran, cottonseed meal, and gluten meal or gluten feed. But the list in its entirety includes by-products from nearly all the grains grown. The suitability of these as food for cows is discussed in the book, "Feeding Farm Animals," Chapter XIII, by the author, to which the reader is referred who may desire to carry the investigation further. Wheat bran is clearly a favorite among the purchased foods, and is fed to a greater extent than any other. It is not only an excellent milk-producing food, but it is pre-eminently safe though it should be fed in large amounts. The purchase of milk products should exercise great care as to the source from which the purchases are obtained, because of the extent to which these are adulterated. The hazard that purchased by-products may not be as represented furnishes a strong argument in favor of growing concentrates on the farm as far as this may be practicable. Such foods, when purchased, may not only be far inferior to the representations made with regard to them, but they may contain certain ingredients positively harmful, as mill sweepings and, it may be, nails and pieces of metal, the presence of which it is not the province of the chemist to detect. All this hazard may be avoided by purchasing suitable grains and grinding them at home. But it is not to be understood that all mill foods or even the bulk of them are thus adulterated.

The concentrates that may be grown at home include all the small cereals, corn and, in some localities, the sorghums. The extent to which these or some of them may be grown at home has as yet been but dimly realized by many dairymen. In nearly all localities where milch cows are kept, it is practicable to grow concentrates that will virtually render the dairymen independent of mill feed as a source of the same. This may be accomplished by growing the small cereals in certain combinations. These combinations may include 
wheat, barley, oats, peas, and flax. The number of these that shall be combined in each instance should be deter. mined by relative suitability in growing them. Sometimes only two will be grown together. The aim should be to have one of them wheat to furnish the bran element in the concentrate. In other instances, the mixed crop may contain all the grains mentioned. Oats and wheat make a favorite combination. When grains are thus grown together they yield more, as a rule, than when grown alone. The yield of the oats grown alone could also be greatly increased by improved methods of growing them. No kind of grain taken alone is better or even as well adapted to furnish food for dairy cows as oats, and yet, owing to the shortness of supply, the feeding of oats is relatively too costly. Mature corn, properly grown, may be made to furnish enough of this concentrate for cows in many instances. The growing of such grains also, as oats and peas, in combination, cutting them a little under-ripe and feeding them without threshing, is labor-saving, and will also tend to lower the amount of added concentrates called for. The importance of aiming to grow foods on the farm, rather than to buy them, cannot be easily over-estimated.

When choosing concentrates for cows in winter, the aim should be so to select them that the ration shall be in approximate balance. This will mean that the concentrates fed, and the proportions in which they should be fed, will be largely determined by the nature of the roughage. For instance, should the roughage be clover or alfalfa hay protein foods, it will be in order to make corn a prominent factor in the meal portion, but should the fodder be chiefly corn ensilage or corn stover, or fodder rich in carbohydrates, then the proportion of corn as grain or meal added should be small. It is thus very evident that in selecting foods and adjusting the proportions of each that shall be fed, the necessity for careful thought and careful calculation is ever present. 
For information as to the adjustment of foods so that they shall be in balance, the reader is referred to Chapter $\mathrm{X}$ in the book, "Feeding Farm Animals." But even in the absence of adjustment, if it is remembered that the concentrate fed should be opposite in character from the roughage, intelligent feeding will produce satisfactory results though the ration should not be in exact balance. Authorities are not yet agreed as to the exact balance in the foods fed that will give best results in milk production, and until they are the practical dairyman can afford to go on feeding a ration without serious concern, providing he can be assured that it is in approximate balance. The truth is that the balance in the food is considerably influenced by the amount of milk given. The larger the production by the cow, the more protein does she require. An immature condition as to growth and a pregnant condition also call for an increased quantity of protein. It would seem correct to say, therefore, that food that will give a nutritive ratio of, say, I :5.5 to $I: 8$, according to the conditions present, should cover the extremes of requirement for cows in milk. The standards given by Wolff claim that a cow weighing I,000 pounds and giving 22 pounds of milk daily should be given 2.5 pounds of protein daily in the food. American investigators lean to the view, based on experiment, that the amount of protein called for is less than 2.5 pounds, but more than 2 pounds. Two and a quarter pounds may be given as an approximate average. The wisdom of keeping the amounts of protein reasonably low is based on the higher market values that usually prevail in the case of protein foods. Prof. F. W. Woll, who has given much thought to this question, concludes that a cow in full flow of milk, which weighs 1,000 pounds, will consume, approximately, 25.6 pounds of dry matter. The digestible nutrients in it will be approximately as follows: Protein 2.2 pounds, carbohydrates I3.3 pounds and fat 8 pound, with a nutritive ratio of $I: 6.9$. 
The German standards place higher the amount of dry matter called for.

When good clover hay or alfalfa is being fed to cows in milk, any one of the following grain supplements will give satisfactory results: (I) Corn meal and wheat bran, equal parts by weight; (2) corn meal, wheat bran, and ground oats, in the proportions of $2, I$, and I parts; (3) corn meal, wheat bran, and cottonseed meal, in the proportions of $2, \mathrm{I}$, and I parts. Whether corn meal or corn and cob meal is fed is not very material. Should barley be used instead of corn, it is not necessary that the proportions shall differ materially. Should corn ensilage be fed to the extent of, say, 40 pounds daily along with clover or alfalfa hay, any one of the following grain supplements should suffice: (I) Corn or barley meal, wheat bran, and ground oats, fed in equal parts by weight. This mixture is so eminently suitable that it may be regarded as a standard meal adjunct to be fed along with roughage as found on the ordinary farm. (2) Corn or barley meal and wheat bran fed in the proportions of $\mathbf{I}$ and 2 parts, as when oats may be more costly than bran. (3) Corn or barley meal, cottonseed meal, and wheat or rice bran, preferably the former, fed in equal proportions. This adjunct is one of the best that can be fed in the South. (4) Ground peas and oats, also fed in equal proportions, but the ration will be further improved if fed as ground peas, ground oats, and wheat bran, in equal proportions. The succotash mixtures ( see page 268) may be used alone or in conjunction with meal added, of such kinds as may adjust it more perfectly to the feeding called for. Ground millet may be made to take the place of corn. Oilcake may be used as a source of protein, but not more than, say, I.5 pounds an animal daily should be fed in prolonged feeding, lest the butter resulting should be too soft. When cottonseed is fed at the rate of more than 3 to 4 
pounds daily in prolonged feeding, the flavor and the color of the butter are liable to be affected adversely.

Amount of concentrates to feed.-The amount of concentrates to feed to cows in milk will be influenced by the character of the roughage that may be available; by the market value of the same; by the free milk-giving in the cow, and by such considerations as the requirements of uncompleted growth and a pregnant condition. That roughage rich in nutrients in approximate balance for producing milk, as good clover hay, will call for less concentrates than fodders lacking in such balance and largely indigestible as straw, is self-evident. It is equally clear that if, in addition to such food as good clover hay, succulence in the form of roots or of corn rich in the grain element, that the proportion of concentrates called for will be still further reduced. The market value of the roughage, however, may be such as to make it more profitable to increase the amount of concentrate fed rather than to feed the roughage. With timothy hay at $\$ 16$ to $\$ 20$ a ton, which it frequently sells for in New England, it will usually be more profitable to feed some concentrate as far as this may safely be done in lieu of the hay. But usually the roughage is much cheaper relatively than the concentrate. A cow giving 30 pounds of milk daily calls for more concentrates relatively to enable her to do it than a cow that gives but 20 pounds. The former is unable to consume, digest, and assimilate enough coarse fodders to enable her to furnish the elements called for in such high performance. The relative increase in the concentrates called for would seem to be greater than the relative increase in production, at least after a high standard of production has been reached. Uncompleted growth in a cow in milk and a pregnant condition make additional demand on food nutrients, and, therefore, frequently an additional demand on the concentrates fed.

Owing to the fact that the roughage available is 
usually much cheaper than the concentrate available, the aim should be to utilize the roughage to the greatest extent consistent with prudent feeding. Whether it may be profitable, in some instances, to be content with a somewhat lessened return in milk, may be a disputed question, but the necessity for so preparing roughage that the consumption thereof may, in many instances, be increased, will not be disputed. Such preparation relates to mechanical processes that add to the palatability of the food. (See page 274.)

In practice, feeders differ greatly in the amount of concentrates fed. Some teachers have submitted the following as a safe rule for guidance: Ascertain by feeding the concentrate how much the cow can consume, then lower the amount just enough that all that is fed will be eaten up clean. Such a rule is clearly unsafe. It would mean that the machinery of digestion would be driven at a rate of speed so high that it would prematurely, through over-taxing, impair the digestive powers of the cow, and, through such impairment, would lower her producing powers. Some cows fed by this rule would consume not less than 18 pounds of concentrates in a day, or, probably, twice the amount that will ordinarily suffice in prolonged feeding. While such feeding may be admissible under some conditions, as when the cow is to be sold at the close of the lactation period, it is not admissible in a herd the cows of which are to be retained for production from year to year. Such feeding, in addition to being unduly costly, would in time wreck any herd, since it drives the machinery of digestion at too high a pressure.

When cows are fed on good clover or alfalfa hay, with a liberal supply, say, 30 to 40 pounds of corn or sorghum ensilage, the rule will be safe which would feed daily, to a cow weighing $I, 000$ pounds, about I pound of concentrate to each 4 pounds of milk given when the returns are average. But should they become 
very large, then it may be necessary to increase somewhat the relative proportion of the concentrates. Thus, when a cow gives 16 pounds of milk daily, the concentrate fed would be 4 pounds, but if she gave 30 pounds, the concentrate called for would be more, say, 8 to 9 , or even, in some instances, Io pounds daily. Should ensilage and roots be both wanting, about 25 to 33 per cent should be added to the amounts submitted above, when the production is average. In the absence of ensilage or roots, very large production is not likely to result, hence very large amounts of grain may not be called for. The size of the cow should be considered in determining the amount of concentrate to feed, but increase and decrease cannot always be accurately gauged in this way, since cows differ much in their powers of digestion. When fed the foods outlined above, the concentrate called for will seldom fall below 4 pounds, and will seldom rise beyond, say, Io pounds in prolonged feeding. The aggregate amounts to feed will run somewhere in the neighborhood of 6 to 8 pounds daily. These amounts will probably be looked upon as low by many dairymen, but for prolonged feeding from year to year, viewed from the standpoint of economy in relation to production, in the judgment of the author, they will be found high enough.

If, in the measure used in feeding grain to cows, there are paint lines marking the number of pounds, it is easily possible to increase or decrease the amount of meal fed to correspond with the production of the cow. Close attention to this matter will effect a great saving of the concentrate fed in a large herd in a single season.

Preparing and blending the food.-The conditions that make it profitable, in many instances, to blend foods include the following: (I) When the concentrate is dense or heavy in character, and fed in large quantity that it may be in a less compact condition while in the stomach, so that the gastric juice may act upon it more 
freely. To effect such an end, when fed without admixture, with prepared roughage as silage, it is sometimes simply mixed with some coarser kind of meal. (2) When the aim is to secure more thorough mastication than comes from feeding it directly. When thus fed, remastication does not follow, but when the concentrate is admixed with some prepared roughage as ensilage, it is remasticated in the process of rumination, and, consequently, it is reasonable to infer that it will be more perfectly digested. (3) When some of the fodders available are not sufficiently high in palatability to insure sufficient consumption in the same by chaffing them and mixing them with the more relished concentrate, the larger consumption sought may be secured.

Among the concentrates that profit by admixture with other concentrates when fed directly, are pea meal, cottonseed meal, rye, barley, and corn meal. Among the substances that are concentrates or of the nature of concentrates that are suitable for admixing with them to secure the end sought, are wheat bran, one of the best, rice bran, ground oats, and even oat hulls. Corn cobs ground up with the corn serve the same end, though, probably, in a less degree.

When the concentrate is to be mixed with prepared fodder, that is, with chaffed roughage, no other kind of prepared roughage answers the purpose better than ensilage. The ensilage is fed and immediately thereafter the concentrate is spread over it. The admixture takes place while the animal is eating it. In the same way when cut fodder is the roughage fed, the concentrate strewn over it will be admixed, but the blending will not be so perfect as with the ensilage, since the moisture in the latter influences favorably adherence of the meal. To insure like adherence in the cut fodder, it is sometimes dampened with water applied by a watering can with a nozzle that produces a fine spray. To insure such blending from feeding the concentrate along 
with the cut fodder, it is not so necessary, of course, to cut all the fodder, but only a small portion of it. Any kind of roughage that is even reasonably palatable will effect the end sought, as the blending of the meal insures the consumption of the fodder. When the roughage consists entirely of good hay, it is not usual to chaff it. But when a part of it is straw of the small cereals it is frequently chaffed and fed admixed with hay similarly prepared, which insures a larger consumption of the straw. Corn and sorghum stalks are, in some instances, chaffed and mixed with cut hay with a similar object in view. The profit from such blending will be influenced by various considerations, but most of all the cost of labor. That it will insure a more perfect consumption of the foods grown on the farm is certain; hence, as conditions become intensive, the blending of concentrates will grow in favor.

Where ensilage is fed through all the season, which calls for the feeding of other roughage, the labor put upon the latter in preparing it for feeding will probably be kept at a minimum. It will probably be restricted chiefly to the shredding of corn fodder or stover, but it is different when roots are fed in place of ensilage. They must usually be prepared for feeding to cows by slicing or pulping them. When fed thus directly. meal may be thrown on them to insure admixture, as when silage is fed. But a further purpose may be served by the roots. If the fodders are chaffed and the roots are simultaneously pulped, and the two are blended in a feed room, the consumption of much fodder will be insured that would otherwise be rejected. The same power may be utilized in preparing the respective foods for being blended. Enough may thus be prepared to last for a week at a time. When the fodder thus blended is put into the mangers the concentrates may be spread over it. No method of feeding can be devised that is more economical of food. The serious factor involved is the 
cost of labor. The plan, however, is assuredly to be commended when a threatened shortage of food supplies exists.

Most suitable winter rations.-The most suitable rations for cows in winter in the various states or groups of states are chiefly determined, as may be expected, from the production of the same. Rations that have stood high in favor for such a use in various groups of states will now be submitted. For the amounts to feed where these are not specified see page 273. Where the amounts are specified they are intended for cows that weigh I,ooo pounds.

In the New England states and also in the maritime provinces of Canada, corn ensilage should be used as the basic roughage, and fed at the rate of 30 to 40 pounds daily. In addition, the cows are given all the hay they will consume, whether fed as mixed hay, clover, or rowen. The concentrate fed, of which a chief proportion is usually purchased, is corn meal, wheat bran, and cottonseed meal or gluten meal, fed in the proportion of $2, \mathrm{I}$, and I parts by weight. Relatively large amounts of meal are fed because of the high market value of the roughage.

In the states of New York, Pennsylvania, Ohio, Michigan, Wisconsin, and Minnesota, and also in the Canadian provinces of Ontario and Quebec, the following is a favorite ration for cows in milk: Good corn silage fed at the rate of 30 to 40 pounds daily and all the good clover hay that the cow will consume. As concentrate she is given a mixture of corn meal, wheat bran, and cottonseed meal in the proportions of 2, 1 , and I parts by weight. In some instances, wheat bran only is fed with the corn meal, and in others equal parts of wheat bran and ground oats. As the leguminous hay may be freely and safely grown in all these states, the quantity fed should be moderate, never exceeding ro pounds daily, and usually from 5 to 7 pounds will be 
enough. When the ensilage is from corn, with much grain, even a little less meal will suffice.

In the Dakotas and the northwestern provinces of Canada, cows in milk are fed hay of various kinds as the fodder part of the ration, but, in many instances, corn fodder is fed along with the hay. In the Dakotas, there is no real hindrance to feeding corn as silage. The accompanying concentrate is ground corn, but more frequently ground barley, speltz or millet, ground oats, and wheat bran, equal parts by weight. In some instances, wheat and oats grown together furnish the sole concentrate, and the feeding of the latter is to be commended, as the dairyman may grow such food entirely on his own farm.

In the states of Montana, Washington, and Oregon, clover and alfalfa are, in nearly all instances, fed as the sole roughage given; but, in some instances, the hay is mixed in character, as, for instance, clover and timothy or oats and vetches grown together. As the concentrate ground barley, oats, and wheat bran, fed in equal proportions, are a favorite food, and, in some instances, ground wheat is fed. To a limited extent on the coast, rice meal is fed. The amount of grain fed is small. It seldom exceeds 6 pounds daily along with clover or alfalfa.

In the Atlantic states, from Delaware to Georgia, including also Tennessee, a favorite food is 30 to 40 pounds of sorghum silage. The additional roughage given is clover, alfalfa, or cowpea hay. The concentrate most in favor is corn and cottonseed meal given in the proportions of 2 and I parts by weight. Bran is sometimes fed along with cottonseed or as a substitute, but the price makes feeding it prohibitory in some instances. As in these states, the dry fodders named are usually dear, the tendency is to feed more concentrates than are usually fed in the central and western and the western mountain states. 
In the states with Illinois and Missouri as a center, and in all those states which border on them, one of the most economical rations is corn silage and clover or alfalfa hay for roughage. These states grow corn abundantly, hence the silage has, in many instances, a large proportion of corn in it. The necessity, therefore, for heavy grain feeding is so far reduced. The concentrate high in favor is corn, cottonseed, and gluten meal, in the proportions of $2, I$, and I parts. In these states the feeding of protein concentrates in the forms named will probably grow less, as they will be more and more supplanted by protein furnished by cowpeas and soy beans.

In the mountain states southward from Montana and Oregon and westward to the Pacific, alfalfa and clover, chiefly the former, furnish the roughage given. The concentrate fed is more commonly corn meal shipped in, as barley grown in practically rainless summers is worth more for malting, but, in some instances, both are fed. The quantity given for prolonged feeding is seldom more than 6 pounds daily, and when sugar beets or pulp are fed, as they are in many instances, the meal may be further reduced.

In the states which border on the Gulf of Mexico, from 30 to 40 pounds of sorghum or corn ensilage are fed in many instances for roughage, but this food is frequently supplemented with pasture. The concentrate fed is cottonseed meal and wheat or rice bran, in equal parts by weight. When corn meal is not too dear, a favorite concentrate is a mixture of cottonseed meal, ground corn and wheat bran, or rice meal in the proportions of 2, I, and I parts by weight. 


\section{CHAPTER XIV \\ THE DISPOSAL OF COWS}

The discussion of this question will consider: (I) Disposal of cows in pedigreed herds; (2) Of cows in the city dairy; (3) Of cows in the farm dairy; (4) Fattening of milch cows for the block; and (5) Influence that the source of supply may exercise on disposal. That improvement, in some instances, over the present methods of disposal are possible will be made apparent.

Cows in pedigreed herds.-The professional breeder of pure-bred cattle produces them primarily for sale, whether of the beef, dairy, or dual types, although when of the dairy or dual types, he may obtain from them returns secondary in character in the milk given before he sells them. With such breeders it should be a cardinal principle not to sell the best cows unless the price obtained for them should be extravagantly high, otherwise they will soon lower the standard of excellence in the herd. The best should be retained as long as they will breed successfully.

Nevertheless, there are instances in which it will not only be legitimate but also commendable to dispose of cows while yet young. If they have been proved as to their breeding capacity and found seriously wanting in any of the lines of transmission that are important, they should be sold, but not to others who may be willing to invest in them for breeding, knowing that they are pedigreed, and for that reason mainly. They should go direct to the block. To sell them as breeders may bring more present gain, but it ultimately reflects on the reputation of the breeder, which is his most important asset in his work. But the true value of a young cow for producing milk cannot be determined, in all instances, 
from her first year in lactation, as, in some instances, with more maturity comes production greatly increased. Cows with vicious habits, such as confirmed kicking when being milked, are undesirable in any dairy. Cows also that react to the tubercular test should be sent to the block at the earliest possible moment, but if of exceptional inheritance, it may be proper, in some instances, to breed from them, rearing the calves on milk obtained from other cows. But such cows should be at once isolated. (See page 425.)

The presence of a defective udder or of some deformity, the outcome of some mishap, may not be a sufficient reason for discarding such animals, as, notwithstanding, they may be able to produce most excellent progeny. But, if seriously deformed, the aim should be to keep them separate from the herd, because of the adverse impression which their presence may make upon visitors.

The relative values of immature and mature females, as determined by the average prices paid for these respectively, is a striking comment on the power of custom, even in transactions that deal with material values. During recent years, young females, when purely bred, have sold for prices not much below those obtained for young cows whose producing powers have been proved by actual performance. This curious fact, though greatly to the advantage of the seller of young females, is equally to the disadvantage of the purchaser. The considerably superior value of a young female whose producing powers have been proved, other things being equal, over one whose powers have not been so proved, must be apparent to any one who has thought upon the question.

Although the prevailing tendency is against investment in aged cows, when making purchases, there may be instances when such a course would be commendable, providing these are purely bred. The wisdom of such 
investment will depend upon the value of the cows as breeders, and the low price for which they may be bought. Foundation animals may sometimes be thus obtained at low relative cost. When females aged that are pregnant may be purchased for less than would be paid for a calf yet unweaned, the purchase of the same may be proper and commendable.

The ultimate end for old cows is, of course, the block, and it may be wise to send them there in the absence of other ways of disposal before they become incapable of further breeding. It is a matter of considerable importance with a professional breeder to have the animals in his herd looking well because of the impression made upon prospective purchasers who visit the same. In grade herds it will seldom be profitable to retain cows the full term of their breeding capacity.

Cows in the city dairy.-The practice is common in some city dairies to milk cows for but one season. When thus managed, of course, only cows that are fresh are purchased, and from such sources as may be available. Usually but little can be known about them or their ancestors. They are well fed to insure good returns in milk, and when the milk yield is no longer profitable, they are sent to the block at whatever price can be obtained for them. Dairymen that adopt this plan are usually without facilities for keeping cows during the period when they do not give milk preparatory to freshening.

To this system there are three objections. First, the antecedents of the cows not being known, they are sometimes disappointing in their milk yields. Second, good cows are sacrificed that would be capable of furnishing large returns in milk for successive years if kept for such a use. Third, calves, more or less valuable that would otherwise be forthcoming are not produced. Such a system, though it may, in some instances, afford the most profit to the owner, means the sacrificing of too 
many valuable cows, the supply of which is at all times below the demand for the same.

Such sacrifice of cows may usually be prevented. One method of prevention would be the owning or renting of land on which pregnant cows may be maintained during the season when they are dry. Such a system would, of course, entail outlay, but it would probably be outlay that would give a good return, as it would make it possible to retain free milking cows as long as they continued to milk satisfactorily. Of course, when the dairyman located near a city has an ample supply of land, he will have no more difficulty in carrying pregnant cows when not in milk than the farmer dairyman.

The city dairyman may also be able, in some instances, to make an arrangement with a farmer not too distant whereby the latter can maintain pregnant cows for him, for a cash return, or it may be in lieu of the calf produced by the cow, and for which the city dairyman has no use. It would never pay him to raise such calves, if heifers, for cows, providing he has to buy all the food which they would require during the period of development.

A farmer who desired to grow baby beef without milking his cows by hand could in this way secure his supply of calves in addition to those produced by the cows of his own herd. The cows of the city dairyman could be served by the sire kept by the farmer. In this way he could obtain calves of such inheritance as he might desire, especially on the side of the sire. This would make it easily possible for the farmer to raise more than one cow during the season of milk production, and it would secure for him a sure source of supply. By such a system, the other would be able to retain good cows as long as they milked freely, and this would so far reduce the hazard incurred of bringing in faulty cows when replenishing the dairy.

Cows in the farm dairy.-In the farm dairy, there is 
no excuse for keeping cows that are low in production after the dairy has been brought into regular working order. During the first years of its establishment it is possible, of course, that some animals may be brought into it that prove disappointing, but these, when found wanting, should not be retained any longer than it may be absolutely necessary to keep them. Dairymen thus situated may, and, as a rule, should breed their own cows; hence, by the aid of elimination, they may, within a reasonably short time limit, bring their herd up to a high standard.

The basis on which such elimination should rest is, first of all, production. But there are other considerations that should be weighed. These include robustness of constitution, easy milking properties, qualities that relate to disposition and also to transmission and regular breeding. Production, of course, is best determined by the record kept of the same. (See page 200.) All cows that come short of the standard fixed should, of course, be disposed of.

Cows may come up to the standard of production, and yet they may be less robust than those that yield equally well, as indicated in habitual leanness and in other ways. A high standard of vigor is essential to long-continued high performance in the dairy.

Easy milking qualities relate to the size of the teat and the ease with which the milk is withdrawn. The difference in cows in this respect is very marked. When the teats are so small that they cannot be grasped with the hand in milking, they must, of course, be stripped by grasping them between the thumb and forefinger, which prolongs the milking. This peculiarity appertains to some breeds, as, for instance, the Ayrshire, much more than to others. Hard milking is the outcome of peculiarities of formation in the milk duct and the milk glands. The milking of cows thus characterized calls for the expenditure of arlded force, which makes the milking 
tiresome and tedious. Other cows are unable to retain all the milk in the udder between the times of milking, owing to defective formation of the organs that relate to the retention of milk. Cows defective in these respects are not desirable.

Cows may be good producers and yet, owing to their rustlessness and irritable disposition, are less desirable than others more docile and yet the equal of the former in producing ability. Of course, it may be wise for a time to retain such animals until others that are more desirable become sufficiently numerous in the herd to admit of discarding those less desirable.

When the dairyman rears his own cows, characteristics that relate to transmission may be about as valuable as those that relate to the production of milk. In some instances, all the female progeny of a cow prove to be equal, if not superior, to the dam in producing power, while in others they all prove inferior. It is not necessary to say which of these female progeny should be retained.

The ability to breed regularly is an important factor in the cow in the farm dairy. Nature has decreed that the largest returns in milk are secured in the months that immediately follow the birth of the calf. Then follows gradual declension until the milk flow finally ceases. This renewing of the power in the cow, so to speak, to produce a maximum quantity of milk, should occur not seldomer than once a year. If she fails to breed thus frequently, her value for retention in the dairy is proportionately lowered.

The age to which cows may profitably be kept in the dairy cannot be fixed by rule. This question is discussed more fully by the author in the book, "Feeding Farm Animals," pages 43I-433. It may be said here, however, that the following considerations will aid in determining the age limit to which a dairy cow may be kept: She should be retained (I) as long as she comes 
up to the standard of production fixed upon, on the same food that is given to younger cows; (2) as long as she is able to breed with that regularity which results in the usual period of lactation and at the time desired; and (3) as long as she retains enough flesh to make a respectable appearance in the dairy. This may give to her, in some instances, not fewer than ten years in the dairy, although that is much longer than the average time during which cows are retained in herds.

Fattening milch cows for the block.-There are instances in which it will not pay to fatten cows that have completed their work in the dairy. The more pronounced they are in what is considered straight dairy form, and the older they are, the more certain is it that such fattening will not be remunerative, as the less, relatively, will be the price paid for them in the market. If the food used in fattening must be purchased, as would probably be the case with city dairymen, the cost would certainly be greater than the increased value of the cows when sold. Such cows would be used by the trade in furnishing canned meats.

It is possible, however, to combine the last months of lactation in cows that are to be sold with what is the equivalent of at least partial fattening. This would mean that the food given would be so rich in carbohydrates that she would add to her flesh while yet in milk, so that by the time she was dry she would be reasonably well fleshed. The extent to which such feeding could be carried with profit will depend more or less upon the source of food supplies. This method could be practiced more successfully by the grower of certain foods adapted to fattening than by the dairyman who purchased them.

The farmer dairyman may also be in a position to fatten cows by turning them on grass pasture after lactation. The best pastures for such fattening would 
be those well advanced in growth, and as are found in the late rather than in the early part of the season. The drying of the cows could be timed accordingly. In some instances fattening could be carried as far as grass will carry such conditioning without grain, until the cows would take the market. Such is probably the cheapest fattening that can be given to straight dairy cows.

It is different, however, with cows of the dual types. They may usually be fattened in good form, and, unless when quite old, it may be well in order to stall feed them for a time before they are sold. The method of feeding them will be the same virtually as the method adopted in fattening other cattle, and it may be done winter or summer as described in Chapters VII and VIII. It may not be wise to give them an equal finish with young animals that are strictly prime, as however finished they will not sell for so high a price. They also may usually be most cheaply fattened on grass, but this may not be practicable, in many instances, owing to the season at which they are dried off.

The beef animal, which many farmers kill once a year, may frequently be drawn from this source. A cow even reasonably well advanced in years may furnish excellent meat for home use, dependent on the nature of the fattening. If she can be fattened largely on such foods as rape pasture, field roots, or ensilage, with suitable meal added, and in quantity such as will insure quick fattening, a juiciness and a tenderness will be imparted to the meat that adds greatly to the relish of the same. The quickness of the fattening is an important factor in securing these results, which means that such fattening foods as corn should be fed daily.

Disposal influenced by source of supply.-From what has been stated above it is very evident that the method of disposal is influenced by the source of supply. It is usually practically impossible for the city dairyman 
to breed the females that must replenish his herd. $\mathrm{He}$ obtains them from an outside source, and, in many instances, must pass them on to non-existence at the end of one season. Such a system is adverse to reaching a high level of attainment. The cows for such dairies must be purchased where they can be obtained, and usually from sources where they have been bred in an aimless way.

It is different on farms where cows may be retained for years, and where the replenishing of the dairy comes from the progeny of the cows in the herd. But in these days of specialization, even on some farms where the conditions are intensive, the tendency is to stock them with cows up to the limit of the capacity of the farm to maintain them. This, of course, precludes the possibility of rearing animals on the same with which to replenish the dairies. In such instances the source of supply in the cows becomes the same as with the city dairyman. In the past, such supplies have been obtainable from outlying sources where dairying has not been reduced to a system. But experience has shown that these sources of supply are being more and more cut off, which means continual advance in the price that must be paid. It is coming, therefore, to be a serious question as to where a suitable supply of dairy cows can be secured.

It would seem possible to answer this question by the establishment of farms for breeding such cows. Why should they not be made profitable? They should be established where the conditions are extensive rather than intensive, that food supplies may be grown rather than purchased. The breeding would have to be conducted on principles that would lead to high production in the cows. Of course, the use of sires purely bred and well chosen would be a necessity. But the foundation females could be of mixed blood, chosen with a view to form rather than to blood lines. 
In such a herd, the keeping of records would be indispensable, as these would furnish the basis of price. If sold as cows, the record would show performance, and the individual would know what he was getting. If sold when first coming into milk, the performance of the dam would be some guarantee as to what might be looked for. That cows thus bred would command a high price relatively and find ready sale cannot be questioned. The price obtainable would probably almost approximate the average paid for pedigreed dairy cows, especially such as are without milk records, and such breeding would solve the problem, perplexing to some breeders of pure-breds, as to what should be done with the young males. There would be no necessity for growing them, because of any pedigree value that they may possess. As soon as such females were come into milk, they would bring profit to the grower until sold, hence the risk in such breeding would be small, indeed. Such females, however, would be far too valuable to purchase for dairies from which they would go to the block at the end of but one period of lactation. 


\section{CHAPTER XV}

\section{MARKETING CATTLE WHEN FINISHED}

The marketing of beef cattle when finished is much influenced by such conditions as proximity to or distance from the market, and the method of reaching the same, by the degree of finish made or that can be made, and by the number of animals finished in any given locality. One man may find his best market almost at his door and another may find his thousands of miles away. The ranchman must sell his cattle as the grass finishes them whether as stockers or for beef, while the farmer may finish his for the best markets. Where but few animals are fattened, the markets are restricted for reasons given below (see page 292), while under conditions the opposite marketing is usually of very easy accomplishment.

This chapter considers: (I) Season for marketing; (2) Choice of markets: (3) Preparing the animals for shipment; (4) Care while in transit; (5) Shrinkage in transit; and (6) Disposal at the stockyards.

Season for marketing.-The season at which the animals shall be marketed should be determined. as far as this may be possible, when the cattle are put upon feed. Unless such determination is at least approximately made, it would not be possible to adjust the food requirements to the needs of the animals. The skilled feeder can make a close approximation as to the time necessary to bring the animals to be fed to the finish sought, and also as to the amount of food required to accomplish the same. To be compelled to sell cattle unfinished because of the shortage in food supplies or to buy food in a high market in order to make a better finish, may result in much loss. 
Chief among the influences that determine the season fixed upon for marketing are: (I) The foods available for finishing; (2) the class of the animal to be finished; and (3) the nature of the market.

The ranchman can only market his cattle at one season of the year, that is, the late summer or the autumn, when they are in the best condition of flesh reached at any time during the year. The farmer who finishes on grass is more restricted to the summer and autumn markets in which to make sales of finished animals. The one who finishes by feeding coarse fodders, roots, and concentrates may market at any season of the year. But the aim should be to market at seasons when usually the markets are least crowded, that is, during the months of the year preceding the rush that usually characterizes the last months of the same.

Cull cattle are usually most profitably sold without finish unless they can be fattened on cheap grasses. Light-weight cattle may be sold at any time, but usually bring the best price, relatively, in the late spring and summer months. Heavy cattle may generally be most safely marketed in the winter and early spring months.

Where the market is exclusively local, and sufficient to use all the meat grown, those who fatten cattle may usually sell the animals in the order in which they are ready, so that the local dealer can select the animals for slaughter according to the degree of the finish which they possess, thus leaving the less highly finished for further feeding. But when the animals are to be shipped, the selecting of animals of superior finish for early shipment is not possible when fed in less than carload lots.

The degree of the finish to give is influenced by such considerations as: (I) The capacity of the animals to make finish; (2) the opportunities for making it; and (3) the market in which they must be sold. It will not pay to stall feed some classes of cattle from the inability 
which they show to make high-priced meat. Such are cattle of the scrub and extreme dairy types, and the same is true of old cows lean at the time when they are dried. (See page 286.) The low price paid for such beef will not pay for bringing it to a high finish through stall feeding. Owing to the character of the food production the opportunity for making high finish is not present on some farms, whereas on others the opposite is true. It is true, also, of large areas in both instances. In some local markets the dealers cannot pay such prices for meat of the highest finish as are paid for the same in the best markets, as the local trade will only pay prices such as will purchase a cheaper grade of meat.

When animals are finished, that is, when the fattening process is so far advanced that the increase made is not commensurate with the food used in making it, because of the condition of ripeness to which the animals have been brought, the aim should be to market them with all promptness. The longer they are maintained after that point has been reached, the greater will be the relative loss from the food fed. On page 389 in the book, "Feeding Farm Animals," by the author, this question is more fully discussed.

Choice of markets.- The choice of the market in which to dispose of fat cattle is determined by such influences as: (I) The facilities for reaching the market; (2) the character of the stock to be shipped; and (3) the degree of the finish possessed by the animals. In less than carload lots it may not pay to ship even well-finished animals of high quality to distant markets, because of the highness of the freight charges. It has been shown above that the less the degree of the quality possessed by the animals, and also the less degree of finish given to them, the less profitable will it be, relatively, to ship to large and distant markets.

While those who feed prime cattle in small lots may be handicapped in the shipment of the same, in small 
lots, because of the expense, the difficulty may, in some instances, be met by sending some other class of stock in the same car that the grower may desire to dispose of. This difficulty may also be overcome in time through co-operation, as it were, in feeding and shipping. Where prime cattle are finished in small lots in the same neighborhood, the lots from different farms may be bunched, as it were, for shipment in the same car. If deemed advisable, the choicest may be selected for such shipment and the less choice disposed of locally. In brief, the aim should be to dispose of cattle of high quality and finish in the best market within a reasonable distance and to dispose of the common sorts in markets in proximity. For the former there is a sure demand in good markets at all seasons of the year, but for the latter the demand is never brisk, because of the excess at all times in the supply.

In very many localities there is great room for improvement in the methods of disposing of fat cattle. Improvement may be made by the adoption of measures that will bring dealers in fat cattle and those who finish them in closer touch. This can be done by growing them more numerously in any locality. Where animals fattened in small lots are sold to local dealers for shipment, the dealer does not care to spend time operating in such a locality. Where an increased number is only sufficient to invite the attentions of but one dealer, he is in a position, in a large measure, to fix the price that he will pay. When many such animals are finished, buyers are attracted and there is competing between them, which improves the price to the seller.

Improvement may also be made by the establishment of live stock fairs in certain centers where they may not exist. These fairs may be held monthly or bimonthly, or as often as may be necessary, in some convenient center. At these the sellers of various kinds of stock may exhibit what they have to sell. The dealers 
are thus brought into direct touch with those who have stock to sell, and this results in competition in prices. Such fairs are more helpful to small than to large producers for reasons that will be manifest. It is not every locality, however, that can sustain such fairs, owing, it may be, to the newness and sparseness of the settlement or to the absorption of interest in other lines of production.

Preparing for transit.-When cattle are to be shipped by rail, a car or cars, as may be needed, should be secured in ample time beforehand to make sure that the animals will be shipped on time. The more distant the market, and the fewer the competing lines of railroads, the more important is such timely application for cars. Only a few days' delay may mean the loss of the best market for the time being, and after the cattle are ready. for shipment it always means loss of food.

When the car is in place, it should be well bedded with dry straw. If the run will call for more than 24 hours, many shippers furnish 200 to 300 pounds of hay to each car. It is strewn around the sides and ends of the car. Some cars have racks for hay, but these are of necessity placed so high as to be little use.

When the cattle are shipped from the pastures they should be kept away from grass, unless when it is largely cured on the ground, for a day or two, and fed on good hay, as such feeding will lessen the tendency to a loose condition of the bowels which is so frequently an accompaniment of the excitement and jostling which result from shipping. The cured grasses are more suitable for such feeding than the clovers or alfalfa, as they are less laxative. The usual grain food given to cattle in the feed lot or stable should be cut down gradually from one-half to two-thirds for, say, two days, before shipping. This compels the animals to eat more hay. They should be watered in the usual way previous to shipment. Any attempt to induce them to take more 
water than usual by giving them large quantities of salt before shipping will only result in loss to those who thus connive to cheat their fellows, loss in money, loss in reputation, and loss in moral consciousness.

Unless in the case of show stock, they are driven to the cars in nearly all instances. In cool weather this may be done at any time during the day, but when the weather is warm, it is greatly important that they shall make the journey from place of feeding to the cars in the cool of the morning or the evening. They should be driven gently and slowly, and loaded with the least possible excitement.

When cattle are shipped in large numbers, it is quite possible to grade them according to size and finish, but this may be done also at the stock yards where they are sold. Cattle thus graded may usually be sold more advantageously than when put upon the market in lots made up of animals that vary in age and quality. Animals of less complete finish may be retained for further feeding or may be sold locally, as may seem best to the owner.

The cars for shipping cattle vary in size. More commonly they are 33 or 36 feet long, but, in some instances, they are longer. The charge is based on a certain weight for each car, even though it should carry a less weight. For instance, should the standard load for a car of cattle be 20,000 pounds, however far short of that amount the actual weight carried may be, the shipper will be charged for the carriage of 20,000 pounds. Additional charge is made for any weight carried in excess of the standard, and up to a certain limit the shipper is allowed to load in excess of the standard weight. Heavy loading is preferable to light loading, as it allows less movement among the cattle, and, in consequence, they do each other less harm. A car 36 feet long should carry from 24 to 26 cattle which weigh from, say, I,000 to $I, 200$ pounds 
When cattle are driven to market, they should be prepared for the journey, should it exceed a mile or two, in much the same way as though they were to be shipped by rail. In warm weather the journey should be made at night when the market is distant. For such marketing, what is known as the "stock wagon" may be used with much advantage in carrying prime animals in small lots to such markets.

Care while in transit.-When the journey does not exceed 28 hours, the attendant can do but little until the cattle reach their destination. They are given no additional food or water, as there is no opportunity for this after they are loaded into the car. It may happen sometimes that an animal may get down in a car, in which position it may get bruised by the tramping of other animals. Should this happen, there is opportunity at wayside stations to look the cattle over and to prod any that are down until they rise. The presence of horns adds much to the liability to injury during shipment.

When the cattle are more than 28 hours on the road, the federal law, as it stands at present, calls for the unloading, feeding, and watering of cattle at certain places provided by the railroad companies for such use. This is an instance in which a well-meaning law may work hardship without effecting the purpose sought. Humane men who have had experience in shipping cattle are quite generally of the opinion that when cattle can be made to reach the market within 36 hours of the time of loading, they will be less harmed if they are not unloaded on the way. There is liability to more or less of jamming during the loading and unloading, and it is also true that animals will eat and drink but little during a short stay at a feeding place. The delay consequent upon such unloading and the labor incurred are, in a great measure, without adequate results. Such unloading, however, when more than $3^{6}$ hours in transit, 
will be helpful chiefly because it allows the animals to rest in a lying-down posture. The food for such feeding can usually be obtained by purchase at such feeding stations at the cost, of course, to the shipper.

The aim should be to have cattle come into the stock yards at night or in the early morning. When properly consigned, they will be unloaded as shown below, with much promptness and will also be properly fed and watered long enough before the time of inspection by intending buyers to enable them to satisfy their wants. If they arrive after the sales for the day are over, they remain in the yards on expense until the following day before they are sold. As will be manifest, however, the time at which the loaded cars reach the unloading shoots cannot, in all instances, be controlled even by the railroad authorities.

Shrinkage while in transit.-The loss of weight by cattle when in transit varies greatly. In some instances, it is not more than Io to 20 pounds. In other instances, it is not less than 60 to 70 pounds. That such variation should occur will be readily apparent upon considering the causes that lead to variations given below.

The following are chief among the influences that affect shrinkage in cattle while in transit: (I) The age of the animals; (2) the foods used in fattening them; (3) the degree of docility possessed; (4) the exercise taken while being fattened; (5) the degree of the finish given; (6) the time occupied in the journey; and (7) the character of the weather.

Young animals, as a rule, shrink more in proportion to the live weight than animals that are older, as the flesh contains more water, which is more readily lost than fat. Likewise animals that have been fed large quantities of succulent food while being fattened will lose more than animals finished chiefly on dry concentrates, as the flesh of the former is more juicy. Animals that have exercised freely while being fattened, as when 
finished in the feed lot, or yard, will shrink less than those finished in the stall, as they have greater power to accommodate themselves to the jostling which is the accompaniment of conveyance to market. The more docile they are, the less they will shrink, as the degree of the disturbance felt decreases with increasing docility, hence there is less of disturbance to the digestion. The higher the finish, as a rule, the less will be the shrinkage, as high finish brings with it increased firmness of flesh and increased weight in proportion to the contents of the digestive organs, which are largely lost in transit. The time occupied by the journey is probably the most potent influence with reference to loss of weight, but this loss is proportionately greater in the early stages of the journey because of the larger amounts of waste products that are expelled from the digestive organs. The more uncomfortable the weather, the greater will be the loss of weight, because at such times the disturbance to the functions of the system is greater. The character of the food fed just before shipment also exercises an influence which it has on the condition of the bowels. (See page 294.) It may also be mentioned that dairy cows will shrink more, relatively, than other cattle of similar age, because of the greater relative capacity of the paunch which they usually possess.

When the animals are sold locally, the time and place for weighing are determined by mutual agreement. When they are driven a few miles and are then weighed at the end of the journey, no further shrinkage, as a rule, is required. When they are weighed on the farm, without fasting, the shrinkage is more commonly put at 5 per cent of the live weight. In some instances it is mutually agreed that they shall be fasted 12 hours before being weighed, and in addition the shrinkage will be a certain percentage of the live weight, not usually more than 2 or 3 per cent. Stall-fed cattle shrink heavily when they must be driven far to market, and the heavier 
they are and the higher the finish, the greater will be the distress of the journey and consequently the greater the loss of weight. While the shrinkage, as has been shown, varies greatly, under average conditions, it will not usually be much less than 5 per cent when the animals are to be shipped long distances.

Disposal at the yards.-When cattle are shipped to be sold at the stock yards, usually it is better in every way to consign them to some reputable commission house. Among the advantages of so doing are the following: (I) The cattle are cared for with more promptness than would be otherwise possible, providing the commission firm has duly been informed of the time and place of shipment. (2) Being more familiar with the grading of the animals for sale, they can generally do this to better advantage than the owner. (3) Being more familiar with every step to be taken, the animals will be disposed of with more dispatch than would be possible on the part of any outsider. (4) Being acquainted with all the ins and outs of selling, they are in a position to make the most out of the cattle that can be obtained for them. It is to the interest of the commission firm to do the best that it can for its employer, as in its line reputation is the most important asset.

The cattle are no sooner left at the unloading chute than they are unloaded with all possible dispatch, whether they arrive in the night or during the day. They are counted when put into the yards and locked in them. In the early morning they are fed and watered under instructions by employees of the stock yards company. The food and water are furnished by the company. In some instances the cattle are sold without grading, as grading may not be necessary. In other instances they are graded according to quality and sold as different lots on the basis of the grading. In some instances they are sold to one and the same buyer, notwithstanding the different grades. In other instances they go to dif- 
ferent buyers, as each may only want animals of a certain grade. When the animals are properly graded before sale, the returns are usually more satisfactory than if not so graded. When sold ungraded, animals not prime will discount the price on prime or high class animals more than the latter class will raise prices on the former.

The inspection of cattle at the stock yards is being brought to a high condition of efficiency. Cattle that are to be slaughtered if found diseased are virtually subjected to three inspections, but if not found diseased, the third inspection is not necessary. The first inspection takes place under federal supervision in the yards to which the cattle are consigned on their arrival. The object is to detect the presence of any easily communicable disease. If such is found, the pens are quarantined until disinfected.

The second inspection takes place as the animals are weighed. It is a dual inspection. It is made in the one instance by a federal officer whose duty is to detect disease such as may affect the quality of the meat, as, for example, lumpy jaw or tuberculosis. In the other instance it is made by an official who represents the stock yards, and it is his duty to detect animals which, though not diseased, may be of such character as to produce meat that does not kill well or is inferior. Such are cows too far gone in conception, and stags. In all instances animals that are suspects or physically defective are tagged by one of the inspectors. When so tagged, the price is discounted in the case of animals for slaughter, and cows too far gone in pregnancy are not slaughtered, but removed.

The third and final inspection is that given to the carcass of animals tagged by the federal inspector at the weigh scale. If the carcass of these is not condemned as human food, there is no further discount on the same. If it is condemned, it goes to the rendering 
tank and the owner is allowed for it a merely nominal price accordingly.

The cattle for slaughter are weighed, as a rule, in the forenoon when the weighing can be overtaken within that time. They have thus had time to take all food and drink they would take subsequent to the morning feeding, and previous to the weighing. The weights then made are taken as the basis of computation without further discount. When stockers are sold they are weighed at any time agreed upon.

When it can be accomplished, the cattle are sold to the highest responsible bidder early in the day. A glut of that kind of stock in the market, or other causes, may render it necessary to hold the stock over to the nexit day or even for a longer period. The commission firm then hands over a check to the owner if present, or forwards it by mail if he is absent. The check represents the price received for the cattle, less the commission and other expenses. The other expenses include terminal charges for shunting the car, yardage, food, and weighing, but the seller has no part of the cost of inspection to bear. The commissions, though they vary, hover in the neighborhood of 50 cents for each cattle beast beyond the age of calfhood, and of 25 cents each for calves. 


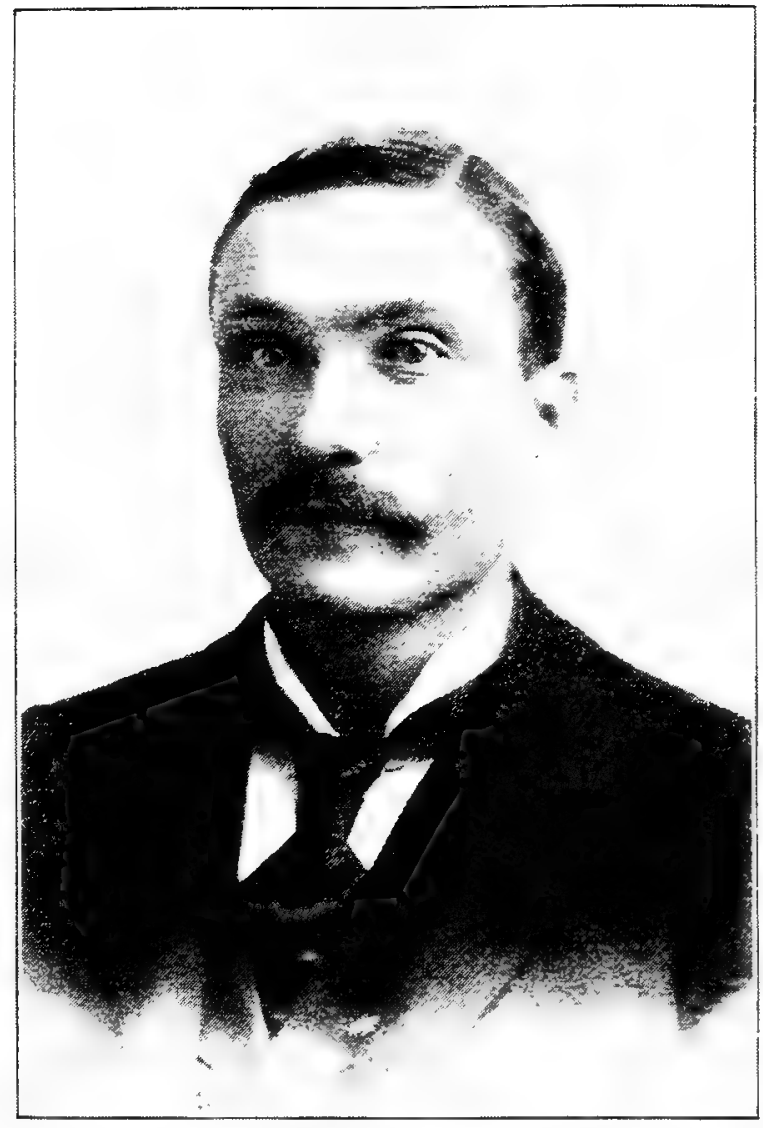

GEORGE CRAIG

Feeder and Fitter of Several International Prize-Winning Animals at the University of Mincesota 


\section{CHAPTER XVI}

\section{GROWING AND FITTING CATTLE FOR EXHIBITION}

In the discussion the following phases of the subject will be considered: (I) How to secure the animals; (2) When the calves should come; (3) Milk furnished and its sources; (4) Fodders fed at different ages; (5) Grain fed at different ages; (6) Roots fed at different ages; (7) Management on pasture; (8) Training for the shows; (9) Washing cattle to be shown; (I0) Fat cattle in transit for the fairs; (II) Management on returning from fairs; (12) Exhibiting bulls in the beef classes; (13) Exhibiting females in the beef classes; (I4) Exhibiting dairy and dual types; and (I5) Miscellaneous observations.

The discussion, in so far as it relates to selection, will scarcely touch upon the question of inheritance and the influence which it exerts, as these have been discussed at length by the author in the books, "Animal Breeding" and "Feeding Farm Animals." It will dwell mainly upon the feeding and details of management that, under average conditions, will be found helpful in the growing and fitting of animals for exhibition in the fat classes. The fitting of breeding animals will only be discussed in so far as the methods differ from those that should be followed when growing and fitting animals in the fat stock classes.

How to secure the animals.-As those animals only that have an aggregation of best qualities centered in their conformation and development have any chance of winning, and as heredity exercises a powerful influence on the possession of such qualities, those that 
attempt to grow cattle for exhibition should give due thought to the performance of the near ancestry when this can be ascertained. But in growing animals purely for the block, this may not be ascertainable, as, in some instances, the future winners have been obtained from feed lots even, in which young animals from the range have been gathered to be grown into baby beef.

When grown for breeding, the rules of the fairs of today make it necessary that they shall be purely bred, and properly so. In what is known as the fat classes, that is, the classes which consider only fitness for the block, in some instances, purity in breeding is called for, but in others it is not. The fact is significant that in the grand sweepstake prizes, that is, the highest prizes in the classes shown according to age, the grades or crossbreds are more frequently winners than purebreds. Such a result would seem to indicate that there is, in some instances at least, a renovating power in alien blood.

In some instances, pure-bred animals shown are bred by the exhibitor, but more frequently the very highest winners are not so bred, but purchased. This fact shows the comparative infrequency with which animals possessed of what may be termed phenomenal possibilities of development appear. Those prepared for the fat classes only are purchased to a greater extent even than the former. The instances in which herds of but ordinary size produce phenomenal winners from time to time are very rare, but they are not entirely wanting, and when found they reflect great credit on the judgment and skill of the breeder. Even the agricultural experiment stations have not in the past been able to produce many of the prize-winning animals which they have shown at the leading live stock fairs.

When the effort is made to breed such animals at home in the pure-bred form, the necessity for a high standard of excellence in the form of the parents and 
performance in the near ancestry will be at once apparent. The expectation may also be legitimately cherished, that the progeny of highest promise will come from parents approximately or full mature, and moving toward or at but never much beyond the zenith of development. The dam should also be maintained in that condition which is most favorable to normal development of the kind wanted; that is, she must be maintained in vigorous health and in that condition of flesh that will furnish a reserve in the system from which some materials may be drawn to feed the young calf after birth, but without being present in a degree that will in any way hinder development before birth.

The indications at birth are not absolutely safe guides as to future possible development, but they are of considerable value, more especially when viewed from the negative standpoint; that is, when they are viewed from the standpoint of unsuitability. Such evidences include undersize, undue smallness of bone, too much flatness of rib, and too much length of limb. Usually, however, such positive indications are present as are furnished by robust and symmetrical development, accompanied by much depth and width of body, straightness of top and bottom lines, and strength and mellowness of skin. The evidences of much capacity for development can be secured with unfailing certainty after some days or weeks of actual demonstration through the growth made. This explains why it is possible to secure animals in herds where such production is not especially sought, and even among calves from the range that are being grown for baby beef.

The character in the development sought in the various classes of animals reared will vary. With animals of the dairy types, a high condition of flesh is not essential to preparedness for exhibition, but it may count rather against than for the chances that the animal will win in the competition. It may be inter- 
preted as indicating a tendency in the animal to take on flesh unduly, in a degree beyond which it may actually exist. On the other hand, a lean condition may represent the capabilities of the animal unfairly. Cattle of the beef types are usually developed to the fullest extent possible, both with reference to symmetrical growth and finish that is not considered excessive. It is excessive when the flesh becomes flabby and the animal becomes so overloaded that the walk becomes gouty. The degree of the finish in dual types is more of the intermediate character, but is influenced considerably by the precise object for which the animals are shown.

When the calves should come.-In the show ring, size and weight are considered as well as conformation and finish, hence, if two animals should be equal in all other respects save in size and weight, that which excels in these respects will carry the award. The advantage from getting all the size and weight possible, therefore, in the competing animals will be at once apparent, hence the importance of securing the greatest age possible in the animals within the time limit which determines the class in which they will show. This fact should never be lost sight of when animals are mated from which progeny is sought which may, in due time, be exhibited.

The rules governing the classification with reference to age are usually the same in all the leading fairs. Animals in the fat classes show as calves, yearlings, and two-year-olds. No classes are opened for fat cattle beyond the age mentioned, as it is not thought desirable to encourage growing fat animals to a greater age than that mentioned, owing, first, to the profitless character of such feeding, and, second, to the little demand for such meat.

The fair circuit usually opens sometime in August, and continues virtually until the near approach of the Christmas season. By the fair circuit is meant the suc- 
cession of leading fairs held in contiguous states, and so arranged as the result of conference between representatives of the various boards that show animals may be taken from one fair to the next with the least amount of travel in transit. More commonly the fat stock fairs are held in November or early in December, that highly finished meat may come into the market at the Christmas season when it is much in demand.

September I is the date now generally fixed upon as the period from which the age is determined in the classes mentioned. Suppose that an animal is born September I or subsequently, it can show in the calf form or class any time the following year, as a yearling any time the next year, and as a two-year-old any time the year next following. Thus a calf born as stated, if shown in August, would be exhibited in the calf class when not quite a year old, and it would still show in the calf class until more than 5 months old. The same would be true of animals in the one-year form, which could show as yearlings until more than 27 months old, and of two-year-olds which could show as such until more than 39 months old. But should the animal be born one day before September I, it could not be exhibited in the calf class at all. It must be shown as a yearling the first year that it appears in the ring and as a twoyear-old the second year.

Since it is not always possible to control the age at which calves will be born, and since, in many instances, calves which show much excellence subsequently, will come into existence at a period much later than September $\mathbf{r}$, it is manifest that these will be shown at a disadvantage when pitted against animals that are considerably older. To meet this difficulty, many leading fairs have opened two classes for exhibiting in the calf form and also in the yearling form, but not in the two-year form. These are known as the senior and junior classes. The date from which the age is counted 
for the senior classes is September $\mathrm{I}$ and for the junior classes January I. Calves of the latter class are generally allowed to show with those of the former, if entry to that effect has been duly lodged with the secretary of the fair, but the reverse of that is, of course, never allowed.

The same rules apply to reckoning the age of breeding animals, including animals of all three classes. But there is an additional class for breeding animals of both sexes, known as the aged class. All animals beyond the two-year form are allowed to compete against each other in this class. With breeding animals that are immature, it is quite important that they shall be born as near as possible to the date from which age counts as with animals grown only for meat.

Milk furnished and its sources.-The calf is allowed to remain with the dam from the time that it is born until it is two or three weeks old. Being thus allowed to take food in a natural way, the functions pertaining to digestion are almost certain to be normal in their action, and because they are the foundation for future development is well laid. But since the animals are to be large consumers of food, if they are to win in the show rings, proper distention of the stomach and digestive organs should begin early, hence they are shut away from the dam within the time limit mentioned, in order to encourage them to take other food, which they will do toward the end of the period stated, if separated from the dam. If with her, instead of taking such food to satisfy the appetite, they will take milk from the dan.

After removal from the dam, they are to be allowed to nurse three times daily for a week or two, and subsequently are allowed to nurse but twice daily. Careful attention should be given to the feeding and management of the cow in order to stimulate the milk flow to the greatest extent possible, especially after the calf becomes able to take all the milk furnished by the cow. 
This, of course, is accomplished by feeding the dam foods rich in protein and possessed of the desired succulence. As soon as it is clear that the calf will take more milk than the dam furnishes, the aid of a nurse cow should be sought to furnish milk that will supplement that of the dam. This, though it may be expensive, is expedient, for the reason that no food has been found equal to new milk in promoting large and mellow growth during the first year of the calf's life.

The calves are allowed to nurse until 12 months old, and, in some instances, until 15 months. This is gauged largely by the date at which the calves are put on exhibition, as, except in the junior classes, milk is usually withheld on the return from the fairs. Its withdrawal at such a time becomes one element of reduction in the forcing process that has been found a necessity with animals that are to be shown the following year.

It is of vital importance that the nurse cow chosen shall be healthy and sound in every respect. It is especially important that she shall be free from tuberculosis, or the danger will be present that the disease may be transmitted to the calf and thus destroy its chances of being a winner in the show ring, especially after the first season. The future of many an animal of rare promise in the beef cattle classes has been blasted in this way.

The nurse cow should be of a quiet disposition, otherwise she may resent the nursing of a large, strong calf and the rough bunting of the udder which is an accompaniment of his nursing. It is not every cow, by any means, that can be trained to allow such a calf to take milk from her. Moreover, she should be a large producer of milk and a persistent milker in order to furnish milk for a period sufficiently long. Suppose she is introduced at the end of the fourth month, and the calf is allowed to suck until I2 months old, she would be required to furnish milk for eight months. If the calf 
takes milk until I5 months old, a second nurse cow would be required to furnish the same. The nurse cow, as in the case of the dam, should be fed with a view to secure a large milk flow. Of course. it would be possible to furnish milk in excess. It would be in excess if it seriously disturbed digestion in the calf, or if it too much hindered the taking of other food.

The character of the milk is important. It is more than questionable if milk high in butter fat is the best. In some instances, especially with young and delicate calves, milk that tests unusually high has unsettled the digestion beyond the possibility of recovery, and when the results have not been so serious the appetite has been lessened. Quantity in production in a nurse cow is far more important than high rank in butter fat. The fact is significant that grade Holsteins are, in nearly all instances, selected as nurse cows. It is also important that the cows wlich furnish milk shall not be chased or worried lest the influence on the milk should disturb the rligestion of the calf.

Fodders fed at different ages.-Reference has alrearly been made to the necessity for distention in the digestive organs, which should begin at a comparatively early period. (See page 8o.) Such distention is, of course, brought about by feeding fodders and roots, that is, by feeding the more bulky foods. The proper relation in such distention is preserved by feeding the bulky and concentrated foods in due proportion. To preserve this relation calls for the exercise of no little skill and of continual watchfulness on the part of the feeder. Too little distention will retard development. Too much distention means too much of paunchiness which would hold back from show-yard honors.

The best fodders for feeding in the calf form include clover cut when in blossom and well cured, but early cut alfalfa and pea and oat hay are also good, and the same is true of timothy of fine growth and clover 
mixed, providing the timothy does not preponderate in the mixture. Any kind of clover will answer, that is, of fine growth, hence the pre-eminent suitability of alsike clover for such feeding. When the fodders can be varied somewhat, the consumption will be greater, a result that is not to be desired. The same fodders should form the bulk of those fed in the yearling and the twoyear forms. During the period between the return from the fairs and the grazing season, good fine grown com fodder may be fed once a day, and it should not be fed to any considerable extent, if at all, between the season for pasturing and the fair season following. As the animals are then being fed large quantities of grain, they will not consume any large amount of such fodder.

The calves will begin to take good sweet fodder when not more than two weeks old. It should then be furnished to them continuously from that time onward. High quality in the fodder is essential all the while, but never so much so as during the first months of the life of the calf. The fodder should be fed in two or three feeds daily, according to circumstances. It should not be fed much in excess of the needs of the animals. and any rejected portions should be promptly removed at each time of feeding.

While in the calf form, green food should be given when in season. Such food may include green clover in its different varieties, oats and peas of reasonably fine growth, small turnips fed along with the tops, rape, green corn, and sorghum, also ensilage. More or less of these will be consumed by the animals when on pasture, and they will be consumed in large quantities subsequently, but they are not to be fed on it up to the time of the fairs, as they may hinder too much the large consumption of grain necessary as the fair time is approached, and may tend too much to produce soft flesh. Ensilage is not much fed, if at all, to calves, especially when they may have a sufficiency of field roots, but it 
may be fed at certain times to older cattle. Green food may be made to take the place of pasture entirely, when the latter may not be had, but some grazing is to be preferred, because of the gentle and enforced exercise which it produces.

Grain fed at different ages.-When cattle are grown for breeding, it is absolutely necessary to guard against feeding to the extent of injuring the breeding powers. When grown for exhibition in the fat classes, this caution is not necessary, but the necessity still exists for exercising care, lest the concentrates fed overtax the digestive organs through feeding them over-strong and to excess in quantity. To feed just that amount of this class of food and of such strength as will produce growth and fatness in the proportions sought without overtaxing the digestive organs is a problem that calls for the exercise of continued skill and watchfulness on the part of the feeder.

The standing grain and by-products for such feeding are ground oats, wheat bran, ground corn or peas, and oilcake. Peas are considered superior to corn if the choice must be made between these, except when the show season approaches. Corn would then, on the whole, be superior. Barley and rye may be used to a limited extent, but are not considered so suitable as the foods named, nor has cottonseed meal shown adaptation so high as oil meal.

While in the calf form, the feeding will, in outline, be as follows: Start the calves on a mixture, say, of equal parts, ground oats and bran by measure. This should be made constantly accessible to them until they are, say, three months old. If kept before them much longer than the period named, the appetite will be less keen for other kinds of food, because of the extent to which the meal would be consumed. The importance of so regulating the food that the various kinds will be eaten in due proportion cannot easily be over-estimated. 
The calves will begin to take such food when they are not much more than two weeks old, if given access to it. This would be accomplished by putting grain in a box even when the calves are still with the dams, providing the latter are tied. Though made constantly accessible during the period named, it is better not to feed it much in excess of the needs of the calves, and the unconsumed residue should be removed sufficiently often to keep the food in the highest condition as to palatability.

About two weeks subsequent to the time when the calves begin to take meal, or when they are about four weeks old, it will be in order to add ground corn or peas so as to make the mixture contain, say, Io per cent by weight of the factor added. Two months later, or when the calves are about three months old, oil meal should be added and the grain mixture should then be about as follows by weight: Oats, 50 per cent; bran, 35 ; corn or peas, Io, and oil meal, 5. When the calves are, say, five months old, it should be further changed so as to contain by weight: Oats, 45 per cent; bran, 30 ; corn or peas, 20, and oil meal, 5. If the calves are not carrying enough flesh, as the season for exhibiting draws near, the mixture should be strengthened by adding corn or peas. By the time the calves are 12 months old they will take from, say, 8 to 12 pounds of meal daily, and should weigh from 900 to 1,000 pounds.

In the one-year form, when returning from the fairs, the grain should be reduced from 2 to 5 pounds daily, for reasons given below (see page 325 ), but the proportions in the mixture are virtually the same as those fed preceding the fairs, except that, in some instances, the proportion of corn fed is reduced. The reduction thus made should continue until April or May. The amount fed should then be gradually increased, taking about four weeks to bring the animal up to the maximum amounts; that is, to all that they will eat with good 
relish. The proportions fed are then changed to the following: Oats, 35 per cent; bran, 30; corn or peas, 25 , and oil meal or oilcake, 10 . The object of the change is to secure a higher condition of flesh. If still too low in flesh, more corn or peas should be fed than in the proportions given above. If the animals are to be sold

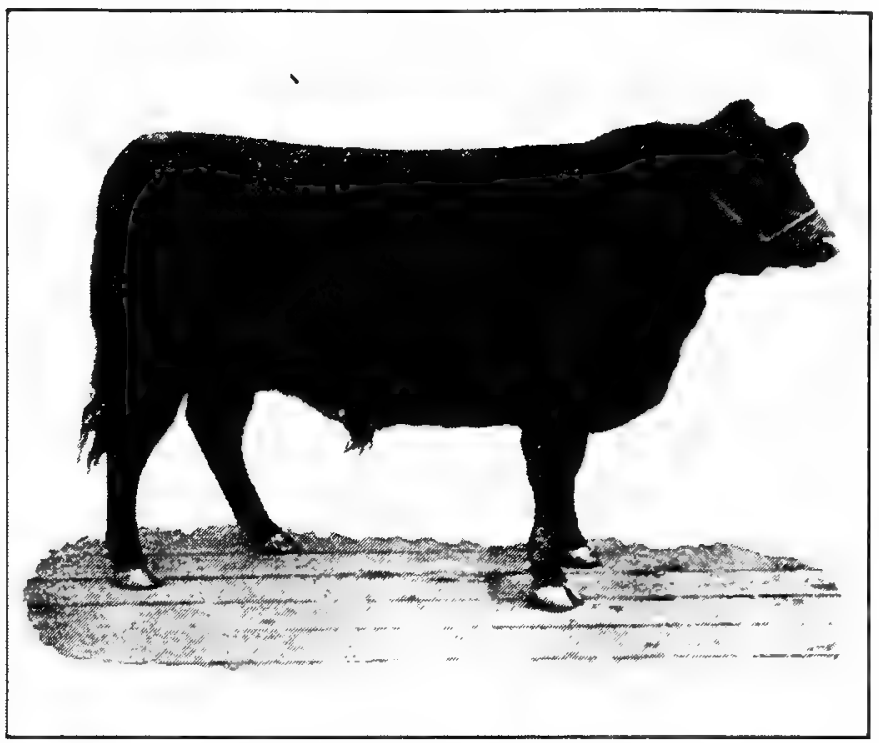

ABERDEEN ANGUS STEER, BLACK ROCK

Grand Champion at the International Fat Stock Fair, 1905

(By courtesy of the owner, lowa Experiment Station)

at the close of the exhibition following, for, say, two months before the time of exhibiting, the proportions of the meal should be about as follows: Oats, 35 per cent; bran, 20; corn or peas, 35 , and oilcake, Io. In the one-year form they should consume a little more than I pound daily to each Ioo pounds of live weight. They should then weigh from I,350 to I,500 pounds. 
In the two-year form, on the return from the fairs, the grain fed should be reduced to the extent of nearly 50 per cent of the amount previously fed, and this reduction should continue, as in the case of the one-yearold cattle, until April or May. As with the former, also, about four weeks should be consumed in leading up again to the maximum amount of concentrates to be fed during the remaining months of feeding. The proportions, as in the case of finishing animals in the oneyear form, will be: Oats, 35 per cent; bran, 20; corn or peas, 35 ; and oilcake, Io. If more of fatness is wanted, the corn or peas may be further increased, but this will seldom be found necessary. The amount of concentrates consumed will be a little more than I pound for each too pounds of live weight in the animals, which means heavy feeding, as, when finished, they should weigh from $\mathrm{r}, 700$ to $\mathrm{I}, 800$ pounds.

Roots fed at different ages.-If young cattle are to make the greatest growth which it is possible to secure from them, they must be given a certain proportion of the food in the succulent form. Succulence favors correct digestion, and thus promotes correct development, and it also influences juiciness in the meat. In summer succulent foods may easily be obtained through pasture or soiling sources, but in winter their chief sources are field roots and silage.

If succulence is fed as roots only, or as silage only, the former is the superior food of the two for such feeding, but its superiority decreases with advance in the age of the animals. In roots the elements of nutrition are more perfectly adjusted to the needs of young animals, and they have a more beneficent influence on the digestive organs. But to furnish variety, and for other reasons, after calfhood is passed, both may be fed with higher advantage than either alone. Rutabagas and mangels are chiefly fed, but, in their absence, turnips or sugar beets may be substituted. 
To animals in the calf form, roots should be fed to the full extent of the consuming power in the calves, from the time that they will take them until the pasture season begins. They will begin to eat roots, if thinly sliced or pulped, as soon as they will begin to take grain, and soon they show much fondness for them. They are not fed during the season of grazing, but they should be fed again as soon as the grazing ceases, and even earlier to the full extent of the consuming powers when the roots are obtainable at so early a period. By the time that the second winter is reached they will consume from $I 5$ to 20 pounds a day.

In the one-year form, the feeding of roots should be continued and up nearly to the limit of the consuming powers, but if corn ensilage can be fed, also, then it may be advisable to feed, say, I 5 pounds of roots daily, and Io to I5 pounds of ensilage. The feeding of both ceases as soon as the grazing season is reached. When the grazing season is over, roots should be given as before, but not ensilage, except in the absence of roots, until the show season is past, as roots have higher adaptation for keeping the system in tone than ensilage.

In the two-year form, the feeding of roots is continued on much the same plan as the feeding of the same to cattle in the one-year form. On the return from the fairs, roots should be fed freely, but not necessarily to the extent of the consuming powers of the animals. The frame has now become well developed, hence it is not necessary to feed roots so well adapted to such development in quantities so large, relatively, as at an earlier age. About I5 pounds of roots daily will suffice, and from Io to I 5 pounds of corn ensilage, or from 25 to 30 pounds of roots daily in the absence of ensilage.

Management on pasture.-Cattle that are being thus grown for exhibition should be grazed during a portion of the year. The object sought is not to cheapen the cost of food so much as to secure benefits which accom- 
pany the grazing. These are such as relate to exercise and comfort at night when the weather is warm. Exercise is to some extent enforced when the animals are grazing.

The pasture should be located near the stables as a matter of convenience. A large pasture is not necessary, as the consumption of grass is relatively small because of the amount of grain that is being fed all the time. Nor is it absolutely necessary that the grazing shall be abundant, for the reason just given, but it is better that it should be plentiful. Clover pastures furnish excellent grazing, but good bluegrass is also very suitable while it retains its succulence. Other cattle should not be allowed to graze on such pastures, especially when the show animals are present, as the influence of their presence would be disturbing. Nor should such stock as sheep or swine graze in those pastures, as such grazing wotld make the pastures less acceptable to the show cattle.

The grazing period may begin as soon as the days are fine, and the grass is reasonably plentiful. This, in the northern states, will be about the first of May. As these are receded from southward, it will, of course, be earlier. The cattle should not be allowed to graze later than from four to six weeks of the season for exhibiting, as the consumption of other foods that firm the carcass for the show ring will not be eaten in sufficient quantities.

When first turned out to graze, it should be only for a short season at first, morning and evening, gradually lengthening the period until the cattle may be out from one to two hours each end of the day. Later, when the nights become warm, they remain out at night between the close of the evening meal and the time for giving the morning meal. More coolness and consequently more comfort can then be obtained without than within the stables. 
When thus kept out at night, they should be kept in the stables during the cay, but in well-ventilated apartments that are made dark during the time of flies. These conditions may be secured by covering the open windows with some substance, such as coarse sacking. Wire netting is objectionable, because it does not sufficiently darken the stables. Flies seek the light and shun the darkness. While grazing, the animals should be given as much good cured hay as they will eat. The system seems to crave some dry fodder at such a time.

Training for the shows.-The training to which the cattle are subjected has an important bearing on the placing of the awards. By training is meant practicing the animals in leading, so that they will lead readily and show to advantage when they are led. It also includes practicing them in standing in positions that are calculated to make the most favorable impressions on the judges. Intractability in an animal when in the show ring makes an impression so unfavorable that such an animal is seldom awarded high honors in a close competition.

The training begins by tying the calves daily or frequently for a time in their stalls. This is done to get them familiar with the halter. They should then be led out quite frequently to secure that ready submission to the requirements of the attendant which is so necessary in such animals. It is scarcely possible to begin such training at too early an age, as the earlier it is begun, the more easily is it accomplished, and the more ready and complete is the submission to the requirements of the attendant. Thus carefully trained to lead and to submit, the animal, so to speak, never becomes fully aware of its own strength.

For some time before the fairs, the animals should be led out quite frequently and trained to follow readily under conditions in which the surroundings vary, at least in some instances, as when they are'led among 
other animals, to accustom them to such surroundings. Especially when beyond the age of calfhood, they should be led some distance on the near approach of the fairs. The rule with some herdsmen is to have them led, say, half a mile every day, or half a mile each way every other day. This means time and labor, but it keeps the animals well upon their feet; that is, it helps to give them an ease and grace in action which they would not otherwise have. They are also accustomed to stand or advance at the command of the attendant, and to stand in show attitude, that is, with the feet evenly and naturally placed, the fore feet and the hind feet being in line when viewed from the side, and the head carried a little higher than the line of the back. Should the feet be misplaced, the herdsman touches the hoof that may be too far forward with his foot, in response to which the animal will move it back. Should the hoof be set down too far back, the animal is led up far enough to secure a forward movement of the $\operatorname{limb}$, because when the feet are misplaced the back is affected. The cattle should be made to go forward or backward readily and also to turn around and get in place again when necessary.

The award, as intimated, may be much influenced by the behavior of the animals in the show ring. If a cattle beast acts nervously in the ring, it will not stand naturally, and if it does not, the judge cannot properly estimate its merits. If it is restless in the ring and is frequently getting out of position, a prejudice toward it is created in the mind of the judge, which is certain to result in lowering the place that might otherwise be assigned to it. The attendant cannot afford to be otherwise than alert in keeping the animal in position when the judge is inspecting, as in a very close contest an impression made on the mind of the judge by some particular pose on the part of the animal may result in securing for it victory or defeat. To work out the 
details of the training referred to takes much time, but they are usually part of the price that must be paid for show ring honors.

Washing cattle to be shown.-While the practice of washing from one to several times is extended, more or less, to all classes of beef cattle, and, in some instances, to the other breeds of cattle, it is done to a much

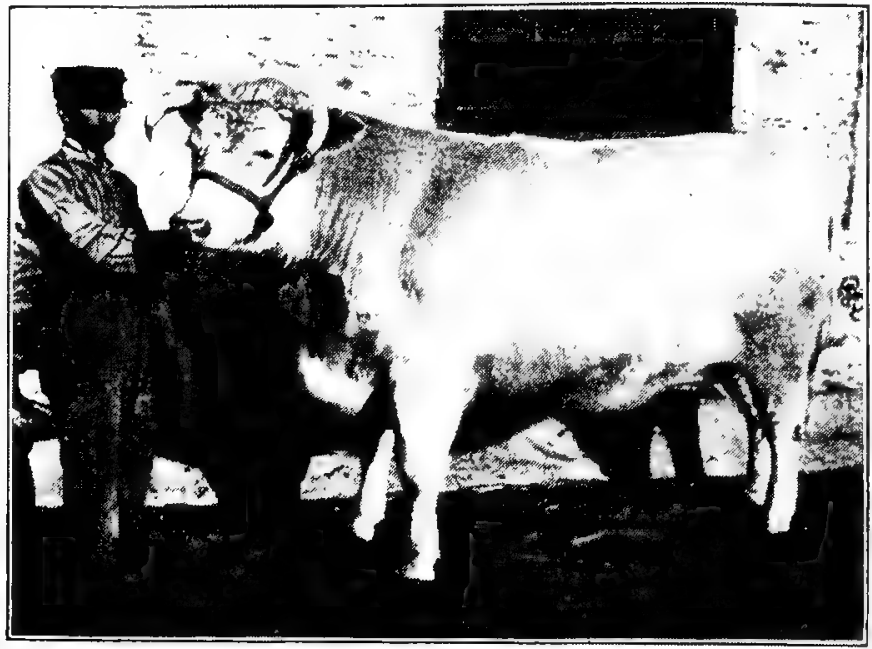

PURE SHORTHORN STEER, CRIMSON ROBE An International Cuampion

(By courtesy of the owner, Minnesota Experiment Station)

greater extent with the former. The following are prominent among the benefits claimed for washing: (I) The dust, which would otherwise be present, is removed from the hair, and this effects a considerable saving in the amount of grooming that would otherwise be necessary, and (2) this healthy action of the pores of the skin is thereby promoted, and this has a beneficial 
influence on the hair, as it tends to make it more soft, pliable and luxuriant in its growth.

In some instances advantage is taken of the elements to do a part of the washing. The cattle are allowed to remain out occasionally while a warm rain is falling, and which, in due time, is followed by careful grooming. The soft character of the water adds to its suitability, but the alkaline element is lacking which is so helpful in loosening the hold that all foreign matters may have on the skin, as in hand-washing, hence, thus far, it is less potent than hand-washing. But when the shower is copious and prolonged, the benefits are pronounced.

Except in the case of beef cattle, more than one washing is seldom given, and not till within a few days of the fair; but, in many instances, they are not washed at all. With all animals, however, that are much groomed, some washing will prove labor-saving. In some instances, washing is accomplished through the medium of the hose. This method, though speedy, is not so efficacious as hand-washing, but the hose may be profitably used in removing the alkaline substances from the hair which have been applied by the brush used in hand-washing. It is common to hand-wash fat cattle from two to four times during the season preceding the fairs, especially when they come late, as in early December. These washings will be given, say, one in September, one or two in October, and one in November, from four to seven days before the opening of the fair. Some exhibitors practice washing as soon as the fair is reached. This may be necessary when the animals have been long on the way, as when delayed in transit, and not sufficiently supplied with litter, or when exposed, going from fair to fair, to the dust, which is inseparable from such transit. But the aim should be to avoid it as much as possible, as there is not sufficient time for the accumulation of the oil removed by washing to allow the hair to recover its usual pliant condition before 
the animals are put in the ring. Exhibitors are by no means agreed as to the amount of washing that is beneficial, but all are agreed that some is helpful. Excessive washing, besides being wasteful of labor, is thought to tend to the promotion of a harsh condition of the hair, a result probably of removing too much of the oily principle from the hair which it would other-

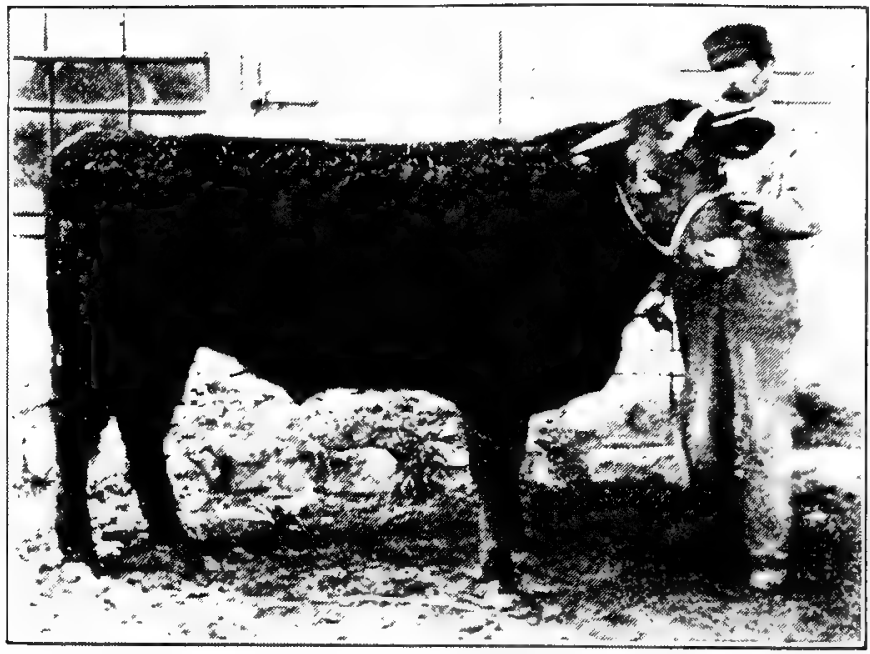

GRADE SHORTHORN CALF, COLLEGE BOY

A Great Prize Winner at the International Fat Stock Show, Chicago

(By courtesy of the owner, Minnesota Experiment Station)

wise possess. There may, however, be other reasons for the harshness of hair thus referred to.

For hand-washing, a mild day is chosen, and, preferably, a fair one. Soft water is used, which is furnished in buckets as it is wanted. Tar soap or soft soap should be added in sufficient quantity to make a good suds. With a suitable brush this is applied to all parts of the animal, and is rubbed in sufficiently to raise 
or loosen all foreign substances. Clean soft water is then applied, also with a brush, and for a period long enough to remove all extraneous matters. With a piece of shingle or ordinary barrel hoop, the water is swept out of the hair, and the animals are covered with a woolen blanket until dry. Much care should be exercised as to the kind or kinds of soap used, as the tendency with some of these would be to injure the hair.

Fat cattle in transit for the fairs.-When cattle have to be transported to the fairs by rail, which is usually the case, the food should be reduced and more or less modified, according to the kinds on which they have been maintained. This applies to grain and green food, but not to hay. For several days before shipping, not fewer than four or five, the grain portion of the diet should be reduced gradually, until the reduction has reached, say, 2 to 5 pounds daily, according to the size of the animals. At that time the proportion of the oats in the grain should be increased considerably, and this change should be adhered to until the fair grounds have been reached. Oats tend less to a lax condition of the bowels when cattle are in transit than other meal factors. The whole amount of grain fed should be reduced by one-third, while the cattle are in transit. To further lessen the tendency to such a condition, the proportion of roots fed should also be reduced by a similar amount.

When at the fairs, the food should be the same, as far as possible, as that fed at home. It may be the same exactly, except that it may not be possible to secure the variety of green food that may be desired, nor is it always practicable to get the same or an equal quality of hay. The grain fed as meal, also, and cut fodder necessary, should be carried along in sacks. The meal may be mixed where all get the same mixture of meal, but it is better to have a quantity of some kinds also separate for certain emergencies that may arise, calling for varia- 
tion in the feeding. The roots should also be taken along, but, of course, in the unprepared form, save when they are fed, as dried sugar beet pulp.

The same reduction in food should follow when the return journey is made that was made on the outgoing journey, except that it cannot begin so long beforehand, and, probably, not until the day before shipping. Full amounts of food should be fed when on the grounds, but not immediately, as the somewhat hungry condition of the cattle may result in gorging if they are carried forward too quickly.

When taking cattle to the place of shipment, except in cool weather, choose the early or late portion of the day. The character of the weather, the weight of the cattle, and the distance from the shipping point should decide whether the animals should be drawn or may be led. Unless in unsuitable weather, they may usually be led a mile without harm, all the conditions being favorable. On the return journey, even a longer walk should d) them no harm. Ample bedding should be provided, soft and dry, also water in barrels properly covered. Each animal should be tied in a suitable part of the car, and crowding should be avoided.

The shrinkage in weights will depend on such conditions as the age of the animals, the length of the shipments, the frequency of the exhibits, the length of the fair circuits, and, to some extent, the disposition of the animals. Other things being equal, the younger the animals, the less will they shrink. The longer the journey, the more frequent the exhibits, and the longer drawn out the contests, the larger will be the shrinkage. Animals quiet in disposition lose less than nervous ones. It sometimes happens that some growing animals will make considerable increase during a fair circuit of three or four weeks, but it more frequently happens that they remain without much change in weight in either direction. 
Management on returning from the fairs. - When fat cattle have been returned from the fairs, the grain fed should be reduced. The following are chief among the benefits which come from such reduction: (I) The tension on the digestion is relaxed for a time; (2) the system is cooled, as it were; (3) premature finish in the animals is avoided; (4) more continuous and prolonged increase is secured, and ( 5 ) it thus becomes possible to have the animals reach the next show in proper bloom. If the tension of the heavy feeding of grain is continued throughout the year, unless when animals are to be shown but once, the digestive and assimilative organs weaken through overwork, and when this point is reached, they are slow to recover, which means reduced gains, and, in many cases, they never regain their former vigor. When the carcass is in shape for the show ring, it is firmer than it was at an earlier period. This increased firmness is the outcome of feeding large quantities of nutritious concentrates reasonably rich in carbon. This condition of the system which makes the animals enjoy lower temperatures than they would under ordinary feeding has, no doubt, given rise to the common phrase that the animals should be "cooled off," a result that is brought about by slacking on the grain food and increasing on the green food. The green food brings increase of the juices in the flesh, and, in consequence, the premature finish or ripening that would otherwise result is warded off. This change in the system makes continued increase possible as long as it may be necessary to practice it. The system thus prepared is ready when the time comes to undergo another forcing period, which should be so timed that the animals may be shown when in finest bloom. Should an animal be overdone, when exhibited, it is virtually impossible, however managed, ever again to bring it into a really good condition of bloom.

The proper reducing of the food, the time that should 
be covered by the reduction, the duration of the period of the forced feeding that should follow, the timing of this so that the animals may be shown when in best bloom, and the apportioning of the rations so that this result will follow, call for the exercise of much skill and judgment on the part of the feeder in charge. In the case of breeding animals, the preservation of the breeding powers must be maintained, as it is against the rules of live stock exhibitions, and, therefore, morally wrong, to show animals of sufficient age in the breeding classes after they have become unable to propagate their kind. This is a more difficult problem than any that confronts the grower of show cattle with no other mission than the production of flesh. The difference in the ability of feeders to thus sustain breeding power is marked; nevertheless it is seldom that it is accidental.

On the return of calves from the fair circuit, the grain should be at once gradually reduced in quantity and in strength. The extent of the reduction necessary is influenced to some extent by the condition of the animals. The proportion of the more carbonaceous concentrates in the food, as corn, should be reduced. The reduction in quantity will be from 2 to 5 pounds daily. There should be increase in the roots and other food fed. (See page 3I6.) This reduction should continue until the latter part of April or the first part of May following:

On the return of yearlings from the fair circuit, a similar reduction should follow in the strength of the concentrates, as in the case of calves. The extent of the reduction should be greater, amounting, in some instances, to fully 50 per cent. The green food fed should be correspondingly increased. (See page 3I3.) The period covered by the reduction with these also continues until late in April or early in May.

Exhibiting bulls in the beef classes.-The food given to bulls when growing them with a view to exhibit them, as well as for service, is not far different from that given 
to fat cattle grown for the show ring, as above outlined. Two points of difference, however, should be observed. The first is, that the bull should not be fed so large a proportion of carbonaceous food like corn, as is given to the steer, and the second is that he should not be loaded down to the same extent with fat. Unless these points are well guarded, the breeding powers of the bull will fail. This means, therefore, that he will not develop quite so quickly as the steer, nor should be be shown in so high a condition. He must not be loaded down to the utmost with Frm flesh, but this does not mean that he shall not be in a high condition of flesh.

The reduction in the food on returning from the fairs is even more pronounced than in the case of steers, but the extent of the reduction called for is, of course, much influenced by the character of the feeding previously. The feeding of large quantities of corn ensilage when it is possible to feed roots instead should be avoided, but, in the absence of roots, moderate quantities may be fed. These points of difference in feeding apply to all the years during which the bull is shown. After maturity is reached, the amount of concentrates called for to maintain the bull in good flesh is less, relatively, than previously, unless he is much used in service.

The difference in the amount of exercise called for by bulls thus grown as compared with fat steers is even greater than the difference in food requirements. Though the food furnished should be of those kinds most favorable to the development of the generative functions, without ample exercise these will not develop healthfully. This means that the young bull niust be given larger liberty from the first, and that he must be more in paddock or pasture, even at the risk of. less rapid growth, than would result from taking less exercise. This difference applies to all the years of the show yard career of the bull, but its importance is greatest, rela- 
tively, while the generative organs are in process of development.

The extent to which such a bull may be used in service cannot be given by rule, because of the great difference in inherent energy in such males. The statements given below regarding service must, therefore, be taken as approximate only. It is about certain, however, that in the calf form the males should, as a rule, be held back from all service, but to a very limited extent there may be exceptions. In the one-year form no harm should follow mating with 12 to 15 females, the time of service not being in too close succession. Any excess in service would draw too heavily on the energies of the system, and this would so far retard development. On the other hand, the generative powers are strengthened rather than weakened by judicious use. In the two-year form service may be given to not more than 25 to 30 females, observing the same precautions as previously mentioned with reference to the timing of the services, which, to some extent, it may be possible to control. In the three-year form, the amount of service called for may be materially increased, and this may be continued through succeeding years. But the amount of service required from such a male should in no instance be so much as may be exacted from breeding bulls that are not fitted for being exhibited.

It is fortunate for all concerned that the season when service is most required is that which follows the show season. That is the season when they are being given food that is the best suited to sustain in healthy action the generative functions. This makes it less necessary to draw thus on the energies of the male during the season of most active fitting for the fairs.

The proportion of males who may thus be carried from year to year and yet prove valuable as breeders is not large, and the proportion of feeders who are masters in such management is probably still smaller, and 
yet instances are on record in which such males have been sure of good breeding until the meridian of vigor had been reached, and which, at the same time, had begotten a fairly numerous and valuable progeny. But in a large majority of instances, the breeding powers fail at an early age under prolonged exhibiting. Even when they do not fail entirely, the progeny are frequently lacking in average vigor, the weakened condition of the vital forces through heavy feeding seeming to descend to the progeny.

Exhibiting breeding females in the beef classes.The method of growing heifers in the beef classes is not materially different from the growing of bulls given above. As in the growing of bulls, the feeding must not be so forced as in the growing of young animals in the fat classes not intended for breeding, nor should the proportion of carbohydrates fed be so large, lest the breeding powers be injured, if not, indeed, destroyed. This means that corn should be fed to them with prudent caution.

When shown in the breeding classes, the aim should be to have heifers in the two-year form pregnant from six to seven months before the date of the show, and the same is true of cows that are exhibited as breeders, whatever may be their age. The evidences are then usually present to the eye of the skilled judge, that the rule of the prize list has been complied with, which calls for a pregnant condition in the females; but in the case of females excessively fat, it may not be easily possible to detect them. In any event, when breeding females are thus forward in pregnancy, the effect upon the appearance is helpful rather than harmful. When the pregnancy of females is thus timed, they may be shown under conditions the most favorable as to appearance. If more forward in pregnancy, the paunch is distended so as to disturb the harmony in symmetrical proportions. If shown while nursing a calf, the drain upon the system 
makes it not easy to sustain enough flesh. The calf is born during a period when the feeding is least forced, that is, two to three months subsequent to the fair season, and this is favorable to safe parturition.

The nursing period with such females should not extend beyond four to five months. If continued longer, the fleshy condition called for in animals that win mav not be sufficiently attained. It is the practice with some exhibitors to dry off their show females within a few weeks after the calf is born. This practice, favorable to the maintaining of high flesh, is adverse to the maintenance of healthy action in the breeding powers. It is usually very difficult to maintain continuance in breeding in females thus managed.

As in the case of breeding bulls, such females must be given more exercise than will suffice for animals shown in the fat classes that are not breeders. This means that the amount of exercise called for before the time of breeding and subsequently may be such as to hinder accumulation in the direction of highest finish. If the females fail to breed, no honest owner can show them in the breeding classes. This exercise can most easily be secured by allowing them to graze more than would be considered judicious in non-breeding animals in the fat classes.

On returning from the fairs, the reducing of the food, especially the concentrates, must be given due attention. The extent of the reduction should, in some instances, if not in all, be as much as half the entire amount fed. The meal should consist mainly of oats and bran. Roots should be increased, as with cattle in the purely fat classes. The hazard is not present that the heavy feeding of these will so stimulate the milk flow that milk fever will follow at parturition, an occurrence to be guarded against with females of the dairy and dual types when free milkers. But when the cows are nursing their calves, the proportion of the grain fed 
must be large to properly maintain flesh, and it should be rich in carbohydrates. In this way undue depletion in the system will be prevented.

The duration of the show career of a female in the fat classes varies much. This period is much influenced by the individuality of the animal and also by the skill of the feeder. Some young females thus grown fail to breed, and, therefore, never enter the show ring in the breeding classes beyond the one-year form. Other females again have appeared in the breeding classes and win every year until they are 7 or 8 years old. The latter instances are very rare, but some such may be cited. Usually a female does not appear again in the breeding classes beyond the age of 4 years. It is difficult to secure the fine bloom required in winners after they have been made to possess it for two or three successive seasons, while on exhibition. If a female has not been fitted for exhibition prior to maturity, it is probable that she will stand the pressure of fitting annually for a longer time than if shown at an earlier period.

That the high pressure feeding called for in fitting such animals for exhibition is antagonistic to good breeding is universally conceded. To so great an extent does this opinion prevail that the continued exhibiting of such animals is usually spoken of by breeders as a sacrifice, which is compensated for by the advertising which it furnishes. Nevertheless, the difference in feeders in ability to carry such animals on through successive years of showing is very great. If breeding animals could be shown in flesh less high than is usual, their breeding powers would not be so frequently injured, but up to the present time very high fitting only stands a chance of winning in the beef classes.

Exhibiting dairy and dual types.-The exhibiting of cattle in the dairy and dual classes is a very different proposition from exhibiting the same in the beef classes, 
and fitting them for exhibition is likewise very different. The aim is to show both when giving milk after a sufficient age has been reached to admit of showing them thus. This is not always adhered to in exhibiting cattle of the dual types, as with these even cows are sometimes shown in the beef form. Of course, males of the dual types are shown in a reasonably high condition of flesh, and also heifers not yet in milk. While condition does not count for very much with dairy animals in the show ring, it must not be entirely ignored. Though free milking has a tendency to lower the condition of the cow, there is a point beyond which leanness should not be allowed to go even in a dairy cow that is well fed, lest her vitality be lowered beyond that degree of vigor which is necessary to insure maximum production. This means that great milk producers will call for more carbohydrates in the food than other cows, in order to maintain a sufficiency of flesh. It is safe to say that the weight of opinion on the part of good judges is that dairy cows should not come into the show ring in a condition of leanness that is unattractive to the eye of the judge. On the other hand, they should never be put in that condition of high flesh that will weaken their bulk-producing powers. Happily, it is never necessary, when fitting these types of cattle for exhibition, to put them in flesh much different from that which they should carry in the home stables. But they should be given enough grooming to insure that the coat at the time of exhibiting will be decidedly attractive.

Except in the case of heifers that are shown quite young, the aim should be to have the cows shown in the best form possible for milk production. This means that they should come into lactation just long enough beforehand to allow the udder to get into normal condition by the time the animals are shown. One evidence of milk-giving capacity is thus presented to the eye, 
should the cows be shown with full udders. The practice of bringing the cows into the show ring with udders unduly distended, the result of deferred milking, is unnecessary and cruel, and should be frowned upon by the judge. In close contests it would aid the judge could he see the udders of very heavy milkers when both full and empty, but the fullness should be only that which the udder shows when the usual time has arrived for milking. When an udder is unduly distended because of deferred milking, its glandular quality cannot be determined because of the distention. The proper determination of such quality of the udder more than its size is linked with high milk-giving capacity.

The management of these types of cattle in transit to fairs is much the same as that given to cattle of the fat classes. (See page 323.) The temporary reduction in food will result in a temporary reduction in milk, but soon the equilibrium will be approximately regained when on the fair grounds, although it may not be entirely regained, because of the influence of the strange surroundings on the production of a nervous cow. The aim should be to feed practically the same food at the fair as was fed at home.

In contests at exhibitions which relate to the production of milk or butter, the time that the cows have been in lactation is greatly important. It is also important that the cows shall be on the ground some time before the contest begins. This is necessary that they may become accustomed to their surroundings, and that they may have time to regain the producing capacity temporarily lowered while in transit. Because of the disturbing factors which accompany such contests when conducted at fairs, many have grave doubts as to their utility.

Miscellaneous observations.-When growing and fitting cattle that are to appear in the show ring, no attention that may prove helpful in this work is so 
unimportant that it may be neglected. Among the attentions that must be given, though some of them to the casual observer may not seem important, are the following:

I. Careful attention should be given to the udders of the dams from the time the calf is born until it is able to take all the milk furnished by the dam. This period will be determined chiefly by the milking qualities of the dam. It may extend from only two or three weeks on to as many months. During this period, the dam should be milked twice a day, and, preferably, after the calf has taken its meal. The milk left in the udder is richest in butter-fat and when it does not go to the calf, it would seem correct to say that the hazard of disturbing the digestion is reduced. Experience has shown that milk overrich in butter fat, if given to calves without restriction, is liable to produce scours. When the excess of milk is thus removed twice a day, the hazard of derangement in the udder is removed and increased production is stimulated in the cow.

2. Castration and spaying should be done reasonably early, the former not later than, say, four weeks, from birth, and the latter not later than three months. (See pages 394 and 390.) Both should be done in the most careful manner and by the most approved method. If the animals are checked in their growth through any want of proper healing after either operation has been performed, it will tell against them when on exhibition. Neither operation should be left in unskilled hands.

3. During the milk period should the evidences of scouring appear in any severe form, the quantity of milk fed should be greatly reduced and with much promptness. It may be necessary to withhold it altogether for a few meals, according to the severity of the attack. Usually prompt action will effect a cure, but full quantities of milk should not be allowed again until the digestion is restored. It happens, in some in- 
stances, that the digestion in such calves is overlax to be really normal, and yet the condition does not lapse into what is termed scours. This condition may continue for some time, and yet may do no serious harm. As long as calves thus affected do not in any sense lose appetite, and continue to make good increase, they are not to be regarded as in a dangerous condition. If scours are severe and prolonged, development is so retarded that the hope of growing such animals for show yard honors had better be abandoned.

4. The time for weaning will vary with the dates of the birth of the calves, and the season at which the fair is held. The usual age for weaning such calves is from I 2 to 15 months. Such weaning should not take place before the fairs, lest it should lead to reduction in flesh at a critical time. After the fairs, some reduction may prove helpful rather than harmful. When calves are fed as those must be fed which are to show in the fat classes, weaning should not check growth at all seriously. The weaning, however, should be gradual. When it begins the calves should be allowed to suck but once a day. This should continue for, say, ro to I4 days, after which they are not allowed to take more milk. When the milk is withheld, they will profit by an increase in the amount of roots fed.

5. The character of the stalls, yards, and paddocks all exercise an influence on development, hence they must be considered. Of course, box stalls are a necessity that the calves may take exercise in them. Bright, airy, and well-ventilated stalls are, of course, the most healthful. Two or three animals of age not far different may be kept in each for a time, but not after that time is reached when any difference in the food requirements becomes apparent. Each animal is given the sole use of the stall after it is weaned, if not before. The aim should be to have the yard attached on the sunny side of the building and sheltered from cold winds. In win- 
ter the cattle may remain out in these on fine days for a couple of hours with profit. There is no objection to keeping such animals in a common yard when such a course may be necessary. The paddock is usually more of a pasture than a yard, and its utility will depend to a considerable degree on the amount and character of the grazing which it furnishes in summer, and the amount and kind of its shade.

6. During the milk period it is important that water shall be accessible to the calves at all times after they have gone beyond the age of, say, three weeks. There is no better way of giving it than by keeping it in a bucket in the stall, at least during much of the day, and it should be renewed so frequently that it never becomes stale. When consuming large quantities of succulent food, they may not take much water, but they will take more or less, and, in warm weather, they will, of course, take water in increased quantities. After the milk period, they should be given water not less frequently than twice a day. The most convenient and, probably, the most seasonable times for giving the water are after the morning meal and before the evening meal.

7. Salt should be kept accessible to the cattle in addition to any that may be given in the food. It may be kept in a box in the stall when they are not on grazing. When on grazing, it is frequently kept in a box in the pasture. They will take more at such times than when on food less succulent. No kind of salt is more suitable than common salt.

8. The cattle are given their food in three feeds daily, but the grain is usually given only in the morning and the evening. When feeding ensilage, the grain is mixed with it, and at other times it is mixed with a little cut fodder, which is considered safer and also preferable to feeding it directly. In some instances, it is fed along with roots that have been made ready for 
feeding. The noon feed consists of some kind of fodder, but under quite high pressure feeding, a part of the grain is also given at noon.

9. During the months of July and August, especially when cattle are being fitted for the late autumn fairs, good results accrue from feeding boiled or steamed grain. If they are to be shown as early as September, the boiled grain should be fed at an earlier period. If continued too near to the season of showing, the flesh may lack somewhat the firmness that is requisite in winners. Oats and peas fed in equal quantities are most in favor for such feeding, but when peas cannot be had, barley may be used instead. A small quantity of bran is added to a little cut hay. The boiled mixture is then poured over the mass while yet warm, and is fed four or five times a week, preferably in the evening, as a matter of convenience. It is fed in quantity sufficient to preclude the necessity for feeding additional grain in order to complete the meal. The following benefits may be looked for from such feeding: (I) The cattle are fond of the food and it furnishes them with a change that leads to increased consumption. (2) It exerts a favorable influence on digestion. (3) It seems also to influence favorably that sappy condition of the system which results in large increase while the final finish is being made.

Io. The litter supply should, of course, be sufficiently abundant to give the animals a good, soft, clean, and dry bed. The removal of the droppings and saturated portions of the bedding should be given early, prompt, and unremitting attention. The careful feeder removes the droppings several times a day, and, as a result, the saving in the grooming far more than compensates for the extra labor involved.

II. Such animals should be groomed once daily. The factors used in grooming are a currycomb, a card, a brush not too harsh, and a cloth used in removing dust 
that may cling to the external surface after the ordinary grooming. It should be done in a way that will soothe rather than irritate. It would be easily possible to make the grooming harmful, rather than helpful, by using implements that are harsh and by using them in a rough fashion. Of course, less grooming will suffice from the time the fair season is over until it draws near again.

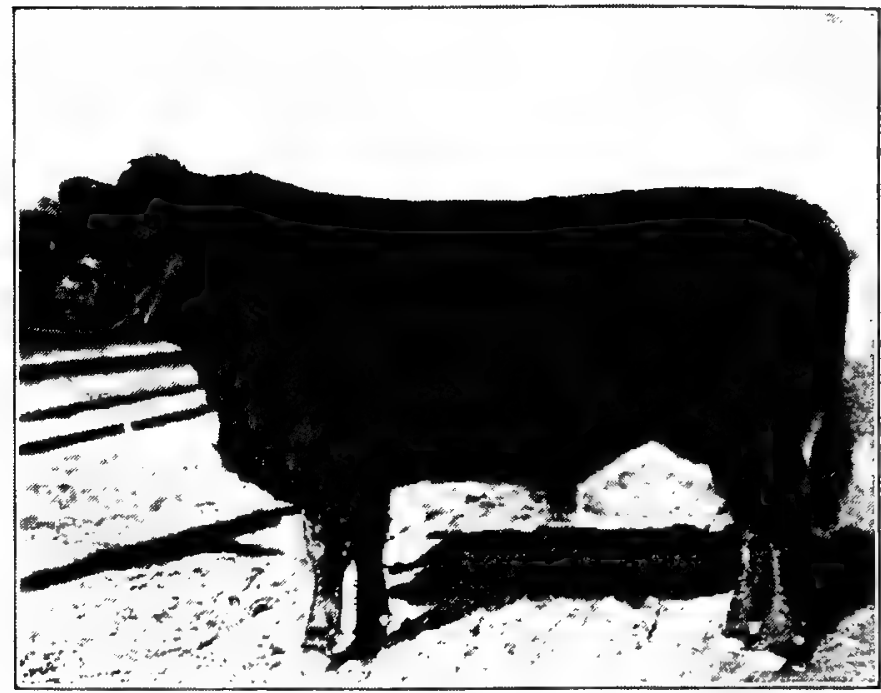

THE TWO-YEAR-OLD PURE ABERDEEN ANGUS STEER, ANDY

A Prize Winner at the International Fat Stock Show, Chicago

(By courtesy of the owner, Minnesota Experiment Station)

Unnecessary grooming would be time worse than wasted, because of its disturbing character.

I2. In the early part of the season, blankets are not wanted. When the fly season arrives, the animals should be furnished with light cotton blankets to protect them from the flies. From three to four weeks before the fairs the cattle should be furnished with light 
woolen blankets, which are only worn during the day. The blankets have a tendency to make the hair lie smoothly at the fairs; they aid also in giving it a gloss that is pleasing. The extent to which they are used is much influenced by the weather. Blankets may be purchased at certain dry goods establishments ready made, or the material may be purchased and they may be made as ordered.

13. The proper trimming of the feet is very important, because of the influence which it exercises on the gait and pose of the animals in the show ring. It also influences the appearance of the hoof, and in a close contest the decision may be made to rest on what is not in itself greatly important. The feet should be trimmed not seldomer than once a year. For the mode of doing this see page 118 . 


\section{CHAPTER XVII}

\section{STABLING SUITABLE FOR CATTLE}

No question pertaining to the keeping of cattle is more deserving of the most careful consideration than that of providing them with suitable stabling. The rapidly advancing cost of the materials of construction emphasizes the necessity of reaching out for the very best results that may be obtained for the outlay when erecting stables to furnish shelter for cattle, and barns in which to house food for them.

Many sketches of barns and stables could have been submitted with details of construction. This has not been done, for the reason that models could not be thus furnished equally adapted to the needs of any two cattle owners, owing to the difference in the conditions of their environment and to the difference in their needs. The aim has been rather to dwell on useful features of construction that may be embodied more or less in stables or barns in which cattle are to be kept, leaving such incorporation to the judgment of those readers who have buildings to erect or remodel. Much of the information given relating to the equipment of stables was furnished by Robert S. Shaw, Professor of Animal Husbandry at the Michigan Agricultural College at Lansing.

This chapter discusses the following phases of this question: (I) The location of a stable; (2) The influence of climate on stable construction; (3) Important requisites in a stable; (4)Convenience in a cattle stable; (5) Stables built on the basement plan; (6) The materials of construction; (7) Barn and stable built by the author; (8) Stalls and mangers in stables; (9) Feed rack and manger for loose cattle; (10) Gutters in stables; (II) The passageway in stables; (I2) Chutes 
in stables; ( $\mathrm{I} 3$ ) The lighting of stables, and (I4) Ventilating stables.

The location of a stable.-The proper location of a farm stable is always a matter of much importance because of the very direct bearing which it has upon the comfort and health of the animals, and on the time occupied in preparing food for them and in feeding it. When selecting a site for a stable, the following considerations are important: (I) That the location chosen shall be as nearly central on the farm as may be found practicable; (2) that it shall be located not too distant from the farm dwelling; (3) that it shall have all the natural protection possible to secure for it; and (4) that it shall be placed on ground easily drained.

The great saving in labor from locating the stable in common with the entire farm steading as near the center of the farm as may be found practicable will be apparent to the refiective mind. This saving will apply to the amount of travel called for in journeying to and from the fields while sowing, cultivating and harvesting the crops, and while driving the live stock to and from the pastures. The farm steading is usually placed near the highway for no other reason, apparently, than to have it near the same.

While it is, of course, possible to locate the stable so near the farm dwelling that odors from the yards would sometimes prove disturbing, it would not be distant from the dwelling. Every day someone. and frequently a number of persons, must pass many times in a day over the space between the farm dwelling and the stable. A few steps thus needlessly taken on each journey may seem to be of small account, but during a lifetime they would aggregate a very great distance. In time of falling storms and drifting snows also this matter becomes one of considerable importance.

It may not be possible to secure natural protection for a steading because of the character of the aspect of 
the land. When locating in the uncleared forest or grove country, it is always possible to secure the protection of trees furnished by nature, by simply refraining from cutting them down around the site chosen for the steading. It may be possible, in some instances, to secure natural protection from a bluff with or without trees, a matter of much importance in a treeless country with cold winters, but in the absence of protection furnished by nature such protection will readily be provided by planting trees and caring for them properly. A fair amount of protection may thus be provided usually in from three to five years from the time of planting, depending on the size of the trees when planted, the natural conditions that affect growth, and the care given to the trees. A protecting windbreak thus running around the outbuildings of a farm, not too near and not too distant, may furnish protection the equivalent of what would be equal to raising the temperature many degrees in time of cold storms.

It should be the aim to place a stable on land with enough slope in at least one direction to carry away readily any surface water that may fall. The instances are few where this cannot be secured. Unless surface water is quickly carried away the surroundings of the stabie are liable to become more or less miry through the treading of the cattle. On the other hand, violent slope is to be avoided because of the washing of the fertilizing elements from the manure in the yards.

Climate and stable construction.-The influence of climate on stable construction is material. In the far South, open sheds may meet all the exigencies of stabling for cattle, unless it be for young calves and dairy cows. For the latter it is not necessary to seek for much warmth in the stable, nor for much space for the storage of food, although some provision should be made for storing more or less of food and litter to meet the exigencies arising from prolonged 
storms. The stabling, however, should be of a character to make it easily possible to exclude draughts, which are always injurious when accompanied by rawness and dampness.

In climates cold and dry, the necessity for closed stables for all kinds of cattle not in milk except cows and calves is less than in climates with temperatures no lower in winter, but air more moist and precipitation more frequent, and with more of dampness in it. This explains why closed stabling is more essential in Maine than in Minnesota, although the winter temperature in the latter is not much different from that in the former, as measured by the thermometer.

In the latter there is much more sunshine than in the former in the average winter, which is so far favorable in wintering cattle in properly protected yards, with such shed accommodation as will protect from falling storms. The stabling for cows, however, should be warm enough to keep them in comfort, and this may call for construction equally warm in dry winter climates as in those much more moist.

In climates which are cold and damp and raw in winter, and in which storms are frequent both autumn and spring, and even in the winter, then necessity exists for providing closed shelter for all cattle kept on the farm during a portion of the year. This does not, of course, mean that all sheds or stables shall be provided with stalls, or, indeed, any of them, but it does mean that the facilities should be such as to make it possible to house the cattle when precipitation occurs. In such climates much more litter is needed to keep the yards dry than in the former, hence the greater necessity for furnishing a bed that precipitation cannot fall upon. The leaching of fertilizer that is exposed is greater in the more rainy climate, hence the greater the necessity for keeping it as far as practicable under cover.

Important requisites in a stable.-The following are 
important among the requisites in a stable whatsoever may be its construction: (I) That there is large capacity for storing food; (2) That the food shall be of easy access; (3) That the stable shall be dry, well lighted, and properly ventilated, and (4) that it shall be easily and cheaply cleaned. It would seem correct to say that, as a rule, such a combination can be most readily found in a stable built on what may be termed the basement plan.

The importance of large capacity for storing food consists, first, in the labor saved in handling the food, and, second, in the better preservation of the food as compared with storing it in stacks. Fodders stored in stacks cannot usually be fed unless drawn to the place of feeding. Those stored in a basement lot can be fed, as a rule, without being drawn. The only objection to furnishing storage room of large capacity is the cost. Under some conditions that objection may be material.

Ease of access to the food has a bearing. first, on the labor involved in getting it, and, second, on the opportunity to furnish the kind of food wanted for each class of stock kept. When storing the food, the necessity for storing it in the various apartments so that it will be easily accessible should be constantly kept in mind. The ease or difficulty connected with such storage is much influenced by the plan of construction of the building.

The importance of freedom from dampness in a stable cannot easily be over-estimated, because of the bearing which it has upon the health of the animals. Undue dampness is most frequently found in a basement stable, with one side and both ends of the basement built well into the side of a bank where the earth is naturally cold and retentive. The proper construction of the walls will go far to remove such dampness, as, for instance, building them hollow; that is, air spaced within. Ample 
light and ventilation both tend to remove the dampness. Damp stables are most decidedly unhealthful.

The presence of ample light has a bearing on the ease with which labor will be performed and on the health of the animals. The amount of labor performed in a given time by a person in a stable well lighted will much exceed that done by the same person in a stable ill lighted. Light, and especially sunlight, is the enemy of disease germs, hence the importance of having it stream in through many and relatively large windows. Even where basement stables are built close up against a bank, provision should be made for admitting light on every side.

The importance of good and ample ventilation cannot easily be over-estimated. The little attention given to this question in previous years is no doubt largely responsible for the prevalence of tuberculosis in many of the herds during recent years. The colder the normal temperature in any locality, the greater is the danger that insufficient ventilation will be provided, because of the effort to exclude the cold. (See page 379.)

The labor of removing the droppings by hand forms one of the largest items of stable work, hence the importance of having the construction of a character that will admit of calling in the aid of horse labor where much of this work is to be done. Carriers also may, in some instances, be used with much advantage. For the construction of the gutters see page 373 .

Conveniences in a cattle stable.-In every stable in which many animals are kept, provision should be made for (I) a feed room in which to mix the feed; (2) a root cellar in which to store roots; (3) a place in which to store meal; (4) a silo within or adjacent to the stable, and (5) a space in the loft in which to store bedding. Where cows are to be kept there should be some box stalls and stalls for calves, and where the cows are milked a milk room of good construction. Water may or may 
not be furnished in the stalls according to the attendant circumstances.

The aim should be to have the feed room located so as to reduce the distance of conveyance of the food to the cattle. In rectangular stables the feed room may usually be conveniently located near the center but on one side of the building. The chaffed feed may conveniently fall into this apartment from the loft overhead. in which it is cut. The roots when pulped may be pulped in the apartment for roots, but when pulped by machine power this will be done more conveniently in the feed room. In this room the mixing of the meal and cut feed, or of the roots and cut feed, or of all three, may be done. Of course, where none of the feed is chaffed a feed room is not an absolute necessity.

The root cellar may usually be most conveniently located on the ground floor of the stable, but in a basement stable with a bank on one side, the root cellar may be made in the bank. Space is thus saved in the stable, but such root cellars, though easily protected, are dark. When the root house is located within the stable it should be placed so as to be conveniently accessible to the feed room. The walls may be of stone or concrete or wood. In cold climates it may be necessary to line the siding with tar paper, and use the same with flooring above and under the joists overhead. Light also should be admitted and provision made for ventilation.

Theoretically the best arrangement that can be made for the storage of meal is to put it in bins above the stable and so located that different kinds of meal may be drawn from chutes coming down into the feed room. In practice these chutes are not always used where they have been constructed, the meal being kept in small bins in the feed room and renewed from time to time. The use of bins overhead is much dependent on the amount of labor involved in putting the meal into the storage bins. 
The silo may be located within the stable or adjacent to it. Space is saved by locating it outside the stable, but closely adjacent thereto. When placed close to the stable, the silage may fall within the stable when thrown into the chute which conveys it from the silo. Whether the silo should be located at the end of the stable or about midway along the side of same, depends upon the arrangement of the stalls and the mode of conveying the food. When the stalls face a passageway which runs from end to end through the stable, and when the silage is carried in a truck or hand cart, the silo is best located at the end of the stable. When the silage is carried in a basket, it is best located at the side of the same.

The place for storing bedding in the loft does not call for any partitioning in order to provide it. It should be accessible at all times when the stable is occupied. The necessity for the reservation of such space when storing food is based on the advantage of being able to secure dry litter in time of storms. At other times it may be legitimate to draw bedding from other sources.

The number of the box stalls called for will depend on the number of the cows in the herd, and, to some extent on the object for which the cows are kept. In a breeding herd made up of valuable pure-breds, more box stalls relatively are usually provided than in an ordinary herd, that the animals in it may have that increased liberty which is believed to be associated with highest development. Cows soon to calve should always, as a measure of safety, be placed in these where practicable. The locating of these stalls, and also of the box stall or stalls for calves, will be more or less dependent on the plan of the stable. The aim should be to have the box stalls for calves as near as possible to the cows which they suck when thus reared.

The milk room may or may not form a part of the 
stable. On the whole, it would seem correct to say that the preference is for a detached milk room, that it may be removed from the odors that are more or less present in stables, which affect adversely the quality of the milk and milk products. But with properly constructed partitions the milk room may also be a part of the stable. The furnishings of the milk room will depend upon what is done with the product in it, but usually it will have in it at least a separator.

Water is sometimes furnished in metal basins in the side of the stalls. Into these it flows automatically. In other instances it is made to flow in a trough in front of the mangers. In yet other instances it is furnished in a tank within a shed where it is not much liable to freeze. Again it is furnished in a tank in the yard. In mild latitudes it may be furnished by a stream near the stables. The first and second methods have the merit of providing water whenever the cattle care to drink it, but they are open to the objection that the water soon loses its sweetness in such an atmosphere, which, with dairy cows, would be objectionable. Water furnished from a tank in a shed, and covered save when the cattle are drinking, may usually be kept in good condition and without the expense of heating artificially, as is required in some instances in tanks in the yard. The animals call for more or less exercise daily, and when thus unloosed may take water When furnished in a trough in front of the stalls, it may, of course, be drawn off when the cattle have satisfied themselves, but the trough is more or less in the way of feeding under some conditions of construction. Stagnant ponds are the most objectionable sources of water supply summer or winter.

Stables built on the basement plan.-It has already been intimated that in basement stables many of the desired requisites relating to convenience in feeding may be obtained more readily than in stables which do not embody the basement idea. (See page 344.) The com- 
mon idea of a basement stable is that it forms the ground story of a barn and that of necessity the basement space has been made by removing the earth from the side of a hill or bank. Such excavation is not always necessary. A basement stable, or more properly a basement barn, for the two are built in conjunction, may be defined as a structure in which stabling is provided for live stock and frequently storage for roots in the lower story, the coarse fodders and grain being stored above.

When constructing basement stables, it is desirable to build more or less against a hill, but they may be built also on level ground. In some instances the side of the stable is built into the bank, and in other instances the end of the same, dependent on the nature of the structure. But in no instance is it wise to have the basement excavated so far into the hill as to exclude in any considerable degree the admittance of light into any part of the same. When the basement is placed against a steep bank, on that side light may be admitted by placing each window opposite to an excavation made in the bank in order to admit light. The material for the walls of basements built into a hill should be of stone, brick, or cement, to resist decay and to provide warmth in winter and coolness in summer. The structure above may be of any material desired.

When the basement is built on level ground, the walls may be of any of the materials just named, or of wood. When of wood, in cold areas, building paper or tar paper is usually put under the boards which compose the siding. In some instances it may also be necessary to make an air space in the wall by sheeting on the inside of the studs to prevent a film of frost or ice from coating the walls inside. When basement stables are thus built on level or nearly level ground, an approach or driveway of considerable length is necessary in order to drive loads into the story above the basement. This, of course, is made of earth, and if, when constructing it, a space of, 


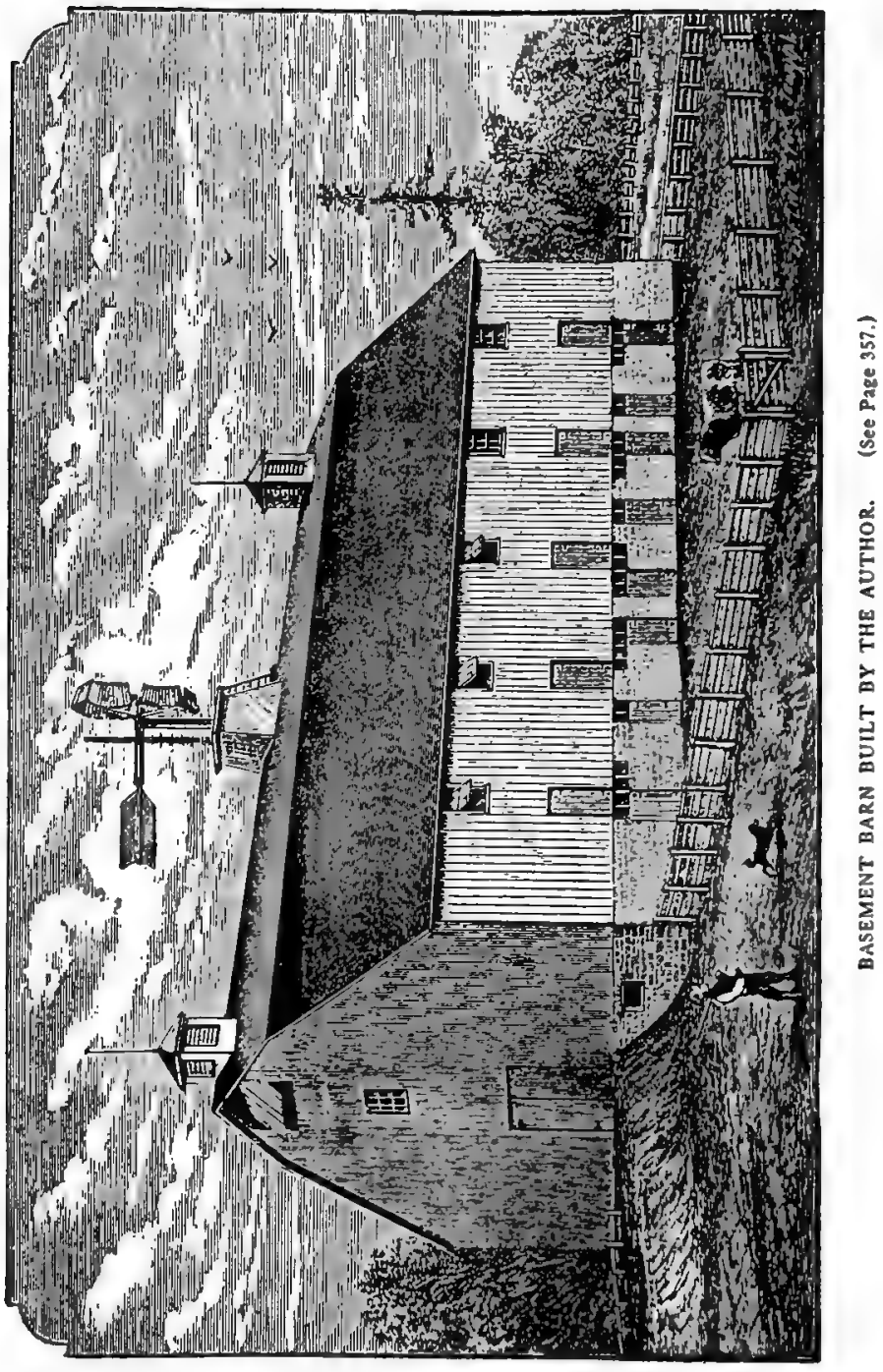


say, I2 feet is left unfilled next to the basement and bridged over with planks, the convenience in getting around the building is thus much increased. The end of the driveway where the bridge begins is protected by a wall of stone, brick, or concrete.

While basement barns may assume many forms. usually they assume one of two forms known respectively as the end-drive and the side-drive. In the former a passageway, wide enough to admit loads of fodder, runs right through the barn above the stable from end to end. The mows are on either side of this passageway. (See page 360 .) In the latter the entrance is from the side, and, in some instances, there is more than one side entrance, dependent on the length of the building. In side-drive basement barns, the mows are on either side of each driveway, and there are no driveways on the other side, which is the yard side of the barn. The enddrive plan of barn makes it easily possible to get at food or litter stored in any mow, and also possible to put the same down into the basement where desired. But to this plan there is the objection that unless after the mows are filled on the two sides of the driveway, much space will be lost unless scaffolding is used and food is stored upon the scaffolding. The scaffolding referred to means poles or sawed timber laid across the passageway and resting on beams between the bents when bents are used. The second objection is the dust that is more or less confined within the building while the grain is being threshed.

Some basement barns built against somewhat high banks of earth have been constructed with three stories. The lower is used as a dump for the manure, the one above this for stabling the stock, and the one still higher for storing the food. Such barns have not met with much favor owing to the unpleasant odors that come from the ground story and find their way into the stable. It would seem safer to say that no other form of 
stable is so cheap of construction as that built on the basement plan, when duration is taken into account, nor is any so economical of labor when caring for the stock, nor so promotive under all conditions of the comfort of the animals. That these claims will be generally conceded by all who examine carefully different systems of stable building is the judgment of the author. That such stables are not more frequently in evidence has doubtless arisen from the lack of knowledge with reference to their merits. Until recent years building materials have been so plentiful that economy of construction has not been much forced upon the attention of live stock owners.

The materials of construction.-The materials of construction used in stables include sods, straw, logs, lumber, bricks, and cement. Sods, straw, or logs usually furnish the materials for stables in new settlements, but these in time are gradually superseded by structures more enduring.

The sod stable is best applicable to dry areas of the western prairies. The tough sods of those areas furnish material that is so interlaced with the roots of the native grasses as to make them strongly adherent. The sods cut in proper lengths are simply laid upon one another until the height of the wall is reached, leaving space for door and windows. The roofing is usually poles and straw. As the sod frequently varies much in toughness with the thickness of the grasses, it is a matter of much importance that the sods be taken from ground that excels in furnishing tough sod. Such stables are warm and may serve the purpose for several years. In building them the outlay in cash is practically eliminated, except for the material for the doors and windows. The objections to them are the lack of loft room, the decay of the sods, and the lack of light.

Stables are sometimes macle from straw and poles, the straw being in the baled and unbaled form. When 
made of baled straw, the walls are made of the pressed bales, which are so placed as to break joints. The roof is made of poles covered with straw, or, what is better, marsh hay. In other instances they are made of poles which take the place of rafters with log supports on end to sustain them. The roof, end, and rear side are composed of loose straw so built around and over them as to shed the rain. A rim of woven wire may extend upward around the inside of the walls to keep the straw from being eaten or pulled out of place. The objection to the latter, though sufficiently warm, is the lack of light, the absence of storage room, and the difficulty sometimes found in preventing the roof from leaking, and yet such sheds serve a good purpose during the early years of settlement on western prairies. Sheds built from pressed straw have never attained that popularity to which their merits entitle them, the reasons for which are not readily apparent, as they should furnish stables cheap, reasonably well lighted and durable.

Log stables are made only in forest areas. They are made by placing logs tier above tier and so fitted at the corners as to prevent spreading. Durable woods, as pine or cedar, are preferred. The crevices are filled with moistened clay. The roof is made of slabs of of boards covered with shingles, but may also, for a time, be made of poles overlaid with straw or marsh hay. Such stables are warm and durable, and serve the purpose reasonably well in new areas, but they are wasteful of lumber material when it has any commercial value, and they are frequently lacking in light, loft room, and even in ground floor space.

Where lumber may be secured without too great relative cost, it furnishes the best material obtainable for the building of stables, as but little labor is involved in the erection of the stables, and they are entirely free from the dampness that, in many instances, characterizes 
stables made of such materials as brick and stone. In many parts of the United States, however, and especially in the prairies of the West, the price of lumber has so advanced as to make its use, in a sense, prohibitory. Because of this, attention during the more recent years is being centered on other materials that may be used in the construction of stables. The use of tar or building paper during recent years has greatly added to the warmth of stables made of lumber where this has been desired. Where stables are made of Iumber, the aim should be to put them on a foundation made of stone, or some other material that will resist decay.

Where stones are plentiful, they may be used in the construction of stables. They furnish material that is most enduring. They have been much used in the construction of basements, even when the structure above is made from lumber. In basements they resist the decay that comes to wood when brought in contact with the earth. When dry, stone stables are warm, but care must be used in their construction or they may be damp. Such dampness may be prevented by building them with hollow walls of proper construction. The chief objectim to the use of stone is the cost of construction. In some localities the stones are so scarce as to render such building prohibitory.

Brick may be made to serve precisely the same uses as stone, but where stones are plentiful they are more costly than the latter. The chief reason why brick stables are not more in evidence arises from the cost of construction. But in estimating the cost of building stables from wood and stone, due allowance should be made for their durability. Drick stables may also be damp, unless due care is taken to prevent this, as when building stone stables.

The indications at the present time point to cement as the material that will be most used in the construction of stables in the future that is not distant. This ma- 
terial is durable, and furnishes stables warm and dry, and, under ordinary conditions, not excessive in cost. When properly reinforced it has great strength. But in some localities sand and gravel are so far distant as to add greatly to the cost of construction.

The most costly item, relatively, in the construction of stables, viewed from the standpoint of permanency, is the roof. The materials used for roofing in permanent structures include shingles, felting of various kinds, and roofing made from metals. Roofs made from shingles require frequent renewal. Shingles that are sawed are less durable than those shaved, since they have less power to resist the penetration of moisture, and nearly all the shingles now put on the market are sawed. Felt roofing, which is laid on in strips, has some commendable features, as the ease with which it may be laid. It is so constructed as to be impervious to water, but its use is not so rapidly extending as its merits would seem to justify. Of the various kinds of metal roofing that have been put upon the market, that known as steel roofing is one of the most satisfactory. It is laid on in strips, and should be laid securely to prevent its being lifted in severe windstorms. Painting a steel roof occasionally adds much to its duration. The merit of some of these materials is yet in the tentative stage.

Earth, planks, blocks, and cement are materials chiefly used in the construction of stable floors. The objection to earth floors in cattle stables is the difficulty found in keeping them dry, and from becoming more or less filled with holes through the treading of the cattle. The objection to plank floors is the cost, the liability to decay, and, in cow stables, the extent to "which they absorb urine, the odor from which injures the flavor in milk. Blocks are objectionable also in such stables, because of the extent to which they harbor offensive odors, and get out of repair. Cement, although at present one of the most costly materials used in stables for flooring, 


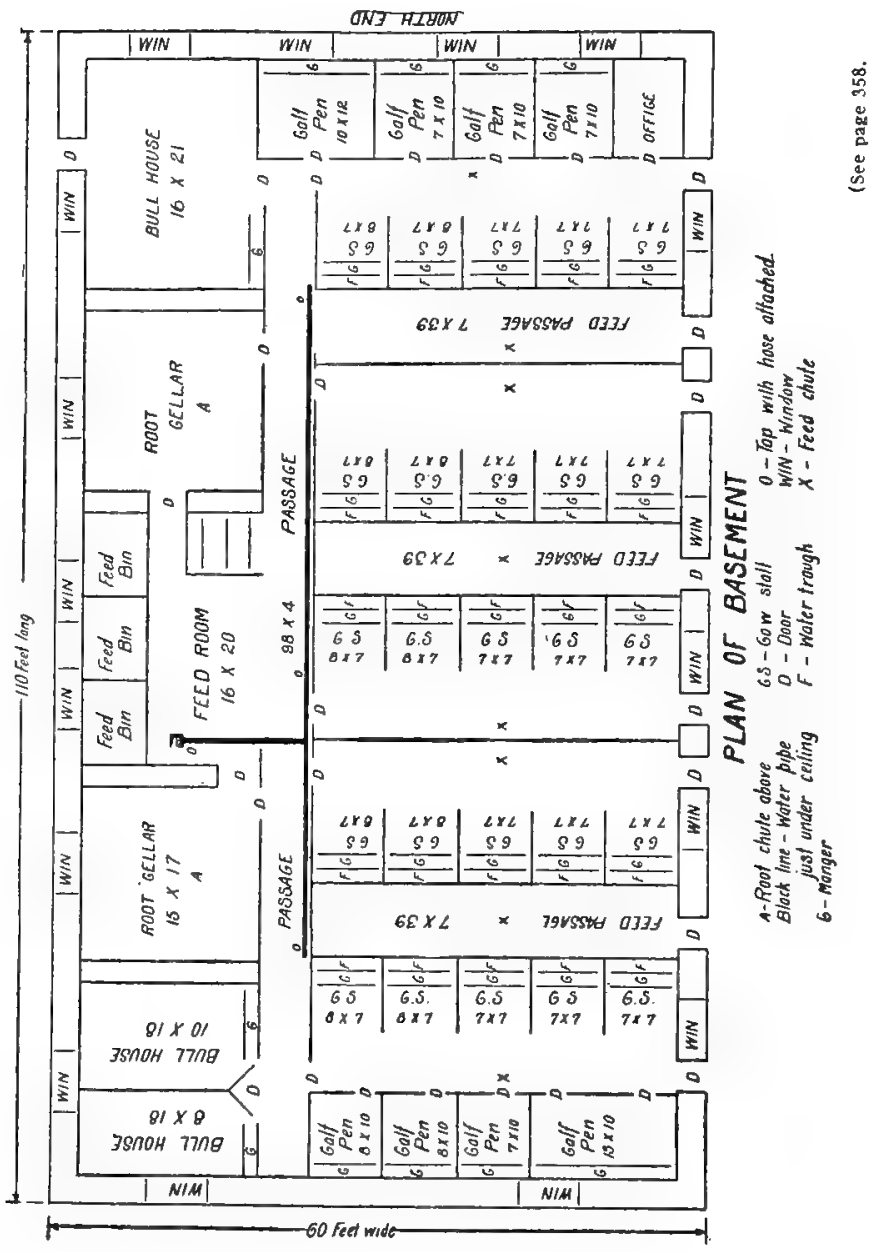


is one of the most satisfactory. The objection to the slippery character of such floors is largely obviated by leaving the surface a little rough when laying them. The objection to their being cold for animals to lie on in northern latitudes is said to be obviated by putting down an intervening layer of tar paper when constructing the floor. Unless where the temperatures are extremely low, no harm will result from keeping cattle in stables with cement floors where liberal supplies of bedding are furnished. When such floors are well built, they will last indefinitely, and where a hose can be used they are easily flushed.

Barn and stable built by the author.-The sketch on page 350, represents a barn erected on the basement plan by the author on his Riverside farm, Ontario, Canada, in I886. It was built for cattle only, but could be so modified in the basement, and without much additional outlay, as to accommodate a number of horses and a flock of sheep. But it may be mentioned in passing that where sheep or horses occupy the same basement with cattle, the separating partitions should extend from the floor upward to the ceiling of the basement for sanitary reasons. The essential features of this barn, or, at least, many of them, were embodied in the plan of the cattle barn subsequently erected by the government of Ontario, at the provincial experiment station farm located at Guelph.

It is not intended that the sketch thus submitted will furnish an exact guide to any one in building a barn. For the average farm it would be far too costly. It is submitted for the reason that many of its features may be embodied in a basement barn of very moderate dimensions. Those readers, therefore, who are about to engage in building barns or stables may find it to their advantage to examine carefully into the details of construction submitted.

The building is IIo feet long and 60 feet broad, 
and has a hip or saddle roof. The posts, which stand upon plank sills that rest upon the stone walls of the basement, are 20 feet high, and the height of the basement inside is about 8 feet from the floor of the basement to the floor above it. The basement will accommodate 50 animals tied in stalls, and from 30 to 40 animals young and old in the box stalls. The barn above the basement has storage capacity for fodder, grain and bedding, sufficient for the wants of as many animals as can be properly kept in the basement from early autumn until the grass is plentiful in the spring.

On page 356 the plan of the basement is shown. It was planned to accommodate a pure-bred breeding herd of beef cattle, but it will answer quite as well for a dairy herd. If one or two silos were wanted, they could be given the space now occupied by one or both the root cellars, or, to save room, they could both be erected quite outside the basement. If but one bull pen was desired the additional one could be, of course, used by cows or young cattle.

A cement floor covers the whole of the basement. The soil underneath it is hard, tenacious clay. Above the clay small and broken stones were placed to the depth of 4 inches, but gravel will answer equally well. Above the stones a coating of 2 to 3 inches of water lime was applied, and above the water lime good Portland cement was spread to the depth of $3 / 4$ of an inch. The floor has given much satisfaction. Notwithstanding the years of wear to which it has been subjected, it has not given way to any appreciable extent.

The plan of the stalls is also given in the sketch on page 356 . It shows that they are double, and gives their climensions. The partitions between them are boarded up from the floor to the height of about $3 \%$ feet. Each of the uprights to which the division boards are nailed aids so far in supporting the great weight of the floors above, thus giving to it great solidity. 
The mangers rest on the floors. They are made of planks I5 inches wide at the top inside measure, I2 inches at the bottom and ro inches deep. The mangers would call for more of size but that feed racks are used. The floor on which the cattle stand varies in length to accommodate those of different ages and of different sizes. These variations run from 4 to $5 \frac{1}{2}$ feet. It inclines from $I$ to 2 inches between the manger and the drop and toward the latter.

The feed racks are upright on the side next the manger. The space between the slats is 6 inches from center to center. The opposite side is close boarded and slants inward and upward into the passage. The distance between the bottom of the rack and the top of the manger is $181 / 2$ inches, a space that is left to enable the animals to take water as shown below, and to feed cut food from the passages.

The water troughs are in the passage in front of the manger. They are raised sufficiently high from the floor to admit of using the sloping cover of the trough as a slide for conveying cut food or roots into the manger. When drinking, the animals simply reach the head forward over the manger. They drink at openings in the trough made by pulling up the slides in the cover of the same. The cattle are tied around the neck with chains. At the farther end of the tie is a ring which slides up and down on an" iron rod bolted to the side of the stall. The length of this iron rod is 2 feet Io inches.

The water supply is obtained from a well drilled into the rock underneath the feed room to an endless supply of water. It is pumped up by a windmill into a circular tank Io feet in diameter and 8 feet high, and from thence it is conducted by pipes to where it is needed. The tank is placed over the chaffing room. Although only covered by straw in the winter, it has not given any trouble through the freezing of the water in 
360 THE MANAGEMENT AND FEEDING OF CATTLE

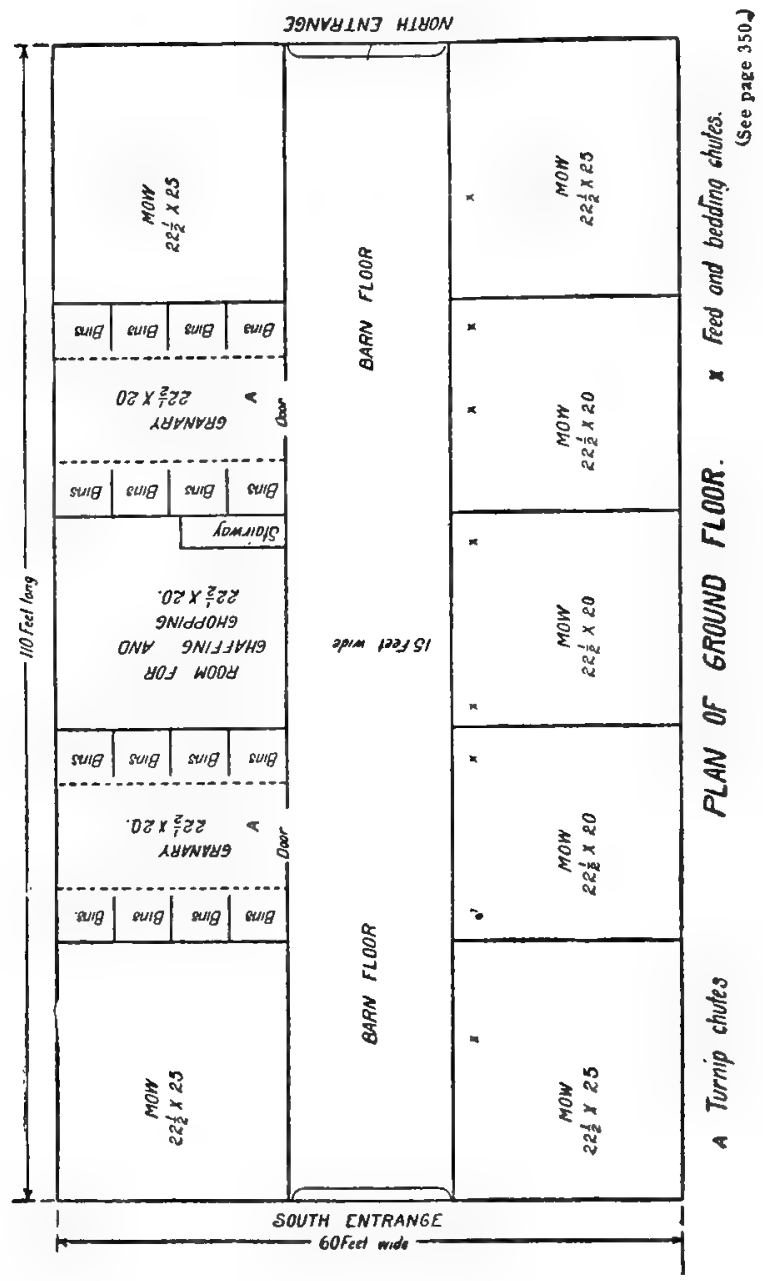


the tank or in the pipes. This, however, might not hold good in all climates. A hose is sometimes attached and the floor is flushed, in consequence of which foul odors seldom give trouble.

The passages behind the drop average 4 feet 6 inches in width. The drop is $4 \frac{1}{2}$ to 6 inches high, and is made by planting a row of flag stones on end so that they are of uniform height. The floor of the passage slants upward for some distance as it recedes from the drop. The liquid in the droppings thus finds its way to the edge of the drop. The gradual slant in the floor admits of the use of a scoop shovel, if need be, in lifting the droppings. These are removed by a stone boat drawn by one horse. It is so arranged that it may be drawn by hitching to either end.

The ventilation of the basement is secured in part by box ventilators which extend upward from the basement along the walls; in part by small doors hinged on the corners of stable doors; in part by the sliding windows, and in part by the openings through which bedding and fodder are thrown down from above. These could all be regulated so as to be used for ventilation only when needed and to the extent needed.

The drawing on page 360 shows the ground plan of the barn. It will be noticed that it is built on the enddrive plan. The fodder and grain are elevated by means of power. One person can usually put the food in place in the mows when it has reached the same, unless when up near the roof. When the mows are filled to the roof, the center can be then filled as far as necessary by using scaffolding. The windows, six on each side, and one in each end, are hung on a rod so that they may be tipped in and out, and two large doors, one at each end, just under the ridge, are also made to swing in and out, by the aid of a pulley and rope coming down to the ground floor. It will be observed that the granaries are convenient to the room for chaffing and grinding the food. 
The floor under the mows is tight. By leaving one mow open, say, at the rear end, the straw from the grain in the mow opposite could be thus stored when threshed. Similarly the grain in the other mows can be threshed, moving the thresher forward, as required. The driveway at the south end of the ground floor comes directly up against the wall. This is one of the few mistakes that have as yet been discovered in the plan. The earth driveway should stop at least 12 feet from the wall, the intervening space being bridged over by planks. More light could thus be admitted to that end of the basement.

Stalls and mangers in stables.-Stalls and mangers will be considered together, for the reason that the description of a stall cannot be considered complete without including the description of the manger connected therewith, and vice versa. The elimination of wood in the construction of cattle stalls is advocated by many at the present time on sanitary grounds. Such advocacy may be correct in theory and may be fitly embodied in stables where dairying is conducted on a large scale, but the cost involved is more than many farmers can afford to incur.

When constructing a cattle stall, regard must be had to the platform on which the cattle stand, to the divisions between the animals, and to the methods of tying. It will be found advantageous, whenever it can be accomplished, to have the platform made from cement, to have it elevated slightly above both passageways and to have it slope, but only very slightly, from the manger to the drop. The distance from the stall side of the nanger, where the latter is of proper width, need not be more than, say, 5 feet 8 inches for the largest cattle, nor less than, say, 4 feet 6 inches for cows that do not weigh more than 700 pounds. The distance from the stall side of the manger to the passage in front will depend on the width and shape of the stall.

The partitions of the most approved make should be 
strong if they are to stand, being made of 2 -inch planks rather than of inch boards, and should rise to the height of not less than 4 feet. They should extend forward to the passage side of the manger. The distance backward should depend to some extent on the class of stock kept in them and the method of tying the same. For dairy cows that are not tied, they should come back to the verge of the drop.

No method of tying has proved more satisfactory than that which ties with the swing stanchion. It gives as much liberty as the tie around the neck which moves up and down on an iron rod at the side of the stall. It prevents the cows from stepping forward into the manger or backward into the gutter, and by no means can they be fastened or loosed more quickly.

When constructing mangers, regard should be had to the freedom which they give to the cow, to the capacity for holding food and for retaining it, and to the ease with which they may be cleaned. Usually the stall side of the manger should not be more than, say, 8 inches above the floor to allow the animals to lie at ease with their heads extended over the manger. The capacity for holding food, and, consequently, the size of the manger, should depend somewhat on the kinds of food fed, and as to whether the cattle are required to consume fodder in the stall or when at liberty in a shed. The ability to retain food depends materially on the shape of the manger on the side remote from the stall. and on the protection furnished on the stall side. The Michigan experiment station has found that when the passage side of the manger is perpendicular to about half its height and then slants outward, the food cannot be thrown out so easily into the passage by the animal as when the outward upward slant is continuous from the floor upward. Mangers with plank bottoms can be kept clean more easily than those made of concrete. 
The simplest form of stall is made by placing a pole or scantling between the cattle, the lower end of which is fastened to the floor near the drop, and the upper end secured in place sufficiently high above the mangers. The simplest arrangement for tying is a pole planted upright on the stall side of the manger, on which a ring with tie attached moves up and down. The simplest form of manger is that which has a board or plank fastened on edge on the passage side, and a scantling or pole held firmly in place on the stall side. In case of need these may be made to answer the purpose with beginners.

The old-time double stalls are still in favor with many, in which the ties slide up and down on iron rods bolted to the side of the stall above the manger. In clairy stables milking is made easily practicable by causing the cow not being milked to stand, for the time being, toward the far side of the stall. But this form of stall, notwithstanding its simplicity, and the saving effected in the stall divisions, has been objected to for milch cows, on the ground that a cow standing may occasionally injure the udder of one lying down by treading on it, but this rarely happens.

Several stalls are on the market, for some of which patents have been secured, and all of these have more or less merit, but, on the other hand, they have their weak points. A careful study of the question has led the author to the conclusion that the cattle stalls now in use at the Michigan experiment station at Lansing are not only highly adapted to the needs of the station in relation to the feeding of the cattle under experiment and otherwise, but that in their essential features they may be adopted with much advantage in the construction of stables by farmers and dairymen. Through the courtesy of those in charge, several sketches of stalls and mangers are given that are now in use in that institution, accompanied by a brief description of the same. 
Further particulars may be obtained, if desired, by consulting Bulletin No. 250, recently issued by the Michigan Agricultural College.

The sketch given below shows the cross-section of a stall constructed for animals which approximate 1,000 pounds in weight. They stand on a cement platform 8 feet 6 inches wide, which is raised above the level of the alley floors 3 inches at the front and 2 inches at the rear, thus giving the stalls a slope of I inch toward the gutter, which has been found sufficient, and more than 2 inches would be an excess. It will be observed that the space occupied by a meal box on the feed alley side is included

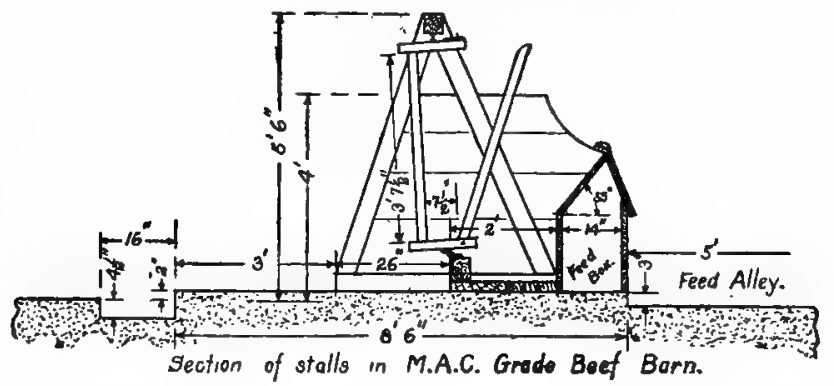

in the width of the platform. In ordinary feeding this may not be necessary, hence the width of the platform could be shortened by the width of the meal box. The stalls are 3 feet to 3 feet 7 inches wide from center to center, and they have been found amply wide. For very small cows even $23 / 4$ feet in width may suffice. The distance from the manger to the drop is 5 feet 2 inches, and this has proved quite satisfactory for such cows. For a cow weighing $\mathrm{I}, 300$ to $\mathrm{I}, 400$ pounds 5 feet 8 inches has proved sufficient, while for a cow of 700 pounds not more than 4 feet 6 inches has been found necessary. The bottom of the manger consists of two planks $2 \times 12$, lying side by side on the cement floor. The front of the 
manger is built up by a $2 \times 4$ scantling spiked to the plank below, and above this lies a $4 \times 4$ scantling in which is fastened the lower end of the swing stanchion. The manger is thus 6 inches deep in front. Where the cows are inclined to throw their feed out into the stall, this may be prevented by nailing $2 \times 6$ pieces placed on edge to the front of the manger and the side of the stall partition. When in place these rest at an angle. Such

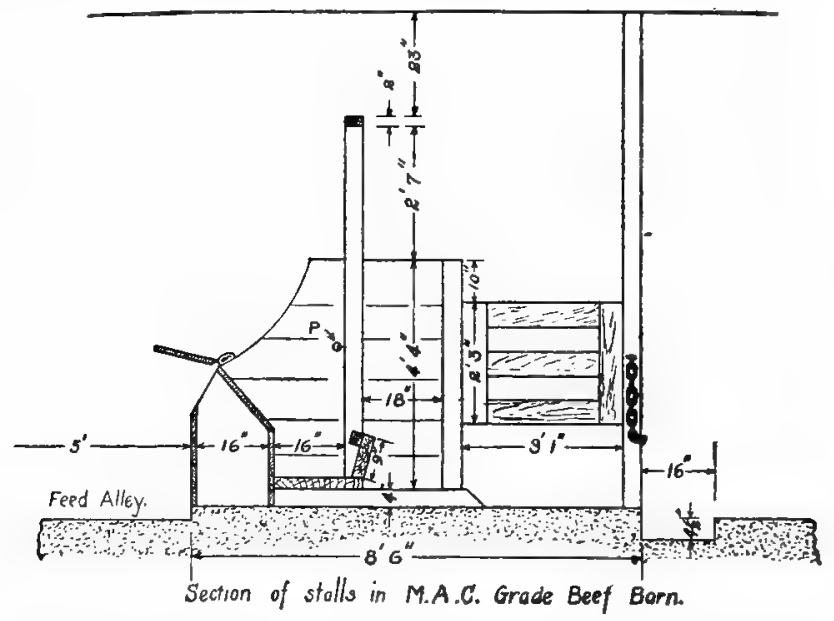

mangers should not be less than 18 inches wide at the bottom, inside measure. The feed alley side of the manger is perpendicular to a height of 18 inches when it slopes toward the feed alley at an angle of about $45^{\circ}$ for 18 inches more, hence the animals cannot toss the roughage fed into the feed alley. The stall partitions which are built up 4 feet from the floor extend back toward the gutter from the manger but 25 inches. This gives the calves more freedom when sucking their dams. 
The partitions are all made of 2 -inch material. The $4 \times 4$ pieces underlying them are pinned to the floor.

The sketch on page 366 represents stall and manger fixtures devised especially for the use of dairy cows. The stalls are constructed on a raised cement platform, the same as described on page 365. In these stalls the cows are not tied. They are confined in the stall by a chain at its rear, which extends from side to side of the stall. The description following is virtually in the language of the bulletin:

The manger bottoms are raised 4 inches above the floor. They rest on the $4 \times 4$-inch scantlings used as bed pieces for the partitions. The mangers are 16 inches wide inside on the bottom. The front side is 9 inches high and slopes somewhat toward the stall. It has a $2 \times 2$-inch strip stretching along inside at the top to prevent waste in the food fed. The rear part of the manger is constructed as described in the sketch on page 365 . As the animals in these stalls are not tied, the partitions were made 4 feet 4 inches high.

Three special features appertain to this stall. The first is the iron pipe shown at $\mathrm{P}$ in the illustration. This runs through all the stall partitions at a point 4 inches back from the stall side of the manger, and 35 inches above the cement floor. This pipe keeps the cow from moving forward into the manger and dropping manure on the stall platform. The proper adjustment of this pipe has an important bearing on the comfort of the cow, as also on the efficiency of the stall. If properly placed, the cow cannot move too far forward, but may stand at ease with the head above the pipe or eat comfortably with the head below it. The second is the swinging gatelike part of the partition. It is intended to be opened part way at least while the cow is being milked, in order to give the milker more room than the single stall affords, and to protect him from the movement of the animal in the adjacent stall. The gate has a hasp 
fastener with a loop turned on the end of the hasp. When the cow is shut in the stall, the hook is placed in the stable extending through the eye of the hasp. When the cow is to be milked, the hook is removed to the loop in the end of the hasp, when the gate swings open, thus allowing the milker to enter the stall, but preventing the cow from backing out. The third is a chain attached to the post by a bolt running through the same with an eye on one end, into which the chain

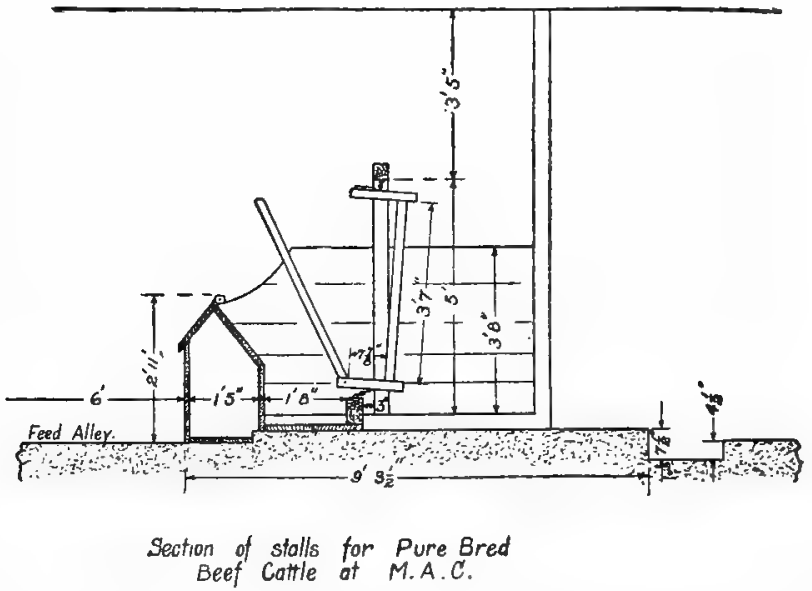

link is welded, and a thread and nut is on the other end. The chain has a hook on one end to facilitate fastening the cow in the stall or letting her out of the same.

The mistake of making such stalls too wide must be guarded against. A width of 3 feet from center to center is about right for a I,ooo-pound cow. If made as wide as 3 feet 6 inches, the cow may put her head under the gate partition and thus turn around in the stall. The adjustment relating to length and width in these is about the same as given in the sketch on page 365 . 
On page 368 is shown a stall intended to accommodatc cattle that weigh from $\mathrm{I}, 000$ to $\mathrm{I}, 600$ pounds, and that may or may not suckle their calves. The construction is the same as in the stall represented on page 365 except in the partitions and general dimensions. The partition is built squarely at the rear, and a little more than half the distance back from the manger to the gutter. This brings the upright $6 \times 4$-inch oak posts at the rear of the partition about in front of the hook or hip joint of the cows. The posts are guttered on the inside to receive the partition boards. The width of these stalls is from 3 feet 6 inches to 4 feet from center to center. The distance from the manger to the drop is 5 feet 8 inches.

The sketch on page 370 shows the stanchions used in feeding calves and also the mangers. The stanchion part of the structure is 3 feet 6 inches high. It slopes away from the manger to increase the capacity of the latter, and to allow the calf greater freedom in withdrawing the head from the stanchion. The material used is inch elm lumber, well seasoned before put in place, and it has proved sufficiently strong and otherwise satisfactory. The next space for the youngest calves need not be more than 5 inches at the first, but as they develop more space is required. To meet this exigency, a number of holes have been bored into the stanchion frames, so that the movable upright pieces may be shifted accordingly. This excellent device is peculiar to these stanchions. When the calves approach the age of one year, the movable pieces may with advantage, in some instances, be entirely removed.

The bottom of the manger is made of 2 -inch hemlock. It is 16 inches wide inside, and is raised 6 inches above the floor. The side of the manger over which the calf feeds rises up 8 inches above the bottom of the same. The lower half of this distance is filled by a $2 \times 4$ scantling resting on the manger bottom, and the other 


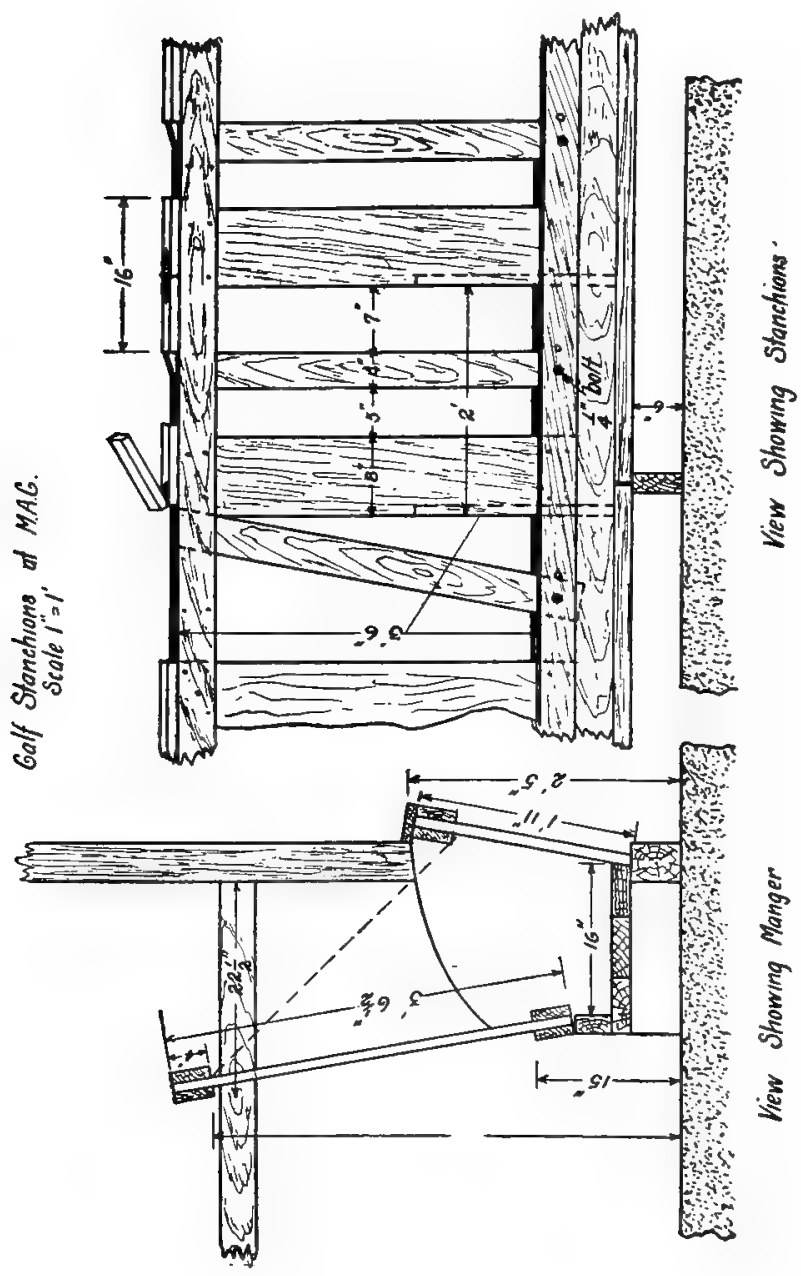


half by the bottom framework of the stanchion. The top part of the manger over which the calf feeds is 15 inches from the floor, and should not be higher for young calves. These should not be left thus fastened even during the day, as they will be unable to lie down properly. The side of the manger next to the feeding alley is practically 2 feet high and rises $2 \frac{1}{2}$ feet above the floor. The outward slope given is a very decided advantage when placing milk buckets in the manger and when removing them while the calf is confined in the stanchion. The divisions in the mangers are 2 feet apart, and this should be regarded as a minimum. The divisions extend upward only to the curved line shown in the illustration, but these are to be raised, as shown in the dotted line, to prevent the calves from sucking one another's ears. Each of the four calf pens, including manger space, is $15 \frac{1}{4}$ feet by $121 / 4$ feet. This has been found sufficient for eight calves up to the age of five to six months, when these are also given the liberty of an adjacent yard or paddock.

Rack and manger for loose cattle.-Young cattle properly graded may usually be cared for more cheaply, as already intimated (see page 58 ), when they run together in a stable or shed and take their food from a common rack or manger. A feed rack and manger that has been found very suitable in feeding such cattle at the Michigan experiment station is submitted on page 372.

The manger is 16 inches wide on the bottom, 20 inches at the top, and 9 inches deep, inside measurement being given in each instance. The bottom of the manger is 22 inches above the ground and the top is $3 I$ inches. The rack for roughage, which projects into the alley, rests on the back of the manger. It is 2 feet 4 inches high and 2 feet wide at the top, and is close boarded on the side next the alley. The front part through which the roughage is drawn while being eaten is 2 feet 

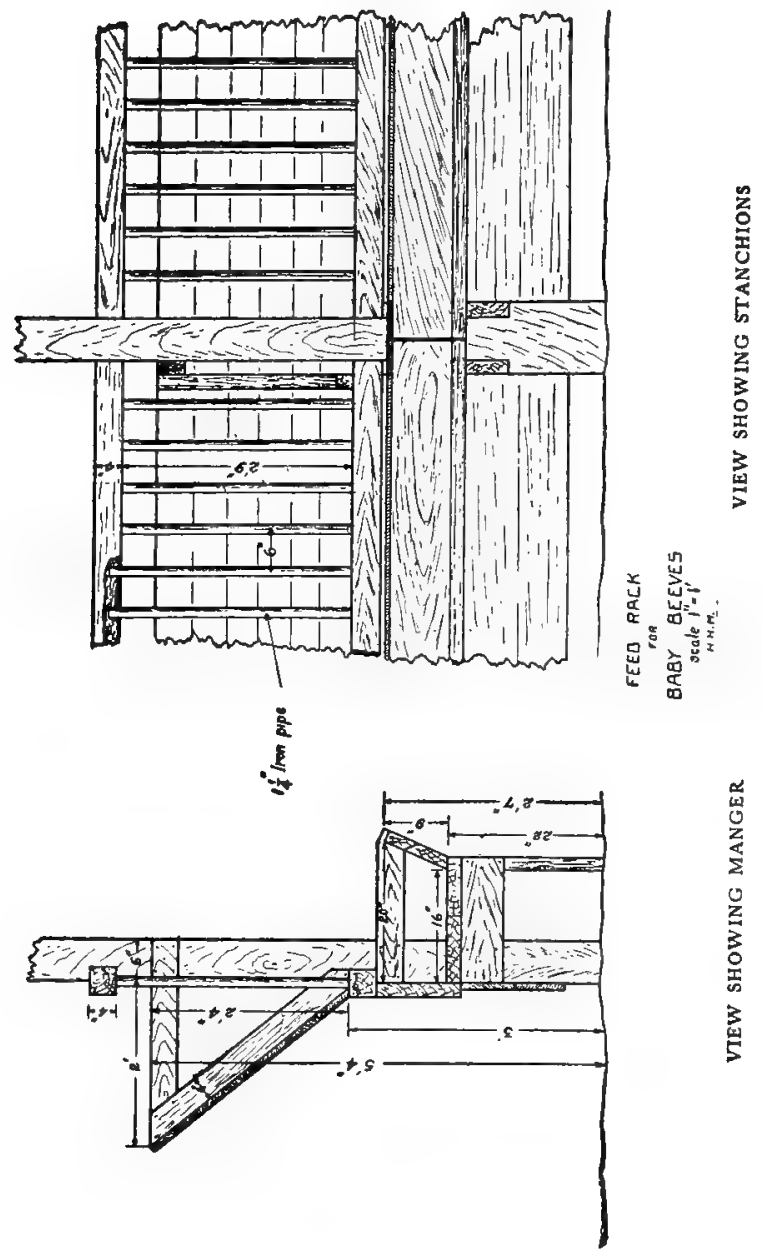
9 inches high, and is made by using $1 / 4$-inch gas pipe, obtained from discarded material, but, of course, hardwood of similar dimensions will answer. The gas pipes were placed 6 inches apart from center to center, and are imbedded about 2 inches in $4 \times 4$-inch pieces, both at the top and bottom. The dimensions given have been very suitable for feeding animals from 700 pounds up to $I, 000$ pounds in weight.

This rack and manger may, of course, be enlarged proportionately to meet the needs of larger animals. The distance of the ground to the bottom of the manger should also be proportionately increased. Such distance, however, is influenced by the frequency with which the manure is removed, and the converse of that is also true, the necessity for frequent renewal being considerably influenced by distance of the manger from the ground. Dry cows of average weights could feed from such racks, but the feeding of very coarse fodders would call for a wide spacing in the uprights in the rack. When meal and fodder are both fed from the alley, the floor of the same should be considerably higher than the bottom of the manger. Such a rack will be found quite satisfactory for feeding such foods as hay, ensilage, meal, and field roots.

Gutters in stables.-Gutters are receptacles for the manure, solid and liquid, voided by cattle confined in stalls. Of whatever form, they are, of course, made at the rear end of the stall. The necessity for gutters is based (I) on the necessity for keeping animals confined in stalls as free as possible from contamination by their own voidings; (2) on the necessity for keeping the passageways clean at the rear of the cattle, and (3) on the advantage that comes from collecting the voidings in a receptacle from which they may be easily removed and without loss.

The form of construction in the gutter is influenced by the method followed in removing the voidings. In 
some instances the purposes of a gutter are served by simply slanting the floor of the passageway at the rear of the stalls upward and outward for some distance from the drop at the rear of the small platform. When this method of construction is followed, the depth of the drop should be as little as will suffice to protect the animals; not more than 5 inches and even 4 inches may suffice. The less deep the drop, the less the distance that is necessary to continue the upward slope. This method of construction admits of the use of a shovel of any desired width in removing the droppings, and it makes it possible to use a horse and scraper in cleaning the stables. The objections to it are, first, that it does not keep the passageway so clean as the form of gutter described below, and, second, that the slant in the floor makes it more slippery.

The form of drop most commonly used is simply a sunken trough at the rear of the platform on which the cattle stand. This form of drop practically confines the voidings within its own limits, which is a material aid in keeping the stable clean. But with this form of drop, the manure must needs be lifted out of the gutter by hand labor, howsoever it may be conveyed subsequently.

Gutters are usually constructed of wood or cement. The objections to wooden gutters are, first, the offensive odors that emanate therefrom, and, second, the quickness with which they decay. Although cement gutters are costly at the first, viewed from the standpoint of duration, they are cheaper than those made of wood and no offensive odors can follow as the result of absorption.

When constructing gutters they should be made wide rather than narrow, as the width of the shovel used in removing the manure is influenced by the width of the gutter. At the Michigan Agricultural College the gutter in the cattle stables is 16 inches wide, $61 / 2$ inches deep on the stall side, and $4 / 2$ inches on the opposite 
side. The fall is but one-half inch in a distance of 35 feet, and these dimensions have been found satisfactory. Where sufficient bedding is used or other absorbent it will soak up the liquids voided.

The passageway in stables.-The passageway in a stable is simply the aisle space in front of the animals or at the rear. In the former food only is conveyed to the animals. In the latter litter is conveyed to them and the droppings are removed. Through the latter the animals also have ingress to the stalls and egress from them. The width in both instances will be influenced by the method followed in conveying food to the animals and in removing the manure. Owing to the value of space in stables the passageways should be no wider than convenience calls for in caring for the cattle.

When there are no racks in front of the animals or meal boxes extending into the aisles, it is not really necessary to have the front passageway wider than 4 feet. Racks are but seldom used in stables now, and meal boxes are chiefly advantageous in relation to experimental feeding. Where a car or truck is used in conveying feed, the width should not be less than 5 feet. When fodder is conveyed by drawing it from meal to meal, as is sometimes done in feeding large herds in areas where the fodder is but little housed, the width of the passage should not be less than io feet.

Where the manure is removed by hand by the aid of a scraper or carrier that runs on a track, the rear passageway, including the gutter, does not necessarily call for a width of more than $5^{\mathrm{I} / 2}$ feet. But where the manure is removed by loading it from the gutters into a wagon or sled, the width, including the gutters, should not be less than 8 feet. The conveyance of food in carts or wagons, and the removal of manure similarly, is usually only resorted to in passageways that run through oblong buildings in which two rows of cattle 
face each other, or stand tail to tail on each side of the passage.

When a stable is erected oblong in form, to accommodate two rows of cattle facing the walls, the following measurements will be found close approximations: The stable should be 36 feet wide, which would leave 35 feet within the walls. The feed passages along the walls should be 5 feet wide, which would admit of the use of a hand truck in feeding. The platform for the stalls from front of manger to drop should be 8 feet for medium sized cattle. The rear passageway, including 18 inches of a gutter on either side, should be 9 feet, which will admit of driving a wagon from end to end. By taking out reasonable space for a feed room and for a box stall or two, and by allowing 3 feet as the width for a stall, the holding capacity of such a stable can be easily ascertained.

Chutes in stables. - A chute is a box through which fodder, litter, meal, or grain are conveyed from a higher to a lower level. These, of course, are not required where loft room is not furnished, but in a great majority of instances chutes are wanted to convey fodder, and it may be litter, to the stable or shed underneath. They may also be necessary frequently to carry meal or grain from a place of storage above to a feed room below.

The chute for hay or bedding in a cattle stable may consist simply of four $2 \times 4$-inch scantlings rising up into the loft from its floor, and kept in place by nailing inch strips, say, $I \times 6$ inches, across the sides of the inclosure thus formed. The inside width of the chute should be about 30 to 36 inches each way. The strips nailed across should be about 3 feet apart from center to center. The floor space underneath is removed. The chute should open down into a front or rear alley, according as fodder or bedding is wanted.

The chute in the edge of a mow beside a driveway in the upper story may consist simply of a triangular 
box, the hypotenuse side of which goes back into the mow. The door is on the side next to the driveway, and the floor underneath is cut away.

Chutes for meal may be of any size called for, but usually they are small, not more than, say, $6 \times 8$ inches.

The lighting of stables.-This question, though greatly important, is too seldom given that attention which its importance deserves. Abundance of light greatly facilitates the performance of work. An ample supply of sunlight admitted into stables is exceedingly helpful in destroying hurtful forms of germ life, and in otherwise promoting the health of the animals confined within them.

It would not be possible to state the relation that should always exist between the area of a stable and the window space that would light it perfectly, as this is influenced materially by the width of the stable, by the height of the ceiling and by the relation of the stable to adherent appendages that may be conjoined to it. The wider the building, the lower the ceiling, and the greater the wall space covered by banks of earth or by adherent structures, the greater is the necessity for large window space.

The agricultural experiment station at Lansing, $\mathrm{Mich}$ igan, has given much attention to this question. The conclusions reached from these pioneer investigations, as stated in Bulletin 250, are that a well-lighted cattle stable should have I square foot of window space for every 20 to 25 square feet of floor surface. It also calls attention to the fact that the light secured, both as to quantity and distribution, is much influenced by the shape of the window and the height at which it is placed. The narrower the window and the higher it is placed, the less is the admittance and diffusion of sunlight.

Although it would not be possible to lay down hard and fast rules for the admittance of light into stables, the following statements should be considered by inter- 
ested readers: (I) Windows broad and large are to be preferred to those narrow and small, even though the latter, through increase in their number, should furnish as much glass space as the former. A favorite size for a window in the cattle stables of the above-mentioned station is one that has in it three lights $10 \times 12$ inches from top to bottom and five from side to side. While placing windows too high should be guarded against, they should be placed high enough to avoid hazard from breaking by the stock. They should not come nearer than $4 \frac{1}{2}$ feet at the bottom to the stable floor. (3) The most satisfactory method of opening stable windows would seem to be that method by which they could be slid down and held in place as desired. When they swing in and out on a pivoted rod, in cool weather cold air comes in below as well as above, which is undesirable, and they cannot be darkened in hot weather without admitting flies. Windows on hinges that swing in are in the way, and for several apparent reasons are otherwise undesirable. Windows that slide horizontally are more suitable, but in winter may give trouble through ice adhering to the frames. (4) The lights in common use, as IO X I 2 inches, should be preferred to lights of odd sizes, since those in common use can be renewed without the necessity of cutting the glass. (5) In very cold climates double windows with a space between may be advantageous. For convenience in opening the outer windows are frequently hinged. (6) Windows should not be made in stable doors to give additional light, as the slamming of the doors will result in much loss from breakage of the glass.

Ventilating stables.-Notwithstanding that much study has been given to this question, it cannot be said that a system of ventilation has yet been devised that is entirely free from defects. Probably the best system that has yet been devised is that known as "the King 
system," from its originator, Prof. F. H. King, formerly of the Wisconsin agricultural experiment station. The essential features of this system are as follows: (I) Cold air from without is admitted into box ventilators placed in the walls. It enters these just above the sill, is carried upward through them into the stable, which it enters by means of openings a short distance below the stable loft. The dimensions of these and the number called for is dependent on the size of the stable. The width of these is seldom more than 18 inches and the distance across from side to side more than 6 to 8 inches, or the distance between the outer wall and the lining of the building. The inner opening should be provided with an adjustable cover to shut off the intake when desired. (2) Foul air is carried away by box ventilators of sheet iron or wood. It enters the ventilator in an opening near the floor, which is always open, and, if covered with coarse wire netting, light material, as straw, will not be sucked into the same. They extend upward above the plate and are then carried along under the roof to an opening usually crowned with a cupola. (3) Just below the ceiling, a door is hinged on the front side of the ventilator which may be drawn up with a rope and pulley as far as desired. A slide of equal dimensions will answer, but is not so convenient. The object sought is to create an air current in warm, muggy weather, which will aid greatly in carrying out the warm air.

One of the best ventilated cattle stables at the Michigan experiment station is 80 feet long and 45 feet wide. It has four intakes on each side of the building, $18 \times 8$ inches, and two ventilators $22 \times 14$ inches, also on each side. The openings of the intakes outside and in are about 7 inches broad, and the openings into the ventilators near the floor and near the ceiling are about 24 inches from top to bottom. These have furnished what has been considered sufficient ventilation. 
380 THE MANAGEMENT AND FEEDiNG OF CATtLE

Where a system of ventilation has not been constructed, much may be done to secure pure air by the judicious use of windows, of air spaces made well up in the walls and covered with air-admitting cloth, and, to some extent by the chutes for fodder and straw. At all times, however, care should be taken to guard against exposing the animals to draughts. 
CHAPTER XVIII

\section{DEHORNING, SPAYING, AND CASTRATING CATTLE}

Properly speaking, dehorning means removing the horns, but the term has also come to be applied to preventing their growth in animals naturally horned. Among domestic animals, it is chiefly practiced on cattle. Spaying means removing the ovaries from a female animal. The ovaries are the organs or glands of the female that give rise to the ova or essential products of generation. Castration is usually understood to mean the removal of the sexual germ-bearing glands of the male; that is, the removal of the testicles, but, in some instances, it is also used as meaning the removal of the essential organs of generation from both male and female. In this chapter, these are discussed in the order named, and in the discussion the respective objects sought are stated. The discussion considers the following: (I) Dehorning of recent introduction; (2) Why cattle are dehorned; (3) When cattle should be dehorned; (4) When cattle should not be dehorned; (5) Facts which bear upon dehorning; (6) Methods of dehorning; (7) Facts regarding spaying cattle; Females that should be spayed; (9) Methods of spaying; (10) Facts regarding castrating cattle; (II) Males that should be castrated; and (12) Methods of castrating.

Dehorning of recent introduction.-Horns were doubtless given to cattle as weapons of defense. In primeval days they were probably a necessity. In the absence of such weapons the hazard of extinction would have been more or less continually present with the 
herds that were not subject to domestication. No sooner, however, do they come under the care of man than this necessity ceases to exist, whatever may be said as to the value of horns in improving the appearance. That they do thus add to the majestic beauty of some breeds, particularly the West Highland cattle, now so frequently found in the parks of noblemen in Great Britain, cannot be denied. It is seldom, however, that asthetic considerations are allowed to bear adversely on the attainment of practical results in connection with the keeping of cattle.

The widely prevalent opinion that horns are no longer a prime necessity in cattle subject to domestication is witnessed in the evolution of hornless breeds in recent centuries. Certain strains of hornless cattle are now found within nearly all the horned breeds in America, in addition to the distinctively polled breeds that have been introduced. That public sentiment is growing in favor of the production of cattle without horns is thus evidenced.

The general practice of dehorning cattle is of but recent introduction. History is apparently silent as to whether cattle were dehorned in ancient times. It came into practice in certain feed yards in Great Britain at sundry times during the nineteenth century. The general attitude of the public toward it, however, was one of hostility. It was looked upon as being unnecessarily cruel. It was not much practiced in the United States or Canada prior to 1890 . The necessity for dehorning was most felt in the feed lots located within the Mississippi basin, and there it was first generally introduced.

The introduction of dehorning into the United States and Canada was strongly opposed. The practice was violently assailed in the press of both countries as being cruel and unnecessary. The Ontario government deemed the subject sufficiently important to justify the appointment of an investigating committee to report 
upon it. Even humane societies, in some instances, lent their influence in opposing it. It does seem strange that such opposition should come from those who not only tolerated but commended the practices of spaying ancl castrating, which would seem to involve quite as much suffering as dehorning.

Why cattle are dehorned.-The principal reason, of course, why cattle are dehorned is to prevent them from injuring one another through goring. The desire to lessen such injury before dehorning became general was shown in sawing off a part of the horn in some instances and by putting brass knobs on the tips of the horn in others. The injury inflicted by cattle on one another through goring, especially when feeding together in sheds, yards, or paddocks, has been serious in some instances, and such injury has followed the animals during shipment to the place of slaughter. In the nature of things, animals in advanced pregnancy are peculiarly liable to harm from the goring of other animals. The instances of abortion that may be traced to this cause are numerous. In the case of males, the retention of horns adds much to the danger incurred in handling them.

It would be stating the question too strongly to say that fattening animals while running loose in shed, yard, or feed lot possessed of horns cannot be fattened with success and profit, but the degree of the success and the amount of profit will certainly be materially less when the animals are in possession of their horns.

The loss from animals goring one another is not to be measured by the injury they sustain from goring that is apparent and tangible, nor by the interference of the stronger with the weaker when taking food in the feed lot, but it is also to be measured by the hindrance to growth and the less degree of thrift that follows the abuse which at all times horned animals are liable to inflict on one another. Too much, however, must not 
be made of hornlessness in the polled breeds. Individuals of these may also injure one another by pushing and also by striking with the head. Individuals among the males of these are sometimes so vicious as to be positively dangerous to those who have them in charge and to others, but it is very evident that the degree of danger arising from viciousness in a hornless animal is less than from one that is horned. The difference in viciousness in breeds and also in individual animals is considerable, and, fortunately, it may be modified by selection in breeding. It is also influenced by the character of the management.

When cattle should be dehorned.-Cattle should be dehorned when grown for meat on the arable farm, and when not marketed till they have reached that age when they may do harm to one another or to other animals through goring. There may be some difference of opinion as to the age in young cattle when horns become really harmful, but all will probably subscribe to the decision that they do not become so to any serious extent until the animals are beyond the age of one year. When they are confined in stanchions or stalls when taking food, or overnight, dehorning is not so necessary as when they feed together when not on pasture, and yet it is now thought that it will pay well to dehorn cattle sold as baby beef when they get beyond or much beyond the age limit mentioned.

All grades, without exception, to be kept for breeding on arable farms should be dehorned. The reasons given below for exempting pure-breds do not apply to grades. A grade that is restless or vicious and possessed of horns may prove a disturber to the peace of a whole herd, and for years in succession. Many grades are not thus vicious, but if these are not dehorned, it may give an advantage over the other animals that they will sometimes use to the injury of the latter.

When horned animals are purchased for feeding in 
the shed, yard, or paddock, it will certainly pay to dehorn them before they are put on feed. They will not harm each other when thus dehorned during the fattening process. They will feed more quietly. The strong will not crowd the weak when taking food. The greater quiet thus secured results in better gains. The animals do not injure one another while being shipped for slaughter. Those who slaughter them have the assurance that bruises not apparent to the eye, the result of goring, will not be present in the carcass. The dehorning of animals prior to feeding, when they have been grown on the open range, is no easy task, but it is one that should not be neglected.

When cattle should not be dehorned.-It is not necessary to dehorn any class of cattle when they are to be slaughtered at an early age, as during the first months of life the horns which they possess do no serious harm. The age limit for the retention of horns by these has been fixed above at one year or not much beyond that age.

Usually pure-bred cattle should not be dehorned, for the reason, first, that value is attached to the horns because of what they indicate with reference to the bony framework; second, because considerable stress is laid upon the correct style of horn, and, third, because the head of a dehorned animal is less attractive than the same with the horns on, and is less shapely than that of a cattle beast naturally hornless.

The size of the horn is, to some extent, an indicator of the relative amount of bone in the carcass. The texture of the bone in the horn is, to some extent, an indication of the character of the bone in the frame. Horns overstrong would indicate too much bone and those unduly small too little of the same for the maintenance of size. Horns coarse in texture would indicate coarseness rather than quality in the bone of the body, 
and, probably, also coarseness more or less in the grain of the flesh.

Each pure breed has a style of horn peculiar to itself, and, in this respect, horns differ greatly. The style of the horn, that is, its setting, its shape, and its curvature, is a distinct indicator of true and desirable breeding. Unless, therefore, the horns are retained in pure-breds kept for breeding, the value of horns because of what they indicate is lost. Thus far the possession of horns serves a useful purpose, and, in this respect, the horned breeds have one advantage over those that are hornless. Should the horns be removed, however, the purchaser of such animals for breeding would be deprived of the opportunity to judge of the factors referred to on the basis of testimony furnished by horns. Not one purchaser in one hundred would care to invest in a male that had been dehorned to place the same at the head of his pure herd. Purchasers also would desire to see the style of horn possessed by the dam, and also other ancestors before investing in pure-breds to add to their herds.

When the horns are removed from pure-bred cattle, the style of the head becomes less attractive. The poll of horned breeds is level and more or less broad, while that of the hornless breed is more or less arched, and, in some instances, also a little pointed. The head of the dehorned animal, therefore, is always more or less lacking in shapeliness. The flat poll is no way objectionable when graceful horns grow out of it, but when these are removed it certainly has a repellent plainness. Such removal of the horns would have considerable influence in withholding a prize from pure-bred animals when in the show ring. But, of course, it would be legitimate and commendable to dehorn such pure-breds as may be singled out for the shambles.

Whether cattle grown on the open range should be dehorned may be an open question. The possession of 
horns may be of some service when used in defense against predatory animals. When, however, cattle are kept on the semi-range plan, the arguments that bear upon dehorning on the arable farm will also apply, and almost with equal force.

Facts which bear upon dehorning.-The best age for dehorning has not yet been determined to the satisfaction of all, and possibly never will be. Some cattlemen prevent the horns from growing by applying some caustic substance over the part where the horn would first appear, and before it has penetrated the skin. Others prefer allowing the horns to grow until the young animals have come to know their use and yet are not able to use them to the serious detriment of other animals. This would mean that they would retain them until one year old. The argument most commonly urged in favor of the method first submitted is that it causes less pain than removing the horns later, a conclusion that would seem to be open to question.

The chief objection to it is that unskilled operators are more or less liable to succeed but partially in the work, from doing it in a defective manner. The chief argument in favor of the method next submitted is that when the animals are not deprived of their horns until they come to understand their use, they are more docile and unoffending than animals whose horns have not been allowed to grow and than animals even of the hornless breeds. Animals of both classes last referred to iearn to push and strike with the head in the process of clevelopment, a method of attack unknown to those dehorned at the age mentioned. To deferring dehorning to the age mentioned, there would seem to be no serious objection.

When there is a real necessity for it, cattle may be dehorned at any season of the year, but some seasons are much more suitable than others in which to dehorn. It may be done in cold weather in winter, providing the 
animals are kept comfortably housed for a few days subsequently. It may also be done in the heat of summer, providing the wounds are protected from flies. But those seasons when the temperature is mild, as in the spring or autumn, are more favorable than when the weather is extreme. Of the two seasons, the spring just after the cattle have been turned out on pastures is somewhat more favorable than the fall, on the principle that any operation that tends to give a temporary shock to the system is better performed when the vital forces are being invigorated through the abundance of the nutrition which succulent grass furnishes.

The loss from dehorning is only temporary when the wounds heal properly. The decrease in the milk flow from the dehorning of cows is marked for not more than two or three days. The adverse effect upon production is seldom felt much beyond one week; the conclusion, therefore, would seem safe that the adverse infiuence resulting would not be felt in beef production for a longer period.

To prevent the horns from growing the substance most commonly used is caustic potash. This should be rubbed well over the "buttons," that is, the horn cores or rudimentary horns, while they are not yet attached firmly to the head. This must be done before the calf is three weeks old, and may be done after the calf is three days old. The younger the calf is after it has made a good start in life, the more easily and successfully the operation will be performed. The hair should first be clipped away for a short distance around the horn button. The parts to be touched with the potash, and those only, should be wiped with a small piece of cloth moistened with soapsuds.

A stick of causic potash is then rubbed over the button until the skin becomes a little inflamed and quite sensitive to the touch. The stick of potash used should be rolled in a piece of paper to protect the hands. The 
exposed end is dipped in water to moisten it. When not in use, the potash should be kept in a closely stopped vial with a rubber stopper. Failure or partial failure may follow an application insufficient in quantity or when the application has been too long deferred. When only partially destroyed, the horns continue to grow more or less until the animals are matured, and they are more or less deformed. The Bureau of Animal Industry of the United States Department of Agriculture recommends the use of a liquid preparation made up of 50 per cent of caustic soda and 25 per cent each of kerosene oil and water.

Methods of dehorning cattle.-The removal of horns by the use of clippers or dehorners is the speediest method of removing them. Dehorners are instruments that work on the same principle as shears and implements used in pruning trees. The power to cut off the horn increases with the length of the handles up to a certain limit. When horns are to be removed with a dehorner, the head of the animal should be tied firmly to a post of sufficient strength. The horns are then quickly removed. The implement should come down close against the skull at the base of the horn. The danger of cracking the horn at the skull is thus reduced and the appearance is less objectionable. The chief merit of this method of dehorning is its quickness.

Horns are frequently removed by the use of the saw. The animals are secured as in the former instance and the horns are then sawed off close to the poll. It has been noticed that when they are sawed thus close, the healing is more rapid than when sawed off less close. When the saw is used, bleeding is less profuse than when the clippers are used, as the saw makes a rougher cut, and it does not crack the shell of the horn at the base as the clippers sometimes do. Many cattlemen prefer to dehorn with the saw for the reasons named. 
It has been argued that under some conditions, as when cattle are kept in large herds, a small percentage of the animals should be left undehorned to prevent them from "bunching;" that is, from huddling together in the pastures as a protection against flies. Bunching thus in hot weather tends to make the heat excessive and under some range conditions accelerates destroying the grass by constant treading. The wisdom of thus trying to prevent such a condition is problematical, as it would in a considerable degree defeat the objects sought in dehorning.

Facts regarding spaying cattle.-The three principal objects sought in spaying are, first, to prevent conception; second, to promote fattening, and, third, that males and females may be more profitably fattened together. Conception is, of course, not desired in females that are to be grown only for meat. It is not desired, first, because of the adverse influence that it would have on the production of meat, and, second, because of the lowering influence which it has on the quality of the meat. The first is the result of diverting the energies of the system from building up the carcass to the maintenance of the young animal in embryo. The second arises in part from the same cause, but, in addition, the quality of the meat is lowered in certain respects, especially in the advanced stages of pregnancy. But these influences are so little pronounced during the first two or three months of pregnancy that some cattlemen countenance rather than oppose such pregnancy. The third object seeks convenience as well as profit.

Fattening is promoted by spaying, first, through removing the draught on the energies of the system used in the maintenance of the generative organs as to condition, even in the absence of conception; second, by insuring more quiet to the animals through the nonoccurrence of the disturbance that accompanies the periods of heat. Such disturbance not only affects the 
individual animal, but it also extends to other animals in the same herd. In large herds, the aggregate of loss from this source would be very considerable in the absence of measures to prevent it.

When heifers are grown for the production of meat, they should be spayed in the one-year or in the two-year form. As a rule, the earlier that such an operation can be safely performed, the more quickly will the animal recover therefrom. Owing to the physical difficulties to be overcome, heifers are not spayed at so early an age as males. The necessity for spaying cannot be said to exist before the animals are capable of breeding, hence heifers are seldom spayed under the age of six months, when spayed through an opening made in the flank. But when spayed through an opening made through the belly, they may be spayed more easily between the ages of three and six months than at a later age. Breeding cows, of course, cannot be spayed until the time comes when it is decided not to breed them again.

While spaying can be done at almost any season of the year, it is true, nevertheless, that some seasons are less favorable than others for doing it. The least favorable season is when flies are abundant and the most favorable, all things considered, as in the case of dehorning, is the spring. (See page 387.) Extremely cold weather brings some hazard to animals spayed at such a time, unless they are carefully and warmly housed.

Females of the bovine species, and, indeed, those of any species, should not be spayed when in a feeble condition, when ill, or when pregnant. When ill or ill conditioned, they have less power to resist the shock to the system which spaying brings with it; and if pregnant, the complications that would follow are liable, in some legree, to prove fatal. Wounds inflicted on animals heal most quickly when the energies of the system are in the highest condition of vigor; for then the energies 
can most quickly bring healing to the wounded parts of the body. It is also deemed advantageous to fast the animals for several hours before spaying them.

As will be manifest to the reflecting mind, spaying is a more difficult operation than castration. It is more difficult because it seeks to remove what is not apparent to the eye, and what cannot be reached without making a wound in some part of the body before the organs to be removed can be reached. Because it is more difficult, it calls for higher skill to perform it without hazard, hence where much spaying is to be done, the services of a veterinary surgeon or of some one else accustomed to the work should be secured.

Females that should be spayed.-It is safe to say that all females grown under range conditions should be spayed when not reserved for breeding. When not spayed it would be difficult, if not impossible, to prevent them from breeding. They would also be liable to breed at an age too early for successful breeding. They will also make better gains within a given time since the energies of the system cease to be drawn upon to maintain the organs of reproduction as soon as the animals are spayed.

Females reared for meat on the arable farm should be spayed unless they are to be slaughtered young. There is not the same hazard that they become pregnant as when grown on the range, but the disturbance to them and to other animals of the herd by the periods of heat are ever recurring after they become capable of breeding. If they are to be sold as baby beef, the wisdom of spaying them is to be questioned, as the operation is always attended with some hazard.

In some instances, it may be profitable to spay cows that have been used for breeding or milk production, or for both uses, before they are sent to the block. Especially may this be done with cows of the classes named that are to be fattened before sending thein to the block. 
When these are to be spayed, the sooner that it is done within a reasonable time of the birth of the previous calf, the greater will be the resultant benefit. The wisdom of spaying cows that are to be sent from the dairy to the block when they cease to give milk is open to question.

Methods of spaying.-Three methods of spaying have been practiced. The first, known as spaying through the vagina, is adapted to the spaying of large animals, as cows and mares; the second, as spaying through the flank or side, sometimes practiced on heifers and sows; and the third, as spaying through the belly, frequently followed in spaying heifers, sows, and bitches. The object sought is, of course, to remove the ovaries. They are ovoid in form and are composed of a firm and dense structure which makes recognition easily possible by those who have once handled them. In size, they vary from a large hickory nut in mature cows to a size considerably less in young heifers.

When females are spayed through the vagina, they are confined in a standing position and so that they must be reasonably quiet. An opening is then cut in the upper front wall of the vagina just above the neck of the uterus. The left hand is inserted through the incision made and the ovaries are removed with an emasculator made for the purpose. One ovary is found on each side of the uterus.

When spayed by the flank or side method heifers are, in some instances, confined in a stall or stanchion and on the left side are crowded against a wall. After clipping off the hair, an incision 4 to 5 inches long is made through the flank or properly the barrel depression at a point between the hook and the last rib. The left hand, properly cleaned and oiled, is then inserted and the ovaries removed with an emasculator or special shear. The wound is then closed with two or three stitches. Many operators prefer throwing the animal, 
and when thus secured and unable to struggle, to remove the ovaries.

When spayed through the belly, which has now come to be a favorite method of spaying heifers, they are thrown and the hind legs are so drawn up by the necessary tackling that the hind parts of the animal are virtually raised from the ground, thus leaving it to rest upon the shoulders and a portion of the back. Ample room is thus furnished to enable the operator to perform the operation without interference from the stomach. The hand may then be inserted in the opening made in the underline, and the ovaries are removed by a shear or emasculator. This method is the best and safest of the three submitted, but it is less speedy than the flank method. To accomplish it in the best fashion a block and tackle are a necessity. The objection has been made to it that it involves some hazard that the intestines may give trouble in the wound made. This should not follow where the stitching is properly done.

When undertaking this work, scrupulous care should be exercised against contaminating germs that may make trouble. The implements used should be sterilized by boiling in water, say, ten minutes. The hands should be treated with disinfectants. For this purpose carbolic acid and water in the proportions of 3 and Ioo parts, respectively, will be found very suitable. The same is true of corrosive sublimate in the proportions of I of bichloride of mercury to, say, I,000 of water. The wounds should also be thus disinfected. When the wound has been sewed up, if flies are present, it should be smeared over with tar. The tar should have in it enough of spirits of turpentine to thin it so that it may be readily applied. Moreover, when material other than catgut is used in sewing up the wound, in due time the stitches should be cut and removed.

Facts regarding castrating cattle.-The chief object sought in castrating the males of bovines inciude: 
The improvement of the carcass; (2) more rapid fattening; (3) greater tractability, and (4) to make possible and practical the feeding and grazing of males and females in the same feed lots and pastures. These objects are of much moment to the growers of beef.

When males intended for beef are not castrated at a somewhat early age, they develop undue strength of bone and muscle in certain parts of the carcass, especially in the head and neck. Such development is obtained at the expense of development in other parts of the carcass through the operation of that law of breeding known as correlation. The increased development referred to has but slight monetary value when sold as meat, as the parts in which such increase is most pronounced are relatively low-priced on the block. Early castration diverts the energies of the system to the greater relative development of other parts of the system in which the meat is relatively more valuable.

The castrated males also make greater development in a given time and fatten more readily when being prepared for the block. That it should be so is what is to be expected. First, the essential organs of generation. cease to draw upon the energies of the system after castration, and, second, disturbing influences that come to uncastrated males through sexual desire are entirely absent. When such animals are fattened, the food is not used to little purpose in depositing fat in the parts of the carcass that are possessed of little value.

Males castrated are immediately improved in their tractability. The moment that castration is completed, the headstrong, determined spirit so often shown in bulls is broken, and, though formerly vicious, they, as a rule, become docile. The management of a herd of bulls running together in the herd or feed lot would be a constant menace to the attendant. When these are castrated, the danger is, as a rule, entirely eliminated. 
When males are uncastrated and yet are allowed to mix promiscuously with females in the feed lot or in the pastures, a sort of pandemonium would be introduced into the same. The outcome would be pregnancy in the females whether desired or not, and much retarded increase in the males. The necessity for the general castration of males is not for one moment to be gainsaid, whatever the view that may be taken with reference to the pain involved in the operation.

The best age at which to castrate males among cattle is when they are not more than, say, a week old, and certainly when not more than three or four weeks old. The best time to castrate is when the calves have got well started in the direction of a robust growth. In strong calves this will be when they are about one week old. At no time subsequently will they be castrated with so small an amount of hemorrhage, with so little resistance on their part, and with so slight a shock to the system. Calves that are weakly, however, should be allowed to go beyond the age of one week before they are castrated. But certain males should be castrated later, as is shown below.

The season at which castration shall be performed is of less importance than the age at which to castrate. If calves are to be castrated at the best time in their development, they will be castrated at all seasons, when they are so born. Nevertheless, the aim should be to avoid castration, when practicable, during the coldest and hottest weather, especially during the season of flies. Should any one season be fixed upon as the most favorable, it would be the spring and soon after the animals are on grass. The system is then building up and improving, hence it can withstand a shock better than when the energies are low. The food also is very suitable for keeping the bowels in that condition which is favorable to correct digestion. Males of the bovine species should not be castrated when in a weak or debilitated condition 
when this can be avoided; especially is this true of calves. When castrated when yet in the sheds or stables, they should have a good and dry bed of fresh litter on which to lie to lessen the hazard from germs in contaminated surroundings.

Males that should be castrated.-Of course, all male calves grown for meat beyond the milk period should be castrated. In other words, all the males should be castrated that are not grown for veal. No gain would result from such castration of calves at the age when they are ordinarily sold for veal. In rare instances, but one testicle comes down. When this happens the aim should be to have a skilled operator remove it. as when not removed the animal will be more or less troublesome in a herd, and because of its staggy character the meat will be discounted by the buyer.

Pure-bred males are not usually castrated, as they are regarded as being too valuable for being simply grown for meat. But when it is manifest while they are yet of tender age that they are possessed of development so inferior that it is not probable that they will grow into animals good enough to be used in breeding, they should be castrated. In some instances they promise well when quite young, but develop disappointingly, to the extent of preventing them from being sold as breeders. When this happens, they should be castrated. Usually any considerable surplus of bulls beyond the age of one year in a pure-bred herd is property that will bring loss rather than gain when maintained in the hope of selling them for breeding, as the average buyer tries to get a younger animal. Animals castrated beyond the age mentioned will have more or less of a staggy appearance, and, therefore, may not bring the best price when sold for meat, but even so, disposing of surplus bulls as indicated is usually attended with the greatest profit, although, of course, there are some exceptions. 
Aged bulls may, of course, be castrated, but it is not usual to castrate them. When castrated they are knowil as stags. As stag meat is discounted in the market, the increased profit from castration is usually too little to repay the extra trouble incurred, except when it is desired to fatten the animal so castrated in a feed yard or lot with other animals or on pasture. In such instances, the practice is to be commended.

Methods of castrating.-When calves are castrated, one person holds the calf, which is laid on its side, the hind legs being drawn up toward the body. In the case of calves large and strong, the legs should be tied. A second person cuts off the end of the scrotum and the testicles are drawn out in turn until the cord breaks or is scraped off rather than severed by the knife of the operator. The object sought by severing the cord thus is to lessen the loss of blood. The cord should be drawn down more or less rather than severed abruptly. No treatment is necessary unless it be the bathing of the wound with some antiseptic, and, in the time of flies, smearing it with tar and spirits of turpentine, as in spaying. (See page 394.)

Older animals are castrated, in some instances, while standing; in other cases, when they are thrown. When castrated in a standing posture, the head is securely fastened to a post and an attendant at either side aids in keeping the animal in place. In other instances, the head is securely fastened in a stanchion and is well drawn to one side, the other side of the animal being pressed against the stall. The operator stands squarely behind the animal, seizes the scrotum with the left hand, gives it a half turn around, and draws it out between the hind legs. With a knife in the right hand a large incision is made over the testicle, which cuts through all the covering of the same. The testicle is then drawn out and the cord is severed with an emasculator or by scraping it with the knife blade. When the animal is thrown, 
the process of throwing is the same as when trimming the feet (see page II9), and when thrown the testicles are removed in practically the same way as when the animals are standing.

In some instances, mature bulls and also rams are castrated by the aid of ligatures. A strong elastic band is placed around the scrotum above the testicles and close up to the body. The pressure interrupts the circulation and deadens the parts, which finally drop off. The same result will follow tying a strong cord around the scrotum. In some instances, the scrotum and testicles are cut away about an inch below the ligatures after three or four days and antiseptics are applied to the wound.

When males are castrated, they should be given close attention until they are properly healed. The wounds may heal over too soon to admit of proper drainage, and if they do should be re-opened. In time of flies, tar and turpentine should be applied as previously intimated in the case of females that are spayed. (See page 394.) In cold weather suitable protection should be provided amid clean surroundings. 


\section{CHAPTER XIX \\ INSECTS INJURIOUS TO CATTLE}

In this chapter it will be the aim to discuss only such insects as are most frequently found on cattle. The object specially sought in the same and also in the following chapter on the more common ailments of cattle is to aid the readers who may not previously have access to information on these subjects given in concise form. The student of the agricultural college will be given information pertaining to them in the class room, which will be far more comprehensive and complete. In the preparation of both chapters, the author has received most substantial aid from Prof. M. H. Reynolds, D. V. M., M. D., who fills the chair of veterinary science at the College of Agriculture, University of Minnesota.

In this chapter the following subjects are discussed: (I) Ringworm on cattle; (2) Warbles on cattle; (3) Lice on cattle; (4) Flies on cattle; (5) Mange on cattle, and (6) Southern or Texas cattle fever. Ringworm, though not caused by an insect, is included, first, because it is caused by a parasite and affects the skin, and, second, because the treatment is much akin to that called for in removing insects. Texas fever, viewed apart from its cause, comes properly under the head of the subjects discussed in Chapter XX, since it is a blood disease. The medium of communicating it, however, is the Texas cattle tick, hence the discussion of the tick and also the fever are considered together.

Ringworm on cattle.-Ringworm, sometimes called barn itch, is a skin disease most commonly found in cattle, but it may occur in horses, dogs, and also in the human family. It is of two kinds, known as Tinea 
tonuraus and Tinea favosa. Both are due to a fungous growth vegetable in character. In many respects they act similarly notwithstanding some points of difference, and the treatment for both is the same.

Ringworm is so named doubtless from the circular shape of the patches in the affected parts. These are, of course, more or less irregular in shape, and vary in size from, say, $\mathrm{r} / 2$ inch to several inches. The hair from the parts affected has broken or dropped off, and the skin underneath is slightly thickened and covered more or less with light-colored scales. More commonly it is found on the necks and heads of calves that have been confined in stables during the winter and generally toward the arrival of the spring season. Very frequently the skin is affected around the eyes, and, in some instances, patches appear on the body. It is a contagious affection.

The injury resulting comes, first, from the unrest caused by the itching, which is more or less present, and, second, from the extent to which its presence renders the animals unsightly. Being contagious in character, the wisdom of combating it promptly will be at once apparent. Although contagious it is not readily transmitted from one species of animal to another. Such transmission, however, is possible under favorable conditions.

Whatever the application used as treatment, it will be more effective if the affected parts are well soaked with soap and warm water. A brush should be used to remove the dead skin scales or crusts, and the same should not be used on other animals until sterilized. Then follow with any one of the following treatments as may be most convenient: ( I ) Carbolic acid and glycerine in the proportions of I and Io parts; (2) tincture of iodine and tincture of iron equal parts; (3) iodide of sulphur and good pure lard in the proportions of $\mathrm{I}$ and 8 parts; (4) nitrate of mercury ointment. The first remedy should be applied every other day by rub- 
bing it onto the affected parts with the hand or with a cloth; the second should be applied every other day with a small brush; the third and fourth every day with the hand or with a cloth. A few days of faithful treatment will check and remove the disease. Isolation of the affected animals is not necessary when treatment is promptly administered.

Warbles on cattle.-Warbles are grubs which mature in the flesh of cattle immediately underneath the skin and usually in the region of the back. It was formerly believed that they were produced by the ox bot fly of Europe (Hypoderma bovis), but it has been satisfactorily demonstrated that the egg which produces warbles is laid by another species, Hypoderma lineata, which more or less resembles the former in appearance and habits. The general color of the fly is black, and in conformation it resembles a bee. For many years it was believed that the fly laid its eggs in the body of the animal after piercing the skin. The preponderance of evidence, however, points to the fact that the eggs are laid somewhere in the hairs of the body, supposedly in the region of the heel, though this is by no means certain, and that they are conveyed to the mouth by the tongue of the animal when licking itself. In the first stages of development the larvæ have been found in considerable numbers in the esophagus of cattle in the month of November. Usually by the latter part of January they have all disappeared from the esophagus and by that time the small lumps traceable on the skin of the back indicate their presence. In the interval it is thought that they have worked their way through the tissues. They continue to grow in their final home and then work their way through the skin frequently as late as April or May, when they fall to the ground, into which they burrow, pupate and emerge in about a month as a fly. When the grubs leave the body they are about threequarters of an inch long, and they quickly change from 
grayish white to a dark brownish color. Although they occur on the buffalo of the western plains, it is thought that these animals were not thus affected till after the introduction of cattle.

The sure indication of the presence of warbles is the small elevations in the skin which may be distinctly traced along the region of the back by moving the fingers flatwise over the same subjected to light pressure. Later, minute openings appear, and these enlarge until the larvæ finally escape from them. The infestation is not confined to animals low in flesh, for the eggs are laid at a season of the year when cattle are generally in good condition.

The injury from warbles, though not very serious in the individual animal, is large in the aggregate. It is felt in the following ways: (I) In the irritation caused by the fly when depositing the eggs; (2) in the weakened vitality resulting from the warbles when numerously present; (3) in the loss in milk and flesh consequent upon these influences, and (4) in the injury done to the hides. The last named is probably the greatest source of loss. It has heen estimated that from 33 to 73 per cent of the hides in the upper Mississippi basin are more or less injured by the presence of warbles.

The remedy should seek to destroy the grubs. This can be done by squeezing them out and destroying them at the proper season. Should the opening be too small to admit of their escape, it may be enlarged by using a sharp knife. Some authorities have also recommended the use of kerosene and mercurial ointment for destroying them. The kerosene may be applied by using a small can of suitable make, but care must be exercised not to use it in excess or it will remove the hair. The ointment is applied by rubbing it over the openings. While the use of the kerosene and the ointment would doubtless kill the grubs, it would seem to be objectionable to have them left in the cells in which they died, and as to the precise 
value of remedial measures, individual opinion is not in agreement. Some authorities claim that the flies do not travel far and that as a result individual effort will be efficacious. Others claim that concerted action would be necessary if the work is to be effective. No remedy has yet been devised that will apply to animals that cannot be handled.

Lice on cattle.-Two classes of lice infest cattle, viz., the suctorial and the biting lice. The former obtain their food through suction, the latter by biting. Of the former there are two kinds, known as the short-nosed louse (Hamatopinus eurystornus) and the long-nosed ox louse (Hamatopinus vituli). The former is the larger of the two. The latter, which is more common, is about one-eighth of an inch long, and in width it is about onethird as much. In color both are of a bluish tint. The eggs are deposited on the hair near the skin, being glued to the former by an adhesive substance. The biting louse (Trichodectes scalaris), very common on cattle, is small and red in color. The suctorial lice attack chiefly the neck and shoulders, but the biting lice are most numerously found at the spine and on the hips and rump, and to a less extent on the head and neck. Contamination comes from contact with infested cattle or the surroundings which they have frequented. Chicken lice may annoy cattle to some extent, but it is believed that they do not propagate on them.

The indications of the presence of lice on cattle are uneasiness, more particularly as manifested by their rubbing against external objects. This, however, may result from other causes. Their presence may be determined by examining the parts where the rubbing is most apparent, but the examination should be carefully made, as they may not be readily seen amid the dust and scurf that may be present.

The injury resulting from the presence of cattle lice is caused by the incessant itching which they produce. 
As their increase is very rapid, remedial measures should be very promptly administered. To free a large herd from lice when they have become numerous is no easy task, hence remedial measures should begin at once when their presence has been discovered. It has been claimed that lice are only found on cattle in low flesh. This, however, is a great mistake, as they are frequently found on cattle that are far advanced in preparation for the block.

Various preparations have been used for the destruction of lice. Prominent among these are treatment with kerosene emulsion, a decoction of tobacco, and a decoction of fish berries. The kerosene emulsion made by Prof. Riley's formula is prepared as follows: Take kerosene 2 gallons, soft soap $1 / 2$ pound, or I pound and water I gallon. Dissolve the soap in water by boiling and add the kerosene slowly while still boiling, but to avoid danger, not in close proximity to the fire. Churn the mixture ten minutes, which means to stir it rapidly in the absence of a better method, and then dilute by adding eight times its bulk of water. The tobacco decoction is made by steeping for an hour tobacco in water at the rate of 2 ounces of tobacco to each quart of water. The decoction of fish berries, Cocculus Indicus, is made by taking $1 / 2$ pound for each animal, pounding the same until fine and adding 2 quarts of vinegar. These are allowed to simmer for one hour. The kerosene emulsion treatment is cheap and efficacious. The tobacco treatment is not costly, but some caution must be used lest an application too liberal should sicken the animals. The decoction of fish berries, though dearer, has the merit of destroying the nits. These are usually applied with a brush, and should be present in quantity sufficient to penetrate the hair to the skin. In cold weather care must be taken to keep the animals warm when applying liquid remedies. Various other remedies are used which have more or less merit. Among these are coal 
tar products, corrosive sublimate and gray hellebore. The coal tar products include some of the proprietary dips. The corrosive sublimate treatment is prepared by adding I5 grains of corrosive sublimate to I pint of water. The gray hellebore is dusted into the hair over the parts infested after the hair has been raised by brushing it in the opposite direction from which it naturally lies. A perforated box is used as a duster. Persian insect powder is probably more efficacious, but is more costly. A little kerosene applied occasionally with a bristle brush as a spray, and, with caution, is efficacious, but freely applied would remove the hair.

As the nits hatch out in from five to ten days, a second treatment should be given at an interval of a week, and, in some instances, a third at a similar interval. A complete deliverance, however, is not likely to be attained unless measures are taken at the time of the first application of the remedy to clean the stables. This may be done by whitewashing them after the litter has been removed and burned or carted quite away, or by spraying them thoroughly with a 3 per cent solution of carbolic acid and water or with some reliable proprietary dip.

Flies on cattle.-In the United States and Canada, two classes of flies afflict cattle more or less during the warm months of the year. These are known as the common fly (Musca domestica) and the horn fly (Hamatobia serrata). The former has doubtless been present from the earliest colonization period, if not, indeed. earlier. The latter was introduced from Europe about 1885. Its distribution is already continental. The appearance of the house fly is too well known to call for any description. The horn fly is not more than about half the size of the house fly. Flies of the species frequently congregate in great numbers when resting at or near the base of the horn, hence the name. 
The horn fly deposits eggs preferably in soft or moist manure, but will also lay them in decaying vegetable matter. In about 24 hours, dependent more or less on temperature, they hatch out. The larvæ then live near the surface of the earth and in about 15 days emerge as flies. The life of the common fly is not greatly different. Both multiply with amazing rapidity, and, doubtless, are usually harmful in proportion to their numbers.

The season for flies varies in duration with variations in normal temperatures. The longer and the more intense the period of summer heat, the more favorable is it for the continuance and prolongation of the season for the flies. Flies come with the advent of settled warm weather and remain until the season of the earliest frosts. In the northern states, they usually become troublesome in the latter part of June. Southward they appear earlier with decrease in latitude, and northward later with increase in the same. The period of fly invasion, therefore, covers from three to more than five months.

Flies are harmful to cattle in various ways. They lay eggs in wounds, not protected, which produce maggots and may become the carriers of disease, as in the case of malignant anthrax. But the chief loss from flies comes from the unrest which they occasion. This unrest, it is generally believed, lowers the milk yield in cows and is antagonistic to the laying on of flesh in other cattle. The horn fly injures by its bite, which is in the nature of a sting. While common flies do not sting, it is evident that their presence produces discomfort by the way in which cattle try to. dislodge them by striking with head and tail. It is reasonable to suppose that in proportion as they are present, they would hinder production in the fly season. But experiments conducted by some of the experiment stations to protect cows in milk from flies showed what may be termed only 
negative results. They succeeded in protecting the cows more or less completely from flies, but got no increase virtually in the milk yields. In view of these results, the conclusion is irresistible that unrest from this source does not act similarly to unrest from other sources. It may be true, however, that, viewed from the standpoint of production, it may not pay to use repellents in the effort to protect cattle from the common house fly.

The protective measures that have been used against flies include the following: (I) Darkening the stables provided with proper openings and screens for ventilation; (2) contrivances for catching flies or brushing them off as they enter the stables; (3) the application of certain powders, as tobacco, to destroy them, and (4) the application of repellents, as Io to 15 per cent kerosene and water, kept properly agitated, fish oil with 3 per cent of carbolic acid and kerosene emulsion, also proprietary remedies of which there are many in the market. The repellents are applied with sponge, brush, or spray, according to the nature of the material and the number of animals to be treated. It would seem correct to say that of the above, a properly darkened basement stable to which the animals are given access during the warmer portion of the day is the most effective protection against common flies that can be devised. It will not protect equally against the horn fly, the annoyance from which goes on by night as well as by day. The common fly is more active by far in the light. But such protection will not increase production unless the ventilation secures more coolness than is obtainable outside. Screens made from material used in making sacks, with or without wire screens underneath, may sufficiently exclude the light. More coolness may be obtained in a basement ordinarily that rests against a bank than in one that does not. 
It would further seem correct to say that one of the most effective applications for protecting against the horn fly is kerosene emulsion. It is best applied daily as a fine spray. In a large herd it can best be applied in a specially prepared chute through which the cattle pass and by a pump with several nozzles. The emulsion as used at the Virginia experiment station is prepared as follows: Take yellow soap $1 / 2$ pound, soft water I gallon, and kerosene 2 gallons. Shave the soap fine and dissolve in the water at a boiling temperature. Place the kerosene in the barrel containing the spray pump and add the hot soap solution. Churn vigorously for 15 to 20 minutes to emulsify, and add I gallon of water to prevent from becoming curdy. Before using, add 5 gallons of water. The above should spray more than IOO cattle, and the emulsion should only be prepared as needed. Daily spraying for two weeks at the aforementioned station well-nigh resulted in annihilating the flies.

To remove the droppings as made from the yards and stables will no doubt aid very much in preventing increase in flies, scattering them frequently when dropped in pastures may help some, and strewing lime over the droppings when not removed will also render substantial aid. There is no doubt but that the best return is obtained from the manure when it can be drawn out and spread every day or two. Should maggots be produced in wounds from eggs laid by flies, carbolic acid and water in the proportions of $I$ and 20 parts will dislodge them and tar smeared over the wound will further protect it.

Mange on cattle.-Mange on cattle is sometimes called cattle scab or cattle itch. Its most serious form is caused by a mite (Psoroptes communis, var. bovis). Mites are of three classes, viz., sarcoptes, psoroptes, and symbiotes. The second and third of these affect cattle, but nearly all the trouble caused by mites on cattle 
comes from those of the class mentioned second. The sarcoptes burrow channels and live in or beneath the cuticle. The psoroptcs live on the surface of the skin and move about freely over it. The symbiotes affect parts near the feet. The psoroptes increase very rapidly. They produce a scurfy and scabby condition of the skin, and it is under these scabs that they live and multiply. The infestation of cattle is far more common on the western ranges than elsewhere. On these it is commonly referred to as Texas or range itch. During recent years, largely through the influence of contamination from cattle exhibited at the live stock fairs, this trouble has come to be present in an annoying degree in many of the most valuable of the pure-bred herds. Fortunately each class of live stock is infested by mites only which do not flourish on the others, notwithstanding the similarity of the results which they produce. Mites are so minute that their presence cannot, in all instances, be detected without the aid of a lens.

The cattle mite psoroptes usually begins its attacks on the parts around the top of the shoulder and the root of the tail. It gradually spreads along the back, sides, and down on the outer portion of the legs, but is seldom or never found on the inside of the legs, thighs, or abdomen. From the irritation of the skin, pimples are formed, which develop into vesicles filled with a fluid and from these comes a gummy exudation which forms a thick crust. The hairs for a long time stand up through these crusts, but finally fall off, leaving bare patches of calloused and wrinkled skin. The mites soon abandon the bare parts and begin work in parts adjacent to them. The trouble is communicated by contact with affected animals or with surfaces against which they may have recently rubbed. Mange in cattle is much less prevalent in summer than in winter.

The most prominent indications of cattle scab mites are the staring condition of the coat on the 
parts affected in the earlier stages of infestation. and the incessant manifestation of a disposition to rub against surfaces, accompanied at first by a scaly and wrinkled condition of the thickened skin, and later by a falling off of the hair from the affected parts. The presence of lice may lead to rubbing off the hair, but they do not cause that scaly, wrinkled, and thickened condition of the skin which results from the presence of mites. This affection may certainly be distinguished from eczema, which, in several respects, it resembles, by the actual presence of the mites.

While the attacks of mange come most readily to cattle that are weak and debilitated, they come to all classes of cattle, even to animals so high in condition as to be able to win honors when shown in the fat classes. When mange gets into a herd, ill-doing is the invariable result. The cattle lose flesh and the milk flow from cows thus affected decreases rapidly. Unless remedial measures are applied, the whole herd would soon become a wreck, and deprived of all power of recuperation. It spreads so quickly in a herd that remedial measures cannot begin too soon when its presence is discovered.

When mange first appears, if the healthy animals can be separated and moved to other quarters, they may escape infection. If they cannot be thus removed, the infected animals should be taken from the others, and the quarters occupied carefully disinfected by using a solution of carbolic acid and water, of which the proportions are $I$ and 20 , respectively.

Where but few animals are affected, treatment may begin by giving the affected parts a thorough scrubbing with soap and warm water. Should some of the crusts remain, apply sweet oil to soften them and wash again the day following. Any of the dips with coal tar as a base, as zenoleum and chloro-naptholeum, should prove efficient, if freely and thoroughly applied according to the directions. Two, or even three, applications, may 
be necessary at intervals of five or six days to destroy the mites that may be hatched in the interval. Of course, thorough disinfection of the stalls, mangers, and floors should be given. Remedial measures should not be allowed to slacken until the trouble has been completely removed, or soon the entire work will have to be done over again.

Under range conditions, it is, of course, only practicable to treat cattle for mange by means of dipping or spraying. The Department of Agriculture has given formulas for making various dips, as, for instance, those known as "lime and sulphur" and "tobacco and sulphur" dip. They are used in properly constructed vats, in passing through which the cattle are submerged. They remain in the dip for two minutes and must be dipped again in eight or ten days before a clean bill of health can be secured for them. If dipped in an emulsion of crude petroleum and water made as directed by the department, but one dipping is called for.

The labor involved in dipping has apparently, in a great measure, been rendered unnecessary by the invention of what is known as the Seabury spraying machine. It operates at one end of a cattle chute through which the animals are driven. The crude oil and water, used in the proportions of I and 4 parts, respectively, is so continuously agitated as to become thoroughly admixed. It throws the liquid with such force through numerous nozzles that it saturates most thoroughly. The oil remains on the skin and hair for several weeks, hence the nits that hatch are destroyed so that but one dipping is necessary, and lice, if present, are destroyed at the same time. Cattle sprayed but once by this machine, under proper supervision, will be given a clean bill of health.

This remedy is best applied in the spring, the reasons for which are as follows: (I) The cattle are removed from winter quarters, where disinfection is dif- 
ficult; (2) it is claimed that the oil in the coat tends to protect from storms of snow, rain, and sleet; (3) the oil tends to cause an early shedding of the hair. In the late autumn, in climates where changes are sudden, there is hazard in spraying thus, insomuch that serious loss has been known to result therefrom. The materials thus used should be effective in treating small lots, providing the water and oil could be kept properly stirred. Notwithstanding the efficiency of this method of treating mange, it will be manifest that for some time to come, owing to the magnitude of the work, dipping will still be done in large measure by means of vats and by the various formulas outlined by the United States Department of Agriculture.

Southern or Texas fever.-This disease, more commonly known as Texas fever, is so designated doubtless because of the extent to which it was carried to cattle in the states northward by natives drafted from Texas to graze on the ranges. It is called southern fever, because its settled home is in the South, since it cannot survive the cold of the northern winter. It is also known by such names as Spanish, acclimation, splenic or tick fever, red water, bloody murrain, and town-cow disease.

Texas fever is caused by a microscopic animal germ, Pyrosoma biglminum, which lives within the red corpuscles of the blood and breaks them up, usually, but not always, with great rapidity. When the destruction is rapid the disease is present in the acute form, and it is fatal. When the destruction is slow, it is present in a mild form, which is not usually fatal. All the disease processes in Texas fever result from the red corpuscles of the blood.

The disease is transmitted, as it were, indirectly. It is communicated by means of the southern cattle tick (Boophilus annulatus), and indirectly as shown below. This is the only known medium of communication. Animals which sicken and die from it do not directly 
infest others. The infection is not spread by means of the saliva, breath, urine, or manure of infected animals.

The ticks do not migrate from one animal to another. The full-grown female tick, gorged with the blood of the animal which has sustained her, usually a cattle beast made immune to the disease, drops from the body to the ground, and within about a fortnight has laid from, say, 1,500 to 2,500 eggs. They hatch in from two to eight weeks, according to the condition of the weather. The young ticks, so minute as to be scarcely visible at first, are nevertheless very active. They crawl up the grass and other forms of vegetation and cling to these, where they are able to live for three to four months in the absence of live stock. From the pastures they reach the legs of cattle grazing on them and crawl up to their feeding grounds, that is, the parts where the skin is thin, as the inside of the thighs and flanks and portions of the udder and escutcheon. Except in cool weather, they attain full size in from three to four weeks, and are ready to infect pastures. In some instances symptoms of the fever are manifest within ten days of the exposure. Usually, but not always, from 30 to 40 days elapse from the time that cattle which bring the ticks pass over the pastures before the outbreak occurs on the other cattle that have been exposed.

When cattle from without are taken into the infected areas, they usually contract the disease the first summer. Young cattle may survive, especially calves, but mature animals of whatever class will nearly all perish. Calves and other animals which recover are practically immune. When the infection is carried by tick-infested animals beyond the permanently infected areas, the pastures, roads, and inclosures where they have been are dangerous to susceptible cattle. The ticks may also be conveyed in litter from cars which have carried infested animals. 
Since the ticks cannot survive the cold of northern winters it will be apparent that the pastures north of a certain line cannot be permanently infected with what may be called the disease germs of Texas fever. On the other hand, where the winter climate is sufficiently mild, areas exist in which, as managed in the past, the ticks are always more or less present. It will also be apparent that this dividing line will be to some extent a shifting one, varying more or less with the character of the winters. The United States Department of Agriculture has recognized this fact when establishing the so-called quarantine line south and east from which cattle may not be shipped north and west except for immediate slaughter, unless properly dipped according to government regulations, between the dates of February I 5 and December $\mathbf{r}$. In a general way, the quarantine line may be said to run from the Atlantic westward through central Virginia and Tennessee. It then deflects southward somewhat east of the central portions of Indian territory and Texas. It also includes lower California. As early as I8I4, the people of Virginia had taken measures to prevent cattle in certain areas farther south from being brought into the state. Protective measures sought at sundry times in various states culminated in the establishment for the whole country of protective measures governing the movement of cattle from infected areas.

Texas fever occurs in the acute and chronic forms. In the latter form it may be in the nature of a relapse, which usually occurs in the autumn, and is so mild that but for the emaciation which follows its presence would scarcely be recognized. In the acute form, the temperature is always high, in some instances as high as IO $8^{\circ}$, and it usually remains high from five to seven days, within which period many of the animals die. Should it drop suddenly to sub-normal, the danger is imminent that collapse may follow. The affected animals usually 
stand apart from the others with head downward, the ears lopped and the back arched. In cows in milk the secretion ceases. The urine assumes a dark cherry color as the disease progresses. At first the bowels are constipated, but later diarrhœa is not uncommon. The presence of the ticks on the body furnishes confirmatory evidence, but they are so small that diligent search may be necessary to find them when but few are present. Death may ensue in three days from the attack or not until several days subsequently. Recovery is, in all instances, very slow, owing to the poverty of the blood.

The loss incurred by death in cattle from Texas fever, though very great, by no means represents all the loss resulting therefrom or probably the larger share even of the same. It also comes: (I) From the less high condition of finish which animals frequently possess that may have had mild attacks of the disease; (2) from the restriction which it puts upon the movement of stockers that could be finished more profitably in other states; and (3) from the lack of improvement that would otherwise result from the more general introduction of superior animals brought in to effect the same.

No treatment for Texas fever has been found of much avail. Purgatives not too severe are given to open the bowels when constipation is present and stimulants are given when collapse threatens. Succulent food is fed if the animals will take it, which, in severe cases, they will not. But it is greatly important that all animals that have not shown any symptoms of the disease shall be at once removed to other pastures. It is also recommended to grease the parts usually affected with ticks to kill them if present. A mixture of any cheap grease and kerosene in the proportions of 2 and $I$ parts will answer.

While treatment for Texas fever has proved of but little avail, fortunately the same is in no sense true of the protective measures that may be adopted in rela- 
tion to it. These may be divided into three classes: Protective influences within the infested area, outside of the same, and for cattle brought into the infested area.

It should be quite possible to exterminate Texas fever on any farm, although this is not always easily done. The fact that the fever cannot be imparted except through the medium of the ticks, and that the ticks cannot survive apart from the bodies of cattle for a longer period than, say, four to five months, is of great significance. It means that the pasture infested may be freed from the presence of ticks in one season if cattle are kept aloof from them from September onward. If cattle without ticks are then introduced and confined within a properly fenced yard, the work is done. The introduction of such cattle, even from infested areas, has been made quite possible through subjecting them to dipping in or spraying with the crude petroleum preparation, according to the regulations prescribed by the United States Department of Agriculture.

Outside the infected district infection cannot follow unless cattle are brought from the infected district within the months during which such removal is not permissible or unless they are exposed to infection from quarters occupied by infected cattle when being sent northward for slaughter. The dipping process referred to above makes it possible to ship in cattle from infected areas. This, however, is but little desired except when the cattle are brought in for grazing or finishing for the block.

It is frequently desirable to bring cattle within the infected area for breeding uses chiefly with a view to effect improvement in the cattle ordinarily kept within the same. Happily this is now quite possible by rendering them immune to the disease by means of inoculation. This is usually done in the following way: Some of the blood of an animal over two years of age that was 
well known to be affected the preceding summer is injected immediately under the skin of the animal to be inoculated. The best age for such inoculation is 9 to I5 months, and the best season is the three winter months. In this way the percentage of loss from this class of animals is greatly reduced. Another method is to bring such animals within the area under the age of four months, and to allow them to become immunized like native cattle by tick infestation. 


\section{CHAPTER XX}

\section{THE MORE COMMON AILMENTS OF CATTLE}

In this chapter no attempt is made to discuss the ailments of cattle in a sense that even approximates completeness. Only those are touched upon that are most common in herds at the present time, and that are, in consequence, most likely to give trouble to owners of cattle. In the discussion the aim has been to dwell upon the cause or causes which give rise to the various ailments discussed, the symptoms that characterize them, and the means that may be adopted to prevent them, rather than to dwell at length on the treatment. This course has been followed on the principle that an ounce of prevention is worth more than a pound of cure. Nevertheless, treatment in some forms of disease is greatly important, but in nearly all the ailments discussed it can only be properly given by a trained veterinarian. On the other hand, the preventive measures may, in nearly all instances, be applied by the owner of the cattle.

The ailments included in the discussion are the following: (I) Tuberculosis in cattle; (2) Abortion in cows; (3) Milk fever in cows; (4) Actinomycosis or lumpy jaw in cattle; (5) Anthrax in cattle; (6) Blackleg in cattle; (7) Hemorrhagic septicæmia in cattle; (8) Corn stalk disease in cattle; (9) Removing the afterbirth from cows; (IO) Eversion of the womb in cows; (II) Hoven or bloat in cattle; and (12) Scours in calves.

Tuberculosis in cattle.-Tuberculosis is a common germ disease that affects all domestic animals kept on the farm except, possibly, sheep. It is most extensively present among cattle. In the human family it is commonly called consumption. The germ which produces 
it, Bacillus tuberculosis, is always present in the system of infected animals. It may affect any organ or tissue of the body, but is more frequently found in the lungs and intestines. Especially when the udder is diseased the germs are present in the milk. A post mortem will usually reveal diseased tissue in some part of the organization. Nodules, usually called tubercles, wiil be found in or upon the parts attacked. These vary in size from a pin head to a good-sized marble. Tubercles contain a cheesy or gritty substance, which, in many instances, has turned to pus, usually of thick consistency.

The symptoms which indicate the presence of tuberculosis, especially in the early stages of the disease, are frequently elusive, so much so that in the absence of the tuberculin test the most skillful veterinarian may be unable to say whether the germs are or are not present in a given instance. In the summer of 1905 the author was shown a collection of high-bred Shorthorn cattle numbering more than 30 animals, every one of which was high fleshed and appeared to be in finest bloom, and yet, in every instance, the tuberculin test had shown them to be tuberculous. These had been sifted out from many others, bought to secure representatives of certain families of Scotch cattle. The owner, Hon. W. C. Edwards of Rockland, Ontario, Canada, was raising calves from them by what is known as the Bang system. (See page 425.)

In some instances the germs may be present for years, and yet the animals will live and thrive, but, in many instances, there comes a sudden breaking down, of which it may be said that they literally fall to pieces. When the lungs are seriously affected, a chronic cough is likely to be present which is stirred into action by sudden exposure to cold air or by exertion which calls for much effort. When the intestines and mesenteric glands are seriously affected, chronic diarrhœe is present. When the lungs or the intestines are thus seri- 
ously affected, the animals may fall away in flesh and carry a staring coat. But so varying are the symptoms of tuberculosis, and so unreliable, that in a great majority of instances the only absolutely assured diagnosis is that which is obtained by means of the tuberculin test.

Tuberculosis is a communicable rather than a transmissible disease. In rare instances only is it congenital as when the generative organs are diseased. With the exception named, it cannot reach cattle or other animals in the absence of germ infection communicated from an outside source. There are, however, predisposing causes through which animals become less germ resistant, so to speak, than they would otherwise be. Any influence that lowers the stamina of the animal lowers also its germ-resistant power. Prominent among this class of influences are stables dark, damp, or illventilated, injudicious inbreeding, lack of proper exercise, and poor food.

The germs may reach the animal: (I) Through the medium of the lungs by inhalation; (2) through the stomach and intestines with food and drink; (3) through inoculation, as in contact with broken skin or mucous membrane; and (4) through infection in utero. Infection from the lungs probably never comes as the result of quiet inhalation. Germs may be in the saliva, in nasal discharge, in matter from the bronchial tubes, as when coughing, and in the fæces. When these become dry, they may float in the air with dust and thus reach the lungs. Similarly they may come in contact with the food and through saliva or nasal discharge may get into the water. Especially are they liable to reach calves which take the unsterilized milk of tuberculous cows, either in the form of whole milk or of skim milk. During recent years tuberculosis in swine has greatly increased through feeding to them unsterilized skim milk from creameries. The instances of infection through inoculation when in utero are rare. 
Costly experience has shown that even one tuberculous animal is a menace to all the animals kept in the same stable. How much greater, then, must the hazard be with many diseased animals in the same stable? Within a few months, how many is not certainly known, from the time the germs reach the animal, cattle will respond to the tuberculin test.

Tuberculosis has, it is thought, been more prevalent among dairy cattle than in beef types, owing, first, to the tax which much milk giving puts upon the system, and, second, to the close confinement to which they are subjected in winter. In city dairies it is more prevalent than in farm dairies, owing to the more frequent introduction of cows from outside sources. In the pure breeds of beef cattle it is more common than among grades, owing to the more artificial conditions to which they are subjected. It has been present in greatest degree among the families of pure-breds that have been much inbred, as in certain families of the Shorthorn, Aberdeen-Angus, Jersey, and Guernsey breeds. It decreases as open range conditions of environment are approached, thus showing the closeness of the relation between abundant fresh air, ample exercise and plenty of sunlight and the absence of tuberculosis.

Tuberculin is usually seen in the fluid form. It is a chemical product obtained from the bodies of the bacilli of tuberculosis. It is excreted by the tubercle bacillus during the process of growth. It is germ free, and, therefore, cannot communicate the disease. Careful experiment has shown that tuberculin has no important influence favorable or unfavorable to the health of sound cattle or to the milk flow of healthy cows. Making the test calls for two days. The temperature of the animal or animals is taken the first day at intervals of two to four hours, usually commencing at $8 \mathrm{~A}$. M. and ending at 8 P. M. At 9 P. M. the tuberculin is given by hypodermic injection. Temperatures are taken again 
the second day every two hours, beginning at 6 A. M. The temperatures are taken by inserting a self-registering clinical thermometer into the rectum or the vagina. If the temperature rises more than $2^{\circ}$ above the normal range shown on the first day, the animals may be pronounced tuberculous, and if the rise is $1.5^{\circ}$ to $2^{\circ}$, they should be regarded as suspicious and reserved for further test. In a typical reaction the temperature gradually rises for four hours or more, until it attains a maximum and then it gradually falls.

Although the testing of cattle is, in a sense, a simple work, there are many things about it that the unskilled may fail to notice, hence the importance of having it done only by qualified men. Cattle owners have frequently paid dearly for the mistake of unskilled operators. Tuberculin is now made in a commercial way by certain manufacturing firms from whom it may be obtained directly or through the medium of druggists. The dose of Bureau tuberculin approximately is $1 / 4$ of a dram for each 500 pounds of live weight. The testing should not, except in special cases, be more frequent than once each six months or the system may reach a condition in which it will fail to respond. The tuberculin does not furnish an absolutely infallible test, as when the disease is in the most advanced stages there may be no response, and yet the percentage of such errors is but a fractional part of I per cent.

The losses resulting from tuberculosis in cattle have been very great. There is no means of estimating them correctly, for the reason, among others, that they occur in so many different ways. There is, first, the direct loss from death in herds yet untested and from animals found infected and condemned; second, the less direct loss from ill-doing on the part of many of the afflicted animals; third, the indirect loss in swine which have been affected by tuberculous milk; fourth, the loss from what may be termed deterrent influences to continu- 
ance in the breeding of good stock on the part of many breeders because of the depressing influence of such losses and the extent to which they thwart the laudable ambitions to grow high-class stock. To these it is legitimate to add the cost of protective and remedial measures in fighting the disease. The direct losses by death are enormous in the aggregate, and these losses to the individual and to the state meanwhile have been greatly augmented since legislation has made compulsory, and rightly so, the testing of milk shipped into cities. The less direct loss, but none the less real, through decreased production in afflicted animals during decline is very great. In many instances pure-bred herds and good dairy herds have been so decimated that the breeders and owners have gone out of the business, seeing which others have been deterred from going into it. It has sometimes been said that the cost of protective measures provided by authorized state authorities is greater in the case of tuberculosis than of all other diseases combined, and that the losses incurred from the disease are greater in the aggregate than the losses from all other communicable cattle diseases combined.

The tuberculin test is the only sure means of correctly diagnosing the disease, unless in its more advanced stages. In view of the beneficent character of this discovery it does seem strange that it should have met with so much opposition from the owners of cattle and from some editors who posed as leaders in agricultural thought. Happily, however, this foolish hostility is gradually growing less. Since no treatment for tuberculosis is completely satisfactory, the relative importance of protective measures with a view to prevention is increased.

The protective influences against tuberculosis in cattle include the following: (I) Breeding them on correct lines; (2) managing them according to sane methods; and (3) using the tuberculin test to make 
possible the removal of tuberculous animals when present and to prevent any that are infected from coming into the herd. Injudicious and close confinement are no doubt responsible for the much greater prevalence of tuberculosis among pure-bred herds than among other cattle. Too close breeding must be shunned and also environment that tends to enfeeble. Rugged cattle, of course, have far greater resistant power to germs that produce tuberculosis than cattle that are enfeebled. Every reasonable attention. should be given to sanitation; that is, to furnishing stables dry, well ventilated, and with provision for access to much sunlight. Nor should the animals be closely confined in these even in winter, though something should be sacrificed in milk production from cows, for instance, in order to give them the necessary exercise.

When cattle are tested and found tuberculous, they should be slaughtered under proper inspection when not specially valuable as breeders. This may be conveniently done at the stock yards. When thus slaughtered the carcass may be used in whole or in part as food. Should they be condemned as unfit for such use, in many of the states provision is rightfully made for compensating the owners for a large proportion of the loss. Should the animals be considered too valuable for breeding to justify immediate slaughter, they may be managed after the Bang system.

The Bang system means: (I) The careful separation of the healthy from the unhealthy cattle as indicated by the tuberculin test, to prevent the occurrence of further infection. The aim should be to give them separate stables, yards, drinking places, and pastures. (2) That the calves shall be reared apart from the dams on sterilized milk from the same or on the milk of healthy cows. Sterilized milk is milk heated to a boiling temperature and maintained at the same for five to ten minutes in the case of tuberculous infection to 
destroy the germs. These may not be present in the milk of more than one dam to, say, four or five, but the uncertainty with reference to this should preclude the feeding of all such milk, whole or skimmed, to calves or swine, unless sterilized. (3) That the calves shall be tested under the age of, say, six months, and again about once a year until matured. They must, of course, be kept away from mingling with infected cattle or from the stables occupied by the former in the absence of disinfection. Less than 10 per cent of the animals reared thus will react.

During recent years the system of vaccinating cattle with a vaccine that has been extensively tried in an experimental way is being introduced. It is obtained from tubercle, and is injected into the blood of the jugular vein. The process is much akin to vaccination against smallpox in the human family. Two vaccinations are given, the first usually when the calves are not more than two to three months old, and the second, 90 days later. So successful have the results proved that even now it is believed such vaccination may prove a great aid in freeing infected herds from tuberculosis, notwithstanding that the animals infected and immune inhabit the same quarters.

Regarding the proper course for cattle owners to adopt with reference to tuberculosis, there need be no controversy. Where there are any grounds for suspecting its presence, the herd should be tested and any cattle found diseased at once removed. Within the next I2 months two tests should be made and subsequently one each year until no reactions occur. The stables should be disinfected with a 5 per cent solution of carbolic acid and water, or what is cheaper and equally effective a solution of bichloride of mercury, that is, corrosive sublimate and water, in the proportions of $\mathrm{I}$ and $\mathrm{I}, 000$. This should be done after each test in which any of the animals respond. Under no conditions should outside 
animals be introduced into the herd unless they have first been tested or come from herds guaranteed free from the disease. The wide dissemination of tuberculosis has arisen more from the introduction into herds of tuberculous pure-bred cattle, and especially pure-bred males, than from any other source. If such action were to become general, the owners of pure-bred herds who refuse to test their cattle would have to go out of business and this dread disease would be greatly circumscribed.

Abortion in cows.-In the strict sense abortion means the expulsion of the fetus before it can exist independently of the dam, but more commonly the term is used to indicate the expulsion of the fetus at any time previous to the usual completion of the period of pregnancy. Such expulsion, after the offspring is capable of existence apart from the dam, is more accurately expressed as premature birth. Abortion is of two kinds, viz., sporadic, that is, occurring singly and non-infectious, and infectious. Non-infectious abortion may lead to considerable loss in the aggregate, but should not be serious in any individual herd. On the other hand, in certain areas, infectious abortion has come to be, in a sense, a scourge, especially pure-bred cattle. While abortion may occur at any time, its occurrence is less frequent previous to the third month of conception.

Prominent among the causes of non-contagious abortion are: (I) Mechanical injuries such as may arise from slipping, jamming in doorways, and being hooked by other cattle and kicked by horses; (2) exercise violent or sudden such as the animal is not accustomed to; (3) indigestion in its various forms which usually results from feeding food unsuitable in kind or badly cured; (4) ergotized grasses, smut in fodders, foods that are frozen or so lacking in succulence as to induce constipation; (5) administering strong medicines, especially purgatives; (6) water that is putrid from 
stagnation or that contains sewage; (7) disease acute or chronic in various organs of the body, and especially disease of the womb or the fetus. Inheritance from parents lacking in stamina is frequently a predisposing cause.

Contagious abortion is a germ disease. It is caused by the action of living germs upon the uterus and placental membranes. It is now believed that it is produced by one of several germs, which differ from each other in minor particulars, and these differences may account, in part at least, for different degrees of virulence in the action of the disease. The infection may reach cows through contact of the genital organs with a fence, rubbing post, floor, or litter previously soiled by infected animals. It may also be conveyed to the uterus through service from a male that has previously served an infected cow. It is possible to keep cows in proximity somewhat close without taking the disease, but, in such instances, there must be no individual contact in any way between the herds.

The indications of approaching abortion, whether sporadic or infectious, are frequently meager and not prominently in evidence. During the first months of pregnancy they may entirely escape detection. In advanced pregnancy they are more pronounced, and may include more or less the following symptoms: (I) Dullness and an inclination to remain aloof from the herd; (2) a discharge of mucus from the vagina, which is enlarged; (3) the enlargement of the udder and the presence of milk secretion in cows that are dry; and (4) slight labor pains some hours before the fetus is expelled.

While the losses in the aggregate from noncontagious abortions are heavy, in a great majority of instances they are preventable. Frequent sporadic abortions and poor management frequently go hand in hand, but this may not be true of contagious abortion. It 
occurs in the best managed herds. It usually clings so persistently to a herd and remains for so long a period, generally not fewer than two or three years, that it has come to be a veritable nightmare to breeders where it has become prevalent. It entails loss, first, in the calves that fail to come to birth; second, in the greatly diminished milk flow resulting from the absence of freshening and from the debility that results from abortion, and, third, in the great expense and labor involved in maintaining animals apart and in disinfecting the stables and also the cows. Next to tuberculosis, it would seem correct to say this disease entails the most loss upon those who keep cattle.

The preventive measures that may be adopted to protect cows against non-contagious abortion include the avoidance of the causes given above. In other words, they include intelligent breeding where breeding is practiced and management watchful and intelligent all along the line. Where these measures are followed, there will be few instances of abortion. But these, though helpful, are no certain protection against contagious abortion.

The more important of the protective measures against infectious abortion are the following: (I) When purchasing or breeding animals, seek vigorous development; (2) When purchasing animals, make sure that they come from sound herds. (3) In no instance use a bull unless assured that he has not served infected cows. (4) Use disinfectants where the disease has appeared, promptly, wisely, and perseveringly. The importance of vigor in relation to successful breeding is so constant that the aim should be to maintain vigor as far as possible by careful feeding in the infected herd. It should be possible for owners of cattle to be sufficiently vigilant with reference to the introduction of other cattle into their herds, and also the use of males, as to prevent this disease from getting a foothold. When a cow has aborted, 
she should be isolated at once and cared for by a separate attendant, and not returned to the herd until three days after all discharge has ceased. The fetal membranes, if retained, should be at once removed by hand, and they, along with the fetus and bedding, burned or buried. After scraping the stall and floor, and even the stalls adjoining, they should be disinfected with a 5 per cent solution of carbolic acid. Disinfection so elaborate is sometimes recommended that it would seem almost better to fatten and sell the herd than to carry it out. Animals that have aborted should not be bred again short of two to three months.

Treatment as follows, if timely, may be effective in some instances in preventing abortion of the sporadic type after the labor pains have begun: Give 1 to 2 ounce doses of laudanum according to the size of the cow, repeated, if necessary, in three or four hours; or, what is even better, 2 ounces tincture of opium, 3 ounces fluid extract of Viburium prunifolium and Io ounces syrup, repeated every two hours until the labor pains cease. The after-effects of abortion on cows result in much debility.

Milk fever in cows.-Milk fever affects cows only among domestic animals and usually those whose milking qualities are of a high order. Its attacks are almost entirely restricted to the improved breeds, and especially to cows of the dairy and dual types. It never occurs with young cows at the birth of the first calf and rarely with the same at the second birth. Old cows past the zenith of highest producing power do not have it, and it occurs but rarely in cows thin in flesh. Its attacks are almost entirely confined to cows when giving birth to the third, fourth, fifth, or sixth calf, that is, to cows that have reached maturity and whose powers during this period of greatest vigor are centered on the production of maximum quantities of milk. Moreover, its attacks are usually confined to cows that are great consumers 
and possessed of more than ordinary powers of digestion.

From what has been stated, it will be apparent that one chief predisposing cause of milk fever is a plethoric condition of the system in cows of mature age, and that are great producers of milk. According to Prof. James Law, F.R.C.V.S., the red globules in such cows are sometimes reduced to more than half their usual size, thus attesting to great richness and density of the blood. Some distinguished veterinarians, however, incline to the view that heavy feeding and lack of wear are responsible for many cases of milk fever, without material change in the size of the blood corpuscles. The other predisposing causes include: (I) Easy delivery; (2) high temperatures in stables; (3) a costive condition of the bowels; and (4) lack of exercise. In easy delivery there is but little expenditure of energy and loss of blood. Heat conduces to fever, and fever means lessened secretion. Costiveness leads to retention in the system of certain matters that should pass off in the bowels. Exercise aids in maintaining all the functions of the body in a condition conducive to good health. It is thought that the immediate precipitating cause is the production subsequent to calving of certain poisonous products in the udder, acting on nerve centers, a condition that may follow the distribution into other vessels of the body of the large quantities of blood circulating in the walls of the womb. This condition is intensified by any shock given to the system, as exposure to cold and dampness.

The indications of the disease are, of course, influenced by the degree of the suddenness and intensity of the attack. The disease assumes two forms, known as the congestive or violent and the torpid, with graduations between these. Among the symptoms that indicate the possible approach of the disease are uneasiness accompanied by switching of the tail, a stupid or wild 
condition of the eye, sudden constipation and a checked milk flow. According to Dr. M. H. Reynolds in "Veterinary Studies," if these occur within two days of calving they should be taken as danger signals.

Prominent among the diagnostic symptoms are sudden manifestations of dullness, uneasy movements of the hind limbs and increasing weakness leading to inability to rise. As the disease progresses the cow lies stretched out with the head on the ground or stable floor; the eyes become glazed and the pupils dilated; the fore and hind legs struggle convulsively through unconscious nervous spasm; the insensibility is complete, and death may follow without a struggle. In the torpid type, the symptoms are much akin to those of the other type, but they act more slowly, and, in the absence of recovery, they merge into those of the other type.

The losses from milk fever, especially to those engaged in dairying, have been heavy in the aggregate during recent years, as under what is now called the old treatment a majority of the cases were fatal, and the stricken ones were the choicest animals in the herd, viewed from the dairyman's standpoint. Happily, this costly disease may be almost, if not entirely, prevented by the adoption in time of the measures that conduce to such an end, and the new treatment makes it possible to cure nearly all cases when it is properly administered. Prevention in this, as in all other diseases, is immensely ahead of cure, as it saves much labor and expense without in any way hindering production.

Prominent among preventive measures are: (I) A diet spare, light, laxative, and easily digested for a week, or even longer, before parturition, and for four or five days subsequently. (2) Abundant exercise during the later months of pregnancy. (3) The administration of a mild laxative within two to five days of calving, and a cathartic within I2 hours after calving. (4) Refraining from drawing milk for 12 to 24 hours after calving. Rich 
clover pastures are regarded as especially dangerous. If in no other way, the food may be regulated by feeding it as soiling food. A pasture so sparse that the cow must travel much to get barely sufficient food to satisfy her furnishes an ideal condition for such cows before calving. For the laxative, I quart of linseed oil may be given and for the cathartic 1 to 2 pounds of Epsom salts and 2 to 5 ounces of powdered ginger, according to the size of the cow. Breeders in the island of Jersey claim that delayed milking, as outlined above, has greatly reduced milk fevers.

The remedial measures of former years were laborious and costly and largely ineffective. But these are not to be decried, as practitioners acted in good faith according to their light. The principle which underlies the new treatment is the distention of the udder and the maintenance of such distention for periods long enough to insure recovery by injecting into it some substance that will insure such a result. These, of course, reach the udder through the milk ducts. Various substances have been used, but those which now stand high in favor include atmospheric air filtered and sterilized and well-boiled water, but the weight of the latter is dragging on the udder. The material used is pumped into the udder through tubes inserted in the teats. Treatment should only be given by veterinarians or by those only who are thoroughly acquainted with careful antiseptic methods. Relief usually follows the treatment within a short time of administering it, but some attention to the condition of the bowels may be necessary as recovery progresses.

Actinomycosis, or lumpy jaw, in cattle.-This disease infectious and chronic in its action, is also known by the name of big head, and in Britain it is sometimes called wooden tongue. It is characterized by the development of peculiar enlargements or tumors, chiefly about the head, but it may also affect the internal organs 
of the body. It is caused by the presence and activity of a vegetable organism. This fungous parasite is known as Actinomyces. As it multiplies and spreads, the tumor growths increase. The animals chiefly affected are cattle, sheep, and horses, but it also occurs in the human family. The disease develops slowly. A small swelling appears somewhere, more commonly about the head, sometimes it is under the tongue, but more frequently it is on the lower jaw, though, in some instances, the upper jaw is also affected and likewise the throat.

The disease is not directly communicable from one animal to another. It is now generally believed that it reaches its subject through the medium of the food, but that it cannot be taken into the system in any other way than through inoculation, which, if true, means that the germs can only reach the system through some abrasion, as, for instance, the mucous membrane of the mouth, gullet, or stomach. Avenues of entrance may also be furnished by decayed teeth or when teeth are being shed.

That the organism comes from the food finds countenance in the facts, first, that the presence of a diseased animal before discharge occurs from the tumors is no menace to the health of the other animals of the herd; second, that when animals graze on certain pastures, the disease is of more frequent occurrence than if grazed on other pastures; and, third, in different areas, there would seem to be some relation between the parts of the animal most frequently attacked and the germ-bearing plants that produce the disease. The parasite, it is thought, may live through one stage of its development in the tissues of such fodder plants as barley and rye. This view finds countenance in the quantities of the fungus that have been found between the vegetable fibers of barley which have penetrated the gums of cattle and on the awns of certain grains imbedded in the tongues of cows. 
The indications of the disease when external are apparent in the firm-handling swellings which slowly increase in size until they burst. As intimated, they most frequently occur on the head and throat, but they may occur on different parts of the body. When the swellings are opened, there is usually found in the interior pus containing minute-like grains. These, sometimes visible to the eye, are masses of the inoculating germs. When the tumors burst, a thick, sticky-like pus exudes laden with the germs. They may heal temporarily, but growth continues even in the presence of discharge. The interior of the tumor is somewhat honeycombed, and the same is true of the bone when affected. When the organs affected are internal, the difficulty of diagnosing the disease is greatly increased. It may affect the lungs, mouth, and some other organs.

The losses incurred by the presence of the disease are found in: (I) The lack of thrift resulting when the diseased condition of the teeth hinders mastication; (2) the cost of treatment for the disease during the tedious process of recovery; and (3) the depreciation in the price obtained for the diseased animal when marketable. The animals affected may thrive as long as mastication is not hindered. The long period usually covered by treatment would seem to make early disposal of the animals commendable without treatment, unless they are of more than ordinary value. Cattle dealers will not pay as much for animals with lumpy jaw and usually they are chary about buying them at all. When the disease is local, the carcass may still be good for food save where the disease is seated, but such animals should be killed under inspection, as there are instances in which the carcasses are condemned as unfit for human food.

Until the life history of the ray fungus, as the parasite is sometimes called, is known, preventive measures will be less complete than they would otherwise be. 
All authorities are agreed, however, that as a measure of safety, affected animals should be separated from the others. The discharge from tumors being laden with disease germs are liable to get into the food in the mangers or on the pastures. Certain pastures inundated seem favorable to the spread of the disease.

Treatment for lumpy jaw may be given as surgical, by the use of some caustic or by means of medicines administered. When not adherent to the bone, the tumors may be removed with a knife and the parts treated as an ordinary wound. But this should only be done by a trained veterinarian, because of the complicated nature of the structures involved. The tumors may sometimes be removed by the deeply caustic action of powdered arsenic introduced into the same, but the time called for is six to ten weeks. Iodide of potash given as a drench has been highly effective in working a cure before the disease has invaded the bony structure. It is given as a drench, or in the water drunk in about I/: dram doses daily, until the animal partially gets off feed, and discharges freely from the eyes and nose. The treatment should then be discontinued for three or four days, and during the period there should be given as a drench I pound of Epsom salts for each I, Ooo pounds of live weight. Similar treatment may again be given for six to ten days, followed by a similar cathartic. After the tumor has been reduced to about one-third of the original size, no further treatment should be given. The time covered by treatment is from four to seven weeks. Should this treatment be given to cows in milk, the secretion of the same will be greatly reduced or will cease altogether, and the milk given will be unfit for use.

Anthrax in cattle.-Anthrax, sometimes known as charbon, is one of the most malignant diseases that occur among domestic animals, and also one of the oldest. It affects cattle, sheep, swine, goats, horses, mules, and some of the smaller animals, both domesticated and wild. 
It occurs most frequently with cattle and sheep. It may also occur in the human family. It is caused by a microscopic organism known as the anthrax bacillus, which is a minute rod-shaped germ that may be found in the blood and tissues of affected animals. These germs are susceptible of rapid and endless multiplication. Death follows as a result of the extent to which they introduce poisonous substances into the system. In the spore stage the germs live outside of the body and may retain their virulent properties for years in the dried form, and their power to resist heat is such that water must boil in order to destroy them. On the other hand, outbreaks may occur in the cold weather of winter.

Anthrax germs may be conveyed in many ways, as (I) through imported hides, hair, and wool; (2) through fertilizing materials made from animals infected by the disease; (3) by running water coming from tanneries or areas previously infected; (4) by the bite and feet of insects that have come in touch with the virus; (5) by the feet of dogs and birds that have been feeding on the carrion; and (6) through food materials from infected lands. It sometimes reaches the human family through the handling of materials, as wool from animals that have been affected with the disease. Certain conditions, as heat and moisture, favor the spread of the disease, and this is also influenced by soil conditions. The disease thrives best in moist areas, in mild and warm climates, and in black humus and peaty soils.

Anthrax may reach its victims, first, through respiration; second, through the skin; and, third, through the digestive tract. By the first of these methods, the disease reaches chiefly the individuals of the human family, as those engaged in sorting infected wool; by the second, it more frequently reaches the less thickskinned animals, as the horse and the mule, the virus being carried to a considerable extent by insects; by the third, it usually reaches cattle in their food and drink, 
but may reach them also by the other methods. It may come through fodders green or dried grown on sporeinfected land, or through the water drunk. It may occur sporadically, attacking but one or a limited number of animals, or it may be epizootic, attacking simultaneously a large number.

The indications of anthrax in cattle only will be considered. They vary considerably, but usually they include the following: ( I) Sudden attack, accompanied by great depression, prostration, and stupor; (2) temperature running as high frequently as 106 to 107 ; (3) hurried respiration and irregular and violent beating of the heart; and (4) the turning bluish red of the visible mucous membrane. In some instances swellings appear in various parts of the body, but these are frequently absent. Death follows within one or two days and may occur within a few hours. The presence of germs in the blood taken from some external organ, as the ear, and examined microscopically furnish evidence as to the nature of the disease when the germs are present. The danger of infection comes from being in close touch with the disease, and should not be lost sight of.

The losses from anthrax, especially when epizootic, are very great, owing to the great mortality which characterizes it. The long period during which the germs may lurk in an infected district are a vexatious menace to stock growing in the vicinity. The disease exists in all the continents. In the United States it has not visited large areas in the northern half of the Union, but, unfortunately, it is gradually spreading. In the lower Mississippi basin and in some of the Gulf states, it prevails to a serious extent.

Remedial measures are of so little avail that it is scarcely worth while to consider them. But protective measures by way of prevention are all-important. These include: (I) The safe and deep burial, or what is better, the burning of the carcasses of the dead animals; 
(2) the thorough disinfection of all the stables and surroundings; (3) the draining of swampy lands and stagllant pools that have been infected; (4) the breaking up and cropping of pastures for one or more seasons in succession when infection has occurred; and (5) vaccination by the Pasteur method. Animals should not be buried near streams. Disinfection of stables may be accomplished by using a solution of chloride of lime and water in the proportion of 3 ounces of the chloride to each 2 quarts of water, and by strewing abundantly ordinary slaked lime on infected soil. Draining to prevent inundation of pastures is frequently not practicable. While the pastures are under crop, the cattle may be maintained in summer on soiling food. The vaccine now on the market is usually given twice with an interval of I2 days between. As it may be the means under some conditions of spreading the disease, it should only be given by trained veterinarians and in already infected centers.

Blackleg in cattle.-This disease is more commonly known by the name blackleg, but it is also called black quarter, quarter ill, and symptomatic anthrax. Formerly it was regarded as identical with anthrax, but it is now certain that the two diseases have no relation, notwithstanding the resemblance in some of the symptoms. It is a malignant infectious disease, peculiar to cattle, sheep, and goats. Other domestic animals, and also the human family, are not subject to its attacks. It is caused by a germ (Bacillus chauvaci), which, in some minor respects, resembles the rodlike bacillus in anthrax, and, like the latter, it has the power of forming a spore within itself. The spores, under favorable conditions, may remain virulent for years. This may account for its occurrence occasionally in stables.

Blackleg usually affects young cattle such as are beyond the age of six months and under the age of two years. In some instances the disease occurs in cattle 
in the two-year form and even older. It seldom attacks calves under six months. Cattle that are fleshy and fat fall an easier prey to it than those that are lean. In some countries it would appear to be most virulent in low-lying lands, but that is not true of it in the United States, where soil conditions do not seem to affect it, nor does it seem to be influenced by altitude.

Although the germ may reach cattle through the medium of food or drink, it is now thought that cattle contract the disease by inoculation, either through the skin or mucous membranes, more commonly the former. Punctures of the skin may be caused by such mediun:s as the barbs of wire fences, thorns and the spines on certain plants. Where the germs are numerous, many animals are liable to be infected.

The indications of blackleg are general, or constitutional, and local, and, in nearly all instances, the local symptoms may not be apparent. Prominent among the general symptoms are dullness and great debility, accompanied by a highly fevered condition. The temperature may rise to $107^{\circ} \mathrm{F}$. The local symptoms are manifested in swellings or tumors under the skin, which appear within a few hours of the general symptoms. The stricken animal is usually found lying apart by itself. When roused, it manifests stiffness or lameness in one limb, and sometimes in one side of the body. More commonly the tumors referred to will be found on the hind or forequarter, but they may occur on other parts of the body, as the neck, breast, or flanks. They never occur below the knee or hock. When the hand is pressed over the tumor, a peculiar crackling sound is heard, which is caused by the presence of gas in the same. This fact may serve to distinguish the disease from anthrax, but not always from œdema. The latter, however, usually follows abrasions and wounds of some magnitude. In from one to three days, the animals die, 
with rare exceptions. Death is preceded by convulsions in some instances.

The losses from blackleg have been very serious during recent years. It occurs in all parts of the United States, but it is most prevalent in the western and southwestern states. It gives trouble in many of the provinces of Canada and is found in nearly all countries of Europe. It also occurs in some countries of Africa and South America and on the continent of Australia.

Treatment for the disease is almost fruitless. Not so, however, are preventive measures. Of these vaccination is by far the most far-reaching and effective. A skilled veterinarian should usually be employed in administering the vaccine. The other preventive measures are very similar to those recommended for anthrax. (See page 438.) It is specially important that the carcasses shall be buried or burned and that the contaminated premises shall be disinfected.

Several reliable vaccines are now on the market, and the Federal Bureau of Industry has also distributed a very large amount of vaccine made by the department. Vaccination for blackleg means injecting into the system by means of a hypodermic syringe a minute amount of artificially weakened blackleg virus. Some vaccines call for two inoculations with an interval of ten days between them, and some for only one. The former are the safer. The immunity conferred may last for I8 months, but those vaccinated under six months should be again vaccinated before the next occurrence of what may be termed the vaccine season. With hearty co-operation on the part of cattle owners, vaccination should make it possible to stamp out this disease.

Hemorrhagic Septicemia in cattle.-This infectious and malignant disease is one of the most perplexing that veterinarians have been called upon to combat. It is perplexing, first, because of the several forms which it assumes: second. because it appears suddenly and under 
all conditions; third, because there is practically no information up to the present in regard to the method of infection or spread; fourth, because it is increasing in the United States and is very frequently fatal; fifth, because no method has yet been discovered that will protect from it or lessen its virulence; and, sixth, because it sometimes disappears as quickly as it came. The extent to which it is now being studied by the most skilled among veterinarians will doubtless soon throw much light upon what is now so little understood.

The specific cause is apparently a germ (Bacillus bovisepticus), which, it is thought, belongs to the same group of baccilli as those which produce swine plague and chicken cholera. In the various forms of the disease, there is more or less of a resemblance to anthrax, blackleg, and cerebro-spinal meningitis, but competent veterinarians can correctly diagnose the disease by the difference which characterizes the symptoms. But the differences manifest in post-mortem examinations are much more pronounced. It is supposed that the germs reach the animal through inoculation by means of abrasions in the skin, by injury to the mucous membranes from such naterials as coarse fodders or through the membranes of the respiratory organs. It seems to occur most frequently in swampy areas and in pastures subject to overflow, and also in cornstalk fields. It is said to occur more frequently in the spring when subterranean waters by accumulation are forced to the surface and bring with them harm-laden bacteria. Other authorities believe that conditions of climate and season have nothing to do with the prevalence, virulence, or disappearance of the clisease.

Three forms of the disease have been recognized, based upon the distribution of the lesions, that is, the morbid changes in the structure or functions of the organs or tissues. These are the superficial or cutaneous, the pectoral or thoracic, and the intestinal. Among: 
the indications of the first are swelling of the tongue, throat, or dewlap, salivation and blood-stained discharge from the nostrils, and of the second, a frequent suffocating cough and oppressed breathing. The intestinal form is a usual accompaniment of the other two. Among the symptoms are dullness, cold extremities, a staggering gait, and sudden cessation of the milk flow. These are followed by diarrhoea, contractions of the muscles of the neck and face, and champing of the jaws. Extreme nervousness resembling insanity is very common. Still later come increasing wildness of the eye, intense restlessness and death. Death may result in a few hours, usually it occurs in two or three days, but may, in some few cases, be deferred for several days.

Hemorrhagic septicemia may be distinguished from blackleg as follows: (I) Blackleg commonly affects young animals, whereas hemorrhagic septicemia attacks those of all ages. (2) The swellings in blackleg are almost invariably present, and when pressed emit a crackling sound, whereas in hemorrhagic septicemia they are usually absent, and when present are not located only on the leg above the knee or hock, as is usually the case in blackleg. (3) Blood taken from a blackleg tumor some hours after death is dark, frothy, and has a disagreeable odor, whereas even from swellings which may occur in hemorrhagic septicemia it is nearly normal.

The losses from hemorrhagic septicemia have been very considerable during recent years. It has visited several states and some of the outbreaks have occasioned much loss. Among the states visited are Minnesota, Wisconsin, South Dakota, New York, Pennsylvania, Tennessee, and Texas.

At the present time treatment would seem to be of no avail, whatever the future may reveal. The sanitary precautions include separating the affected and nonaffected animals as often as the disease may appear, burying or burning all dead carcasses, and disinfecting 


\section{THE MANAGEMENT AND FEEDING OF CATTLE}

the premises occupied by diseased animals as in the case of anthrax. (See page 438.) Whenever serious symptoms appear, the aid of a skilled veterinarian should be sought with much promptness, that no mistake may be made in the diagnosis of the disease.

Cornstalk disease in cattle.-This very fatal disease is so named because it occurs in herds that are being grazed on the dry stalks of corn yet standing in the fields from which the ears have been removed. It is most prevalent in years when there has been a heavy growth of cornstalks. It may occur any time after the stalks have become thoroughly dry and so late at least as midwinter. The disease is more likely to occur in cattle that are turned into an ungrazed field when hungry, when first turned into the same or when changed from a field well grazed to one not yet grazed. Cattle one and two years old fall an easier prey to it than those that are older, but its attacks are by no means confined to cattle that are so young. The disease may occur under a wide variety of conditions, but is most in evidence when the pastures are dry and succulent food to supplement the ration is not furnished. It has also been said that outbreaks are more frequent just after cold storms, accompanied by rain and sleet, and it prevails to a greater extent among cattle that are allowed to graze on the stalks in the day than among those that remain in the pasture.

The cause of this mysterious disease is yet hidden. It is now certain that it is not caused by corn smut as was supposed at one time. Nor does it come from the eating of cornstalks affected with a bacterial disease, as was at one time claimed. The real cause, as intimated, is not known certainly. The following theories find more or less support among those who have studied the questions: (I) That the cause is some poisonous principle in the cornstalks not definitely known; (2) that it is the result of impaction of the dry and not easily 
digestible fodder in the omasum, that is, the manifolds of the stomach; (3) that it is in some way related to hemorrhagic septicemia. There is much about it that is perplexing, as in one field a severe outbreak will occur, whereas in a field adjoining where cattle are grazed under apparently the same condition, no harm follows. The perplexity is increased by the fact that other ailments sometimes affect cattle that are being grazed in cornstalk fields that are confused with cornstalk disease.

The following are prominent among the symptoms of cornstalk disease: (I) The affected animal, when attacked, remains isolated, assumes a peculiarly humped position, is disinclined to move and when forced to do so walks with an unsteady gait. (2) There is a wild expression of the eye, a peculiar switching of the tail, and frequent striking of the feet at the underline as though in pain. (3) Then follows indication of delirium accompanied by bellowing and moaning, in some instances, the result, probably, of suffering, and these indications are frequently taken for indications of rabies. Death usually follows within 24 hours after the appearance of the first symptoms. The disease is probably not contagious. Many cases may occur in close succession simply because the cattle have been subjected to the same conditions.

The losses from this disease in the corn-belt states are serious, but more so some seasons than others. They do not occur when the stalks have been harvested at the proper season and are fed from the bundle. Notwithstanding the extent of the losses, it is frequently contended that it is better to endure it than to lose the food in the stalks by leaving them ungrazed.

Treatment has proved of so little avail that meanwhile it need not be considered as applicable to this disease. Happily, however, preventive measures are easily within reach. When the disease appears its further progress may be at once checked by removing the 
cattle from the stalk fields. This disease will entirely disappear when the time comes, as it will come, that cornstalks will no longer be thus grazed. They will be harvested and fed either in the form of silage or as dry fodder. When grazed in the field, much of the food value is lost, a loss which this country cannot afford to allow to continue indefinitely, however justifiable the grazing of the stalks may have been in the past.

Meanwhile something can be done to lessen the hazard from such grazing. Among the measures that have been found of more or less benefit are the following: (I) Feed corn fodder for a week or longer before turning into a stalk field to avoid sudden change in the diet. (2) Feed them and water them well before turning them in to graze, and then leave them there or accustom them gradually to the food by grazing them on the stalks, say, half an hour the first day and increasing the time from day to day. (3) Give them access to succulent or laxative food while thus being grazed, as alfalfa, millet, or ensilage, and encourage them to take salt that they may drink freely.

Removing the afterbirth from cows.-The cow among the domestic animals of the farm is the only one which does not expel the afterbirth or placenta with the progeny when it is born. This is owing in part to the firmness of the attachment of the fetal membranes to the walls of the womb. The retention should not continue longer than the third day, or results more or less harmful may follow.

Among the causes of retained afterbirth are the following: (I) Debility in the animal preceding and accompanying parturition; (2) premature birth, in which instances preparation has not been made by fatty degeneration for the severance of the attachments; (3) musty, moldy, smutty, or ergoted fodders fed to the extent of producing abortion; (4) the too rapid closing of the neck of the womb after calving, which may result 
from drinking cold water or eating frosted roots. The first of these causes is the most common of those assigned. While such debility arises from various causes, more frequently it is the outcome of innutritious feeding, injured by the weather or insufficient in quantity. In such instances the immediate cause of retention is the imperfect power of contraction in the womb resulting from the enfeebled condition of the animal.

The indications of retained afterbirth are ustually apparent. More commonly the membranes hang from the vulva and decompose gradually. The odor resulting is very offensive. When retained within the womb through early closure of the neck of the same, or after the protruding parts have fallen away, it decomposes slowly and is discharged from time to time as a yellow or reddish fluid. The discharge is most in evidence when the cow is lying down or when she endeavors to pass urine. The parts about the tail and vulva are soiled by the fluid, which has a most offensive odor.

The results from such retention of the afterbirth are harmful to the health of the cow. The matters thus retained in the womb cause less or more inflammation to its lining membrane, and the products of putrefaction are to some extent absorbed into the blood. The general health of the cow is thus affected. She loses flesh and appears unthrifty and the milk flow is materially lessened.

From what has been said as to the causes which lead to retention of the afterbirth it will be apparent that, in many instances, it may be prevented. Whatever tends to keep the cow in a good condition will also tend to prevent the retention of the placenta. The instances in which it results from abortion may not be preventable, but when it is the outcome of improper food, prevention is certainly in the hands of the owner.

The treatment is mechanical and medicinal. In some instances attaching a weight of $I$ to 2 pounds to 
the hanging portion will result in pulling the membranes from their attachments. In others the placenta is removed by the hand skilled in such work. The right hand and arm of the operator, after being smeared with carbolized oil, lard, or vaseline, is pushed into the uterus and the attachments to the walls of the same are worked loose with the fingers.

Treatment may, in rare instances, prove effective when administered by a competent veterinarian, but more commonly mechanical removal is the more sure method. However, the giving of hot drinks and the judicious feeding of warm and light bran mashes are always helpful. The administration also of any tonic that will aid in building up the system will undoubtedly prove in some degree helpful when the system is debilitated. This is one of the instances in which an approved condimental food may sometimes be fed with advantage.

Eversion of the womb in cows.-This disease, commonly called casting the withers, is most frequently seen in cows. It occurs after calving, and more especially when irritation of the parts is present and the labor of parturition has been severe. The immediate cause is the straining which is continued after the calf is born.

The indications of such expulsion are, of course, apparent to the eye, but the expelled womb may not, in all instances, be distinguished from the protruding vagina or blackler by those who have not heretofore witnessed such expulsion. It may readily be so distinguished by the mushroom-like bodies called cotyledons which cover its whole surface. Each of these is 2 to 3 inches in diameter. The eversion may be partial or complete. When complete, it hangs, an undivided body, from the vulva and extends well down toward the hocks. When the protrusion first occurs, the general health of the cow may not be impaired, but if not rem 
turned with reasonable promptness, it becomes inflamed and gorged with blood, accompanied by continuous increase to a very great size.

The losses occasioned by eversion of the womb are not of great frequency, and yet, in the aggregate, they amount to a considerable sum. One of the most vexatious features of such cases is the disagreeable labor of treating them and the expense incurred in the treatment, also the liability to occur again.

Threatened eversion of the womb may sometimes be prevented. When there is a tendency toward eversion, there is likely to be a protrusion of the vagina as the time of parturition draws near. This will be more or less apparent when the cow is lying down. In such instances the rear of the stall should be elevated not less than 5 or 6 inches by the aid of litter coarse but dry, or of litter overlying dry earth.

In ordinary cases a skilled herdsman can usually return the expelled uterus to its proper place, but, in instances not a few, complications arise which make it necessary to secure the aid of a veterinary practitioner. When the eversion is but partial, and the cow standing, it may be put in place again as follows: The operator makes bare his arm to the shoulder, places his closed fist against the center of the mass and pushes it back through the vagina. The left hand is used at the same time in returning the surrounding parts. While this is being done, an attendant should pinch the back of the cow to prevent straining.

When eversion is complete and the parts still retain their natural bulk, the method followed is the same after preparation has been made for the return of the parts. Such preparation usually includes the following: Two attendants lift the expelled womb by the aid of a sheet to the level of the back. It is then sponged clean with cold water, the cold aiding in reducing the bulk. It may also with benefit be further sponged with 
a weak solution of carbolic acid, using two teaspoonfuls to a quart of water. When the eversion has continued until the cow persists in lying down, the difficulty of treatment is greatly increased. Only a veterinary surgeon should undertake the work of amputation, which is often fatal.

In some instances the uterus is kept in place when returned by keeping the rear part of the stall elevated as described above. In other instances four or five stitches are inserted through the lips of the vulva. The method that seems to be most in favor is that which holds it in place by means of a rope truss, which covers the vagina and is held in position by attached cords or ropes that are fastened to a surcingle, which passes around the body behind the shoulder. When the straining ceases, the truss may be removed. Ounce doses of laudanum may be given every two or three hours, if necessary, to lessen the straining.

Cows which have once everted the womb are very prone to do so again. When, therefore, their value is not superior, the wisdom of disposing of them for meat in due time should be considered.

Hoven, or bloat, in cattle.-Hoven, or bloat, is the distention of the stomach or paunch resulting from an abnormal accumulation of gas. In all instances, except when it results from choking, it is the outcome of disturbed digestion. It is more commonly caused by a sudden change from dry food to succulent pasture. While it may be produced by various kinds of pasture, it is more commonly the outcome of grazing cattle on succulent clover, alfalfa, or rape. It may result from the consumption of considerable quantities of succulent food when frozen, as field roots or pumpkins. In less severe forms it is produced by indigestion that may result from various other causes, as, for instance, simple impaction, or it may be produced by choking. 
When bloating results from grazing on succulent clover, alfalfa, or rape, it is usually swift in its action, so much so that unless relief is prompt the animals affected will die within a very short period. The hazard is greater when the pastures are wet from dew or rain, and, of course, it increases with the hungry condition of the animals. An accompanying condition of sudden bloating in such instances is the partial paralysis of the involuntary fibers of the stomach, which, in turn, is caused by the heavy mass of green food eaten more quickly than the stomach can care for it. With the arresting of the digestive processes, fermentation becomes excessive. Death may result from suffocation with poisoning by carbolic dioxide gas or from rupture of the stomach or diaphragm.

The indications of bloat include the following: (I) The animal stands apart in a humped attitude, and the breathing is labored. (2) There is extreme distention of the stomach in severe cases, particularly on the left side, which bulges both outward and upward. (3) In such instances the animal grunts or moans and may stagger and fall and die in convulsions. The minor indications sometimes include a dripping of saliva from the mouth, protruding of the rectum, and stepping about as when colic is present.

The injury from bloat results, first, from loss when the animal dies, and, second, from the check given to increase when it recovers in severe cases, and, until it is removed, in cases that are chronic so to speak. So great is the hazard from bloat that there should be much hesitancy about grazing high-priced animals upon the pastures that are most liable to produce it. Even when the animals have become accustomed to the grazing, there may be occasional losses, and when these are not looked for. The carcasses of animals that die from bloat, if bled within a short time, are good for food, 
although prejudice to using such food will, no doubt, militate against its being so used.

Measures to prevent bloat are of more value than romedial measures, notwithstanding the service which these can render. The former include the following: (I) Feed cattle liberally on such fodder dry as they relish before turning them in to graze on pastures that are much liable to produce bloat, and use increased caution when the pastures are wet. (2) Do not graze them longer at first than 20 minutes, and increase the time of grazing daily for, say, a week, after which it should usually be safe to give them uninterrupted access to the grazing. (3) Give them free access all the time to such cured hay as they relish or to pastures with dry grass in them along with the green. At such times they will eat considerable quantities of dry food as they seem to crave it.

In severe cases remedial measures cannot be too promptly given. Relief is given at first by tapping the paunch to allow the gas to escape. This is best done by the aid of a trocar and cannula, the former for tapping the paunch and the latter for allowing the gas to escape after it has been inserted in the opening. Frequently a small opening is first made through the skin with a knife over the most prominent part of the swelling, which will be about half-way between the hook point and the last rib. In this opening the trocar and cannula are inserted at the same time and with a downward and more or less forward pointing are thrust into the paunch. The trocar only is withdrawn, leaving the cannula to give vent to the gas. The trocar may be further used, if necessary, to push down the contents of the stomach that may have come into the cannula. Cattlemen should have these implements on hand, as there is usually not time to secure the services of a veterinarian except where after-complications arise. They can be secured through any druggist. In their 
absence a knife may be used to tap the paunch, and a goose quill or other tube, as a small dipper handle, inserted in place of a cannula, but such insertion must be speedily made, as the wall of the stomach may quickly fall away from the incision in the skin. In many instances further treatment may not be necessary. In other instances medicinal treatment, including drenching, will be advantageous.

In mild cases relief may sometimes be obtained by placing a large wooden bit or tarred rope in the mouth, held firmly in place by tying behind the horns. A small handful of salt thrown well back into the mouth will cause the animal to work the tongue, which aids in the escape of gas by regurgitation, that is, belching it up. Medical treatment may include: ( I ) Four tablespoonfuls of common baking soda given as a drench; (2) aromatic spirits of ammonia given in ounce doses. Both may be profitably accompanied by enemas, that is, injections of warm, soapy water. While gentle exercise is good in mild cases, in severe cases it may be highly dangerous.

Scour in calves.-Scour in calves, which means more or less purging, is so much a matter of degree that it is not easy to define the different kinds thereof or to classify them on a basis that is technical and at the same time strictly accurate. It would seem correct to say, however, that the terms indigestion diarrhœa, and white scour will cover with approximate correctness the different kinds of scour. The acuteness of the symptoms, though more or less similar in many respects, increases with the varied forms of the disease given above. Scour arising from indigestion is not contagious, and that form known as diarrhœa is not essentially contagious, but may become so in a marked degree. Th? form technically known as white scour is exceedingly and persistently contagious, since it has been found dif- 
ficult to destroy the infecting germs in a stable, even by the use of disinfectants.

Among the causes that give rise to indigestion are: (I) Overloading the stomach of calves while yet quite young through excess in the richness of the milk or excess in quantity as the result of irregular sucking; (2) giving hand-fed calves improper food, as skim milk, cold, acid, fed from unclean buckets and at irregular intervals; (3) undue exposure to cold and dampness.

Prominent among the causes that give rise to scour technically known as diarrhœa are: (I) The causes that induce scour from indigestion, as given above, which may lead to the more severe form known as diarrhœa; (2) anything that tends to lower the vitality of the calf, as, for instance, the inheritance from parents too closely bred or too artificially maintained; (3) milk from cows fed improper food, as when tainted with molds or even excessively rich; (4) crowded, filthy, ill-ventilated and bad-smelling stables and the absence of sufficient exercise. In addition to these is the contagious character which the disease assumes when present in a prolonged and aggravated form.

The exceedingly fatal disease known as white scour comes from a germ that enters the system of the calf, usually, if not in all instances, through the navel before it has healed. When once it appears in a building, it attacks nearly every calf born there while the germs remain in the same, and they have been known to lurk in the same stable for years in spite of attempts to destroy them through the use of disinfectants. But this does not mean that they cannot be thus destroyea. The bacillus which produces it has the same general characteristics as those which produce hemorrhagic septicemia, and it is thought that the same infective germ produces one type of abortion.

Prominent among the indications of scour from simple incligestion are: (i) The faeces become gradually 
softer and lighter until they assume a cream color and a consistency but little thicker than milk, and the odor therefrom is offensive; (2) colicky pains may occur and frequently there are indications of suffering from the passing of the fæces; (3) the calf, depressed in appearance, frequently stands with the back arched and underline contracted.

The indications of scour in diarrhœa include: Soft ejections at first mixed with mucus; the fæces at first yellow, assume a grayish yellow or dirty white color and increase continually in frequency and they are accompanied by an increasingly repellent odor. (2) Emaciation quickly follows, the hair stands erect and the strength vanishes as shown in the staggering gait. (3) Eventually the anus and rectum become inflamed and may become ulcerated, fever increases, accompanicd by a rapid pulse, and the fæces become more watery and may be mixed with blood.

Chief among the indications of white scour are the following: (I) Its quick occurrence, which may be soon after birth, and generally appears within the first or second day of the life of the animal. (2) The afflicted animal shows great dullness, weakness, and prostration, sunken eyes and short and hurried breathing. (3) The discharges are profuse, yellowish white, and most offensive. (4) The calf lies stretclied and unconscious of what may be transpiring around it. As a rule, death occurs within 24 to 36 hours of the attack.

In all instances scour retards development. When chronic, it usually lessens the degree of possible subsequent development. In the contagious form, it is usually so fatal as to become a menace to successful breeding in the herd, it may be for successive years. This is even more realized when it attacks newly born calves in the form of infectious white scours. The loss of calves from scours is enormous in the aggregate and increasingly so with the introduction of pure blood and the changed 
environment which frequently accompanies such introduction.

For all forms of scour preventive measures are allimportant. The form of scour that accompanies simple indigestion is not likely to occur if the causes which produce it as given above are not present. The following preventive measures, therefore, are important: (I) Suckling or feeding the calves with sufficient frequency, especially when they are young, to prevent overloading the stomach; (2) furnishing milk of whatever kind fed in good condition at a proper temperature and in clean vessels; (3) giving quarters bright, sunny, well ventilated, and comfortable.

The preventive measures for the more severe form of diarrhœa include those given above. To these may be added: ( I ) The adoption of the system of breeding and management that will be conducive to good health in the animals retained for breeding, and (2) feeding foods not too rich, too excessive in quantity, and not tainted with molds or decay. Should the disease be of the infectious form, it is then of the utmost importance to keep the calves away from proximity to all calving cows and their discharges and to institute promptly all reasonable methods of sanitation. In addition to removing litter and manure, the floors and walls of the stables should be disinfected by applying to them libererally chloride of lime 4 ounces to I gallon of water. It is imperative, also, that the well calves shall be kept in quarters not in proximity to any that have been infected. Every care should be exercised when purchasing a pregnant cow or a young calf to make sure that they come from uninfected herds.

For contagious white scours there is practically no remedy, hence any effective remedial measures that may be adopted are greatly important. Where the disease is present, the following management in outline will usually save the calves: Remove the pregnant cow from the 
herd to uninfected quarters several days before calving and for a few days subsequently thereto. The bedding should be abundant, dry, and clean, and sprinkled with a solution of carbolic acid. When calving, the posterior parts of the cow should be well sponged with a solutior: of carbolic acid, say, I ounce to the quart. The calf should come into life on carbolized bedding. As soon as it is born, the navel string should be cut and tied with a cord soaked in a strong solution of carbolic acid. The adherent cord and adjacent skin should be washed with a solution of iodine and iodide of potassium $\mathrm{T} / 2 \mathrm{dram}$ each and I quart of water. When dry, it should be covered with a coating of tar. One week of isolation after the birth of the calf will be sufficient. Different attendants should care for calves that are well and any that may be sick.

What has been said about the non-efficacy of treatment for calves attacked with white scour will also measurably apply to the contagious form of diarrhcea. But for all other forms of scour, treatment may be highly efficacious and may include the following: (I) Immediately reduce the milk supply from one-half to two-thirds or even more proportionate to the severity of the attack. (2) Remove the irritant matter from the stomach and bowels which may have been the inmediate cause of the trouble by giving $I$ to 2 ounces of castor oil according to the size and age of the calf. (3) Feed the milk frequently and in small quantities and diluted with onethird lime water. The lime water is made by water on fresh lime in sufficient quantity so that when the lime has slaked and settled, the water may be poured off for use. Two raw eggs or a cup of strong coffee have been found helpfitl in checking the diarrhoa. In treating the infectious form of diarrhoea, trained skill is a necessity, and this will probably be found true of any acute form of the disease, though not infections. The disinfection of the stables and their surroundings should be most per- 


\section{INDEX}

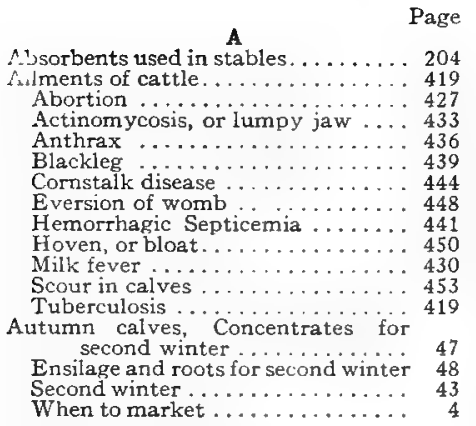

\section{B}

Baby beef ..................

Adaptation in breeds for ........

Age at which to sell ..........

Amount of concentrates for

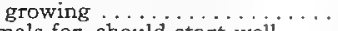

Animals for, should start well ....

Concentrates for growing . . . . . .

Fodders for growing ...........

Rapid gains wanted when growing.

Reared on dams or hand fed ......

Relative profit in growing .......

Succulence for erowing .....

Value of high finish in ......... 88

Barn and stable built by author, 357-362

Beet pulp for finishing cattle ...... 148

Beet tops for cattle ............ 231

Blanketing show cattle .......... 338

Bulls, Exercise for ................ 118

Exercise for young . . . . . . . . . . 112

Feeding and care of .......... 104

Food and care of during milk period ....................... 107

Food for mature ............... 114

Food for, subsequent to weaning . . 109

Management of mature .......... 116

Management of, subsequent to weaning ............. 111

Past meridian of vigot .......... 122

Prejudice against mature ........ 126

Purchase and disposal of ........ 125

Rearing beef by hand .......... 109

Rearing beef on dam ............ 108

Restoring lost power . . . . . . . . . 124

Ringing . . . . . . . . . . . . 114

Service required of ........... 120

Standard ration for ............ 115

Three types of ............... 104

Training to lead ............... 113
Bulls-Continued Page

Trimming feet of . . . . . . . 119

Vicious ................. 123

$\mathrm{C}$

Calves, Amount of milk for . . . . . . . 24

Autumn, second winter......... 43

Benefits from confinement for .... 13

Breeding of the dairy type of .... 11

Breeding of the dual type of ..... 10

Economy of rearing by hand ..... 5

Economy of rearing on dams ..... 5

Ensilage for ............. 24

Excessive fatness in ........ 9

Feeding in stanchions ........ 40

Feeding oats ............. 23

Feeding on arable farms ........ 8

Field roots for .............. 24

Fodders fed to, at different ages .. 310

Fodders for ................. 23

Grazing for . . . . . . . . . . 36

Growing for veal ............. 34

Learning to take meal ........ 28

May not always come in autumn .. 4

Miscellaneous considerations in rearing ............. 38

Modifying methods of rearing .... 9

Nurse cows for show .......... 308

Profit greater from handfed ..... 6

Reared on skim milk ........... 16

Reared on whey .............. 25

Reared without milk ......... 27

Sanitary conditions for ........ . . 41

Skim milk for ........... . . 25

Soiling for .............. 37

Spring, second winter ....... . . 49

Standard meal ration fur . . . . . . 21

Starting in life . ............ 16

When born for exhibiting ....... 306

When should come ........... . 1

Cars for shipping cattle ........ 295

Castration, Age for . . ... ..... 396

Benefits from ........... 395

Facts regarding $\ldots \ldots \ldots . . . .394$

Methods of ................. . . 398

Of show cattle .................... 331

When advisable . . . . . . . . 397

Cattle, Age to purchase for finishing 130

Amount of concentrates for feeding 142

Avoid short grazing periods of frnishing

Care while in transit ......... 296

Carrying through winter ........ 222

Cars for shipping ............ 295

Character of food for, in winter ... 226

Cheap rations for, being wintered . 229

Choice of markets for.......... 272

Coming modifications in fattening. 162

Condiments for being fattencd .. 161 
Cattle-Continued

Conditions for wintering cheaply . . 222

Daily increase while fattening .... 158

Dairy not well adapted to fattening 132

Dehorning, spaying, castrating ... 380

Disposal of, at stockyards. . . . . . . 299

Duration of finishing period for . . . 150

Establishing market days for .... 130

Fat, in transit for fairs . . . . . . . . 323

Field roots for finishing . . . . . . . 147

Finishing, in stall or shed ....... 128

Finishing in stall, shed or grove . . 132

Finishing on beet pulp and grain ... 148

Finishing on grass in early summer 176

Finishing on grass in late summer 178

Finishing on grass, with or without meal ................... 174

Finishing on pasture .......... 165

Fodders for finishing . . . . . . . . 147

Food in winter, before going on grass ................. 165

Foods for winter feeding . . . . . . 227

Frequency of feeding concentrates 158

Grazing corn by .............. 233

Grazing for two-year-old........ 66

Grazing yearling. ............. 51

Growing and fattening for exhibition and fattening for exhibi 303

Important considerations in growing yearling ..............

Important considerations in managing two-year-old ............

Improving ration for, in winter ...2 236

Leading up to full feeding ........ 136

Management of show, on pasture . . 316

Managing show, after fairs ...... 325

Marketing cull ............... 291

Marketing when finished ....... 290

Meal for finishing early on grass ... 167

Meal for finishing late on grass ... 167

Miscellaneous observations on finishing on grass ......... 179

Obtained from ranges .......... 130

One year old-summer and winter. 43

Pasture most suitable for finishing 168

Preparation of fodders for finishing 145

Preparing concentrates for feeding 140

Relative profit from finishing on grass ................. 181

Geason for marketing . . . . . . . . . 290

Securing for exhibition .......... 303

Shade for yearling .............. 53

Shrinkage of, while in transit .... 297

Spring-born third winter ........ 64

Stabling for ............... 340

Succulent foods for feeding ...... 146

Sufficiency of food for, in winter . . 234

Supplementing grazing for twoyear-old................

Supplementing grazing for yearling 53

Supply of for feeding........... 128

Three periods for finishing ....... 141

Training show, for fairs ........ 318

Treatment when "off feed" ...... 161

Tuming out to finish on grass ..... 172

Two years old-summer and winter 62

Washing for exhibition ......... 320

Water for two-year-old .......... 68
Cattle-Continued

Page

Water supply for yearling ...... 55

Winter quarters for . ......... 224

Classes for calves at fairs ........... 307

Concentrates, Amount of, for finishing cattle.............. 142

Amount of, for cows in milk ...... 267

Condimental food for cattle ...... 161

For cattle being fattened ........ 138

For show calves of different ages .. 312

Grown at home ............. 268

Nature of, for cows in milk ...... 267

Not fed to calves with dams ....... 15

Preparing for feeding ........... 138

Reducing after fairs .........326, 330

When fed to calves ............. 20

Cows, Amount of concentrates for, in milk ............. 272

Carrying power of pastures for ... 256

Concentrates for, in milk....... 267

Continuous milking of, lowers stamina .............. 188

Cost of keeping .............. 5

Disposal of ............... 280

Disposal of, infiuenced by supply.., 287

Disposing of pure-bred ......... 280

Drying in milk . . . . . . . . . . . 204

Exercise for, in winter .......... 192

Fattening for block ........... 286

Feeding forward in pregnancy .... 237

Feeding grains to, when on pasture 244

Fodders for, in winter.......... 259

Food and care of beef in summer .. 219

Food and care of beef in winter ...2216

From pasture to stable ......... 253

From stable to pasture ......... 242

Gentle driving of, when in milk ... 197

Grain supplements for, in milk ...2 271

Grazing for ................239

Hand-milking and milk production 184

Housing all winter ........... 193

In milk for successive years . . . . . 205

In the city dairy ........... 282

In the farm dairy .............. 283

Management of beef, when calf is confined ............... 214

Management of beef, when calf remains with dam .........2 213

Management of beef, while piegnant ............... 208

Management of, during period of rest ............... 861

Management relating to breeding... 206

Management relating to breeding beef .................220

Methods of feeding soiling food to 251

Milked by hand ............. 184

Protection for, in summer ........ 194

Removing milk from, that have freshened ............. 190

Removing surplus milk from beef . 212

Rest periods a necessity for ...... 187

Shelter for. in winter .......... 191

Soiling food for ............. 446

Succulence for, in winter ......... 262

That suckle calves ........... 208

Veal calves should not suck ...... 186 


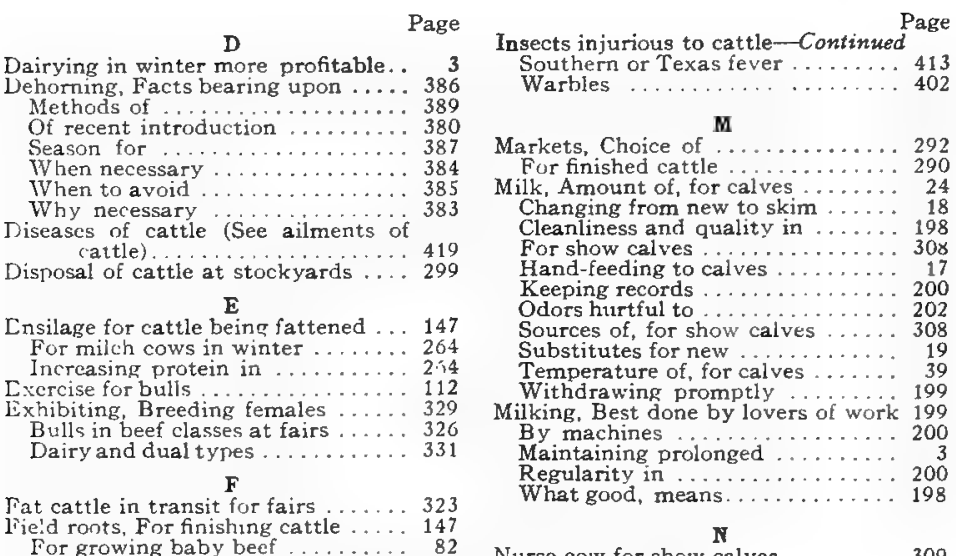

Fizishing, Milch cows for block ..... 286 Miscellaneous observations on show cattie .......... ... 333

Fodders, For feeding cows in winter. . 259 Finr cows from corn ........... 261

Food, Boiled or steamed, for show cattle

261

For bull calves ............... 107

For mature bulls ............... 114

For milch cows in summer ........ 239

For milch cows in winter........ 259

Observations regarding ........ 156

Supplementary concentrates for . 14

For Cows 'rom grain ........... 261

For cows from sorghum ........ 261

For cows from strav ........... 262

For show calves .............. 310

G

Irazing, For show cattle ........ 316

For show calves .............. 316

Lucation of, for show cattle ...... 317

srooming show cattle ........... 337

Heiters, Age at which to breed ..... 90

Breaking in to milk........... 97

Breecling subsequent to first birth. 101

Brecding ton long deferred ...... 93

During pregnancy and subsequently ................

Food and care for when pregnant.

Obiection to breedin? too young .. 92

Progeny from immature ........ 102

Rearing calves from ............ 102

Restraining kicking ............ 100

Treatment of, after parturition..... 100

\section{I}

Insects injurious to cattle, Flies . . 406

Lice .................. 404

Mance ................... 409

Ringworm ............ 400
Nurse cow for show calves ....... 309

Nutritive ratio for cows........... 270

\section{0}

Oats, as food for calves ......... 23

Oilmeal. Fed as jelly ............. 20

For calves on milk ......... 19

For cows in winter ............. 271

Preventing horns from growing . . . 388

Pumpkins for cows ............ 255

Ration, Most suitable, winter, for cows in various centers ..... 277

Standard meal, for calves ........ 21 ages $\ldots \ldots \ldots \ldots \ldots \ldots \ldots, 315$

\section{S}

Salt for calves .............. 40

Scour, In calves ............... 45.1

In show cattle .............. 331

Shelter, For cattle in winter ........ 101

For cattle in summer ........... 104

For two-year-olds ........... 65

For yearling cattle .......... 43

Shrinkage, Of cattle in transit .... 297

Spaying, Facts regarding ......... 390

Methods of .................. 393

Of show cattle ............. 334

Season for .................. 391

When necessary ................ 392

When to be avoided ......... 391

Stables, Absorbents used in . . . . . . . 204

Built on basıment plan .......... 318

Chutes in ................. 376

Climate and construction of ..... 34 ?

Eonveniences in .............. 345
Odors in juring milk ............. 202

For cattle being fattened ....142, 156

Roots, For show cattle of different 
Stables-Continued

Feed room in ............ 346

Fittings in at the Michigan Agricultural College ...364-373

Gutters in ................. 373

Important requisites in ........ 343

Lighting ................ 377

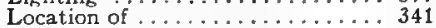

Materials of construction in ..... 352

Place for bedding ............. 347

Root cellar in ............. 346

Silo in .................. 347

Stalls and mangers in ......... 362

Ventilating ............... 378

Water in ....................... 348

Stacking, Corn for winter feeding ... 232

Standard rations, for fattening ..... 152

For beef cows in winter ......, 218

is northern and New England

states $\ldots \ldots \ldots \ldots \ldots \ldots \ldots 153$

In southern and southwestern states.................. 154
Standard rations-Continued

Page

In Washington, Oregon and Idaho 155

Succulence, Amount of, to feed to

cows ................. 266

For cows in milk .............. 262

From field roots for . . . . . . . . 265

\section{$\mathbf{T}$}

Training show cattle for fairs ..... 318

Trimming feet of show cattle ...... 339

\section{W}

Washing cattle for exhibition ..... 320

Weaning calves, Age for .......... 30

Management subsequent to ..... 31

Management while ........... 29

Time for, when shown ......... 335

When hazard is least in ........ 2

Whey, fresh for calves ............ 27 



\title{
STANDARD BOOKS
}

PUBLISHED BY

\section{ORANGE IUDD COMPANY}

\author{
NEW YORK \\ 499-441 Lafayette Street
}

\author{
CHICAGO \\ Marquette Building
}

\begin{abstract}
$B^{O O K S}$ sent to all parts of the world for catalog price Discounts for large quantities on applicatio. Correspondence invited. Brief descriptive catalog free. Large illustrated catalog, six cents.
\end{abstract}

\section{Soils}

By Charles Wiljiam Burkett, Director Kansas Agricultural Experiment Station. The most complete and popular work of the kind ever published. As a rule, a book of this sort is dry and uninteresting, but in this case it reads like a novel. The author has put into it his individuality. The story of the properties of the soils, their improvement and management, as well as a discussion of the problems of crop growing and crop feeding, make this book equally valuable to the farmer, student and teacher.

There are many illustrations of a practical character, each one suggesting some fundamental principle in soil manage ment. 303 pages. $51 / 2 \times 8$ inches. Cloth. . . \$1.25

\section{Insects Injurious to Vegetables}

By Dr. F. H. Chittenden, of the United States Department of Agriculture. A complete, practical work giving descriptions of the more important insects attacking vegetables of all kinds with simple and inexpensive remedies to check and destroy them, together with timely suggestions to prevent their recurrence. A ready reference book for truckers, marketgardeners, farmers as well as others who grow vegetables in a small way for home use; a valuable guide for college and experiment station workers, school-teachers and others interested in entomology of nature study. Profusely illustrated. $5 \frac{1}{2} \times 8$ inches. 300 pages. Cloth. . . . . . \$ז.5n 


\section{The Cereals in America}

By Thomas F. Hunt, M.S., D.Agri.. Professor of Agronony, Cornell University. If you raise five acres of any kind of grain you cannot afford to be without this book. It is in every way the best book on the suhject that has ever been written. It treats of the cultivation and improvement of every grain crop raised in America in a thoroughly practical and accurate manner. 'The subject-matter includes a comprehensive and succinct treatise of wheat, maize, oats, barley, rye, rice sorghum (kafir corn) and buckwheat, as related particularly to American conditions. First-hand knowledge has been the policy of the author in his work. and every crop treated is presented in the light of individual study of the plant. If you have this book you have the latest and best that has beer. written upon the subject. Illustrated. 450 pages. $5 \frac{1}{2} \times 8$ inches. Cloth. . . . . . . . . . . \$1.75

\section{The Forage and Fiber Crops in America}

By Thomas F. Hunt. This book is exactly what its title indicates. It is indispensable to the farmer, student and teacher who wishes all the latest and most important information on the subject of forage and fiber crops. Like its famous companion, "The Cereals in America," by the same author, it treats of the cultivation and improvement of every one of the forage and fiber crops. With this book in hand, you have the latest and most up-to-date information available. Illus1rated. 428 pages. $51 / 2 \times 8$ inches. Cloth. ... $\$ 1.75$

\section{The Book of Alfalfa}

History. Cultivation and Merits. Its Uses as a Forage and Fertilizer. The appearance of the Hon. F. D. ConurN's little book on Alfalfa a few years ago has been a profit revelation to thousands of farmers throughout the country, and the increasing demand for still more information on the subject has induced the author to prepare the present volume, which is by far the most authoritative, complete and valuable work on this forage crop published anywhere. It is printed on fine paper and illustrated with many finll-page photographs that were taken with the especial view of their relation to the text. 336 pages. $61 / 2 \times 9$ inches. Bound in cloth. with gold stamping. It is unquestionably the handsomest agricultural reference book that has ever been issued. Price, postpaid. . \$2.00

\section{Clean Milk}

Bv S. D. BeLCHER, M.D. In this book the author sets forth practical methods for the exclusion of bacteria from milk. and how to prevent contamination of milk from the stable tn the ronsumer. Illustrated. $5 \times 7$ inches. 146 pagns Cioth. 



